\title{
Conceptualizing Doctoral Advising from Professors' and Doctoral Students' Perspectives using Concept Mapping
}

Philip Kontor Adu

West Virginia University

Follow this and additional works at: https://researchrepository.wvu.edu/etd

\section{Recommended Citation}

Adu, Philip Kontor, "Conceptualizing Doctoral Advising from Professors' and Doctoral Students' Perspectives using Concept Mapping" (2011). Graduate Theses, Dissertations, and Problem Reports. 4682.

https://researchrepository.wvu.edu/etd/4682

This Dissertation is protected by copyright and/or related rights. It has been brought to you by the The Research Repository @ WVU with permission from the rights-holder(s). You are free to use this Dissertation in any way that is permitted by the copyright and related rights legislation that applies to your use. For other uses you must obtain permission from the rights-holder(s) directly, unless additional rights are indicated by a Creative Commons license in the record and/ or on the work itself. This Dissertation has been accepted for inclusion in WVU Graduate Theses, Dissertations, and Problem Reports collection by an authorized administrator of The Research Repository @ WVU.

For more information, please contact researchrepository@mail.wvu.edu. 


\title{
Conceptualizing Doctoral Advising from Professors' and Doctoral Students' Perspectives using Concept Mapping
}

\author{
Philip Kontor Adu
}

A Dissertation submitted to the College of Human Resources and Education at West Virginia University in partial fulfillment of the requirements for the degree of Interdisciplinary Ph.D. in Education

\author{
Reagan Curtis, Ph.D., Chair \\ Scott Cottrell, Ed.D. \\ Neal Shambaugh, Ph.D. \\ Sam Stack, Ph.D. \\ Adriane Williams, Ph.D.
}

Department of Technology, Learning, and Culture

Morgantown, West Virginia

2011

Keywords: Advisees, Advisors, Concept mapping, Dialogue, Dissertation completion, Doctoral advising, Doctoral students, Negotiation, Professors

Copyright 2011 Philip Kontor Adu 


\begin{abstract}
Conceptualizing Doctoral Advising from Professors' and Doctoral Students' Perspectives using Concept Mapping

Philip Kontor Adu

Due to the high cost of doctoral education, high attrition of about $50 \%$, and the constraints of higher education budgets, it is important to examine what causes doctoral students to leave their doctoral program without completion. Studies have shown that advising is one of the main contributing factors (e.g., Ferrer de Valero, 2001; Golde, 2000; Lenz, 1997). Document analysis of literature showed five distinct aspects of doctoral advising (i.e. advising approach, selection process, roles, responsibilities, and expectations, advisor-advisee relationship, and power relations) and their relation to the successful completion of students' dissertations. The purpose of this study was to use concept mapping to conceptualize how participants perceived the five components of doctoral advising in terms of their relation to completing one's dissertation effectively. In all, 38 professors and 114 doctoral students from universities with high and very high research activities sorted and rated 40 statements, which were generated from literature. Visual mapping analysis of sorted and rated data revealed that during the dissertation process, the topmost priority of professors was to promote their interaction with students and provide students with needed support, while doctoral students were more concerned with seeking guidance and structure in carrying out their dissertations.
\end{abstract}




\section{Dedication}

I dedicate this work to my dearest daughter, Miriam Violet Adu and my lovely wife, Monique Cheryl Adu. 


\section{Acknowledgement}

First of all I would like to thank Almighty God for giving me the strength to complete this project. Secondly, I would like to thank my advisor and mentor Dr. Reagan Curtis, for the immeasurable support he provided me throughout this work and beyond. He has been such a great blessing to me. He always encourages me to go beyond my dreams, and pursue the best out of everything I do. I would also like thank my committee members Drs. Scott Cottrell, Neal Shambaugh, Sam Stack, and Adriane Williams, for their valuable suggestions, insight, and time. My dissertation would not have been successful without their guidance. I would also like to thank my wife, Monique Cheryl Adu for her insurmountable support and encouragement throughout this process. Lastly, I would like to thank my father, and late mother for being there for me throughout my challenging moments. I also thank everyone who directly or indirectly played a role in the completion of my dissertation. 


\section{Table of Content}

Abstract........................................................................

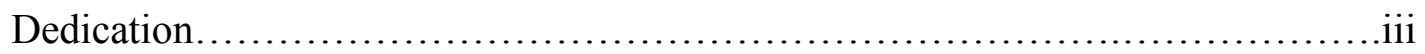

Acknowledgement................................................. iv

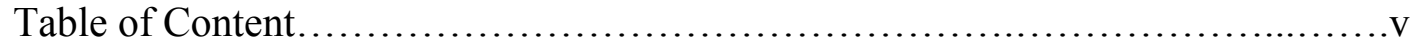

List of Tables........................................................viii

List of Figures.......................................................

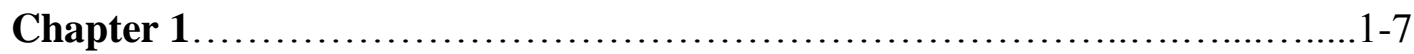

Introduction..........................................................

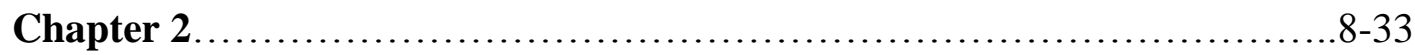

Literature Review................................................8

Historical Perspective...................................... 9

Doctoral Education and Advising...........................12

Doctoral Advising and Dissertation Completion.................14

The Five Components of Doctoral Advising.....................16

Conceptual Framework...................................23

Gap Analysis............................................28

Concept Mapping...........................................30

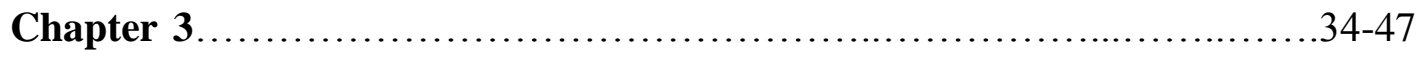

Research Design and Methodology.....................................34

Research Design...........................................34 
Research Method...........................................35

Population and Sample....................................41

Description of Sample.......................................44

Procedure..............................................45

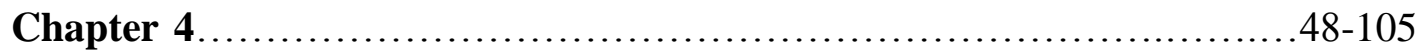

Analysis of Data................................................48

Data Analysis Process.....................................48

Presentation of Findings...................................50

Additional qualitative data...........................100

Summary of Findings............................................ 104

Chapter 5..................................................... 106 152

Discussion.................................................. 106

Overview of Study...........................................106

Summary of Findings....................108

Interpretations of Findings.................................. 113

Implications of Findings................................... 133

Limitations of the Study...................................147

Future Research.......................................148

Summary.................................................. 150

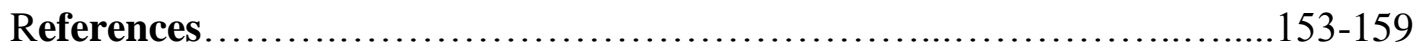

Appendices....................................................... 160-194

Appendix A: Tables and Figures (based on students' data)...............160

Appendix B: Tables and Figures (based on professors' data).............167 
Appendix C: IRB approval letter.................................174

Appendix D: Sample of the online survey.......................... 176

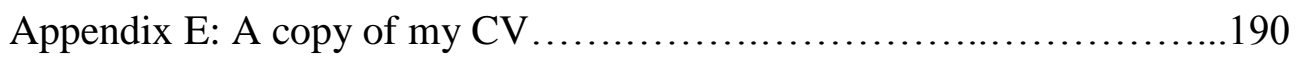




\section{List of Tables}

\section{Chapter 2: Literature Review}

Table 1 Components of doctoral advising and their references......................16

Table 2 Excerpts of the findings of the study on doctoral advising style................20

Table 3 Summary of Phillips' (1979) description of doctoral

experience.......................................................26

Table 4 Limitations of concept mapping with their respective solutions identified by

researchers........................................................33

\section{Chapter 3: Research Design and Methodology}

Table 5 Statements sorted by participants.

Table 6 Demographics of participants and their respective percentages (in the parenthesis)

\section{Chapter 4: Analysis of Data}

Table 7 List of statements in cluster 1 (based on students' sorted data)................52

Table $8 \quad$ List of statements in cluster 2 (based on students' sorted data)................53

Table 9 List of statements in cluster 3 (based on students' sorted data)................53

Table $10 \quad$ List of statements in cluster 4 (based on students' sorted data)................54

Table $11 \quad$ List of statements in cluster 5 (based on students' sorted data)................54

Table 12 List of statements in cluster 6 (based on students' sorted data)................54

Table 13 List of statements in cluster 1 (based on professors' sorted data)..............56

Table 14 List of statements in cluster 2 (based on professors' sorted data)..............57

Table $15 \quad$ List of statements in cluster 3 (based on professors' sorted data)..............57

Table 16 List of statements in cluster 4 (based on professors' sorted data)...............58 
Table $17 \quad$ List of statements in cluster 5 (based on professors' sorted data)..............58

Table 18 List of statements in cluster 6 (based on professors' sorted data)..............58

Table 19 Clusters (generated from students' sorted data) with the number of statements and the advising components they belong to.............................60

Table 20 Clusters (generated for professors' sorted data) with the number of statements and the advising components they belong to.............................

Table 21 Means (standard deviations) of the six clusters (based on students' data).......65

Table 22 Cronbach's alpha $(\alpha)$ coefficients for internal consistency for the six clusters (based on students' data).........................................66

Table 23 List of statements in cluster 1 and their mean ratings in terms of their difficulty and importance (based on students' data)..............................68

Table 24 List of statements in cluster 2 and their mean ratings in terms of their difficulty and importance (based on students' data)...............................

Table 25 List of statements in cluster 3 and their mean ratings in terms of their difficulty and importance (based on students' data)..................................73

Table 26 List of statements in cluster 4 and their mean ratings in terms of their difficulty and importance (based on students' data)...............................75

Table 27 List of statements in cluster 5 and their mean ratings in terms of their difficulty and importance (based on students' data)................................77

Table 28 List of statements in cluster 6 and their mean ratings in terms of their difficulty and importance (based on students' data)...............................79

Table 29 Means (standard deviations) of the six clusters (based on professors' data)......83 
Table $30 \quad$ Cronbach's alpha $(\alpha)$ coefficients for internal consistency for the six clusters (based on professors' data)........................................83

Table 31 List of statements in cluster 6 and their mean ratings in terms of their difficulty and importance (based on professors' data).

Table 32 List of statements in cluster 2 and their mean ratings in terms of their difficulty and importance (based on professors' data)

Table 33 List of statements in cluster 3 and their mean ratings in terms of their difficulty and importance (based on professors' data)

Table 34 List of statements in cluster 4 and their mean ratings in terms of their difficulty and importance (based on professors' data).

Table 35 List of statements in cluster 5 and their mean ratings in terms of their difficulty and importance (based on professors' data)

Table 36 List of statements in cluster 6 and their mean ratings in terms of their difficulty and importance (based on professors' data).

Table 37 Number of statements in common (in terms of how they were sorted) between professor and student clusters

Table $38 \quad$ Number of statements in common (in terms of how they were rated) between professors and students 100

Table 39 Categories of students' response to the open-ended statement; "Please type any statement that you think should be added to the statements above"....

Table 40 Categories of professors' response to the open-ended statement; "Please type any statement that you think should be added to the statements above".... 


\section{Chapter 5: Discussion}

Table 41 List of statements in their respective clusters found in each quadrant of the gozone graph (based on students' sorted and rated data)...................111

Table 42 List of statements in their respective clusters found in each quadrant of the gozone graph (based on professors' sorted and rated data)...................112

Table 43 Content of the statements rated by students as more important and less difficult.

Table 44 Content of the statements rated by students as more important and more difficult.

Table 45 Content of the statements rated by professors as more important and less difficult

Table 46 Content of the statements rated by professors as more important and more difficult. ... 


\section{List of Figures}

\section{Chapter 2: Literature Review}

Figure 1 Illustration of a summary of findings found in advising related literature........9

Figure 2 Illustration of meaning of doctoral education from Petersen's (2007) perspective....................................................14

Figure $3 \quad$ Illustration of the conceptual framework...............................24

\section{Chapter 3: Research Design and Methodology}

Figure 4 Concept mapping process starting with document analysis....................35

Figure $5 \quad$ How participants were selected...................................

\section{Chapter 4: Analysis of Data}

Figure 6 Diagram showing how the concept mapping data was analyzed................50

Figure $7 \quad$ Named cluster map showing the six clusters (based on students' sorted

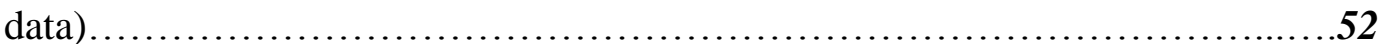

Figure 8 Named cluster map showing the six clusters (based on professors' sorted

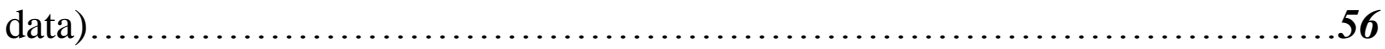

Figure 9 Go-zone graph displaying all 40 statements (based on students' rated data)

Figure 10 Go-zone graph displaying the six clusters in their respective quadrants (based on students' data)

Figure 11 Bar chart showing the mean ratings (importance and difficulty) for the six clusters

(based on students' data). .65

Figure 12 Go-zone graph displaying statements in cluster 1 in their respective quadrants (based on students' data). 
Figure 13 Go-zone graph displaying statements in cluster 2 in their respective quadrants (based on students' data).

Figure 14 Go-zone graph displaying statements in cluster 3 in their respective quadrants (based on students' data).

Figure 15 Go-zone graph displaying statements in cluster 4 in their respective quadrants (based on students' data). .74

Figure 16 Go-zone graph displaying statements in cluster 5 in their respective quadrants (based on students' data). .76

Figure 17 Go-zone graph displaying statements in cluster 6 in their respective quadrants (based on students' data)....... .68

Figure 18 Go-zone graph displaying all 40 statements in their respective quadrants (based on professors' data). .81

Figure 19 Go-zone graph displaying the six clusters in their respective quadrants (based on professors' data) .82

Figure 20 Bar chart showing the mean ratings (importance and difficulty) for the six clusters (based on professors' data). .84

Figure 21 Go-zone graph displaying statements in cluster 1 in their respective quadrants (based on professors' data). .85

Figure 22 Go-zone graph displaying statements in cluster 2 in their respective quadrants (based on professors' data).

Figure 23 Go-zone graph displaying statements in cluster 3 in their respective quadrants (based on professors' data). .89 
Figure 24 Go-zone graph displaying statements in cluster 4 in their respective quadrants

(based on professors' data)........................................91

Figure 25 Go-zone graph displaying statements in cluster 5 in their respective quadrants

(based on professors' data)......................................93

Figure 26 Go-zone graph displaying statements in cluster 6 in their respective quadrants

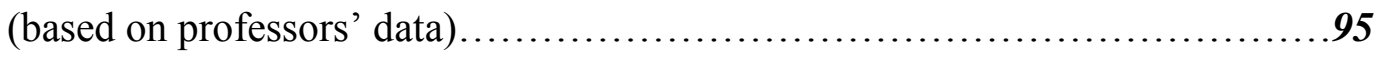

Figure 27 Breakdown of paired clusters that have statements in common...............97

Figure 28 Bar chart showing number of statements in each quadrant of the go-zone graph

for professors and students.

\section{Chapter 5: Discussion}

Figure 29 Statements rated by students as more important and less difficult and their relations with advising components and clusters.

Figure 30 Statements rated by students as more important and more difficult and their relations with advising components and clusters.

Figure 31 Statements rated by professors as more important and less difficult and their relations with advising components and clusters.

Figure 32 Statements rated by professors as more important and more difficult and their relations with advising components and clusters.

Figure 33 Illustration of the four statements related to advisor-advisee relationship and rated as more important by both professors and students 125

Figure 34 A diagram depicting professors' approach to advising. .132

Figure 35 A model conceptualizing doctoral students' perspectives on doctoral advising 135 
Figure 36 A model conceptualizing professors' perspectives on doctoral advising........136

Figure 37 A model depicting similarities between professors' and doctoral students'

perspectives on doctoral advising..................................137 


\section{Chapter 1}

\section{Introduction}

Studies have shown that an average of $50 \%$ of doctoral students leave without completing their education (Ferrer de Valero, 2001; Golde, 2000; Hoskins \& Goldberg, 2005; Spillett \& Moisiewicz, 2004). "In financial costs, doctoral student attrition is extremely expensive for institutions. In its study of doctoral student attrition, the University of Notre Dame found that it would save \$1-million a year in stipends alone if attrition went down by 10\%" (Garden, 2007, p. 724). Moreover, the current economic downturn in the US has further decreased the coffers of most institutions. "Budgets constraints at the department level, coupled with high rates of attrition ... [have placed] doctoral programs and the faculty who teach in them at risk" (Hoskins \& Goldberg, 2005, p. 175-176). Due to these challenges, there is the need to examine the factors that affect students' decisions to leave their doctoral education without completion.

As a doctoral student and advisee, I have realized the impact advisors could have on students' doctoral experience. I became interested in advising after participating, as a coresearcher, in a qualitative study to investigate the preparedness of doctoral students for their dissertations. Results showed disparities of perspectives between the faculty and doctoral students on how they should prepare for their dissertations (Adu, Curtis, Carrick, Kohlmeyer, \& Rahman, 2011). With the desire to know more about advising and its influence on doctoral education, I began reading literature and writing term papers on advising related areas. During this journey, I realized the importance of power relations in the advisor-advisee relationships. My initial plan was to investigate the notion of power in doctoral advising but upon further review of the studies, my interest shifted to focusing on all aspects of doctoral advising including power relations. My plan was to directly involve professors and doctoral students so as to 
understand the complexity of doctoral advising. Coming from the constructivist perspective, I believe in directly incorporating the views of participants during the collection of data and interpretation of the results. All these experiences influenced my intention to study the views of professors and doctoral students on advising using a concept mapping approach.

There are numerous studies that have examined the factors contributing to attrition and relatively long time of completion (Ferrer de Valero, 2001). Reviewing literature related to the rate of students' attrition and completion of doctoral education, I identified advising style, and advisor-advisee relationship, matching and communication as part of the main factors that contribute to the successful completion of doctoral education (Barnes, Williams, \& Archer, 2010; Ferrer de Valero, 2001; Golde, 2000; Hoskins \& Goldberg, 2005; Spillett, \& Moisiewicz, 2004). Most researchers suggested the ideal roles and expectations, which could contribute to the successful completion of doctoral education (see Gardner, 2007, 2008; Gill \& Burnard, 2008; Hoskins \& Goldberg, 2005; Noonan, Ballinger, \& Black, 2007; Sangganjanavanich \& Magnuson, 2009).

However, just assessing the experiences of advisors and advisees and coming up with ideal roles, relationships, responsibilities, and expectations do not necessarily lead to successful completion of doctoral education, as much more is required. We, as researchers, need to acknowledge the complexity of doctoral advising, and devise appropriate strategies to study and understand it (Acker, Hill, \& Black, 1994): in that advisors have to take several roles and are expected to meet the requirements of these roles (Barnes \& Austin, 2009). It takes a substantial amount of time, as advisors have a responsibility to assist students in addressing the many academic related issues they may face (Acker et al., 1994). There is a constant change in the advisor-advisee relationship over time, and differences in the approach of advising from one 
discipline to another (Gurr, 2001; Schlosser, Knox, Moskovitz, \& Hill, 2003). For instance, the “intensity and involvement [of advisors' support varies] ... within and across programs, advisors, and doctoral students" (Sangganjanavanich \& Magnuson, 2009, p. 196). As Mackenzie and Ling (2009) indicated:

Each brings specific expertise to the relationship: the student or supervisee begins the journey with a naïve interest in a topic and over time constructs new knowledge and develops a new voice while the supervisor provides inspiration, knowledge and experience in the research process and the world of academia. (p. 48)

Due to these complexities, advisors “....cannot be 'trained' in any overly simplified way to adopt a series of steps, which will inevitably lead to a satisfied student and a completed thesis" (Acker et al., 1994, p. 496).

As indicated in Gardner's (2008) study, What's too much and what's too little?, a doctoral student struggled with this thought: "If someone holds your hand too much you'll never learn to think for yourself, and if someone doesn't hold your hand enough you'll fall flat on your face" (p.327). No matter how well faculty advisors work out this dilemma; their effort will be interpreted differently depending on students' expectations, needs and the lens they are using. "What students... [interpret] as lack of interest and support, [advisor may see] ... as deliberate nonintervention designed to lead the student[s] toward independence" (Goulden, 1991, p. 40). These disparities, if not resolved, could create tension between advisors and doctoral students and would generate endless criticism from both sides. In my opinion, the complexity of advising in the doctoral level calls for further studies of doctoral experience and advising. 
Barnes, Williams, and Archer (2010) categorized doctoral advising-related literature into four areas, namely; "advisor selection, roles and functions, types of relationships, and outcomes" (p. 34). Generally, most of researchers have suggested and/or shown evidence of how the first three characteristics (areas) of doctoral advising stated above impact doctoral students' completion of their dissertations (outcome) (see Acker et al., 1994; Barnes \& Austin, 2009; Hoskins \& Goldberg, 2005; Mackenzie \& Ling, 2009; Rose, 2003; Schlosser et al., 2003; Zhao, Golde, \& McCormick, 2007). However, not much has been done on the professors' and doctoral students' perspectives of these advising components and their relationship with students' dissertation completion. I have not found any doctoral advising-related study that actively and directly involved participants in grouping and rating of advising-linked actions (statements) that could promote successful completion of students' doctoral education.

To address the limitations of existing studies, I applied a qualitative document analysis approach to the literature: refining the existing categories developed by Barnes et al. (2010), and coding specific statements in each study (Keele, 2000). I sorted the literature into the various categories (Patton, 2002). In all, I came up with five factors that might influence students' doctoral education experience. They include: (a) advising approach, (b) selection process, (c) roles, responsibilities, and expectations, (d) advisor-student relationship, and (e) power relations. Further analysis showed an interrelationship among these factors. Therefore, the purpose of this study was to use concept mapping to conceptualize the perspectives of professors and doctoral students on the impact of these advising components on the successful completion of students' dissertations. The following were the research questions:

1. How can we conceptualize the perspectives of professors and doctoral students on doctoral advising? 
a. How do five components of doctoral advising from the literature map onto both doctoral students' and professors' conceptualization of advising?

b. How do professors and doctoral students rate the importance and difficulty of the advising statements/activities?

c. How are the professors' conceptualizations of advising-related activities similar to or different from that of doctoral students'?

Besides the research questions stated above, there are potential questions that could be answered with the data I have collected. For the long term, I plan to address these questions after the completion of my doctoral education. I have grouped the questions based on the demographic information collected. In the near future, I also intend to develop two types of doctoral advising scale: (a) Doctoral Advising Importance Scale (DAIS), and (b) Doctoral Advising Difficulty Scale (DADS) using exploratory factorial analysis. The DAIS will measure the perception of professors and doctoral students on the importance of the advising-related activities that contribute to the successful completion of students' dissertations, and the DADS will focus on assessing the perceptions (of professors and doctoral students) on the difficulty in implementing advising-related activities. Below are the potential research questions;

\section{Gender Difference}

1. Are there gender differences in the conceptualization of the five components of doctoral advising?

2. How do males and females rate the difficulty and importance of advising activities? 


\section{Doctoral Advising Experience}

1. Are there differences in the professors' advising experience that influence their conceptualization of doctoral advising?

2. Do professors' differences in the level of advising experience reflect how they rate doctoral advising activities in terms of their difficulty and importance?

\section{Doctoral Students and Doctoral Candidates}

1. How do the five components of doctoral advising from the literature map onto both doctoral students' and candidates' conceptualization of advising?

2. How do doctoral students and candidates rate the difficulty and importance of the advising activities?

\section{Part-time and Full-time Doctoral Students}

1. How do the five components of doctoral advising from the literature map onto both parttime and full-time doctoral students' conceptualization of advising?

2. How do part-time and full-time doctoral students rate the difficulty and importance of advising activities?

\section{Ph.D. and Ed.D. Students}

1. How do the five components of doctoral advising from the literature map onto both Ph.D. and Ed.D. students' conceptualization of advising?

2. How do Ph.D. and Ed.D. students rate the difficulty and importance of advising activities? 


\section{Time Spent in Students' Doctoral Education}

1. Are there differences in the students' time spent on their doctoral education that influence their conceptualization of doctoral advising?

2. Do differences in the time spent on their doctoral education reflect how they rate doctoral advising activities in terms of their difficulty and importance?

\section{College or Department Affiliation}

1. How does the categorization of advising-related activities differ from one college/department to another?

2. How do professors and doctoral students from various colleges/departments rate the difficulty and importance of the advising activities?

Identifying the Factor Structure of the Doctoral Advising Importance Scale (DAIS) using Exploratory Factor Analysis

1. How many factors are structured in the Doctoral Advising Importance Scale (DAIS)?

2. How do the five components of doctoral advising from the literature map onto the factor structure of DAIS?

\section{Identifying the Factor Structure of the Doctoral Advising Difficulty Scale (DADS) using Exploratory Factor Analysis}

1. How many factors are structured in the Doctoral Advising Difficulty Scale (DADS)?

2. How do the five components of doctoral advising from the literature map onto the factor structure of DADS? 


\section{Chapter 2}

\section{Literature Review}

When reviewing academic advising-focused study, I came across two types of literature: (1) concentrating on undergraduate advising, and (2) focusing on graduate/doctoral advising (see Figure 2). There were two kinds of approaches under each type of advising. For the undergraduate advising, most universities/colleges adopted prescriptive but later turned to the developmental approach to academic advising. Under doctoral level, the two kinds of advising were technical rationality model, which was a more structured style of advising, and negotiated order model, which centered on giving students less guidance and more room for negotiation and creativity (Acker et al., 1994). I further categorized doctoral advising related studies into five components, which included; (a) advising approach, (b) selection process, (c) roles, responsibilities, and expectations, (d) advisor-student relationship, and (e) power relations. Researchers have suggested that these components/factors have direct or indirect influence on students' ability to complete their doctoral education. Besides this, the studies showed the interrelationship among these factors (see Figure 2). Below are the reviews of: (i) advisingrelated literature from the historical perspective, (ii) doctoral education and its relation to advising, (iii) doctoral advising and its relation to dissertation completion, and (iv) the five components of doctoral advising. This section also includes conceptual framework, gap analysis and brief information about concept mapping. 


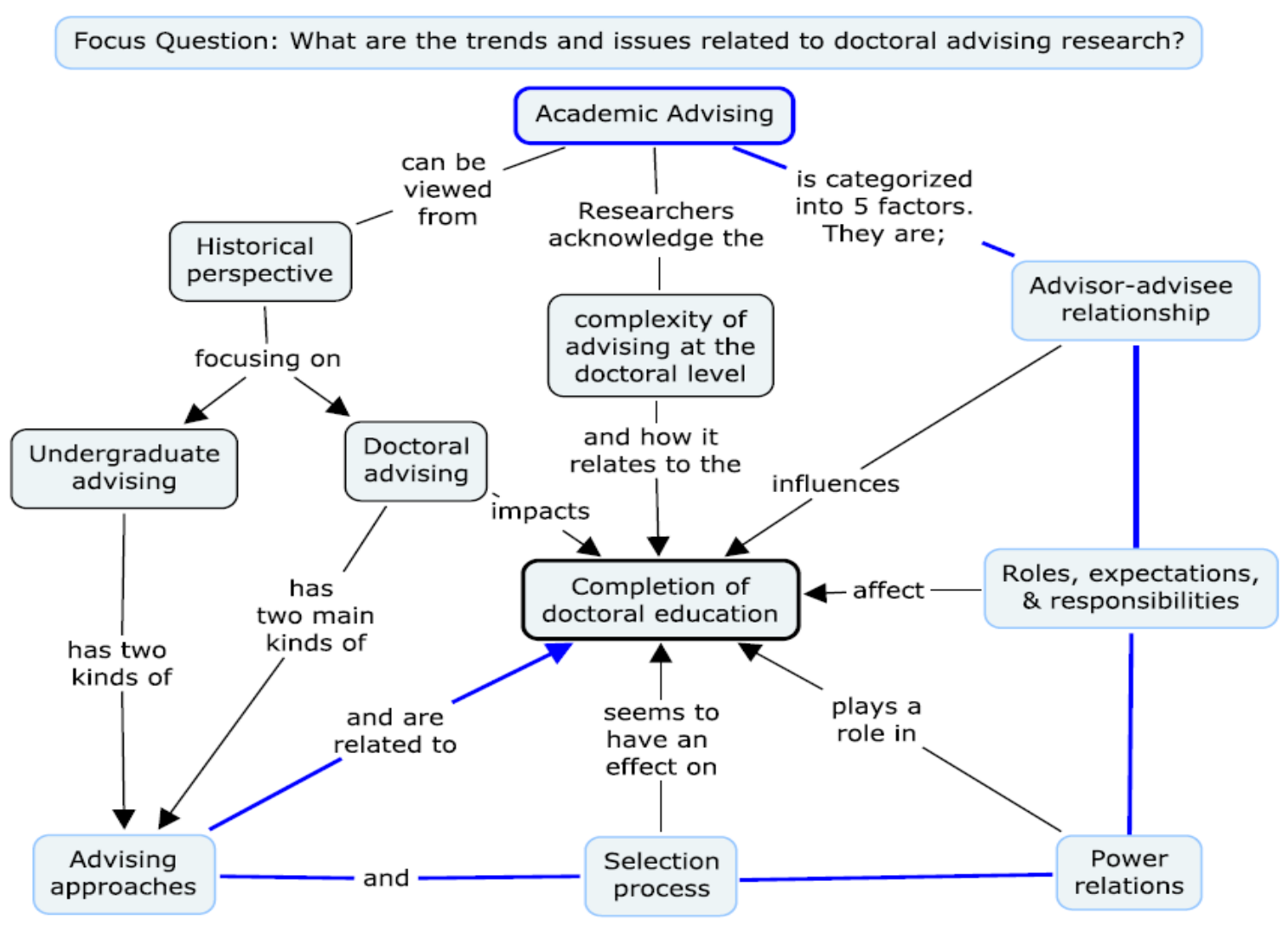

Figure 1. Illustration of a summary of findings found in advising related literature

\section{Historical Perspective}

Undergraduate advising. As Berger and Luckmann (1967) indicated, "it is impossible to understand an institution [or social system] adequately without an understanding of the historical process in which it was produced" (p. 54-55). In response, I am starting this review by giving detailed information about the history of academic advising. Between the $17^{\text {th }}$ and $18^{\text {th }}$ century, college presidents were responsible for giving advice to students (Cook, 1999). It was like "the 'motherhood' concept of leadership" (Watkins, 1989, p. 12) where students looked up to their presidents for care and guidance on both academic and non-academic aspects of their lives (Cook, 1999). Later, faculty members took over the responsibility of advising students from 
college heads. By the 1830s, the scope of academic advising was well-defined but not evaluated. Between the 1900s and 1940s, an increase in curricula in American colleges led to the three main types of advising namely: personal, vocational, and academic advising.

"Traditionally, faculty advisors simply helped students choose courses in a prescriptive approach to advising. Since the 1970s, however, scholars and faculty members have redefined the academic advisor's task to include guidance as well as imparting information" (Frost, 2000, “Developmental Advising," para. 1). With prescriptive advising, the advisor provides specific guidance that students are expected to follow. As Crookston (2009) indicated, "if the student follows the advice, the problem will be solved and all is well! In this context, the advisor presumably 'teaches' and the student 'learns"' (p. 78). To some undergraduate advisors, prescriptive advising was "highly convenient and desirable" (p. 79). Given that it saved time, it was easy to carry out, and required no student evaluation. This kind of advising was like a strict tour guide clearly giving information on where and where not to explore (Crookston, 2009; Frost, 2000; Mackenzie \& Ling, 2009). Advisors were prone to be authoritative, while the creativity of students were not emphasized (Crookston, 2009; Frost, 2000).

"The history of higher education can, at least to some extent, be seen as a power conflict between the desires and needs of students and the will and power of the faculty....The competing interests of these two powers are also seen in early professor-centered versus student-dominated models for higher education" (McClellan, 2009, "Values in Advising," para. 7). In the 1970's, due to "falling enrollments, high attrition rates, and student demand for improved advising", more attention was paid to academic advising (Cook, 1999, "Academic Advising as a Defined and Examined Activity," para.1). In the same period, prescriptive advising evolved into a more engaging and result-oriented advising style called the developmental approach (Crookston, 2009; 
Frost, 2000; Gillispie, 2009; McClellan, 2009). Developmental advising focused on working with students to define clear expectations, and attain shared academic objectives (Crookston, 2009; Frost, 2000). Under this approach, advisors have much concern and care for a students' academic success: inculcating students with a sense of responsibility (Frost, 2000; McClellan, 2009). According to Frost (2000), developmental advising has three goals, which are; promoting “competence", "autonomy", and "purpose" in a students' development. Thus, this advising approach was geared toward empowering students with the tools needed to achieve their academic goals (Crookston, 2009; Frost, 2000; Gillispie, 2009; McClellan, 2009).

Doctoral advising. Because of the decentralization of American higher education, and disparities in the way each discipline runs its graduate education; it is difficult to give a chronological narration of how doctoral advising began and its future trend (Phillips, 1979; Zhao et al., 2007). As Phillips (1979) indicated;

It is hard for one generation to understand the nature of the loyalties and commitments made in preceding generation between graduate professors and their students. We may not know precisely what was meant when aspiring young philosophers gave their loyalty to John Dewey or when nascent historians offered their swords to Donald Grove Barnes. (p. 340)

However, based on the studies done on doctoral advising, I may assume that early practice was informed by the apprentice model (Bargar \& Mayo-Chamberlain, 1983; Heiss, 1970; Phillips, 1979; Rudolph, 1994). In the master-apprentice relationship, the student learns directly from the skilled expert and he/she is expected to work within the confines of the discourse (Zhao et al., 2007). "Discourse is a structured assemblage of words, speech acts, and 
texts, together with a set (formal or informal) of rules as to how the assemblage should grow and how it should be interpreted, that is, how meaning should be assigned to it...." (Gordon, 2000, p. 221). With this model, there was a high level of dependence and support on the part of the student and their expert respectively. According to Rudolph (1994), “...in an apprenticeship interaction, the expert interprets the novice's talk with respect to the target Discourse" (p. 200). He also emphasized that this interaction shapes novice's utterances, actions, and thoughts.

Current doctoral advising focuses on guiding students as they journey to become independent scholars. As I reflect on doctoral education as the highest level in the US educational system, it reminds me of the huge responsibility placed on doctoral students, faculty members, and the institution as a whole. It is an undeniable fact that the institution and faculty members are expected to prepare doctoral students to be independent and knowledgeable scholars (Gardner, Hayers, \& Neider, 2007; Gardner, 2008; Golde, 2000; Leech \& Goodwin, 2008; Noonan et al., 2007). Doctoral students need to take 'required' courses, carry out a plan of study, publish their research, and attend conferences; equipping them to effectively meet their future professional responsibilities as knowledge producers (Golde, 2000).

\section{Doctoral Education and Advising}

Mackenzie and Ling (2009) related their experience, relationship, and roles (as faculty advisor and doctoral student) to the concept of a journey. To some, this journey is an intense inquiry, exciting discoveries and unprecedented support from faculty and cohorts (Gardner, 2008; Mackenzie \& Ling). To others, it is extremely challenging, confusing, frustrating, and unsatisfactory (Gardner, 2007; Gardner, 2008; Goulden, 1991; Hoskins \& Goldberg, 2005; Phillips, 1979; Sangganjanavanich \& Magnuson, 2009). Yet, we all (as doctoral students) may 
often agree to the fact that doctoral education is "truly a solo journey despite support from" faculty advisors (Mackenzie \& Ling, p. 52). For that matter, doctoral students are expected to take "charge of their own destinies" (Gardner, 2007, p. 738).

Petersen (2007) gave a deeper understanding of doctoral education and advising based on observations and interviews conducted with graduate students and their advisors (see Figure 2). Before the research community recognizes students as fellow researchers, they have to undergo an induction process. As part of this process, doctoral students define and build the 'self'. Petersen called this an "identity formation" (p.477). They are expected to work within the boundaries (both stated and implied) of their research community. Academic boundaries are limits used in deciding which academic practices are acceptable in a particular discipline or field of study. These boundaries are intended to shape how students "act, speak, think and write and feel as [scholars]" (p. 477).

Petersen (2007) stated that doctoral advising involved the negotiation of academic boundaries. Technically, advisors are expected to protect those boundaries: determining what aspects of students' academic discourse should be accepted as scholarly practice (Petersen, 2007; Phillips, 1979). However, regarding the nature of doctoral education, which advocates for research autonomy and creativity, doctoral students are prone to cross visible and/or invisible boundaries. Advisors, in the way of shielding their academic identity and solidifying the boundaries, engage in scholarly interactions in deciding what is appropriate and inappropriate in the research community (Petersen, 2007). 


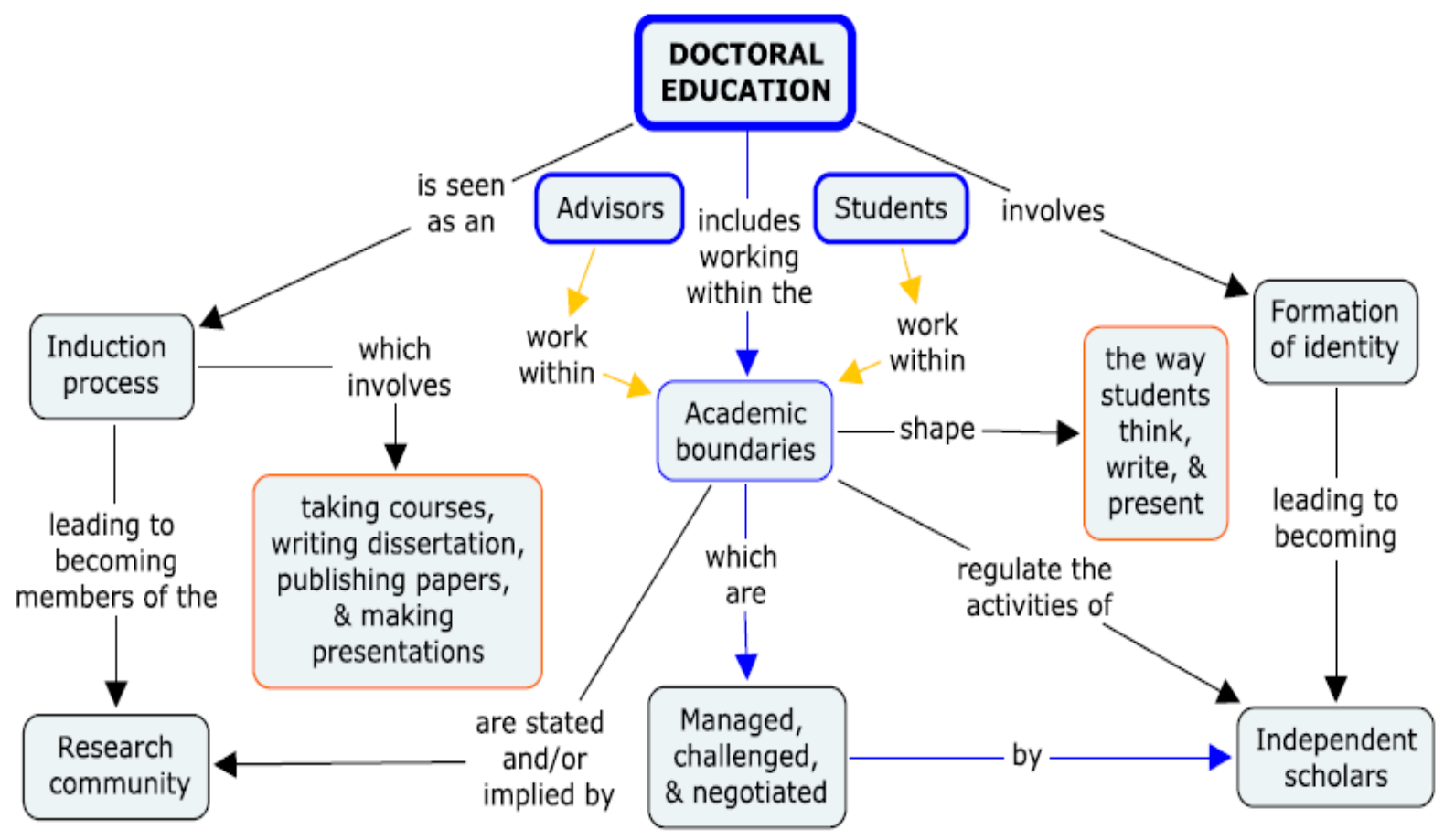

Figure 2. Illustration of meaning of doctoral education from Petersen's (2007) perspective

\section{Doctoral Advising and Dissertation Completion}

A vast amount of research has suggested a direct link between doctoral advising and the completion of one's dissertation (e.g., Ferrer de Valero, 2001; Golde, 2000; Lenz, 1997). For instance, a direct link can be seen in Golde's (2000) qualitative study, which focused on describing factors that contribute to attrition. Golde analyzed the stories of 63 students "who did not complete their initial [doctoral] program" (p.203). Her analysis showed that problems in the advisor-student relationship could influence a student's decision to leave. For instance, one student said that he was assigned to an advisor with similar interests. However, their relationship became sour because his expectations were not met, which eventually caused him to leave. Another student said, "I think the advisor is $80 \%$ of the deal. If you get along really well, and that person is there to support you and you exchange ideas well, I think it can be the driving 
force. ..." (p. 216). Consistent with Lenz (1997), who focused on identifying the factors that affected female students' completion of their doctoral education, she suggested that the women with ABD (All But Dissertation) remaining, had problems with their advisors compared to the completers, who had good and supportive relationships.

Likewise, Ferrer de Valero (2001) also examined the factors that contribute to the rate of completion of students' doctoral program. The researcher used semi-structured interviews to collect data from 24 doctoral students. Students indicated that their cordial relationship with advisors positively affected completion time (Ferrer de Valero). All the students interviewed were about to complete their dissertation. They emphasized that their advisor-advisee relationship was essential in their doctoral experience. Participants also indicated that "changing advisors was considered as an impediment to succeed in graduate school..." (p. 361). Findings showed that students did not want to change their advisors because they had the perception that changing advisors may lead to altering the focus of their dissertation (Ferrer de Valero). However, in Golde's (2000) study, a student who had a challenging relationship with his advisor and moved to another university successfully completed his doctoral education. This implied that sometimes changing one's advisor may be an appropriate action to take although it may be a herculean task (Schlosser et al., 2003). Advisor-student relationship is an important contributing factor in students' successful completion of the doctoral program (Katz, 1995; Miller, 1995; Schlosser et al., 2003). It is a relationship that must be nurtured in order for both advisor and student to gain the most out of their experiences. 


\section{The Five Components of Doctoral Advising}

I used document analysis to thoroughly review studies on doctoral advising. After analyzing the purpose, research question(s), method(s), findings, and implications of several research studies, five aspects of doctoral advising emerged. They include: (a) advising approach, (b) selection process, (c) roles, responsibilities, and expectations, (d) advisor-advisee relationship, and (e) power relations (see Table 1). Subsequently, I categorized all the related literature into these five components. I will be discussing the literature under these categories.

Table 1

Components of doctoral advising and their references

\begin{tabular}{|c|l|}
\hline $\begin{array}{c}\text { Components of } \\
\text { doctoral advising }\end{array}$ & \multicolumn{1}{|c|}{ Some of the sources } \\
\hline Selection process & $\begin{array}{l}\text { Hoskins \& Goldberg, 2005; Rose, 2003; Schlosser et al., 2003; } \\
\text { Sangganjanavanich \& Magnuson, 2009; Zhao et al., 2007 }\end{array}$ \\
\hline Advising approach & $\begin{array}{l}\text { Acker, Hill \& Black, 1994; Crookston, 2009; Frost, 2000; Gillispie, } \\
\text { 2009; Lan \& Williams, 2005 }\end{array}$ \\
\hline $\begin{array}{c}\text { Advisor-advisee } \\
\text { relationship }\end{array}$ & $\begin{array}{l}\text { Barnes et al., 2010; Golde, 2000; McClellan, 2009; Phillips,1979; } \\
\text { Rudolph, 1994; Schlosser et al., 2003; Wrench \& Punyanunt, 2004 }\end{array}$ \\
\hline $\begin{array}{c}\text { Roles, } \\
\text { responsibilities, and } \\
\text { expectations }\end{array}$ & $\begin{array}{l}\text { Bargar \& Mayo-Chamberlain, 1983; Barnes \& Austin, 2009; } \\
\text { Mackenzie \& Ling, 2009; Spillett \& Moisiewicz, 2004 }\end{array}$ \\
\hline $\begin{array}{c}\text { Power relations } \\
\text { Azim \& Boseman, 1975; Butler, 1997; Capper, 1998; Gordon, 2000; } \\
\text { Manathunga, 2007; Petersen, 2007; Watkins, 1989 }\end{array}$ \\
\hline
\end{tabular}

Selection process. This is the process of either assigning advisors to doctoral students or allowing students to choose their advisors. Schlosser, et al. (2003) suggested that the college and/or department should give doctoral students the opportunity to choose their advisors. In that it is a source of empowerment and contributes to students' ability to play an active role in the 
relationship. Sangganjanavanich and Magnuson (2009) also mentioned that before doctoral students are given the opportunity to select their advisors; colleges/departments should make available information on potential advisors' research interests, advising style, and expectations. This may help students to make an informed choice when searching for their 'perfect match' (Hoskins \& Goldberg, 2005). Schlosser et al. (2003) conducted qualitative research to find out how students perceived their relationship with their advisors. They interviewed third year counseling psychology doctoral students. The findings showed that "satisfied students were allowed to choose their advisors, whereas unsatisfied students were assigned to an advisor" (p. 186). They suggested that giving students the opportunity to choose their advisors can positively affect their relationship. Also, it is a source of empowerment and contributes to students' ability to play an active role in the relationship. Schlosser et al. stated that the advisor-advisee relationship would be enhanced if a student is given the "freedom to change to a different advisor" (p. 186).

According to Sangganjanavanich and Magnuson (2009), doctoral students should not only be given the right to choose advisors they would want to work with, but should be briefed about their potential advisors concerning their research interests, advising style, expectations, and the like. They recommended that before a student chooses an advisor, they should be given "advisor disclosure statements" (p. 195). These statements may help doctoral students to make an informed choice of their advisors. To them, giving students a disclosure statement can foster effective communication - clarifying roles, responsibilities, and expectations between advisors, and advisees. This activity empowers students and improves their relationship with their advisors (Sangganjanavanich \& Magnuson, 2009). Rose (2003), with the assistance of 712 Ph.D. students (participants), conducted a study with the main purpose of identifying the qualities of an ideal 
mentor. The findings suggested that the qualities associated with an ideal mentor are adequate communication and feedback abilities, guidance, and good relationship skills. The researcher used a scale called the Ideal Mentor Scale (IMS) to assess these qualities with the intent of assisting students in thinking about the desirable characteristics of advisors/mentors, and also to help shape their expectations. Submitting the results of a scale such as this to their potential advisors would initiate a conversation about the roles, responsibilities, and expectations that were to come (Rose, 2003). In effect, it would help students to choose advisors they could best work with.

Hoskins and Goldberg (2005) interviewed 33 students from 17 doctoral programs. They wanted to find out the factors that caused students to think about leaving or completing their doctoral education. "The participants in this study suggested that an open, honest, and ongoing discussion between students and faculty members about student experiences, expectations, goals, curricula, program focus, and relationships can have a positive influence on students' persistence in counselor education doctoral programs" (p. 187). The results showed that the similarity of the goals and expectations between advisor and advisee is the main factor that contributes to students' decisions of staying or leaving. This implied that when there is a match between the advisor and advisee, much progress can be made on both ends of the student and advisor spectrum. As Katz (1995) mentioned, matching systems need to be carried out. In doing so, advisors would be able to give substantial support to students, based on a pre-determined best-fit. Zhao et al. (2007) conducted a study to find out whether students' strategies of choosing advising and their perceived advisor behavior affect their "satisfaction with the advising relationship" (p. 263). A total of 4,114 doctoral students in 11 disciplines from 27 universities completed a survey. The results showed that the advisor choice factors were positively related to students' 
satisfaction of relationship with their advisors. The advisor choice factors were pragmatic benefits, intellectual compatibility, and advisor reputation. However, there was no significant relationship between advisor reputation and students' satisfaction. This study showed that students were more likely to be satisfied with the advising relationship if their research interest and expectations were compatible with that of their advisors. Also, students would look for advisors who would help them reach their personal academic goals such as publishing and going for conferences. According to the researchers, these findings provide more information about what to look for when searching for an advisor.

Advising approach. Acker et al.'s (1994) study was to identify the main advising style used in education and psychology departments in three universities in Britain. They interviewed "67 students, 56 supervisors, and 14 key persons" (such as tutors and administrators) (p. 487). When participants were asked to describe the degree to which they would want advising directed or managed, there was a mixed response: as some wanted a more structured approach to advising (technical rationality model), while others preferred if room was given for creativity (negotiated order model). However, some advisors preferred switching to any of the approaches depending on the needs of students. In addition, students develop strategies to adjust to an advisors' style. The researchers suggested that the negotiated order model might be an appropriate approach to doctoral advising in the social sciences, due to the mainly independent nature of the doctoral education.

Lan and Williams (2005) sought to find out the perception of students in terms of advising styles. In all, 131 doctoral students completed two questionnaires. The first questionnaire measured students' perceived “demandingness and responsiveness of advisors" whereas, the second instrument focused on measuring "the authoritative, authoritarian, 
permissive, and uninvolved" advisory types as assessed by the students (p. 34). The results showed that students who perceived their advisors as authoritative (i.e. $52 \%$ of participants) scored high in demandingness and responsiveness and had the "highest levels of perceived development in cognition, motivation, professional skills, satisfaction, and professional production" (p. 31) (see Table 2). Students with uninvolved advisors scored low in both demandingness and responsiveness, which correlated with a low level of perceived motivation and "cognitive development" (p. 38).

Table 2

Excerpts of the findings of the study on doctoral advising style (Lan \& Williams, 2005)

\begin{tabular}{|c|c|c|c|}
\hline Advising style & $\begin{array}{c}\text { An example of the advising } \\
\text { style (p.35) }\end{array}$ & $\begin{array}{c}\text { Demandingness - } \\
\text { "My advisor has } \\
\text { high expectations } \\
\text { of me" (p. 34) }\end{array}$ & $\begin{array}{c}\text { Responsiveness - } \\
\text { "My advisor is } \\
\text { willing to spend time } \\
\text { and effort to develop } \\
\text { a mentor-mentee } \\
\text { relationship with me" } \\
\text { (p. 34) }\end{array}$ \\
\hline $\begin{array}{c}\text { Authoritative } \\
\text { (52\% of } \\
\text { participants) }\end{array}$ & $\begin{array}{c}\text { "My advisor helps me to } \\
\text { academic decisions and } \\
\text { activities" }\end{array}$ & High & High \\
\hline $\begin{array}{c}\text { Authoritarian } \\
\text { (7.7\% of } \\
\text { participants) }\end{array}$ & $\begin{array}{c}\text { "My advisor expects me to } \\
\text { follow his/her advice without } \\
\text { question" }\end{array}$ & High & Low \\
\hline $\begin{array}{c}\text { Uninvolved } \\
\text { (9.2\% of } \\
\text { participants) }\end{array}$ & $\begin{array}{c}\text { "My advisor is interested in my } \\
\text { academic progress, but he/she } \\
\text { doesn't have any particular } \\
\text { expectation about how that } \\
\text { progress occurs" }\end{array}$ & Low & Average \\
\hline $\begin{array}{c}\text { Permissive } \\
\text { (30.8\% of } \\
\text { participants) }\end{array}$ & $\begin{array}{c}\text { "When I need advice, I typically } \\
\text { ask another professor rather than } \\
\text { my advisor" }\end{array}$ & Low & \\
\hline
\end{tabular}


Advisor-advisee relationship. Barnes et al. (2010) used an open-ended survey completed by doctoral students to answer the question; "What positive or negative characteristics do doctoral students assign to their advisors?" (p. 34). This was an online survey with participants consisting of 2,391 doctoral students. The results indicated that students who had a positive attitude perceived advisors to be supportive and reachable while those with negative attitudes viewed them to be unsupportive and unreachable. They recommended that due to power inequality, advisors should take the initiative in maintaining a good relationship with doctoral students. This intervention would decrease any of the negative feelings that students may develop.

Similarly, findings of Schlosser et al.'s (2003) qualitative investigation found that satisfied doctoral students reported having a positive relationship (such as working collaboratively, having honest discussions, and negotiations) compared to unsatisfied students. Also, satisfied students indicated that they have regular meetings with and guidance from their advisors. Based on these findings, they made the assertion that the advisor-advisee relationship is essential in doctoral education. When there is mutual respect, well-defined boundaries, and honest communication between advisors and students, there is a higher probability for students to successfully complete their dissertations (Hoskins \& Goldberg, 2005; Mackenzie \& Ling, 2009).

Roles, responsibilities, and expectations. In Barnes and Austin's (2009) investigation, 25 experienced doctoral advisors were interviewed to assess how they perceived their roles and responsibilities. After a qualitative analysis of the data, they identified three themes with subthemes. They included;

1. Responsibilities (a) helping students

2. Functions (a) collaborating, (b) advocating, (c) mentoring, (d) chastising 
3. Characteristics of advisor-advisee relationship (a) friendly/professional, (b) collegial (c) supportive/caring (d) accessible (e) honest (p. 305)

Barnes and Austin stated that these findings would be useful in improving the advisor-advisee relationship.

Spillett and Moisiewicz (2004) focused on explaining "the roles of the dissertation advisor using the framework of support and challenge" (p. 1). Under the support role, the advisor should act as cheerleader and counselor. The challenge role includes the advisor acting as a coach and critic. These assertions show that advisors have an important part to play in doctoral students' education. Thus, there should be a balance between the support and challenge roles as "needs will change at different stages in the dissertation process" (p. 10). Other researchers have recommended that doctoral students should be taught to be independent, which includes training them how to adjust to changing roles, responsibilities, and expectations (Acker et al., 1994; Gardner, 2008). Moreover, advisors should make an effort to know needs of students so as to provide them with the needed support (Spillett \& Moisiewicz, 2004). These roles and expectations should be clearly defined (Schlosser et al., 2003).

Power relations. Power plays a huge role in our daily interactions with people (Capper, 1998; Manathunga, 2007). "Human beings live out their daily lives and socially construct their reality through the negotiations, contestations and resistances of the rules and resources within which their lives are entwined. Through this ongoing dialectic people both influence and are influenced by the structures in which they find themselves" (Watkins, 1989, p. 23). Individuals and the social system or institutions (we have created) possess and use power to sustain their existence (Capper, 1998; Petersen, 2007). As Butler (1997) states, "power is not simply what we oppose but also, in a strong sense, what we depend on for our existence" (p.2). Both advisor and 
advisee have power but in different forms and sources. On one hand, the role as an advisor is empowering because he/she is expected to guide students, especially at the dissertation level. On the other hand, students are expected to be independent and it is empowering because more autonomy leads to more power (Petersen, 2007).

Taking the perspective of Gordon (2000) and Petersen (2007), it can be stated that a specific discourse exists within the academic community and advisors are literally charged to police the academic boundaries as doctoral students are conducting their studies (see Figure 2). Doctoral advising is characterized by "surveillance mechanisms used by supervisors [advisors] and the institutional powers and responsibilities invested in them" (Manathunga, 2007; p. 208). Manathunga (2007) indicated that there are power inequalities in the advisor/advisee relationship. Students see advisors as experts and experienced scholars in a specified discipline. The institutions have tasked advisors to help students develop their identity. During the process, both parties generate, challenge, and negotiate these boundaries (Petersen, 2007). In other words, the students are obliged to work within the boundaries and at the same time are expected to be creative during this identity formation and knowledge production process (Manathunga).

\section{Conceptual Framework}

The conceptual framework is grounded in and clearly emerged from the literature.

Studies have shown that there are multiple factors that influence doctoral students' completion of their education, and doctoral advising is one of the main contributing factors (Ferrer de Valero, 2001). There are basically five components of doctoral advising: (a) advising approach, (b) selection process, (c) roles, responsibilities, and expectations, (d) advisor-student relationship, and (e) power relations (see Figure 3). Researchers have suggested a direct and indirect relation 
of these components with students' dissertation completion. Findings of previous studies indicated interrelationships among the components. My research objective was to identify specific advising activities that are related to any of the five components and find out how professors and doctoral students perceive them. Therefore, the essence of this study is to use concept mapping to conceptualize how participants view the five components of doctoral advising and their relation to completing one's dissertation effectively.

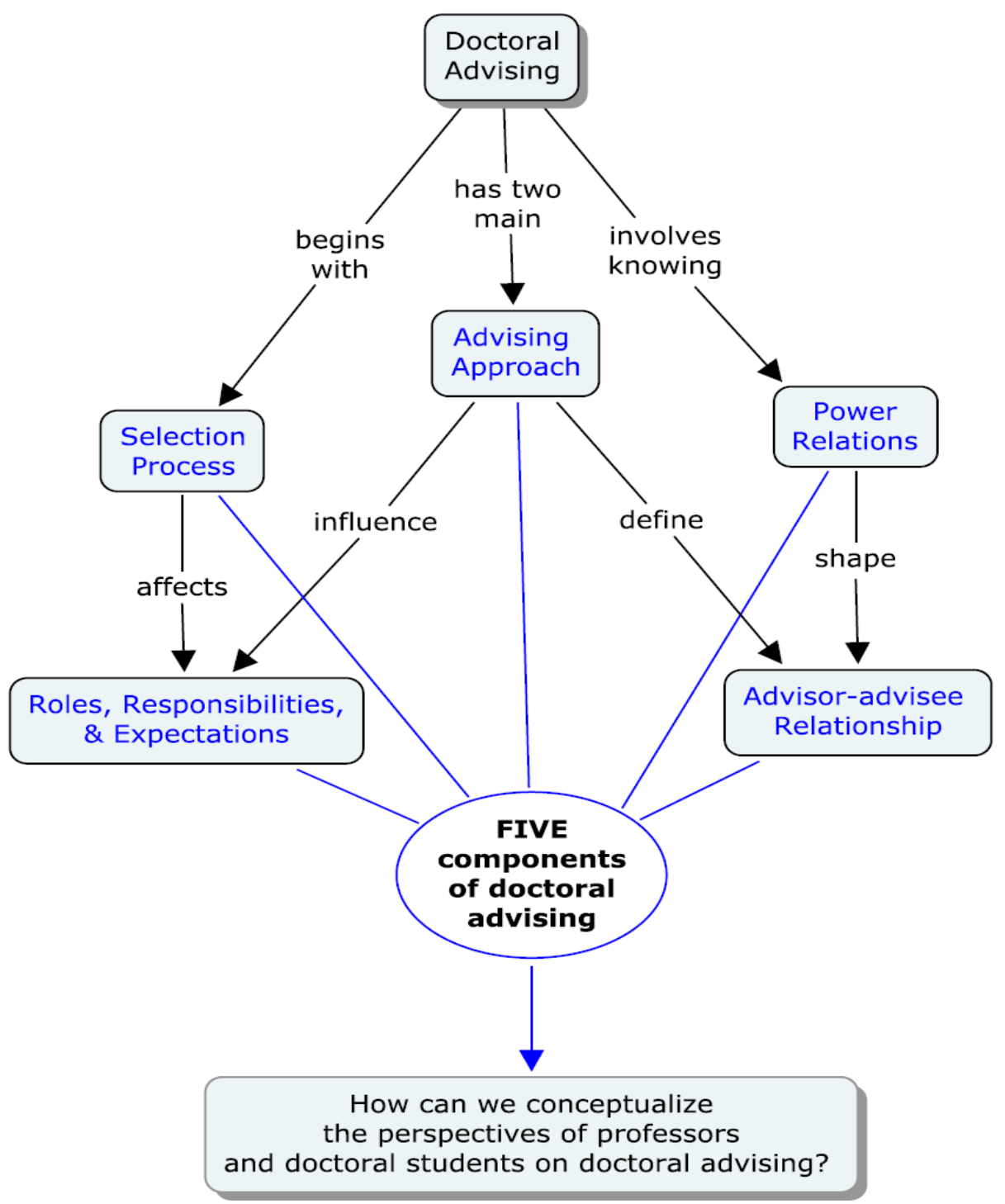

Figure 3. Illustration of the conceptual framework 
Most of the early studies on doctoral advising explored the challenging experience of doctoral students and the existing advising approach and strategies (Bargar \& MayoChamberlain, 1983; Goulden, 1991; Phillips, 1979). The aim of those studies was to examine the advising situation and suggest an effective advising style (Phillips, 1979). For instance, Phillips' (1979) article, The peculiar intimacy of graduate study: A conservative view, portrayed the advising situation and doctoral students' experience in the 1970's. The following is a brief review of his article organized around the five components of doctoral advising. While these five factors were not identified by Phillips, there is evidence of each of them (see Table 3). For advising style/approach, the behavior of the advisor and reaction of students were part of the features of the technical rationality model where roles, responsibilities, and expectations were not negotiated. The advisor-advisee relationship was strictly professional and the role of the advisor was to manage that relationship. Besides this, Phillips portrayed advisors as gatekeepers of academic boundaries. This means that advisors gave no room for negotiation with students. Presumably, most of the higher education institutions at that time assigned students to advisors and it would be difficult (if not impossible) for students to change their advisors when necessary. At the end of the article, Phillips suggested the need for advisors to establish and sustain good working relationships with advisees. 
Table 3

Summary of Phillips' (1979) description of doctoral experience

\begin{tabular}{|c|c|c|}
\hline $\begin{array}{l}\text { Areas (factors) of } \\
\text { doctoral advising }\end{array}$ & $\begin{array}{l}\text { Description of } \\
\text { doctoral experience } \\
\text { in the 1970's }\end{array}$ & Source - Phillips (1979) \\
\hline Advising approach & $\begin{array}{l}\text { Technical rationality } \\
\text { model }\end{array}$ & $\begin{array}{l}\text { "The rules of procedure are generated by faculty (perhaps } \\
\text { with some perfunctory student input) and they are } \\
\text { promulgated, enforced, and adjudicated by that same faculty" } \\
\text { (p. 343). }\end{array}$ \\
\hline Selection process & $\begin{array}{c}\text { The institutions } \\
\text { assigned students to } \\
\text { advisors }\end{array}$ & $\begin{array}{l}\text { "Some matches are easy to make, for students often come to a } \\
\text { particular graduate department because it employs the scholar } \\
\text { with whom they seek to study. If the professor accepts, the } \\
\text { relationship is formed" (p. } 341 \text { ). }\end{array}$ \\
\hline $\begin{array}{l}\text { Roles, } \\
\text { responsibilities, } \\
\text { and expectations }\end{array}$ & $\begin{array}{c}\text { They were not } \\
\text { negotiated }\end{array}$ & $\begin{array}{l}\text { "Students gradually accept their roles as "forms of support" } \\
\text { and accept their professor's argument on behalf of } \\
\text { competency. The professor then seeks to make students as } \\
\text { good as they can possibly become, and if that is not good } \\
\text { enough, students often find themselves cast off, either seeking } \\
\text { another professor or another career" (p. 342) }\end{array}$ \\
\hline $\begin{array}{l}\text { Advisor-student } \\
\text { relationship }\end{array}$ & $\begin{array}{l}\text { Advisors carefully and } \\
\text { strictly managed their } \\
\text { relationship with } \\
\text { doctoral students }\end{array}$ & $\begin{array}{l}\text { "The relationship between graduate students and } \\
\text { mentor/professor is entirely undemocratic. The public goals } \\
\text { for the relationship are dictated by the institution the professor } \\
\text { serves and by the discipline to which he/she is dedicated" } \\
\text { (p.343). }\end{array}$ \\
\hline Power relations & $\begin{array}{l}\text { The advisors' role was } \\
\text { to protect and } \\
\text { maintain the academic } \\
\text { boundaries }\end{array}$ & $\begin{array}{l}\text { "Professors have the power to generate tension, suspense, and } \\
\text { psychic pain. They can inflict punishment if they care to and } \\
\text { may be orderly or capricious in task-setting. The student can } \\
\text { do little about such circumstances except to discuss, } \\
\text { supplicate, or endure. So long as the student remains } \\
\text { dedicated to an academic goal, he/she adjusts to the mentor" } \\
\text { (p. 345). }\end{array}$ \\
\hline
\end{tabular}

Doctoral advising-related articles published between the 1980's and 1990's focused less on describing the doctoral students' challenges than examining advisor-advisee relationship/interaction and its impact on completion of their programs (Bargar \& MayoChamberlain, 1983; Friedman, 1987; Goulden, 1991). Subsequently, studies afterwards took a more diverse pattern. To illustrate, I would categorize the trend of studies done after the 1990's into four phases. These were heavily overlapping phases in terms of the time they were published. In the first phase, most researchers conducted qualitative and few quantitative 
research studies documenting and analyzing the experience of doctoral students. The essence of their studies was to identify ideal roles, responsibilities, and expectations of both advisors and students (Gardner, 2007; Gardner, 2008; Golde, 2000; Heinrich, 1995; Hoskins \& Goldberg, 2005; Noonan et al., 2007). The second phase of research focused on selection of advisors and suggested that the faculty should educate students on factors that should be taken into consideration when searching for potential advisors (Hoskins \& Goldberg, 2005; Rose 2003; Sangganjanavanich \& Magnuson, 2009; Zhao et al., 2007). In the third phase, scholars examined the relationship between some contributing factors of dissertation completion (such as advising style, advisor-advisee relationship, roles and expectations, and selection process) and doctoral education completion (Mackenzie \& Ling, 2009; Schlosser et al., 2003; Wrench \& Punyanunt, 2004). Lastly, the fourth phase of research on advising focused on examining the advisor-advisee interaction. Researchers such as Manathunga (2007) and Petersen (2007) believed that we cannot fully understand the complexity of doctoral advising without critically exploring advisor-advisee power relations. Concerning the methodology, the number of quantitative research studies has increased from the second to the fourth phase. However, qualitative research is still the dominant approach in the area of doctoral advising.

In summary, the literature reviewed showed that there were five main factors that can influence students' completion of doctoral dissertations. They were: (a) advising approach, (b) selection process, (c) roles, responsibilities, and expectations, (d) advisor-advisee relationship, and (e) power relations. To better understand the complexity of advising, I designed this study to find out professors' and doctoral students' perspectives on the importance of these five factors/components using a different and more participatory method like concept mapping, and to assess the level of perceived difficulty in implementing activities under these components. 


\section{Gap Analysis}

Few studies empirically establish direct relation between some of the factors of advising and students' completion of doctoral education. For instance, Golde (2000) and Lenz (1997) indicated the direct connection between advisor-advisee relationship and student's plan to leave their doctoral education. Also, Hoskins and Goldberg (2005) showed a direct relation between advisor-advisee mismatch and attrition.

However, most of the studies presented an indirect link between some of the five factors of advising and completion of doctoral education. Most researchers of doctoral advising conducted their studies with an assumption that good advisor-advisee relationship, perceived satisfaction of the relationship, effective communication, students' ability to choose and change their advisors, students' knowledge of the potential advisor's expectation, research interest and advising style, and awareness of the power relations would influence successful completion of doctoral education. Based on this presumption, researchers focused on finding evidence of the relationship and interrelationship among related factors of doctoral advising (see Acker et al., 1994; Barnes et al., 2010; Lan \& Williams, 2005; Schlosser et al., 2003; Spillett \& Moisiewicz, 2004; Rose, 2003, Zhao et al., 2007).

In response, my aim was to build on the existing studies to find out whether there was any evidence of a connection between the five factors of advising and the successful completion of students' dissertations. I believe that an appropriate way of understanding the complexity of doctoral advising and examining its relationship with students' dissertation completion is to directly involve participants (professors and doctoral students) in the study. 
Doctoral advising studies started out with predominately qualitative methodology and have since included a fair amount of quantitative design but little mixed method research. Due to this, I carried out this study using an exploratory mixed method (Clark \& Creswell, 2007; Kane \& Trochim, 2007). Exploratory mixed method involves qualitatively collecting and analyzing data with the aim of using the findings to develop an instrument that is used to quantitatively collect and analyze the data (Bedi \& Alexander, 2009; Clark \& Creswell, 2008). Similarly, the concept mapping approach used here starts with generating statements using qualitative document analysis, giving participants the opportunity to sort and rate statements, and quantitatively analyzing the data to answer the research questions (Kane \& Trochim, 2007). The following are the research questions:

1. How can we conceptualize the perspectives of professors and doctoral students on doctoral advising?

a. How do five components of doctoral advising from the literature map onto both doctoral students' and professors' conceptualization of advising?

b. How do professors and doctoral students rate the importance and difficulty of the advising statements/activities?

c. How are the professors' conceptualizations of advising-related activities similar to or different from that of doctoral students'? 


\section{Concept Mapping}

Concept mapping is a process of illustrating participant generated and purpose-driven ideas in a meaningful form of "pictures or maps" (Kane \& Trochim, 2007, p. 1). It is simply a visual representation of ideas. In addition, it involves making connections and establishing the relationship between ideas so as to explain complex phenomenon. Concept mapping was developed by Novak (1998). The creation of concept mapping was influenced by the constructivist perspective of learning (Bedi \& Alexander, 2009). The constructivist is of the view that our knowledge about the world or our interpretation of the things around us is shaped by our culture, past experience, and prior knowledge (Plotnick, 1997). This means that we may have a different response to the same situation: concept mapping is used to put together various views in a visual form (Kane \& Trochim, 2007).

According to Novak (1998), representing ideas in a form of maps makes it easy for people to learn, in that it facilitates learners' encoding, storage, and retrieval of information. Concept mapping can be used to conceptualize and/or summarize the diverse views on a phenomenon expressed by a group of people. It is an effective tool for decision making processes. Moreover, it is a great tool to support negotiation and consensus building. Doctoral students can use concept mapping techniques to collect data during dissertations. It is a useful tool for college professors to assess the needs of students, and program valuators to plan and conduct developmental, formative, and summative evaluation (Kane \& Trochim, 2007). The following are the explanations of the strengths and limitations of using concept mapping as a research/evaluation method. 
Reviewing literature on concept mapping, I identified three main strengths. Firstly, researchers will get a reliable understanding of a phenomenon because clients'participants' perspectives are directly incorporated into the concept mapping process, which is aimed at demystifying complex ideas (Bedi \& Alexander, 2009). For instance, Bedi and Alexander (2009) conducted a study on how to use the perspectives of clients to gain an understanding of counseling procedures. The study emphasized the need for researchers to directly engage clients in the research evaluation process. With concept mapping, clients are fully involved from the beginning (with brainstorming) to the end (with the labeling of the clusters). Bedi and Alexander assert that this lessens the researcher's bias when interpreting the experience of clients who are seeking for counseling.

Secondly, concept mapping is a good tool for explaining complex ideas. To illustrate, Wopereis, Kirschner, Paas, Stoyanov and Hendriks (2005) came to the realization that since the emergence of information and communication technology (ICT), Netherland has invested many resources in ICT in the higher education. According to them, there have been successes and failures. After reviewing the literature, the researchers came up with 42 factors that contribute to the success and failure of ICT projects. However, when they carried out concept mapping with “thirteen experts, senior level managers, and professors", they identified 220 factors with 13 clusters (p. 681). Wopereis et al. (2005) used multidimensional scaling (MDS) and hierarchical cluster analysis (HCA) to assess the data they got from the concept mapping process. They found out that "most of the clusters deal with people-issues, also identified as more important factor in the literature study. [In addition], participation, information, and communication and Stakeholder involvement, which are people clusters, score very highly" (p. 683). The researchers 
recommended that clients of ICT projects should be directly involved from the preimplementation process to the end of the project.

Lastly, concept mapping is an effective tool for drawing out rich data from sub-groups. As Robinson and Trochim (2007) mentioned, there is generally a low participation rate for ethnic minorities in "clinical trials" (p. 521). The researchers used convenience sampling to recruit participants for the concept mapping process. In all, 70 statements were identified by participants as factors that contribute to their unwillingness to participate in a clinical trial. After running the MDS and HCA, the 70 statements were grouped into nine clusters. "The data suggest that recruitment and retention will be aided by addressing patient concerns regarding the research process, and assuaging fears about clinical trials" (p. 522).

These three studies show how concept mapping can be used to effectively collect data to understand, explain, and communicate seemingly complicated ideas. Nevertheless, researchers should be aware of the limitation of the concept mapping method. Table 4 shows the summary of the limitations and ways they can be addressed. Difficulty in bringing potential participants to one location, potential participant fatigue, unwillingness to participate, limited number of participants, and tendency to overlook the subgroup views are some of the limitations of concept mapping (Bedi \& Alexander, 2009; Kane \& Trochim, 2007; Robinson \& Trochim, 2007). 
Table 4

Limitations of concept mapping with their respective solutions identified by researchers

\begin{tabular}{|l|l|l|}
\hline \multicolumn{1}{|c|}{ Limitations } & \multicolumn{1}{|c|}{ Solutions } & \multicolumn{1}{c|}{ Sources } \\
\hline $\begin{array}{l}\text { During brainstorming and statements } \\
\text { development process, participants may } \\
\text { be overwhelmed with statements they } \\
\text { come up with. This may lead to fatigue } \\
\text { if they have too many statements to } \\
\text { work on and may adversely affect their } \\
\text { level of participation. }\end{array}$ & $\begin{array}{l}\text { To maintain the high level of } \\
\text { participation, participants will be } \\
\text { allowed to work with 100 or less } \\
\text { statements }\end{array}$ & $\begin{array}{l}\text { Bedi and } \\
\text { Alexander, } \\
2009\end{array}$ \\
\hline $\begin{array}{l}\text { There is the tendency of overlooking } \\
\text { "individual differences and subgroup } \\
\text { differences" when running concept } \\
\text { mapping analysis (p. 78). }\end{array}$ & $\begin{array}{l}\text { Newer concept mapping technique } \\
\text { such as pattern-matching will be a } \\
\text { good tool to address this problem. }\end{array}$ & $\begin{array}{l}\text { Bedi and } \\
\text { Alexander, } \\
2009\end{array}$ \\
\hline $\begin{array}{l}\text { Due to the intensity of the process, } \\
\text { substantial amount of time involved, } \\
\text { and the expected high level of } \\
\text { participants' involvement, few are } \\
\text { willing to participate in this activity. } \\
\text { Therefore, the findings may lack the } \\
\text { external validity. }\end{array}$ & $\begin{array}{l}\text { Targeting people who are directly } \\
\text { affected by the phenomenon being } \\
\text { studied and letting them know the } \\
\text { benefits of participating is one of } \\
\text { the strategies research can use. } \\
\text { However, researchers can get rich } \\
\text { data from 15-20 participants. }\end{array}$ & $\begin{array}{l}\text { Robinson and } \\
\text { Trochim, 2007 }\end{array}$ \\
\hline $\begin{array}{l}\text { It is sometimes impossible for } \\
\text { researchers/facilitators to bring } \\
\text { participants in one location. }\end{array}$ & $\begin{array}{l}\text { Concept mapping can be done } \\
\text { online using online tool such as } \\
\text { survey monkey }\end{array}$ & $\begin{array}{l}\text { Kane and } \\
\text { Trochim, 2007 }\end{array}$ \\
\hline
\end{tabular}




\section{Chapter 3}

\section{Research Design and Methodology}

The literature showed five distinct aspects of doctoral advising that are directly or indirectly related to the successful completion of students' dissertations. They were; (a) advising approach, (b) selection process, (c) roles, responsibilities, and expectations, (d) advisor-advisee relationship, and (e) power relations. The aim of this study was to conceptualize professors' and doctoral students' perspectives on doctoral advising using concept mapping. Also, I found out whether these five components are relevant to successful completion of dissertations, from professors' and doctoral students' perspectives and assessed how they perceive the implementation of the activities under these five components in terms of the level of difficulty. Under this section, I will be presenting the research design, research method, population and sample, procedure, and analysis of data.

\section{Research Design}

This study falls within the realm of descriptive research design, because it focuses on examining and describing the perspectives of professors and doctoral students on advising (Burchinal, 2010). In other words, the purpose of this study was to describe how participants perceived the existing components of doctoral advising in terms of their relationship to the successful completion of doctoral students' dissertation. I started this process by analyzing the literature related to doctoral advising, categorizing the studies into five components, ideewrntifying the theme (i.e. focus statement), and developing theme-driven statements under each category - see Figure 4 (Kane \& Trochim, 2007). These statements, which reflect the activities under each component, were given to participants for sorting and rating. The data was 
then analyzed using concept mapping (Multidimensional Scaling, Hierarchical Cluster Analysis, and data visualization) to conceptualize professors' and doctoral students' perspectives on doctoral advising (see Figure 4).
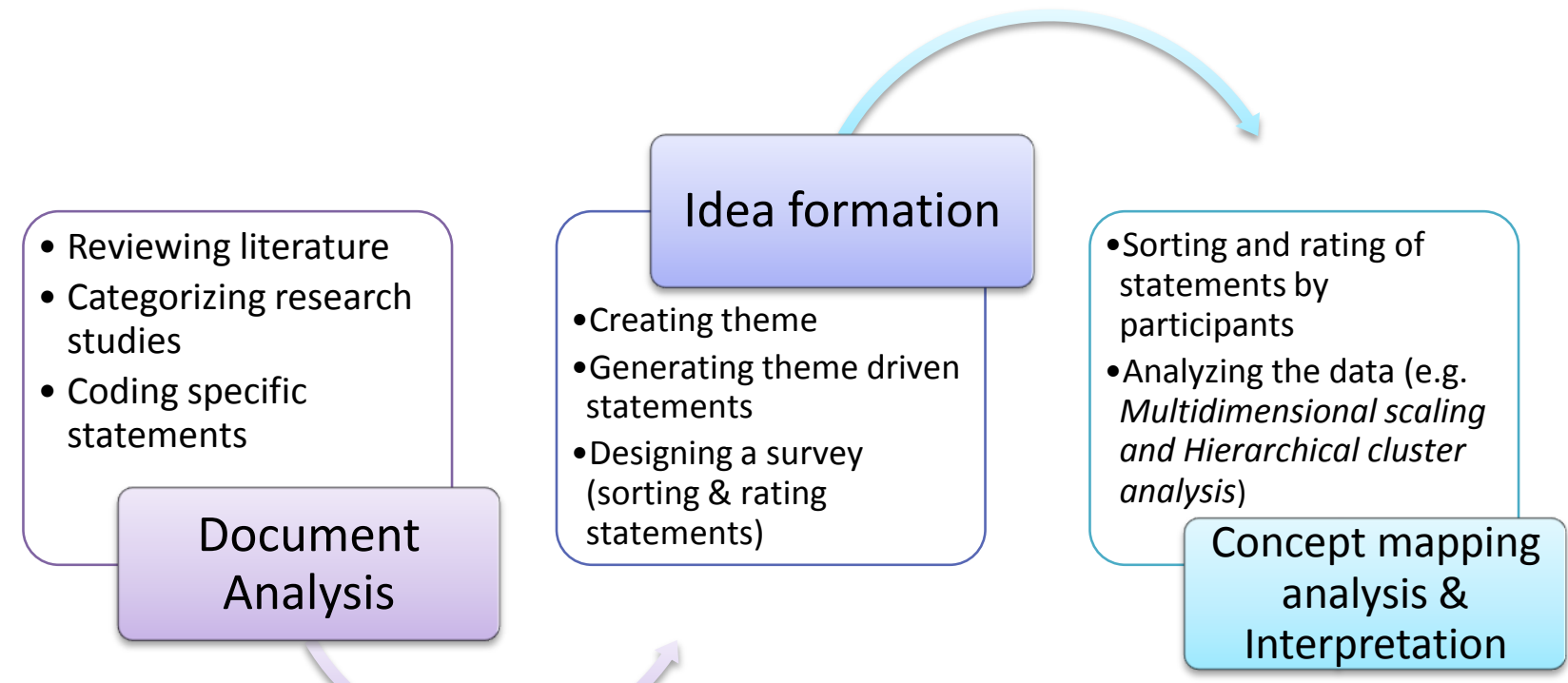

Figure 4. Concept mapping process starting with document analysis

\section{Research Method}

Using concept mapping to conceptualize doctoral advising. Generally, concept mapping begins with brainstorming of ideas, and refining statements by participants with the assistance of facilitator(s) (Kane \& Trochim, 2007). According to Bedi and Alexander (2009), "there are several ways that statements can be obtained, including group brainstorming, individual interviews, self-report questionnaires, and the extraction of statements from text documents (e.g., reports, memos, books, transcribed interviews, field notes)” (p. 79). It is rare 
but possible to conduct concept mapping studies "with no active participant input" especially at the brainstorming stage (Kane \& Trochim, 2007, p. 37).

Document analysis. In this context, document analysis is critically examining literature related to academic advising so as to identify patterns, categorize main ideas, and interpret the findings in a specified framework (Patton, 2002). There are two reasons why document analysis was an appropriate technique for this kind of study compared to the brainstorming process carried out by participants. First, it would be extremely difficult to bring faculty advisors and doctoral candidates from different departments under one roof to brainstorm issues related to doctoral advising (Kane \& Trochim, 2007). Second, there were numerous studies on doctoral advising with diverse methodologies and mostly unified findings, which provided a wealth of information for this kind of study. The document analysis that was done for the literature review purposes previously was also utilized for the first stage of the concept mapping methodology. During this process, I categorized the literature into the five components of doctoral advising. I examined each study and coded statements that reflect the characteristics of the five components. These brainstormed statements were then moved to the next stage for modifications.

Idea formation. This involved developing the theme for the brainstorming and generating statements, which were later sorted and rated by participants. Following Kane and Trochim's (2007) methodology, the following were the concept mapping steps. First, I started this process by creating the theme statement, which Kane and Trochim referred to as the "focus statement" (p. 29). The focus statement for this study was; "to ensure successful completion of their doctoral dissertation ..." This focus statement was based on the notion that there was a direct or indirect relation between doctoral advising and dissertation completion (Barnes \& Austin, 2009; Manathunga, 2007; Schlosser et al., 2003; Zhao et al., 2007). Second, with the focus statement in 
mind and the findings of the studies done on doctoral advising, I generated statements related to the characteristics of the five components of advising. Finally, I trimmed the statements down to eight for each component (making 40 statements in all) (see Table 5). A survey was designed based on these 40 advising statements (activities).

The survey consisted of three sections. The first section focused on demographic questions. Participants were asked to sort and rate the statements in the second and third sections. Under the rating section, they rated the statements in terms of their relevance to students' successful completion of their dissertations and the difficulty in implementing those activities/statements (see Appendix D). Both importance and difficulty ratings were based on 1 to 5 likert scale, where 1 = relatively unimportant, $2=$ somewhat important, $3=$ moderately important, $4=$ very important, and $5=$ extremely important for the important ratings, and $1=$ relatively easy, $2=$ somewhat difficult, $3=$ moderately difficult, $4=$ very difficult, and $5=$ extremely difficult for the difficulty ratings. Also, participants had the option to add a statement which they perceived to be missing from the given list.

Table 5

Statements sorted by participants

\begin{tabular}{|c|c|c|}
\hline $\begin{array}{l}\text { Components of } \\
\text { doctoral } \\
\text { advising }\end{array}$ & $\begin{array}{l}\text { Statements for each component } \\
\text { Focus statement: To ensure successful completion of } \\
\text { their doctoral dissertation ... }\end{array}$ & Source \\
\hline \multirow{4}{*}{ 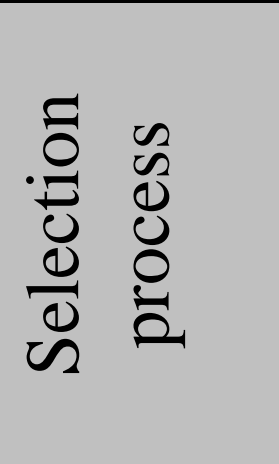 } & $\begin{array}{l}\text { 1. Students should be given the opportunity to choose their } \\
\text { advisors. }\end{array}$ & $\begin{array}{l}\text { Schlosser et al., } \\
2003\end{array}$ \\
\hline & $\begin{array}{l}\text { 2. Students should be well-informed about the research } \\
\text { interest, advising style, and expectations of potential } \\
\text { advisors. }\end{array}$ & $\begin{array}{l}\text { Sangganjanavanich } \\
\text { \& Magnuson, } 2009\end{array}$ \\
\hline & $\begin{array}{l}\text { 3. Students should clearly define what they expect from } \\
\text { potential advisors. }\end{array}$ & Rose, 2003 \\
\hline & $\begin{array}{l}\text { 4. Advisors should have the chance to choose who they want } \\
\text { to work with. }\end{array}$ & Phillips, 1979 \\
\hline
\end{tabular}




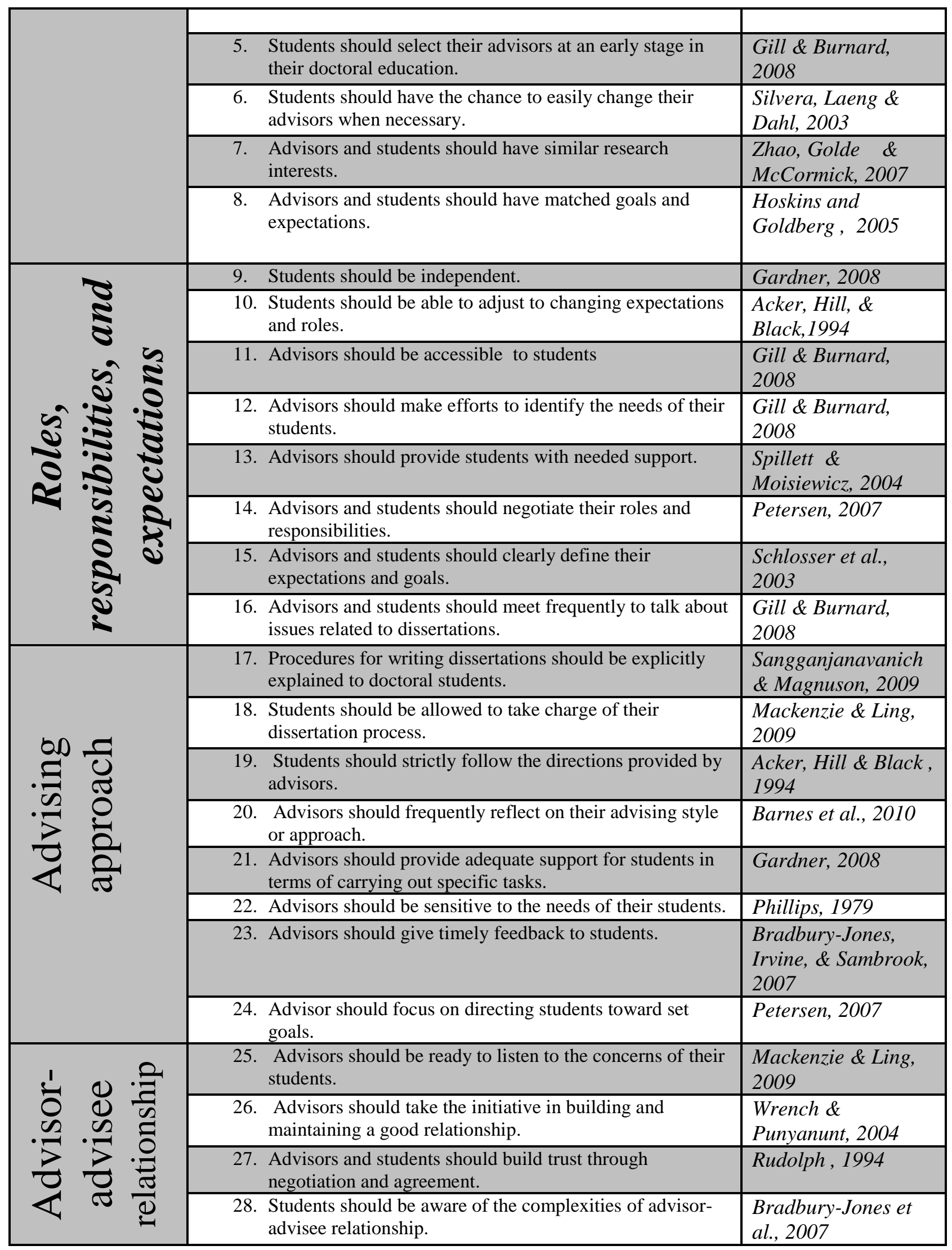




\begin{tabular}{|c|c|c|}
\hline & $\begin{array}{l}\text { 29. Students should feel comfortable sharing their academic } \\
\text { challenges with advisors. }\end{array}$ & Acker et al., 1994 \\
\hline & $\begin{array}{l}\text { 30. There should be mutual respect between advisors and } \\
\text { students. }\end{array}$ & $\begin{array}{l}\text { Mackenzie \& Ling, } \\
2009\end{array}$ \\
\hline & $\begin{array}{l}\text { 31. There should be honest communication between advisors } \\
\text { and students. }\end{array}$ & $\begin{array}{l}\text { Hoskins \& } \\
\text { Goldberg, } 2005\end{array}$ \\
\hline & 32. The boundaries of the relationship should be well-defined. & $\begin{array}{l}\text { Bradbury-Jones et } \\
\text { al., } 2007\end{array}$ \\
\hline \multirow{8}{*}{$\underbrace{3}_{0} \frac{\sigma}{\sigma}$} & 33. Students have to respect the authority of advisors. & Petersen, 2007 \\
\hline & $\begin{array}{l}\text { 34. There should be an equal balance of power between } \\
\text { advisors and advisees. }\end{array}$ & Heinrich, 1995 \\
\hline & $\begin{array}{l}\text { 35. Advisors should be ready to intervene when students are } \\
\text { going off-track. }\end{array}$ & Rudolph, 1994 \\
\hline & $\begin{array}{l}\text { 36. There should be open dialogue concerning making } \\
\text { decisions and resolving conflicts. }\end{array}$ & $\begin{array}{l}\text { Schlosser et al., } \\
2003\end{array}$ \\
\hline & $\begin{array}{l}\text { 37. Students should be able to express their disagreement } \\
\text { when necessary. }\end{array}$ & Manathunga, 2007 \\
\hline & $\begin{array}{l}\text { 38. Advisors should exercise their power (expert knowledge) } \\
\text { when necessary. }\end{array}$ & $\begin{array}{l}\text { Bradbury-Jones et } \\
\text { al., } 2007\end{array}$ \\
\hline & $\begin{array}{l}\text { 39. Advisors should make sure students follow procedures } \\
\text { acceptable to the research community. }\end{array}$ & $\begin{array}{l}\text { Bradbury-Jones et } \\
\text { al., } 2007\end{array}$ \\
\hline & $\begin{array}{l}\text { 40. Advisors should give constructive criticism on students' } \\
\text { dissertations. }\end{array}$ & $\begin{array}{l}\text { Gill \& Burnard, } \\
2008\end{array}$ \\
\hline
\end{tabular}

Validity and reliability of the instrument. To ensure a high level of accuracy of the measure, I included statements that reflected the characteristics of each components of doctoral advising. I incorporated those statements based on my fairly rigorous qualitative analysis of the literature. This form of content-related validity helped me to develop well-represented statements under each component that have strong face validity (Slavin, 2007).

As indicated above, this instrument has not been used before; hence, there was the need to assess whether it was valid and reliable. Because it was a new instrument designed to conceptualize participants' perception on doctoral advising, face validity, content validity, and internal consistency were the appropriate assessment tools needed to ensure the accuracy and 
reliability of the measure. In addition, going through this process served to adequately answer the research questions, and use the findings to further improve items on the scale for further studies.

Pilot study. I gave the survey to potential participants to assess the clarity of the instructions and the individual statements. In all, three professors and three doctoral students offered to go through the survey and make necessary comments. Based on these comments, I modified the survey to be easier for participants to complete. A video on how to complete the survey was needed to facilitate the participants' successful completion of the survey. Below are some of their suggestions.

When you ask about support are you meaning financial, emotional, or something different? That part wasn't clear.

I completed the survey. The second set of questions with the matrix is clear, but it is also hard to complete just because of the number of questions and keeping track of them. [It is] hard to make decisions because you have to scroll up and down. But, I think given the type of respondent they will be able to do that. The questions are not impossible to answer; you just have to be willing to scroll up and down to make decisions about similarity and uniqueness. Perhaps something to that effect could be entered into the directions. With surveymonkey, I don't think there is a better formatting option. 
I think it looks great. I didn't notice any typos, and the directions were clear. The only thing I would suggest is on the second page has the cluster heading repeated mid-page. I had to scroll up and down to see the header once I got to the bottom.

$\sim$ Professor

\section{Population and Sample}

The population was made up of professors and doctoral students from universities with "high research activities" and "very high research activities" in the US (The Carnegie Foundation, 2010). I focused on the high and very high research universities because they have extensive doctoral programs, good number of doctoral students, and experienced doctoral advisors. They were a rich source of information for my area of research.

Sampling. There were two kinds of sampling techniques that were used for this research project: (a) random cluster sampling, which was used to select universities where potential participants were contacted, and (b) purposeful criterion sampling, which helped in choosing colleges/departments in the selected institutions.

Random cluster sampling. This involves identifying or grouping the targeted population into subgroups and selecting participants from each subgroup with the assumption that each member of the group has a chance of being chosen (Patton, 2002; Slavin, 2007). In this study, I obtained the list of high and very high research universities from the Carnegie Foundation website and based on where they were located in the US, I categorized them into four regions: (a) West, (b) South, (c) Midwest, and (d) Northeast Region. I then put each of the four lists on the SPSS to randomly select five universities from each group. In all, I collected data from 20 universities (see Figure 5). 
Purposeful criterion sampling. Carrying out this strategy began by setting a condition or standard, which potential participants should meet before they are allowed to participate in a research study (Patton, 2002). I administered the online survey to 38 professors and 114 doctoral students from the social science colleges/departments, which included: College/Department of Education, Political Science, Communication, Sociology/Anthropology and Psychology. I selected these colleges/departments because they have common structure in their doctoral programs, course requirements, comprehensive exams, dissertation committee formation, and dissertation completion requirements. Also, there was a high probability that all the high and very high research universities might have these colleges/departments. This was to ensure that data collected well-represented professors and doctoral students in high and very high research universities and the various departments stated above (see Figure 5). 


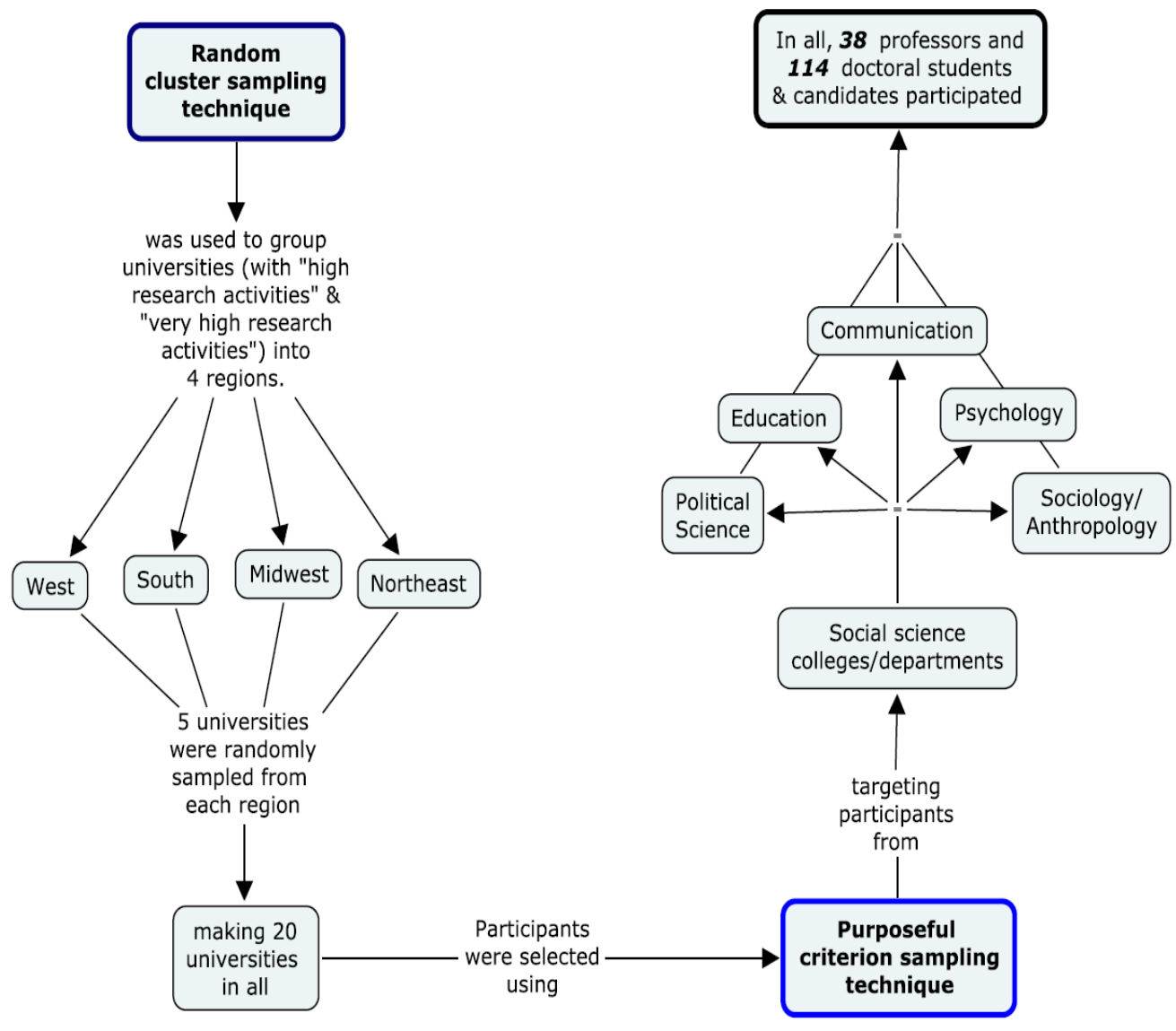

Figure 5. How participants were selected.

Rationale for the sample size. Initially, I was targeting 500 professors and 500 doctoral students for this study because data collected could be used to answer all the research questions stated above. In addition, my intention of targeting 1,000 participants was to generate rich data for future studies. However, I collected data from 38 professors and 114 doctoral students, which were enough to answer the research questions for this dissertation (RQ 1, a, b, and c). As Kane and Trochim (2007) indicated:

There is no strict limit on the number of people who can participate in concept mapping. Although initially designed for use with live groups of 40 or fewer people, it is now 
frequently used with very large, geographically dispersed groups using tools such as the internet. In general, having more participants yields greater amounts of information to be used in the analyses and, consequently, produces greater resolution and clarity of the results, although there are likely to be diminishing returns... as sample size increases beyond a certain point. (p.36)

\section{Description of Sample}

In all, 152 out of 278 completed the survey: a $55 \%$ response rate. There were 38 professors who completed the survey, $47.4 \%$ were male $(n=18)$ and $52.6 \%$ were females $(n=20)$. Most of the professors were whites/Caucasians ( $n=35,92.1 \%)$. In addition, two African American/Black (5.3\%) and one Hispanic/Latino professor(s) (2.6\%) completed the survey. Professors were also asked to indicate their college/department affiliation. The results showed that most professors were affiliated to Education $(n=14,36.8 \%)$ followed by Psychology $(n=8$, 21.1\%), Sociology/Anthropology $(n=6,15.8 \%)$, and Political Science $(n=5,13.2 \%)$. Two professors were affiliated to Communication $(n=2,5.3 \%)$ college/department (see Table 6).

A total of 114 doctoral students (including doctoral candidates) completed the survey. The gender composition included 30 males and 84 females constituting $26.3 \%$ and $73.7 \%$ of student participants respectively. Under ethnicity, $81.6 \%$ of the students indicated that they were Whites/Caucasians (n=93). Also, $6.1 \%$ were Asians/Pacific Islanders ( $n=7), 4.4 \%$ Hispanics/Latinos ( $n=5)$, and 3.5\% African Americans/Blacks (n=4). Lastly, $4.4 \%$ of the students $(n=5)$ stated the race other than the ones mentioned above (see Table 6). Concerning their college/department affiliation, large number of students was affiliated to Psychology $(n=44$, $38.6 \%)$, Education $(n=36,31.6 \%)$ and Sociology/Anthropology $(n=17,14.9 \%)$. Few of them were from Political Science $(n=8,7.0 \%)$ and Communication $(n=6,5.3 \%)$. 
Table 6

Demographics of participants and their respective percentages (in the parenthesis)

\begin{tabular}{lcc}
\hline \multicolumn{1}{c}{ Characteristic } & Professors & $\begin{array}{c}\text { Doctoral students (including } \\
\text { doctoral candidates) } \\
\mathrm{N}=114\end{array}$ \\
\hline Gender & $\mathrm{N}=38$ & $30(26.3)$ \\
Male & $18(47.4)$ & $84(73.7)$ \\
Female & $20(52.6)$ & $93(81.6)$ \\
Ethnicity & $35(92.1)$ & $4(3.5)$ \\
White/Caucasian & $2(5.3)$ & $5(4.4)$ \\
African American/Black & $1(2.6)$ & $7(6.1)$ \\
Hispanic/Latino & & $5(4.4)$ \\
Asian/Pacific Islander & & $36(31.6)$ \\
Other & $14(36.8)$ & $8(7.0)$ \\
College/Department affiliation & $5(13.2)$ & $6(5.3)$ \\
Education & $2(5.3)$ & $17(14.9)$ \\
Political Science & $6(15.8)$ & $44(38.6)$ \\
Communication & $8(21.1)$ & $2(1.8)$ \\
Sociology/Anthropology & $3(7.9)$ & $1(0.8)$ \\
Psychology & & \\
Other & & \\
No response & & \\
\hline
\end{tabular}

\section{Procedure}

Collecting concept mapping data online. Traditionally, concept mapping data collection is done at one location with participants directly involved in brainstorming, sorting, and rating statements (Kane \& Trochim, 2007). However, for this study, it was not feasible to bring all participants under one roof to engage in these activities. I put the 40 items on an online tool used in designing, collecting, and analyzing surveys for participants to engage in sorting and rating these statements. This process was quite different from the ordinary online survey. Participants were informed about what concept mapping involved, how sorting was done online, and how to conduct two sets of ratings on each statement. A four minute video was created to 
explicitly and briefly give potential participants information about concept mapping and how to complete the survey.

Survey approval and distribution stage. I submitted the proposal of this study to the Institutional Review Board (IRB) in my institution for an approval. After the IRB approval, I sent a letter of permission by email to the appropriate college deans and/or department heads of the selected universities. The purpose of the letter was to find out whether the link of the survey could be forwarded to potential participants in their colleges/departments. The letter also stated the purpose of the study, detailed description of the questionnaire, and my intention of providing them with the results if requested. Upon approval, and with the help of the contact person, the link of the survey was sent to potential participants. The data collection lasted for five weeks.

In addition to the 40 statements on the survey, demographic items included participants' gender, college/department affiliation, ethnicity, academic title, advising experience, and how long they (doctoral students') have spent in their doctoral education. Demographic information will help me to answer the potential research questions (listed in the introduction section) later in my professional career as a faculty member.

Expected sampling challenges and solution. I expected that some colleges/departments might decide not to participate. In a situation where more than two colleges/departments in a selected institution decide not to take part in the study, I randomly selected another university to replace it. I was aware of the relatively low returns of online surveys. To address this, I emphasized the possible benefits of this study, which was to improve the quality of doctoral advising, when distributing the survey to potential participants. It was incorporated in the four minute video. They were also informed that they had the option to participate in a $\$ 25$ gift 
certificate drawing and request for the results of the study. Lastly, with the help of the contact person in the various selected colleges/departments, a follow up email reminder was sent to potential participants. All these were done to counter the probability of having low return rate.

Collection of the completed survey. Participants took 25 to 30 minutes to complete the survey. At the end of survey administration duration, I used SPSS to randomly select ten participants and contact them for their $\$ 25$ gift card. In addition, after completing the survey, I provided the result of the study to participants who requested for it. 


\section{Chapter 4}

\section{Analysis of Data}

The inability of a substantial number of doctoral students to successfully complete their dissertations has been partly attributed to challenges in doctoral advising. Studies have shown that there are factors of doctoral advising that directly or indirectly contribute to students' successful completion of their dissertations. Using concept mapping as a research method, I conducted a document analysis on doctoral advising related literature. I identified five components of doctoral advising: (a) advising approach, (b) selection process, (c) roles, responsibilities, and expectations, (d) advisor-advisee relationship, and (e) power relations. I then generated statements that reflect these components. I came up with 40 statements. My aim for this study was to conceptualize the perspectives of professors and doctoral students on doctoral advising. I presented the 40 statements to professors and doctoral students at universities with high and very high research activities to sort and rate them in the form of an online survey. In this chapter I will present a detailed description on how the data was analyzed. I will then present the findings, which directly answer the research questions.

\section{Data Analysis Process}

I collected two forms of data from each participant: the sorting and the rating data. I uploaded the sorting into SPSS to run Multidimensional Scaling Analysis (MDS) (see Figure 6). MDS was used to generate $\mathrm{x}$ and y coordinates for each statement (Kane \& Trochim, 2007). These vectors for the 40 sorted statements determined the location of each statement in the two dimensional graph. The coordinates generated as a result of MDS analysis were used to conduct

Hierarchical Cluster Analysis (HCA): thus, to determine the overall categories that represent the 
sorted statements collected from participants (see Appendix A and B, Tables A1 and B1). The HCA output, Hierarchical Cluster Tree (or dendrogram) showed the number of clusters and specific statements in each cluster (see Appendix A and B: Figures A2 and B2, for the coordinates).

I created scatter plots using the coordinates generated from professors and students sorted data. The scatter plots were transformed into point maps. The point map showed the location of each statement and their closeness on the map (see Appendix A and B, Figures A1 and B1). With information from the Hierarchical Cluster Tree, I plotted the various clusters on the point map. The point map was then converted to the point cluster map, which visually displayed the clusters and their relationships in terms of proximity (Kane \& Trochim, 2007). Based on my understanding of doctoral advising literature and the statements in each category, I labeled the clusters shown on the point cluster map, which was then changed to a named cluster map (see Figures 7 and 8).

The rating data was loaded into SPSS to calculate the mean ratings for each statement. The mean clusters computed were used to create a bar chart using Microsoft Excel. This chart showed the means for each cluster in terms of their importance to the successful completion of students' dissertations and level of difficulty during implementation of the activities (statements). I conducted internal consistency analyses for the rating data and each of the clusters (see Tables 22 and 30). The last statistical analysis I conducted was to use the mean rating for each statement within each cluster to create the go-zone graph. The go-zone graph displayed the location of each statement on a graph with $\mathrm{x}$ and $\mathrm{y}$ coordinates, where $\mathrm{x}=$ difficulty mean ratings, and $\mathrm{y}=$ importance mean ratings. All these analyses were carried out so as to answer the research questions. 
Focus Question: How are the concept mapping data analyzed?

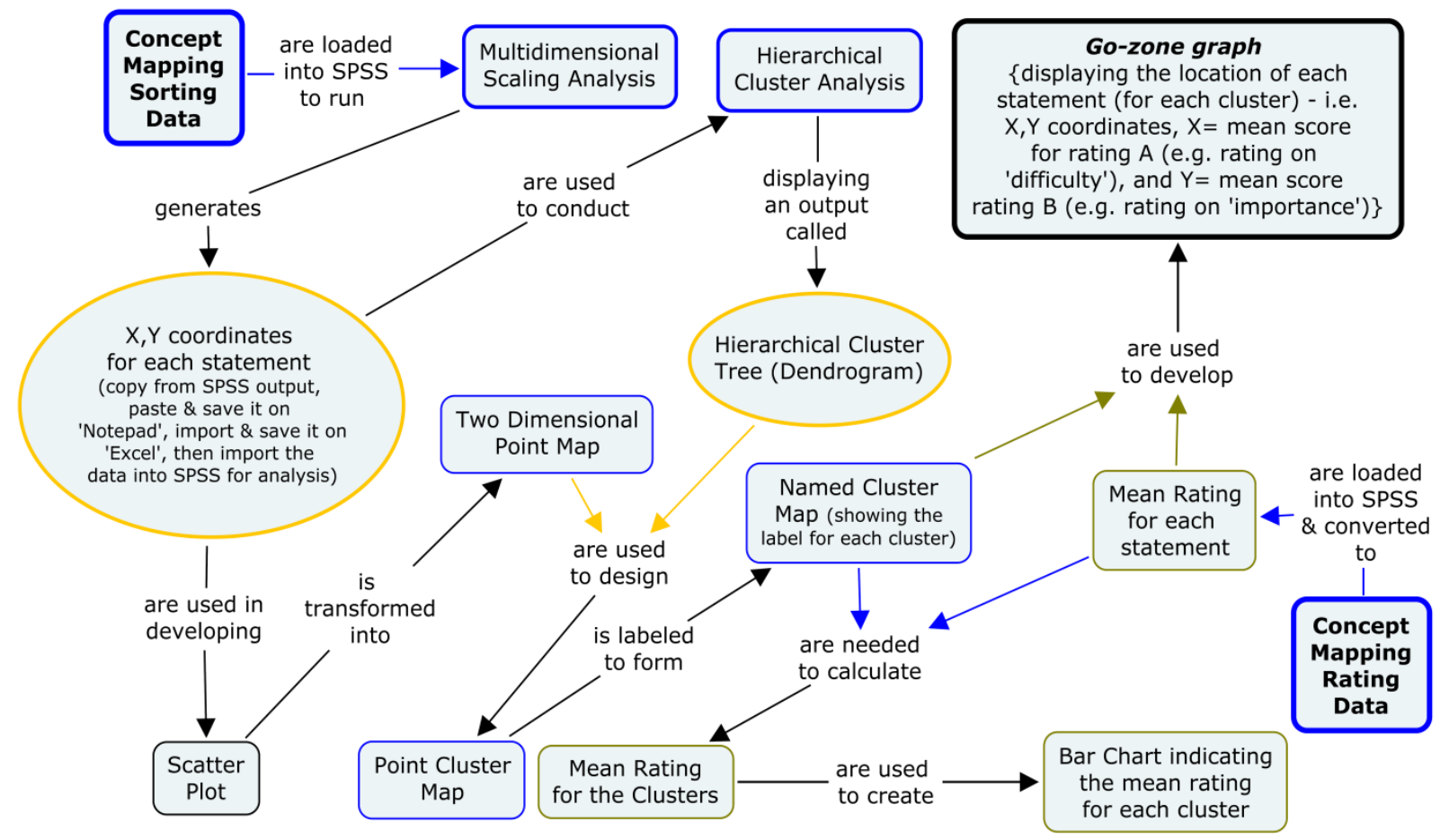

Figure 6. Diagram showing how the concept mapping data was analyzed

\section{Presentation of Findings}

Research question 1. How can we conceptualize the perspectives of professors and doctoral students on doctoral advising?

Findings based on doctoral students' sorted data. The data sorted by doctoral students (including doctoral candidates) were statistically analyzed using Multidimensional Scaling (MDS). I conducted MDS using a two-dimensional solution for the 40 sorted statements. The results showed a stress value of .18. This relatively low value indicated that the two-dimensional 
coordinates was a good fit for the students' sorted data. Moreover, the R square was .88, meaning the model (two-dimensional solution) explained $88 \%$ of the variability in the sorting data.

The output of HCA (i.e. Hierarchical Cluster tree or dendrogram) yielded two to ten possible clusters (see Figure A2). The coordinates were also used to create a scatter plot, or twodimensional point map (see Figure A1). To decide the final number of clusters to represent students' sorted data, I mapped the possible number of clusters (suggested by the dendrogram) on the two-dimensional point map. I then assessed their content and proximity to one another. Subsequently, I concluded that the six-cluster solution best represented the sorted data. Figure 7 shows students' overall groupings of the 40 statements.

Cluster 2 (Promoting a supportive advisor-advisee relationship coupled with negotiations) had the highest number of statements. It had 15 statements. The named cluster map (in Figure 7) showed a relation between cluster 2 and cluster 4 (Guiding advisees in a professional manner as they take a responsible role) in terms of their proximity and labels. Likewise, cluster 1 (Exercising freedom and flexibility in the advisor/advisee selection) and cluster 3 (Attaining the 'best' match during the advisor selection process) mainly focused on the advisor/advisee selection procedure. Although cluster 5 (Understanding the changing expectations and complex nature of doctoral advising) and cluster 6 (Exercising power in advising relationships) were graphically close (on the named cluster map), they were distinct in content. Tables 7 to 12 show the statements in each cluster. 


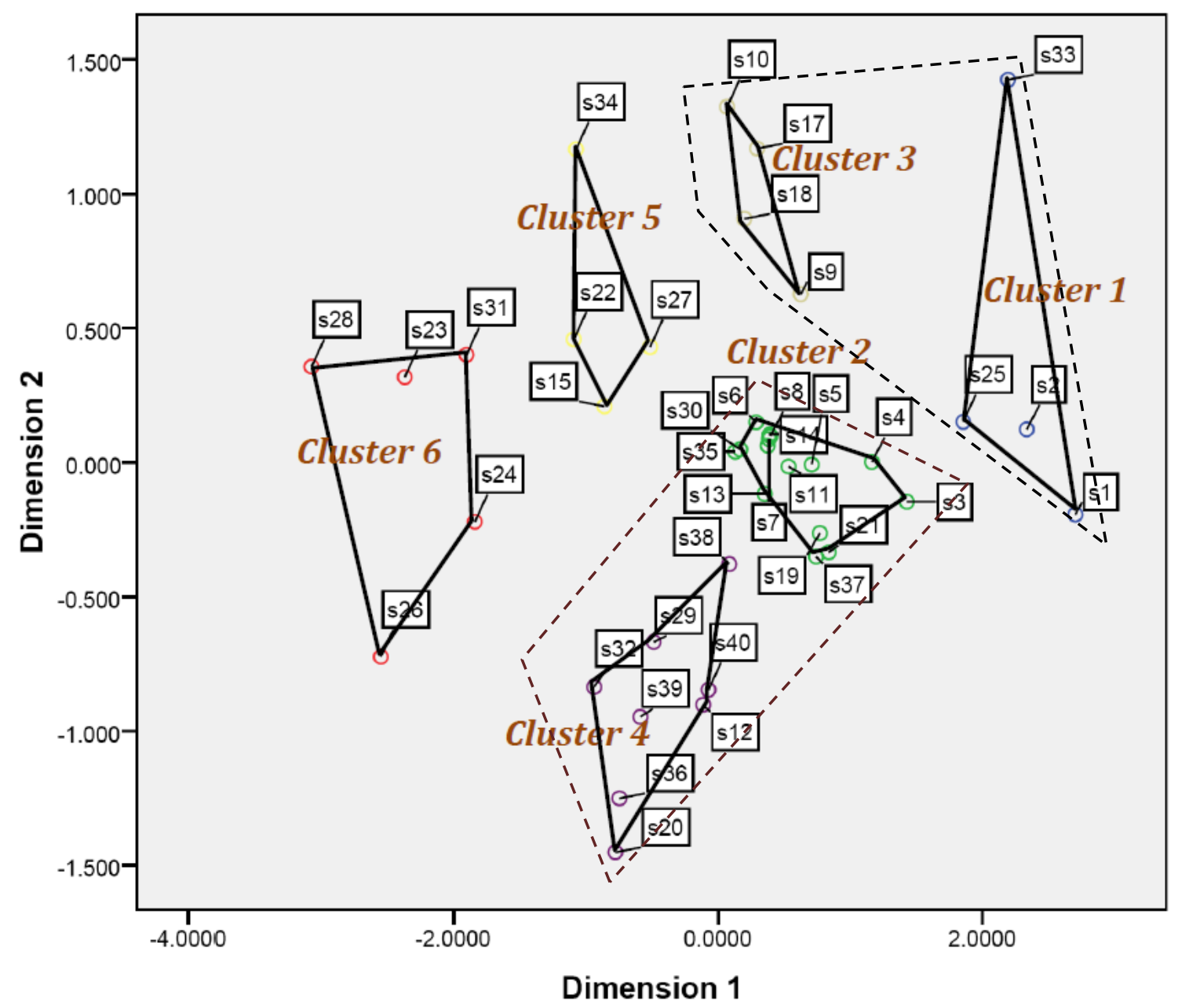

Figure 7. Named cluster map showing the six clusters (based on students' sorted data)

Table 7

List of statements in cluster 1 (based on students' sorted data)

Cluster 1 (Exercising freedom and flexibility in the advisor/advisee selection)

s1 Students should be given the opportunity to choose their advisors.

s2 Students should have the chance to easily change their advisors when necessary.

s25 Advisors should have the chance to choose who they want to work with.

s33 Students should select their advisors at an early stage in their doctoral education. 
Table 8

List of statements in cluster 2 (based on students' sorted data)

\begin{tabular}{|c|c|}
\hline & $\begin{array}{c}\text { Cluster } 2 \text { (Promoting a supportive advisor-advisee relationship coupled with } \\
\text { negotiations) }\end{array}$ \\
\hline s3 & Advisors should be accessible to students. \\
\hline s4 & $\begin{array}{l}\text { Advisors and students should meet frequently to talk about issues related to } \\
\text { dissertations. }\end{array}$ \\
\hline s5 & $\begin{array}{l}\text { Advisors should provide adequate support for students in terms of carrying out } \\
\text { specific tasks. }\end{array}$ \\
\hline s6 & Advisors should take the initiative in building and maintaining a good relationship. \\
\hline s7 & There should be honest communication between advisors and students. \\
\hline s8 & There should be open dialogue concerning making decisions and resolving conflicts. \\
\hline s11 & Advisors should make efforts to identify the needs of their students. \\
\hline s13 & Advisors should be sensitive to the needs of their students. \\
\hline s14 & Advisors and students should build trust through negotiation and agreement. \\
\hline s16 & Students should be able to express their disagreement when necessary. \\
\hline s19 & Advisors should provide students with needed support. \\
\hline s21 & Advisors should give timely feedback to students. \\
\hline s30 & Students should feel comfortable sharing their academic challenges with advisors. \\
\hline s35 & Advisors and students should clearly define their expectations and goals. \\
\hline s37 & Advisors should be ready to listen to the concerns of their students. \\
\hline
\end{tabular}

Table 9

List of statements in cluster 3 (based on students' sorted data)

Cluster 3 (Attaining the 'best' match during the advisor selection process)

s9 Students should be well-informed about the research interest, advising style, and expectations of potential advisors.

s10 Advisors and students should have similar research interests.

s17 Students should clearly define what they expect from potential advisors.

s18 Advisors and students should have matched goals and expectations. 
Table 10

List of statements in cluster 4 (based on students' sorted data)

\begin{tabular}{ll}
\hline & Cluster 4 (Guiding advisees in a professional manner as they take a responsible role) \\
\hline s12 & $\begin{array}{l}\text { Procedures for writing dissertations should be explicitly explained to doctoral } \\
\text { students. }\end{array}$ \\
s20 & Students should be allowed to take charge of their dissertation process. \\
s29 & Advisors should focus on directing students toward set goals. \\
s32 & Advisors should make sure students follow procedures acceptable to the research \\
& community. \\
s36 & Advisors should frequently reflect on their advising style or approach. \\
s38 & There should be mutual respect between advisors and students. \\
s39 & Advisors should be ready to intervene when students are going off-track. \\
s40 & Advisors should give constructive criticism on students' dissertations. \\
\hline
\end{tabular}

Table 11

List of statements in cluster 5 (based on students' sorted data)

Cluster 5 (Understanding the changing expectations and complex nature of doctoral advising)

s15 The boundaries of the relationship should be well-defined.

s22 Students should be aware of the complexities of advisor-advisee relationships.

s27 Advisors and students should negotiate their roles and responsibilities.

s34 Students should be able to adjust to changing expectations and roles.

Table 12

List of statements in cluster 6 (based on students' sorted data)

Cluster 6 (Exercising power in advising relationships)

s23 Students have to respect the authority of their advisors.

s24 Advisors should exercise their power (expert knowledge) when necessary.

s26 Students should be independent.

s28 Students should strictly follow the directions provided by advisors.

s31 There should be an equal balance of power between advisors and advisees.

Findings based on professors' sorted data. The professors' sorted data was analyzed

using MDS. The relatively low stress test of .17 indicated that the two-dimensional coordinates

was a good fit for the sorted statements. The R square was .89: meaning, the model (two- 
dimensional solution) explained $89 \%$ of the variability in how participants (professors) grouped the statements. Analysis of the dendrogram and two-dimensional point map revealed that the sixcluster solution best reflected the professors' sorted data. Figure 2 shows the locations of the six clusters on the point map and their proximity to each other.

The content and closeness of clusters 2 (Enhancing advisor-advisee interaction in a supportive environment), 3 (Maintaining a good relationship through dialogue and clarity of expectations), and 5 (Promoting students' independence with advisors' guidance) indicated existing similarities (see Figure 8). For instance, they all emphasized interaction and support. Although cluster 1 (Selecting advisors in an early stage and having the chance to change them) and cluster 4 (Matching interests through negotiation in the selection process) were far apart, content assessment revealed that they had a common theme: they revolved around the advisor/advisee selection process. Tables 13 to 18 show the statements in each cluster. 


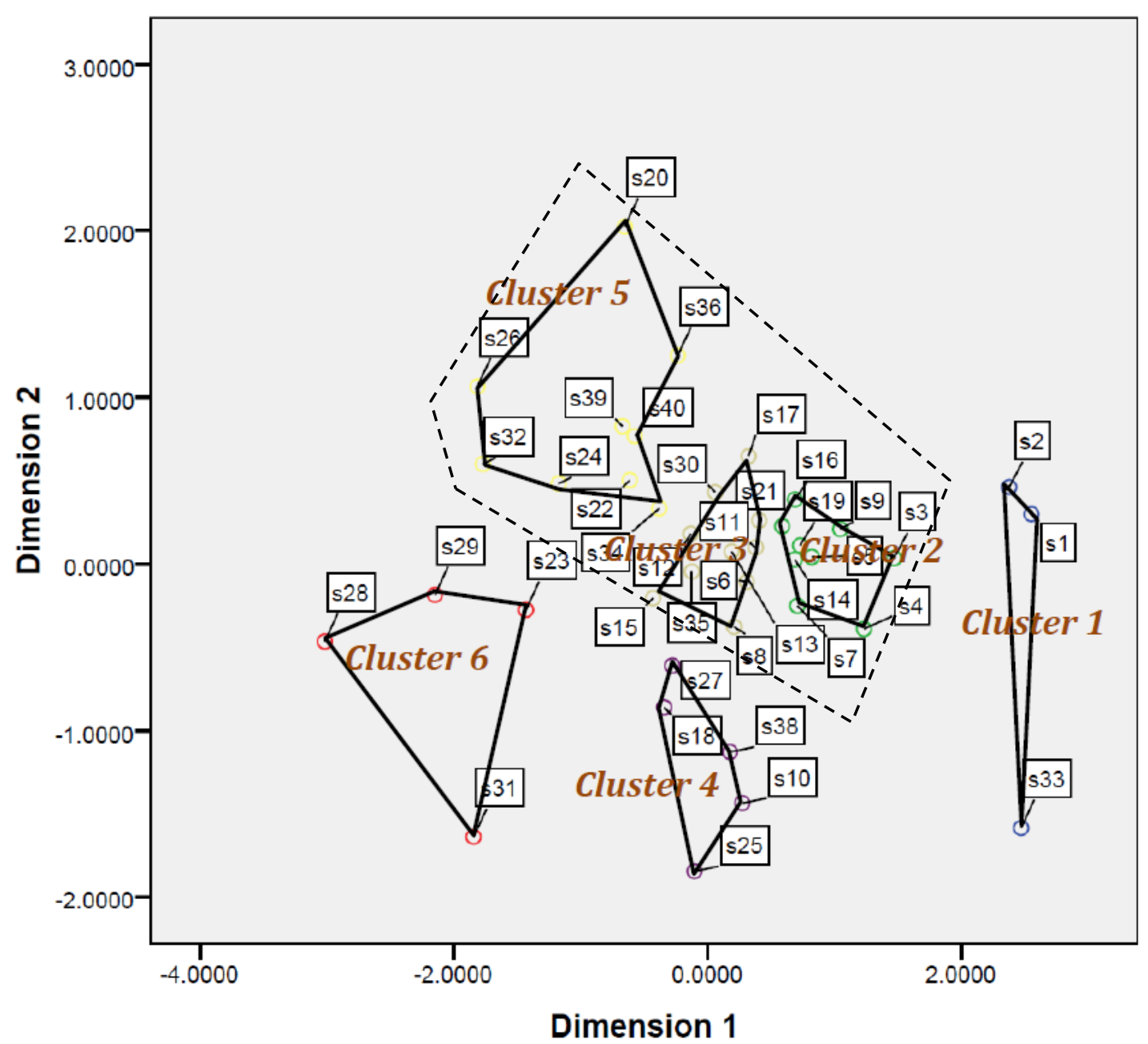

Figure 8. Named cluster map showing the six clusters (based on professors' sorted data)

Table 13

List of statements in cluster 1 (based on professors' sorted data)

\begin{tabular}{|c|c|}
\hline & $\begin{array}{c}\text { Cluster } 1 \text { (Selecting advisors in an early stage and having the chance to change } \\
\text { them) }\end{array}$ \\
\hline s1 & Students should be given the opportunity to choose their advisors. \\
\hline s2 & Students should have the chance to easily change their advisors when necessary. \\
\hline s33 & Students should select their advisors at an early stage in their doctoral education. \\
\hline
\end{tabular}


Table 14

List of statements in cluster 2 (based on professors' sorted data)

\begin{tabular}{ll}
\hline & \multicolumn{1}{c}{ Cluster 2 (Enhancing advisor-advisee interaction in a supportive environment) } \\
\hline s3 & Advisors should be accessible to students. \\
s4 & $\begin{array}{l}\text { Advisors and students should meet frequently to talk about issues related to } \\
\text { dissertations. }\end{array}$ \\
s5 & Advisors should provide adequate support for students in terms of carrying out \\
& specific tasks. \\
s7 & There should be honest communication between advisors and students. \\
s9 & Students should be well-informed about the research interest, advising style, and \\
& expectations of potential advisors. \\
s14 & Advisors and students should build trust through negotiation and agreement. \\
s16 & Students should be able to express their disagreement when necessary. \\
s19 & Advisors should provide students with needed support. \\
s37 & Advisors should be ready to listen to the concerns of their students. \\
\hline
\end{tabular}

Table 15

List of statements in cluster 3 (based on professors' sorted data)

\begin{tabular}{|c|c|}
\hline & $\begin{array}{c}\text { Cluster } 3 \text { (Maintaining a good relationship through dialogue and clarity of } \\
\text { expectations) }\end{array}$ \\
\hline s6 & Advisors should take the initiative in building and maintaining a good relationship. \\
\hline s8 & There should be open dialogue concerning making decisions and resolving conflicts. \\
\hline s11 & Advisors should make efforts to identify the needs of their students. \\
\hline s12 & $\begin{array}{l}\text { Procedures for writing dissertations should be explicitly explained to doctoral } \\
\text { students. }\end{array}$ \\
\hline s13 & Advisors should be sensitive to the needs of their students. \\
\hline s15 & The boundaries of the relationship should be well-defined. \\
\hline s17 & Students should clearly define what they expect from potential advisors. \\
\hline s21 & Advisors should give timely feedback to students. \\
\hline s30 & Students should feel comfortable sharing their academic challenges with advisors. \\
\hline s35 & Advisors and students should clearly define their expectations and goals. \\
\hline
\end{tabular}


Table 16

List of statements in cluster 4 (based on professors' sorted data)

\begin{tabular}{ll}
\hline & \multicolumn{1}{c}{ Cluster 4 (Matching interests through negotiation in the selection process) } \\
\hline s10 & Advisors and students should have similar research interests. \\
s18 & Advisors and students should have matched goals and expectations. \\
s25 & Advisors should have the chance to choose who they want to work with. \\
s27 & Advisors and students should negotiate their roles and responsibilities. \\
s38 & There should be mutual respect between advisors and students. \\
\hline
\end{tabular}

Table 17

List of statements in cluster 5 (based on professors' sorted data)

Cluster 5 (Promoting students' independence with advisors' guidance)

\begin{tabular}{ll}
\hline s20 & Students should be allowed to take charge of their dissertation process. \\
s22 & Students should be aware of the complexities of advisor-advisee relationships. \\
s24 & Advisors should exercise their power (expert knowledge) when necessary. \\
s26 & Students should be independent. \\
s32 & Advisors should make sure students follow procedures acceptable to the research \\
& community. \\
s34 & Students should be able to adjust to changing expectations and roles. \\
s36 & Advisors should frequently reflect on their advising style or approach. \\
s39 & Advisors should be ready to intervene when students are going off-track. \\
s40 & Advisors should give constructive criticism on students' dissertations.
\end{tabular}

Table 18

List of statements in cluster 6 (based on professors' sorted data)

\begin{tabular}{ll}
\hline & \multicolumn{1}{c}{ Cluster 6 (Encouraging students to follow advisors' directions) } \\
\hline s23 & Students have to respect the authority of their advisors. \\
s28 & Students should strictly follow the directions provided by advisors. \\
s29 & Advisors should focus on directing students toward set goals. \\
s31 & There should be an equal balance of power between advisors and advisees. \\
\hline
\end{tabular}


Research question 1a. How do the five components of doctoral advising from the literature, map onto both doctoral students' and professors' conceptualization of advising?

Findings based on doctoral students' sorted data. Based on the Hierarchical cluster tree (dendrogram) and the two-dimensional point map, six clusters were created to represent students' sorted data. As shown in Table 19, all of the statements in cluster 1 (Exercising freedom and flexibility in the advisor/advisee selection) and cluster 3 (Attaining the 'best' match during the advisor selection process) were related to selection process. Most statements in cluster 2 (Promoting a supportive advisor-advisee relationship coupled with negotiations) fell under two components of doctoral advising: roles, responsibilities, and expectations (5 statements), and advisor-advisee relationship (5 statements). Three of cluster 2's statements were from the advising approach component while two of them were related to power relations. Students sorted most of the statements (4 items) from advising approach into cluster 4 (Guiding advisees in a professional manner as they take a responsible role). Also, cluster 4 had three of its statements related to power relations and one statement from advisor-advisee relationship. With four items, cluster 5 (Understanding the changing expectations and complex nature of doctoral advising) had two statements in roles, expectations and responsibility, and two statements in advisor-advisee relationship. Lastly, power relations, roles, responsibilities, and expectations, and advising approach shared three, one, and one of the cluster 6's (Exercising power in advising relationships) statements, respectively. 
Table 19

Clusters (generated from students' sorted data) with the number of statements and the advising components they belong to

\begin{tabular}{|c|c|c|c|c|c|c|}
\hline Cluster & $\begin{array}{c}\text { No. of items } \\
\text { in each } \\
\text { cluster } \\
\end{array}$ & $\begin{array}{l}\text { Advising } \\
\text { approach }\end{array}$ & $\begin{array}{l}\text { Selection } \\
\text { process }\end{array}$ & $\begin{array}{c}\text { Roles, } \\
\text { responsibilities, } \\
\text { \& expectations }\end{array}$ & $\begin{array}{c}\text { Advisor- } \\
\text { advisee } \\
\text { relationship }\end{array}$ & $\begin{array}{l}\text { Power } \\
\text { relations }\end{array}$ \\
\hline Cluster 1 & 4 & & 4 & & & \\
\hline Cluster 2 & 15 & 3 & & 5 & 5 & 2 \\
\hline Cluster 3 & 4 & & 4 & & & \\
\hline Cluster 4 & 8 & 4 & & & 1 & 3 \\
\hline Cluster 5 & 4 & & & 2 & 2 & \\
\hline Cluster 6 & 5 & 1 & & 1 & & 3 \\
\hline Total & 40 & 8 & 8 & 8 & 8 & 8 \\
\hline
\end{tabular}

Findings based on professors' sorted data. Analysis of the dendrogram and the twodimensional cluster map revealed that the six clusters generally represented how professors sorted the 40 statements. Each of these statements was related to one of the five components of doctoral advising. Table 20 shows how the statements were distributed in their respective clusters. Most of the statements from power relations were grouped under cluster 5 (Promoting students' independence with advisors' guidance). Five statements in cluster 5 belonged to power relations while the other four were related to advising approach, roles, responsibilities, and expectations, and advisor-advisee relationship.

All the statements (3 items) in cluster 1 (Selecting advisors in an early stage and having the chance to change them) were generated from selection process. Three statements belonging to selection process were categorized under cluster 4 (Matching interests through negotiation in the selection process), which accounted for most of the items in the cluster. Six of the statements under advisor-advisee relationship were equally distributed between cluster 2 (Enhancing advisor-advisee interaction in a supportive environment) and cluster 3 (Maintaining a good 
relationship through dialogue and clarity of expectations). Three of the cluster 2 statements were related to roles, responsibilities, and expectations while three of the cluster 3 statements belong to the advising approach component. Lastly, two statements from the advising approach component and two statements from power relations were part of cluster 6 (Encouraging doctoral students to follow advisors' directions).

Table 20

Clusters (generated for professors' sorted data) with the number of statements and the advising components they belong to

\begin{tabular}{lcccccc}
\hline Cluster & $\begin{array}{c}\text { No. of items } \\
\text { in each } \\
\text { cluster }\end{array}$ & $\begin{array}{c}\text { Advising } \\
\text { approach }\end{array}$ & $\begin{array}{c}\text { Selection } \\
\text { process }\end{array}$ & $\begin{array}{c}\text { Roles, } \\
\text { responsibilities, } \\
\text { \& expectations }\end{array}$ & $\begin{array}{c}\text { Advisor- } \\
\text { advisee } \\
\text { relationship }\end{array}$ & $\begin{array}{c}\text { Power } \\
\text { relations }\end{array}$ \\
\hline Cluster 1 & 3 & & 3 & & & \\
Cluster 2 & 9 & 1 & 1 & 2 & 3 & 1 \\
Cluster 3 & 10 & 3 & 1 & 2 & 3 & 1 \\
Cluster 4 & 5 & 2 & 3 & 2 & 1 & 4 \\
Cluster 5 & 9 & 2 & & 8 & 8 & 2 \\
Cluster 6 & 4 & 8 & 8 & & & 8 \\
\hline Total & 40 & &
\end{tabular}

Research question $\mathbf{1 b}$. How do professors and doctoral students rate the importance and difficulty of the advising statements/activities?

Findings from students' data. The go-zone graph shows the 40 statements rated by students (see Figure 9). The location of each statement indicated how they were rated in terms of their difficulty of implementation and their importance to the successful completion of dissertations. Out of 40 statements, 21 were in the upper quadrants of the go-zone graph. To students, these statements were more important advising related activities. They likely contribute 
to their successful dissertation completion. However, only nine statements were considered gozone statements because they were perceived as more important to the successful completion of their dissertations and less difficult to carry out. These statements accounted for $22.5 \%$ of all the rated statements. The upper-left quadrant (actionable) statements included; s1 (Students should be given the opportunity to choose their advisors), s3 (Advisors should be accessible to students), s7 (There should be honest communication between advisors and students), s9 (Students should be well-informed about the research interest, advising style, and expectations of potential advisors), s12 (Procedures for writing dissertations should be explicitly explained to doctoral students), s29 (Advisors should focus on directing students toward set goals), s32 (Advisors should make sure students follow procedures acceptable to the research community), s38 (There should be mutual respect between advisors and students), and s40 (Advisors should give constructive criticism on students' dissertations).

Twelve statements, which were located at the upper-right quadrant, were considered more important and more difficult. They included; s2 (Students should have the chance to easily change their advisors when necessary), s4 (Advisors and students should meet frequently to talk about issues related to dissertations), s8 (There should be open dialogue concerning making decisions and resolving conflicts), s16 (Students should be able to express their disagreement when necessary), s18 (Advisors and students should have matched goals and expectations), s19 (Advisors should provide students with needed support), s21 (Advisors should give timely feedback to students), s30 (Students should feel comfortable sharing their academic challenges with advisors), s34 (Students should be able to adjust to changing expectations and roles), s35 (Advisors and students should clearly define their expectations and goals), s37 (Advisors should 
be ready to listen to the concerns of their students), and s39 (Advisors should be ready to intervene when students are going off-track).

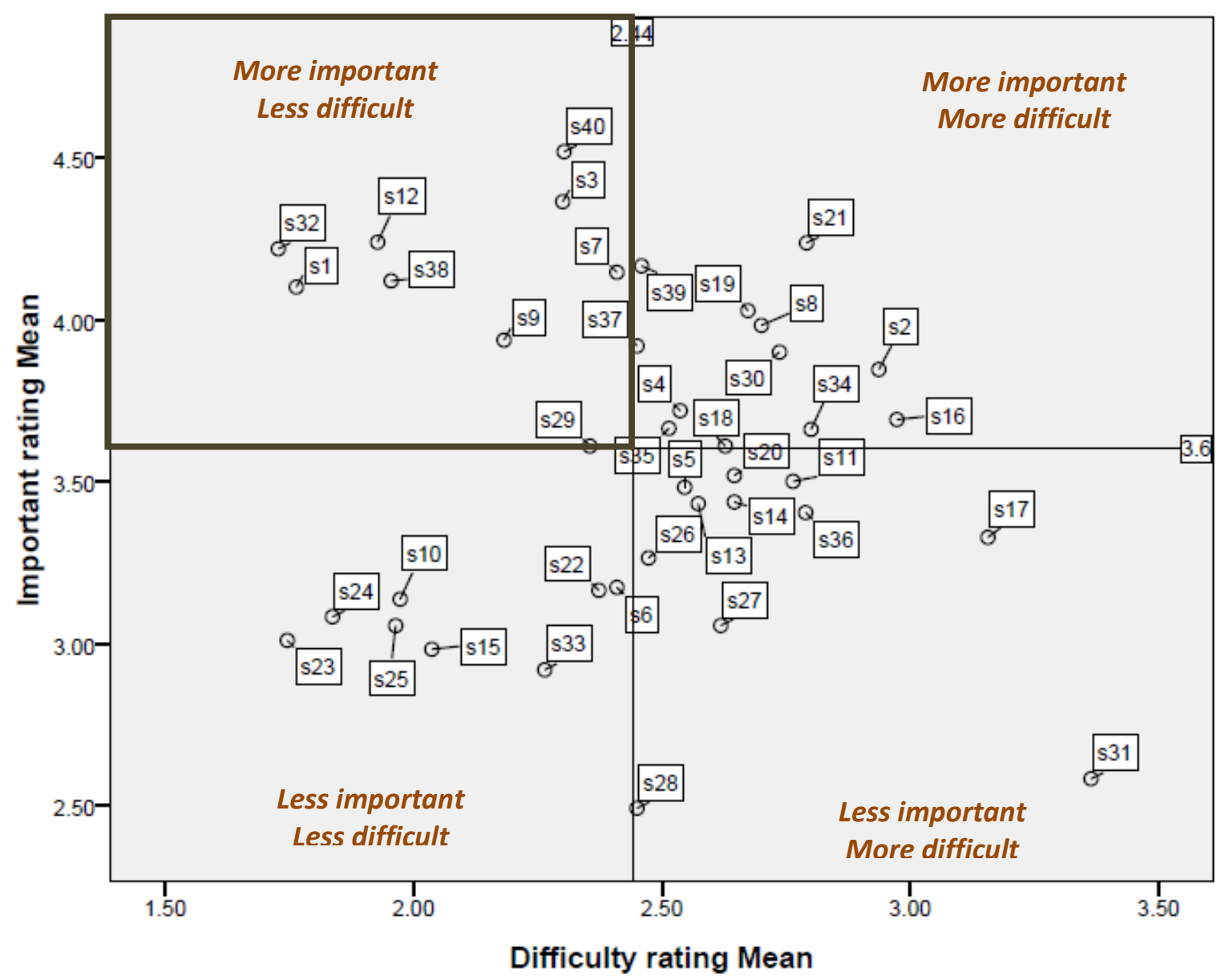

Figure 9. Go-zone graph displaying all 40 statements (based on students' rated data). Note. The quadrants were created based on the overall mean of the difficulty and importance ratings.

The go-zone graph in Figure 10 displays the location of each cluster based on rating data. It shows that students perceived clusters 2 (Promoting a supportive advisor-advisee relationship coupled with negotiations) and 4 (Guiding advisees in a professional manner as they take a responsible role) as more important (on average). However, only cluster 4 was viewed as more 
important and less difficult. Clusters 1 (Exercising freedom and flexibility in the advisor/advisee selection), 3 (Attaining the 'best' match during the advisor selection process), 5 (Understanding the changing expectations and complex nature of doctoral advising) and 6 (Exercising power in advising relationships) were viewed as less important. In terms of implementation, students perceived clusters 1 and 6 as less difficult but viewed clusters 3 and 5 as more difficult (see Figure 10).

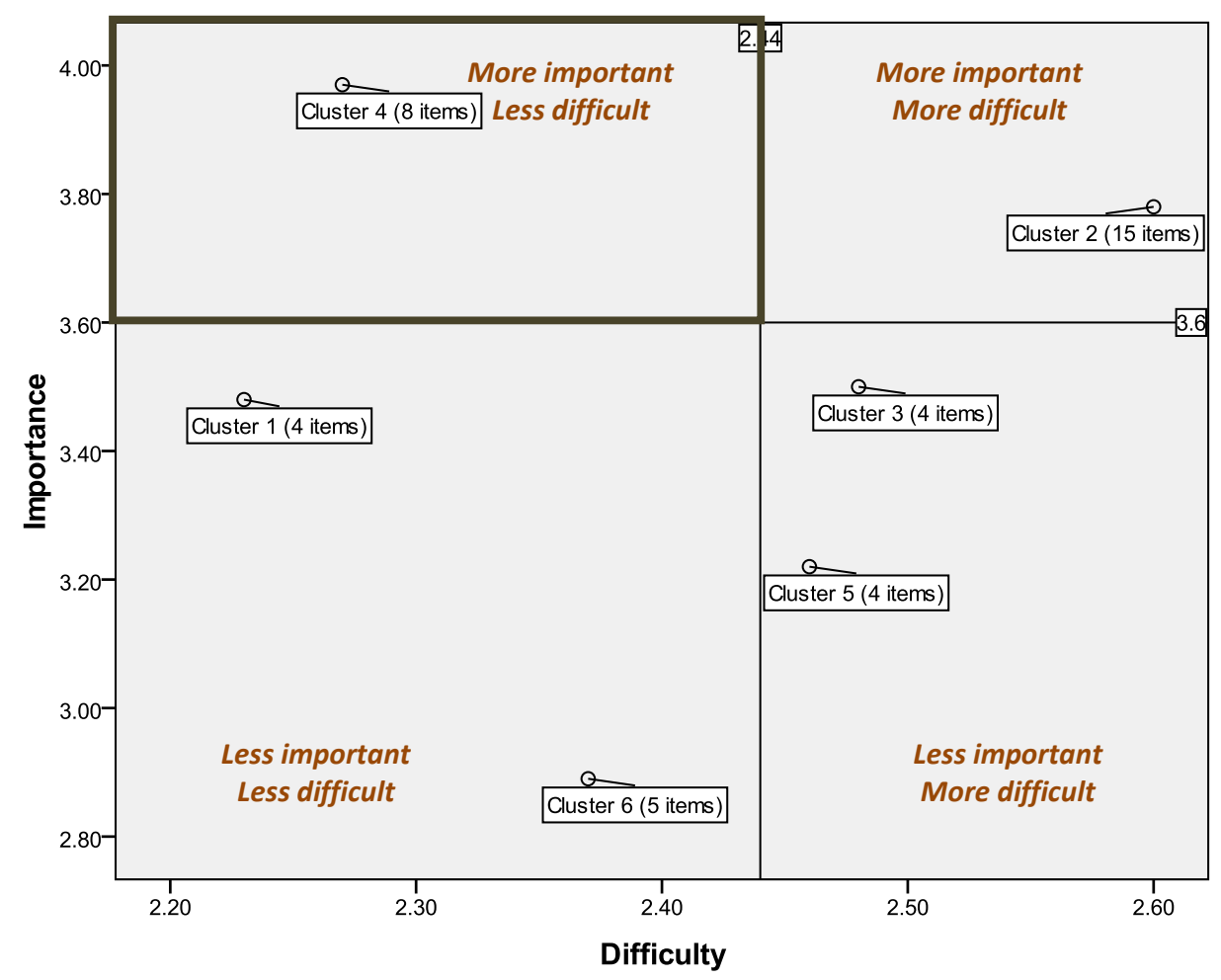

Figure 10. Go-zone graph displaying the six clusters in their respective quadrants (based on students' data). Note. The quadrants were created based on the overall mean of the difficulty and importance ratings. 
Table 21

Means (standard deviations) of the six clusters (based on students'data)

\begin{tabular}{llc}
\hline (Sub)scale & Difficulty & Importance \\
\hline Cluster 1 (4 items) & $2.23(.51)$ & $3.48(.58)$ \\
Cluster 2 (15 items) & $2.60(.18)$ & $3.78(.34)$ \\
Cluster 3 (4 items) & $2.48(.52)$ & $3.50(.35)$ \\
Cluster 4 (8 items) & $2.27(.37)$ & $3.97(.41)$ \\
Cluster 5 (4 items) & $2.46(.33)$ & $3.22(.31)$ \\
Cluster 6 (5 items) & $2.37(.65)$ & $2.89(.33)$ \\
\hline Total $(40$ items) & $2.44(.39)$ & $3.59(.50)$ \\
\hline
\end{tabular}

Cluster 1 (Exercising freedom and flexibility in the advisor/advisee selection)

Cluster 2 (Promoting a supportive advisor-advisee relationship coupled with negotiations)

Cluster 3 (Attaining the 'best' match during advisor selection process)

Cluster 4 (Guiding advisees in a professional manner as they take a responsible role)

Cluster 5 (Understanding the changing expectations and complex nature of doctoral advising)

Cluster 6 (Exercising power in advising relationships)

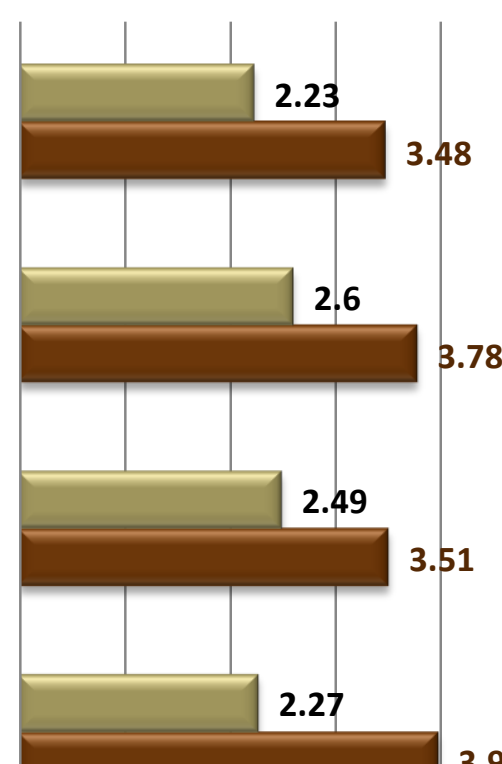

Mean ratings for 'Difficulty'

Mean ratings for 'Importance'

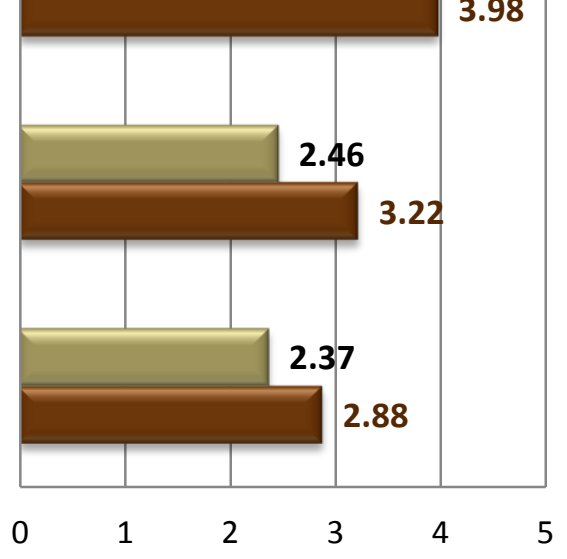

Figure 11. Bar chart showing the mean ratings (importance and difficulty) for the six clusters (based on students' data) 
Table 22

Cronbach's alpha $(\alpha)$ coefficients for internal consistency for the six clusters (based on students' data)

\begin{tabular}{lcc}
\hline \multicolumn{1}{c}{$($ Sub)scale } & Difficulty & Importance \\
\hline Cluster 1 (4 items) & .24 & .41 \\
Cluster 2 (15 items) & .90 & .86 \\
Cluster 3 (4 items) & .59 & .64 \\
Cluster 4 (8 items) & .71 & .68 \\
Cluster 5 (4 items) & .66 & .68 \\
Cluster 6 (5 items) & .45 & .47 \\
\hline Total (40 items) & .91 & .90 \\
\hline
\end{tabular}

Note. According to Field (2005), the acceptable Cronbach's alpha coefficient for internal consistency should be at least .7. The Cronbach's alpha coefficients should be interpreted with caution because a small $\alpha$ value may have been influenced by a relatively small number of items in the cluster.

\section{Statements in cluster 1 (Exercising freedom and flexibility in the advisor/advisee} selection). The cluster go-zone graph indicates that students viewed cluster 1 as less important and less difficult (see Figure 10). Cluster 1 has four items. Because of the relatively low internal consistency $(\alpha)$ of .24 for difficulty and .41 for importance' ratings of cluster 1 , it is particularly important to examine individual statements and their respective ratings. Table 23 provides the means (M) of the statements in cluster 1. On the go-zone graph (Figure 12), statement s1 (Students should be given the opportunity to choose their advisors) was rated as more important and less difficult while statement s2 (Students should have the chance to easily change their advisors when necessary) was rated as more important and more difficult. The two other statements were viewed as less important and less difficult. They were; s25 (Advisors should have the chance to choose who they want to work with) and s33 (Students should select their advisors at an early stage in their doctoral education). 


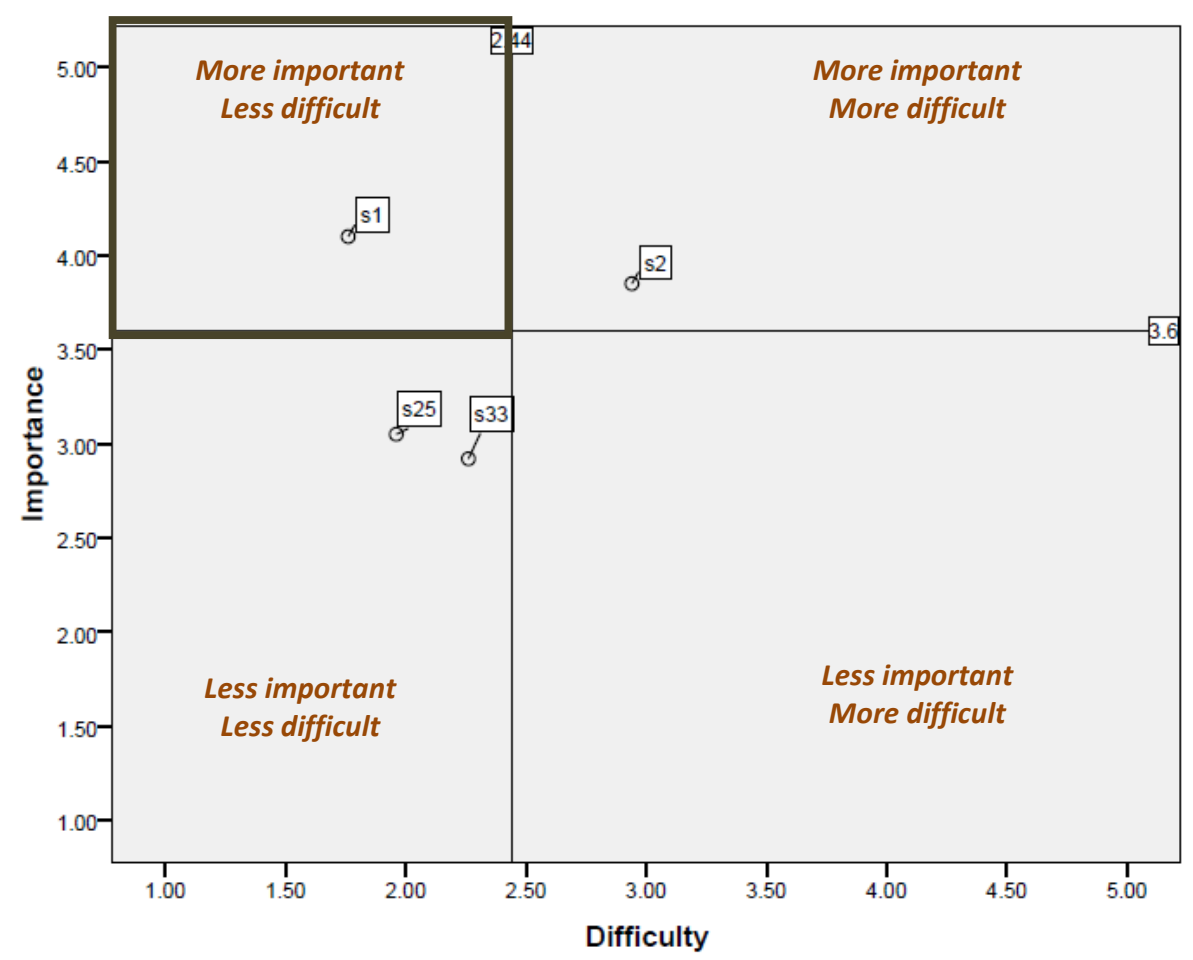

Figure 12. Go-zone graph displaying statements in cluster 1 in their respective quadrants (based on students' data) 
Table 23

List of statements in cluster 1 and their mean ratings in terms of their difficulty and importance (based on students' data)

\begin{tabular}{|c|c|c|c|}
\hline & $\begin{array}{c}\text { Cluster } 1 \text { (Exercising freedom and flexibility in the } \\
\text { advisor/advisee selection) }\end{array}$ & $\begin{array}{l}\text { Difficulty } \\
(\mathrm{M}=2.23)\end{array}$ & $\begin{array}{c}\text { Importance } \\
(\mathrm{M}=3.48)\end{array}$ \\
\hline s1 & $\begin{array}{l}\text { Students should be given the opportunity to choose their } \\
\text { advisors. }\end{array}$ & 1.76 & 4.1 \\
\hline s2 & $\begin{array}{l}\text { Students should have the chance to easily change their } \\
\text { advisors when necessary. }\end{array}$ & 2.94 & 3.85 \\
\hline s25 & $\begin{array}{l}\text { Advisors should have the chance to choose who they want } \\
\text { to work with. }\end{array}$ & 1.96 & 3.05 \\
\hline s33 & $\begin{array}{l}\text { Students should select their advisors at an early stage in } \\
\text { their doctoral education. }\end{array}$ & 2.26 & 2.92 \\
\hline
\end{tabular}

Note. Interpretation of the ratings: Difficulty: 1=Relatively easy, $2=$ Somewhat difficult, 3=Moderately difficult, 4=Very difficult, and 5=Extremely difficult. Importance: 1=Relatively unimportant, 2=Somewhat important, 3=Moderately important, 4=Very important, and $5=$ Extremely important.

Statements in cluster 2 (Promoting a supportive advisor-advisee relationship coupled with negotiations). Cluster 2 has the highest rating value for difficulty $(\mathrm{M}=2.6, S D=.18$, moderately difficult) and the second highest rating value for importance $(\mathrm{M}=3.78, S D=.34$, very important). It was located on the upper-right quadrant of the go-zone graph (see Figure 10). This means that students perceived this cluster as more important and more difficult.

Cluster 2 contains 15 statements with a high internal consistency $(\alpha)$ of .90 for difficulty ratings and .86 for importance ratings. Two statements were found on the upper-left quadrant (see Figure 13): they were labeled as more important and less difficult to carry out. They were; s3 (Advisors should be accessible to students) and s7 (There should be honest communication between advisors and students). Eight statements in cluster 2 were viewed as more important and more difficult. They included; s4 (Advisors and students should meet frequently to talk about issues related to dissertations), s8 (There should be open dialogue concerning making decisions 
and resolving conflicts), s16 (Students should be able to express their disagreement when necessary), s19 (Advisors should provide students with needed support), s21 (Advisors should give timely feedback to students), s30 (Students should feel comfortable sharing their academic challenges with advisors), s35 (Advisors and students should clearly define their expectations and goals), and s37 (Advisors should be ready to listen to the concerns of their students).

Students perceived five statements in cluster 2 as less important. They included; s5 (Advisors should provide adequate support for students in terms of carrying out specific tasks), s6 (Advisors should take the initiative in building and maintaining a good relationship), s11 (Advisors should make efforts to identify the needs of their students), s13 (Advisors should be sensitive to the needs of their students), and s14 (Advisors and students should build trust through negotiation and agreement). In terms of difficulty, only statement s6 was viewed as less difficult compared to the other four statements, which were rated as more difficult. 


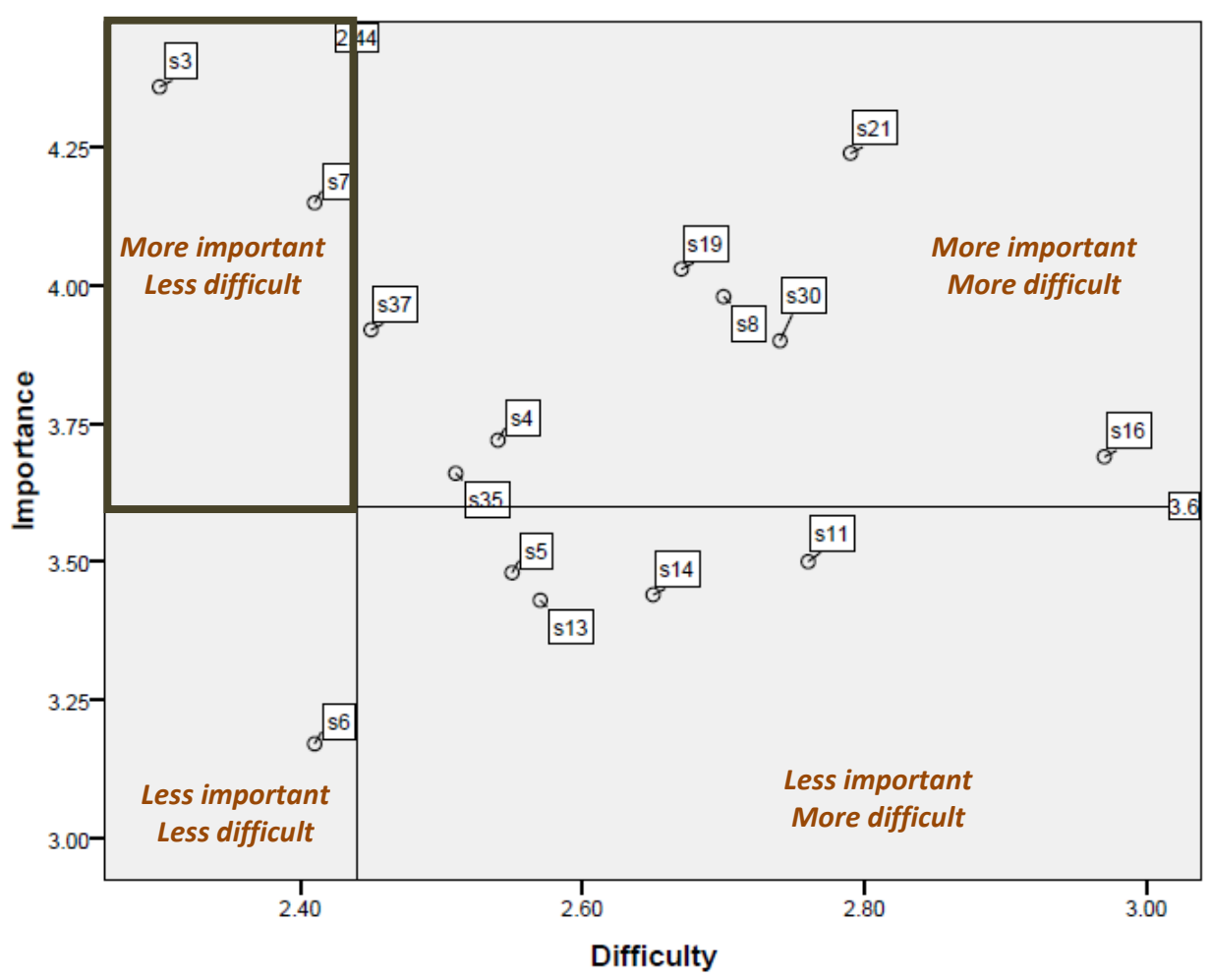

Figure 13. Go-zone graph displaying statements in cluster 2 in their respective quadrants (based on students' data) 
Table 24

List of statements in cluster 2 and their mean ratings in terms of their difficulty and importance

(based on students'data)

\begin{tabular}{|c|c|c|c|}
\hline & $\begin{array}{c}\text { Cluster } 2 \text { (Promoting a supportive advisor-advisee } \\
\text { relationship coupled with negotiations) }\end{array}$ & $\begin{array}{c}\text { Difficulty } \\
(\mathrm{M}=2.6)\end{array}$ & $\begin{array}{l}\text { Importance } \\
(\mathrm{M}=3.78)\end{array}$ \\
\hline s3 & Advisors should be accessible to students. & 2.3 & 4.36 \\
\hline s4 & $\begin{array}{l}\text { Advisors and students should meet frequently to talk about } \\
\text { issues related to dissertations. }\end{array}$ & 2.54 & 3.72 \\
\hline s5 & $\begin{array}{l}\text { Advisors should provide adequate support for students in } \\
\text { terms of carrying out specific tasks. }\end{array}$ & 2.55 & 3.48 \\
\hline s6 & $\begin{array}{l}\text { Advisors should take the initiative in building and } \\
\text { maintaining a good relationship. }\end{array}$ & 2.41 & 3.17 \\
\hline s7 & $\begin{array}{l}\text { There should be honest communication between advisors } \\
\text { and students. }\end{array}$ & 2.41 & 4.15 \\
\hline s8 & $\begin{array}{l}\text { There should be open dialogue concerning making } \\
\text { decisions and resolving conflicts. }\end{array}$ & 2.7 & 3.98 \\
\hline s11 & $\begin{array}{l}\text { Advisors should make efforts to identify the needs of their } \\
\text { students. }\end{array}$ & 2.76 & 3.5 \\
\hline s13 & Advisors should be sensitive to the needs of their students. & 2.57 & 3.43 \\
\hline s14 & $\begin{array}{l}\text { Advisors and students should build trust through negotiation } \\
\text { and agreement. }\end{array}$ & 2.65 & 3.44 \\
\hline s16 & $\begin{array}{l}\text { Students should be able to express their disagreement when } \\
\text { necessary. }\end{array}$ & 2.97 & 3.69 \\
\hline s19 & Advisors should provide students with needed support. & 2.67 & 4.03 \\
\hline s21 & Advisors should give timely feedback to students. & 2.79 & 4.24 \\
\hline s30 & $\begin{array}{l}\text { Students should feel comfortable sharing their academic } \\
\text { challenges with advisors. }\end{array}$ & 2.74 & 3.9 \\
\hline s35 & $\begin{array}{l}\text { Advisors and students should clearly define their } \\
\text { expectations and goals. }\end{array}$ & 2.51 & 3.66 \\
\hline s37 & $\begin{array}{l}\text { Advisors should be ready to listen to the concerns of their } \\
\text { students. }\end{array}$ & 2.45 & 3.92 \\
\hline
\end{tabular}

Statements in cluster 3 (Attaining the 'best' match during the advisor selection process).

Cluster 3 was considered to be less important but more difficult to accomplish. Because of the relatively low internal consistency $(\alpha)$ of .59 for difficulty and .64 for importance' ratings of cluster 1 , it is particularly important to examine individual statements and their respective ratings. Table 25 provides the means $(\mathrm{M})$ of the statements in cluster 3 . The item go-zone graph 
(Figure 8) shows that statement s9 (Students should be well-informed about the research interest, advising style, and expectations of potential advisors) was more important and less difficult. Also statement s18 (Advisors and students should have matched goals and expectations) was considered more important and more difficult. Statements s10 (Advisors and students should have similar research interests) and s17 (Students should clearly define what they expect from potential advisors), which were rated as less difficult and more difficult, respectively, were perceived by students as less important (see Figure 14).

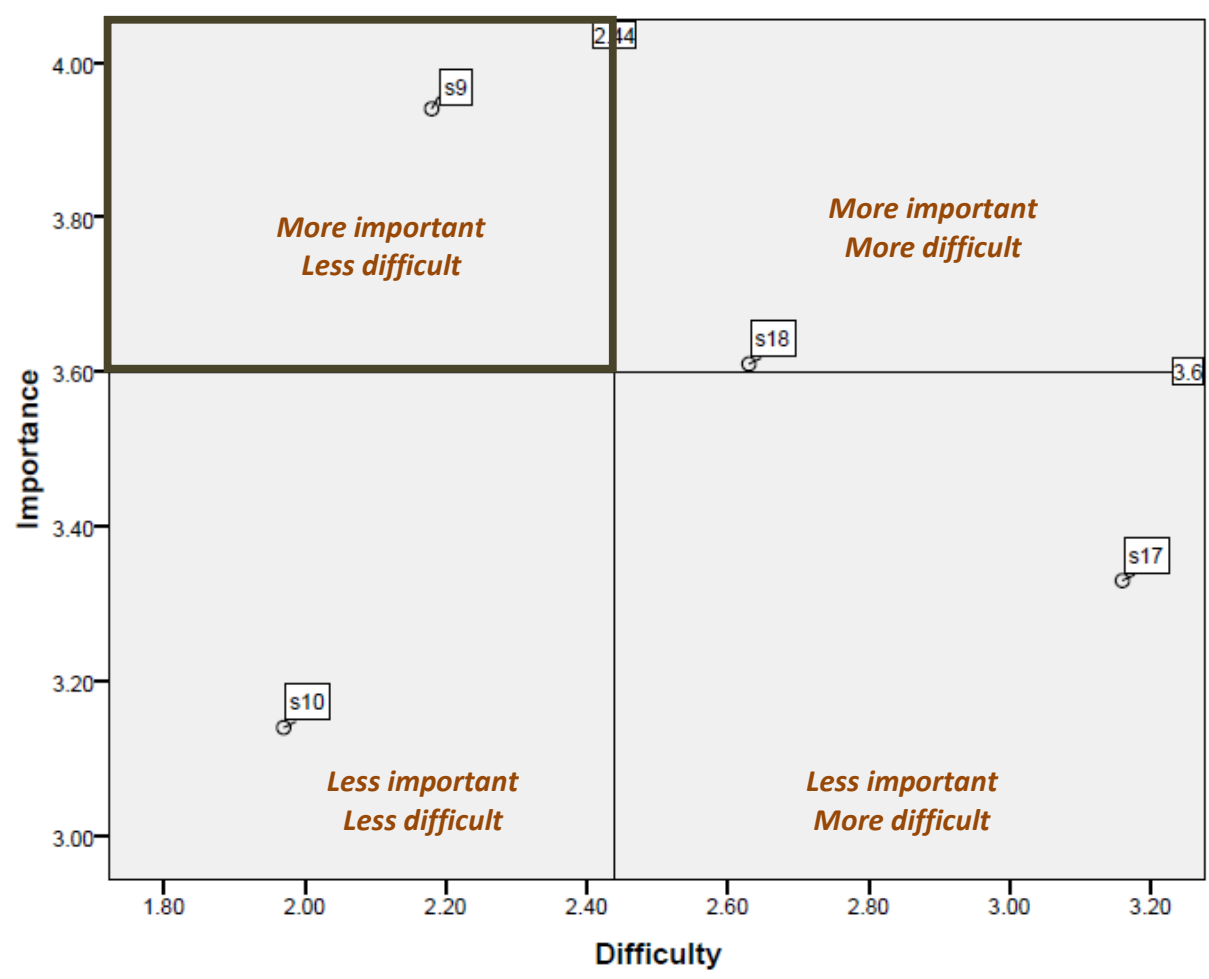

Figure 14. Go-zone graph displaying statements in cluster 3 in their respective quadrants (based on students' data) 
Table 25

List of statements in cluster 3 and their mean ratings in terms of their difficulty and importance (based on students' data)

\begin{tabular}{|c|c|c|c|}
\hline & $\begin{array}{c}\text { Cluster } 3 \text { (Attaining the 'best' match during the advisor } \\
\text { selection process) }\end{array}$ & $\begin{array}{l}\text { Difficulty } \\
(\mathrm{M}=2.48)\end{array}$ & $\begin{array}{l}\text { Importance } \\
(\mathrm{M}=3.5)\end{array}$ \\
\hline s9 & $\begin{array}{l}\text { Students should be well-informed about the research } \\
\text { interest, advising style, and expectations of potential } \\
\text { advisors. }\end{array}$ & 2.18 & 3.94 \\
\hline s10 & $\begin{array}{l}\text { Advisors and students should have similar research } \\
\text { interests. }\end{array}$ & 1.97 & 3.14 \\
\hline s17 & $\begin{array}{l}\text { Students should clearly define what they expect from } \\
\text { potential advisors. }\end{array}$ & 3.16 & 3.33 \\
\hline s18 & $\begin{array}{l}\text { Advisors and students should have matched goals and } \\
\text { expectations. }\end{array}$ & 2.63 & 3.61 \\
\hline
\end{tabular}

Statements in cluster 4 (Guiding advisees in a professional manner as they take a responsible role). Cluster 4 contains eight statements and has acceptable internal consistency $(\alpha)$ of .71 for difficulty but relatively moderate $(\alpha=.68)$ for importance ratings. It was the only cluster located at the upper-left quadrant of the cluster go-zone graph. Further analysis of the statements in cluster 4 revealed that statements s12 (Procedures for writing dissertations should be explicitly explained to doctoral students), s29 (Advisors should focus on directing students toward set goals), s32 (Advisors should make sure students follow procedures acceptable to the research community), s38 (There should be mutual respect between advisors and students), and s40 (Advisors should give constructive criticism on students' dissertations) were viewed as the "most actionable" (Kane \& Tronchim, 2007, p. 22). Because they were located in the upper-left quadrant of the go-zone graph (Figure 15). In other words, they were more important and less difficult to implement (see Table 26). Only s39 (Advisors should be ready to intervene when students are going off-track) was viewed as more important and more difficult. Statements s20 (Students should be allowed to take charge of their dissertation process) and s36 (Advisors 
should frequently reflect on their advising style or approach) were perceived as less important and more difficult.

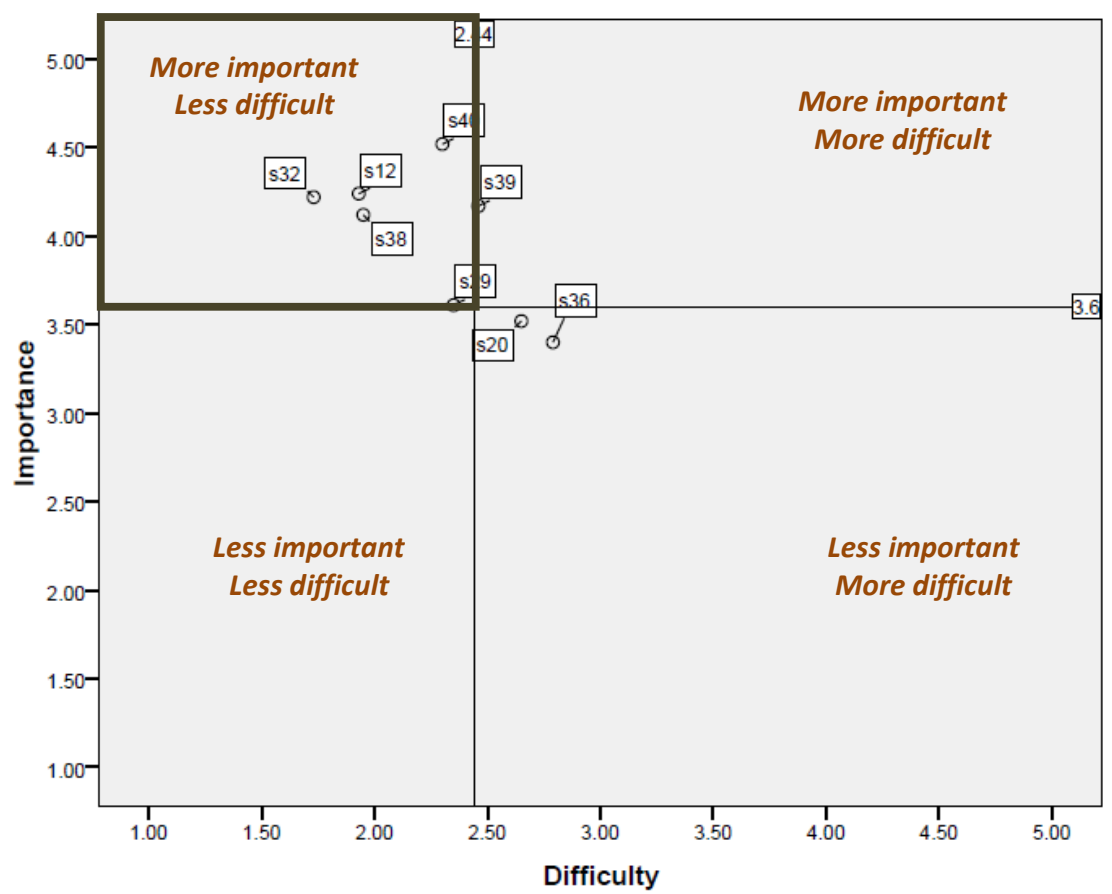

Figure 15. Go-zone graph displaying statements in cluster 4 in their respective quadrants (based on students' data) 
Table 26

List of statements in cluster 4 and their mean ratings in terms of their difficulty and importance (based on students' data)

\begin{tabular}{|c|c|c|c|}
\hline & $\begin{array}{c}\text { Cluster } 4 \text { (Guiding advisees in a professional manner as } \\
\text { they take a responsible role) }\end{array}$ & $\begin{array}{l}\text { Difficulty } \\
(\mathrm{M}=2.27)\end{array}$ & $\begin{array}{c}\text { Importance } \\
(\mathrm{M}=3.97)\end{array}$ \\
\hline $\mathrm{s} 12$ & $\begin{array}{l}\text { Procedures for writing dissertations should be explicitly } \\
\text { explained to doctoral students. }\end{array}$ & 1.93 & 4.24 \\
\hline s20 & $\begin{array}{l}\text { Students should be allowed to take charge of their } \\
\text { dissertation process. }\end{array}$ & 2.65 & 3.52 \\
\hline s29 & $\begin{array}{l}\text { Advisors should focus on directing students toward set } \\
\text { goals. }\end{array}$ & 2.35 & 3.61 \\
\hline s32 & $\begin{array}{l}\text { Advisors should make sure students follow procedures } \\
\text { acceptable to the research community. }\end{array}$ & 1.73 & 4.22 \\
\hline s36 & $\begin{array}{l}\text { Advisors should frequently reflect on their advising style or } \\
\text { approach. }\end{array}$ & 2.79 & 3.4 \\
\hline s38 & $\begin{array}{l}\text { There should be mutual respect between advisors and } \\
\text { students. }\end{array}$ & 1.95 & 4.12 \\
\hline s39 & $\begin{array}{l}\text { Advisors should be ready to intervene when students are } \\
\text { going off-track. }\end{array}$ & 2.46 & 4.17 \\
\hline s40 & $\begin{array}{l}\text { Advisors should give constructive criticism on students' } \\
\text { dissertations. }\end{array}$ & 2.3 & 4.52 \\
\hline
\end{tabular}

Statements in cluster 5 (Understanding the changing expectations and complex nature of doctoral advising). Cluster 5 has a moderate internal consistency $(\alpha)$ of .66 for difficulty and .68 for importance ratings. The cluster go-zone graph shows that cluster 5 was less important and more difficult. None of the statements in cluster 5 were located at the upper-left quadrant (see Figure 16). Statement s34 (Students should be able to adjust to changing expectations and roles) was considered to be more important and more difficult (see Table 27). Students perceived three statements in cluster 5 as less important. They included; s15 (The boundaries of the relationship should be well-defined), s22 (Students should be aware of the complexities of advisor-advisee relationships), and s27 (Advisors and students should negotiate their roles and responsibilities). 
In terms of difficulty, statements s15 and s22 were rated as less difficult while statement s27 was viewed as more difficult.

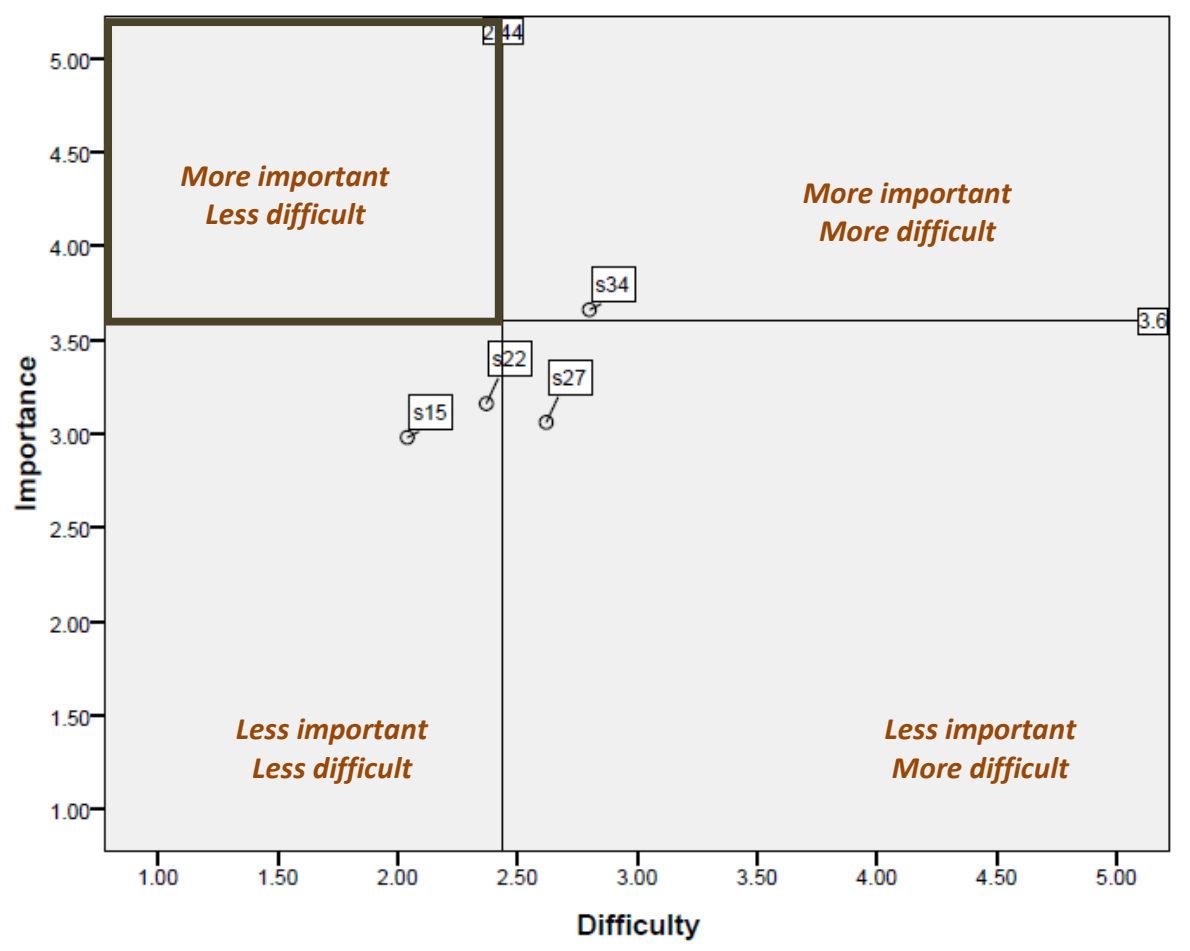

Figure 16. Go-zone graph displaying statements in cluster 5 in their respective quadrants (based on students' data) 
Table 27

List of statements in cluster 5 and their mean ratings in terms of their difficulty and importance (based on students'data)

\begin{tabular}{|c|c|c|c|}
\hline & $\begin{array}{c}\text { Cluster } 5 \text { (Understanding the changing expectations and } \\
\text { complex nature of doctoral advising) }\end{array}$ & $\begin{array}{l}\text { Difficulty } \\
(\mathrm{M}=2.46)\end{array}$ & $\begin{array}{c}\text { Importance } \\
(\mathrm{M}=3.22)\end{array}$ \\
\hline s15 & The boundaries of the relationship should be well-defined. & 2.04 & 2.98 \\
\hline s22 & $\begin{array}{l}\text { Students should be aware of the complexities of advisor- } \\
\text { advisee relationships. }\end{array}$ & 2.37 & 3.16 \\
\hline s27 & $\begin{array}{l}\text { Advisors and students should negotiate their roles and } \\
\text { responsibilities. }\end{array}$ & 2.62 & 3.06 \\
\hline s34 & $\begin{array}{l}\text { Students should be able to adjust to changing expectations } \\
\text { and roles. }\end{array}$ & 2.8 & 3.66 \\
\hline
\end{tabular}

Statements in cluster 6 (Exercising power in advising relationships). Cluster 6 was located at the lower-left quadrant on the go-zone (see Figure 10). Cluster 6 has a relatively low internal consistency $(\alpha)$ of .45 for difficulty and .47 for importance ratings, which may be partially attributed to a comparatively small number of statements. Table 28 provides the means (M) of the statements in cluster 6. The go-zone graph shows that all the statements were less important (see Figure 17). In terms of difficulty, statements s23 (Students have to respect the authority of their advisors) and s24 (Advisors should exercise their power (expert knowledge) when necessary) were rated as less difficult but statements s26 (Students should be independent), s28 (Students should strictly follow the directions provided by advisors), and s31 (There should be an equal balance of power between advisors and advisees) were rated as more difficult. 


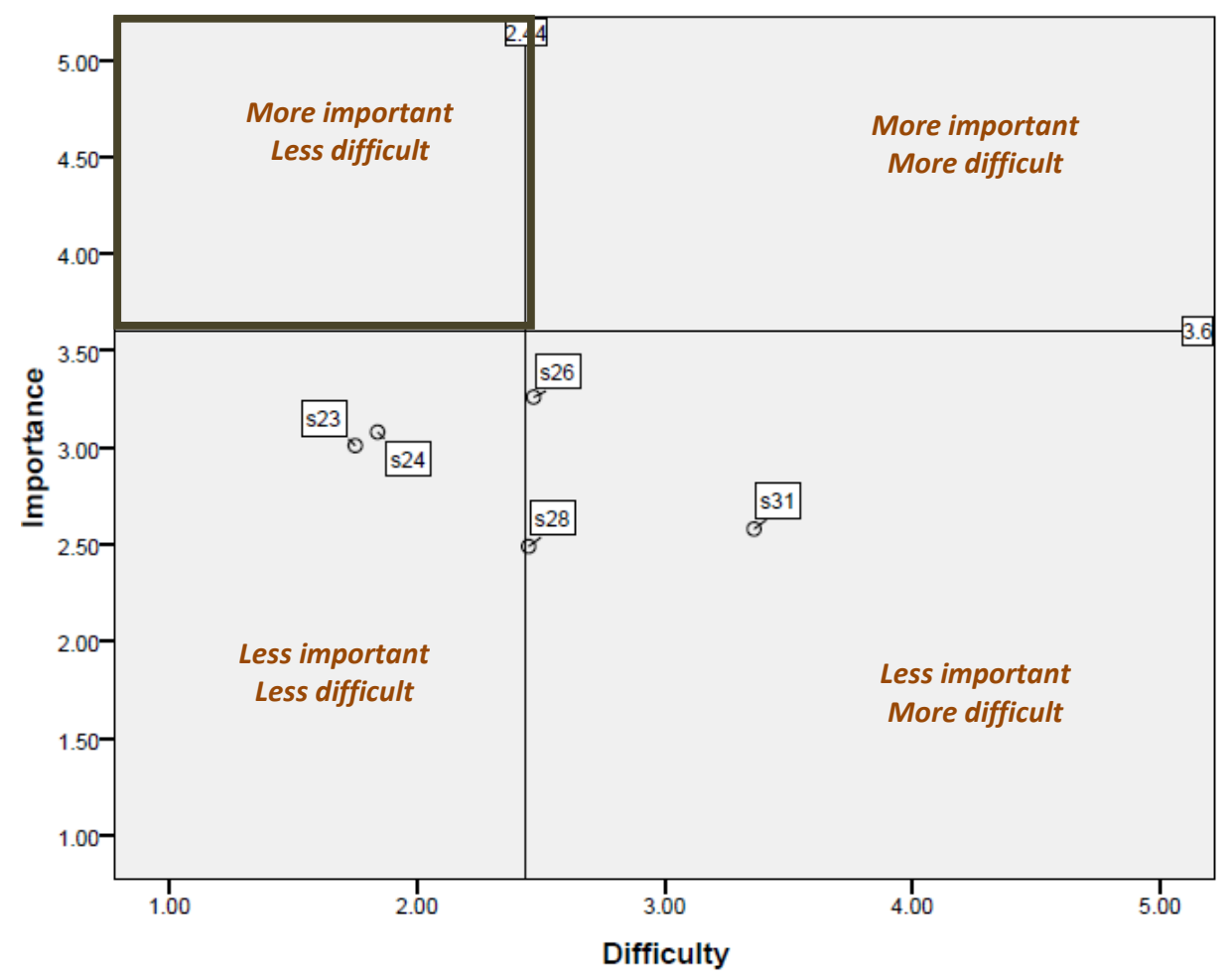

Figure 17. Go-zone graph displaying statements in cluster 6 in their respective quadrants (based on students' data) 
Table 28

List of statements in cluster 6 and their mean ratings in terms of their difficulty and importance (based on students' data)

\begin{tabular}{|c|c|c|c|}
\hline & Cluster 6 (Exercising power in advising relationships) & $\begin{array}{l}\text { Difficulty } \\
(\mathrm{M}=2.37)\end{array}$ & $\begin{array}{c}\text { Importance } \\
(\mathrm{M}=2.89)\end{array}$ \\
\hline s23 & Students have to respect the authority of their advisors. & 1.75 & 3.01 \\
\hline s24 & $\begin{array}{l}\text { Advisors should exercise their power (expert knowledge) } \\
\text { when necessary. }\end{array}$ & 1.84 & 3.08 \\
\hline s26 & Students should be independent. & 2.47 & 3.26 \\
\hline s28 & $\begin{array}{l}\text { Students should strictly follow the directions provided by } \\
\text { advisors. }\end{array}$ & 2.45 & 2.49 \\
\hline s31 & $\begin{array}{l}\text { There should be an equal balance of power between } \\
\text { advisors and advisees. }\end{array}$ & 3.36 & 2.58 \\
\hline
\end{tabular}

Note. Interpretation of the ratings: Difficulty: 1=Relatively easy, 2=Somewhat difficult, 3=Moderately difficult, 4=Very difficult, and 5=Extremely difficult. Importance: 1=Relatively unimportant, 2=Somewhat important, 3=Moderately important, 4=Very important, and $5=$ Extremely important.

Findings from professors' data. The upper-left quadrant (go-zone) shows the statements that were rated above the average for importance ratings but below average for difficulty. The results show that professors perceived 12 of the statements as more important and less difficult (see Figure 18). These statements account for $30 \%$ of all the statements. They included; s1 (Students should be given the opportunity to choose their advisors), s3 (Advisors should be accessible to students), s4 (Advisors and students should meet frequently to talk about issues related to dissertations), s7 (There should be honest communication between advisors and students), s8 (There should be open dialogue concerning making decisions and resolving conflicts), s9 (Students should be well-informed about the research interest, advising style, and expectations of potential advisors), s12 (Procedures for writing dissertations should be explicitly explained to doctoral students), s25 (Advisors should have the chance to choose who they want to work with), s32 (Advisors should make sure students follow procedures acceptable to the research community), s37 (Advisors should be ready to listen to the concerns of their students), 
s38 (There should be mutual respect between advisors and students), and s40 (Advisors should give constructive criticism on students' dissertations).

There are seven statements located at the upper right of the go-zone graph. They were considered more important and more difficult. They were; s16 (Students should be able to express their disagreement when necessary), s19 (Advisors should provide students with needed support), s21 (Advisors should give timely feedback to students), s26 (Students should be independent), s30 (Students should feel comfortable sharing their academic challenges with advisors), s35 (Advisors and students should clearly define their expectations and goals), and s39 (Advisors should be ready to intervene when students are going off-track). 


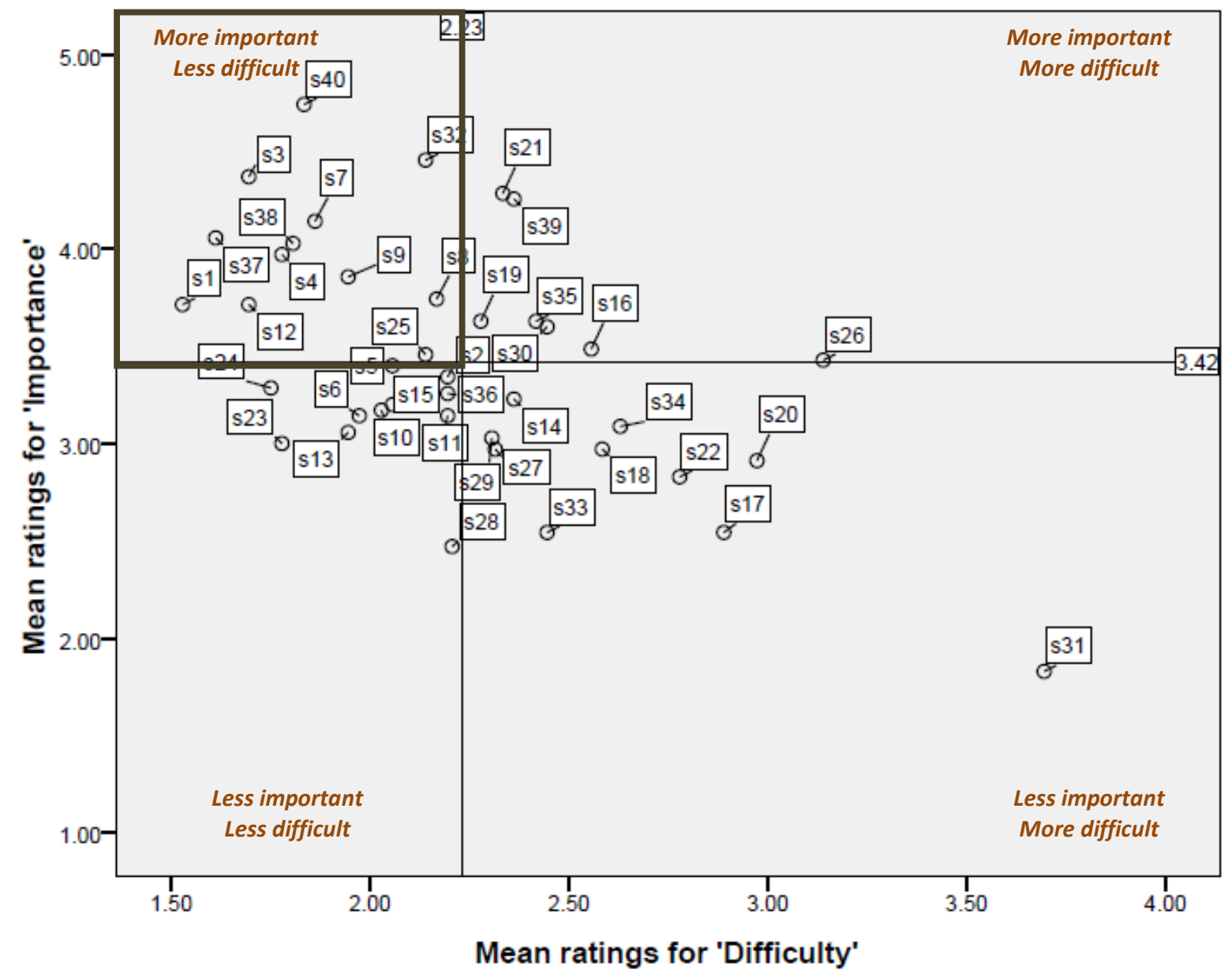

Figure 18. Go-zone graph displaying all 40 statements in their respective quadrants (based on professors' data). Note. The quadrants were created based on the overall mean of the difficulty and importance ratings.

The cluster go-zone graph (Figure 19) for professors shows that clusters 2 (Enhancing advisor-advisee interaction in a supportive environment) and 5 (Promoting students' independence with advisors' guidance) were more important. Cluster 2 was viewed as less difficult and cluster 5 was perceived by professors as more difficult. Clusters 1 (Selecting advisors in an early stage and having the chance to change them), 3 (Maintaining a good 
relationship through dialogue and clarity of expectations), and 4 (Matching interests through negotiation in the selection process) were located at the lower-left quadrant: meaning they were less important and less difficult. The only cluster labeled as less important but more difficult to accomplish was cluster 6 (Encouraging students to follow advisors' directions).

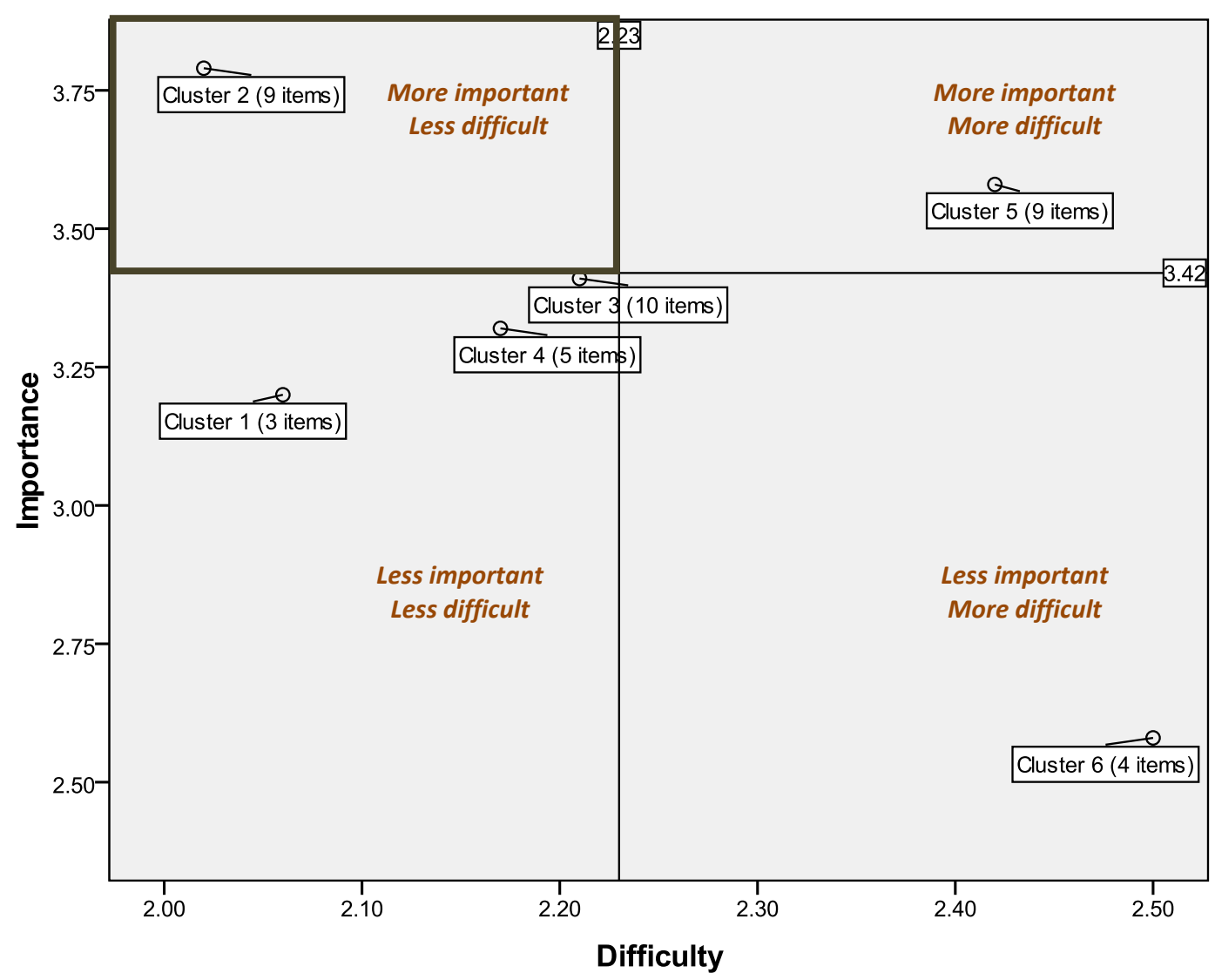

Figure 19. Go-zone graph displaying the six clusters in their respective quadrants (based on professors' data). Note. The quadrants were created based on the overall mean of the difficulty and importance ratings. 
Table 29

Means (standard deviations) of the six clusters (based on professors' data)

\begin{tabular}{llc}
\hline (Sub)scale & Difficulty & Importance \\
\hline Cluster 1 (3 items) & $2.06(.47)$ & $3.20(.60)$ \\
Cluster 2 (9 items) & $2.02(.32)$ & $3.79(.38)$ \\
Cluster 3 (10 items) & $2.21(.33)$ & $3.41(.49)$ \\
Cluster 4 (5 items) & $2.17(.29)$ & $3.32(.44)$ \\
Cluster 5 (9 items) & $2.42(.49)$ & $3.58(.71)$ \\
Cluster 6 (4 items) & $2.50(.83)$ & $2.58(.56)$ \\
\hline Total $(40$ items) & $2.23(.45)$ & $3.42(.61)$ \\
\hline
\end{tabular}

Table 30

Cronbach's alpha $(\alpha)$ coefficients for internal consistency for the six clusters (based on professors' data)

\begin{tabular}{lcc}
\hline \multicolumn{1}{c}{$($ Sub)scale } & Difficulty & Importance \\
\hline Cluster 1 (3 items) & .20 & .41 \\
Cluster 2 (9 items) & .79 & .76 \\
Cluster 3 (10 items) & .76 & .83 \\
Cluster 4 (5 items) & .69 & .65 \\
Cluster 5 (9 items) & .73 & .65 \\
Cluster 6 (4 items) & .64 & .53 \\
\hline Total (40 items) & .92 & .91 \\
\hline
\end{tabular}

Note. According to Field (2005), the acceptable Cronbach's alpha coefficient for internal consistency should be at least .7. The Cronbach's alpha coefficients should be interpreted with caution because a small $\alpha$ value may have been influenced by a relatively small number of items in the cluster. 


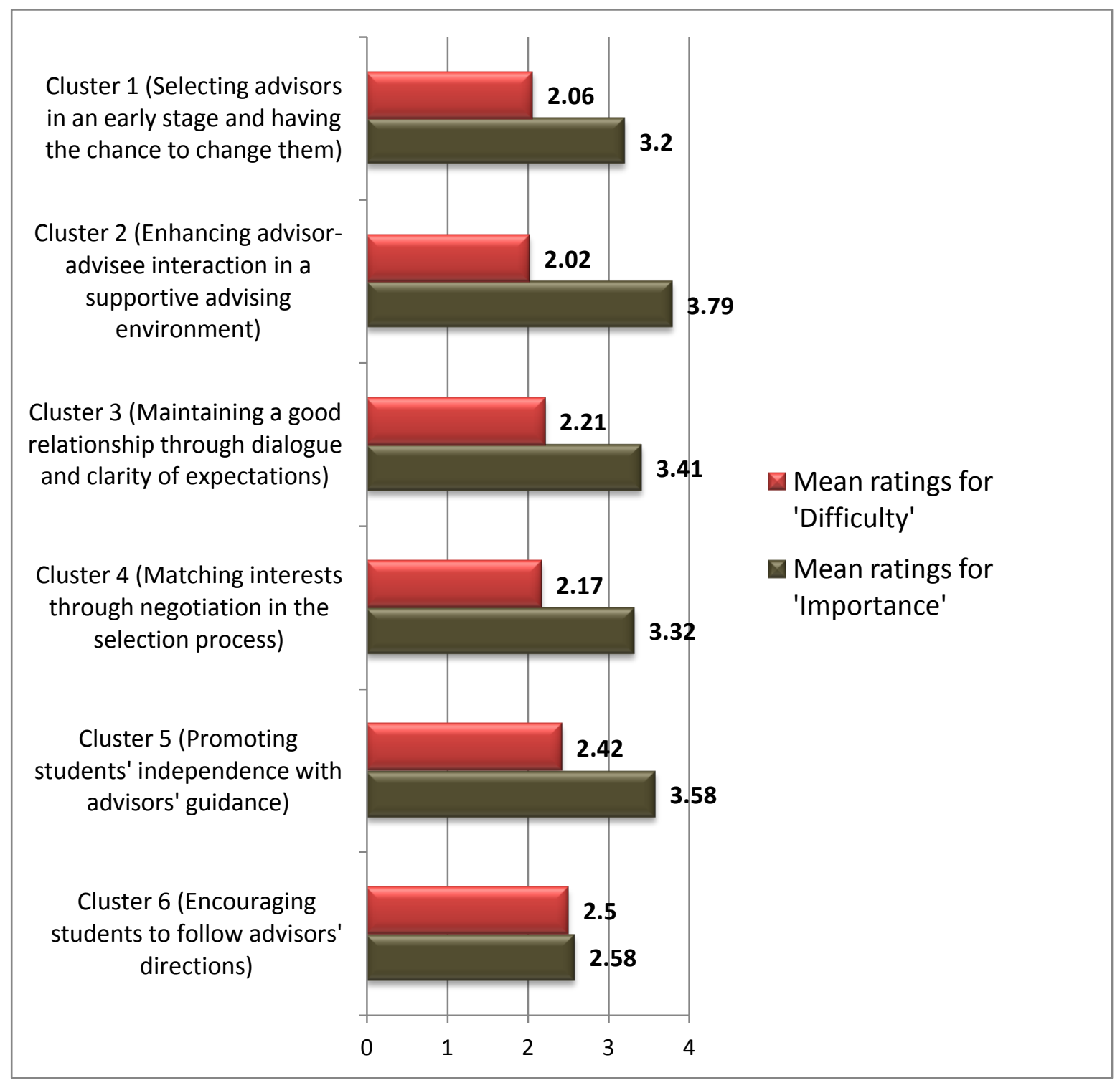

Figure 20. Bar chart showing the mean ratings (importance and difficulty) for the six clusters (based on professors' data)

Statements in cluster 1 (Selecting advisors in an early stage and having the chance to change them). Because of the low internal consistency ( $\alpha$ ) of .20 for difficulty and .41 for importance' ratings of cluster 1 , it is particularly important to examine individual statements and their respective ratings. Table 31 provides the means $(\mathrm{M})$ of the statements in cluster 1. 
Statement s1 (Students should be given the opportunity to choose their advisors) was the only statement located at the go-zone area (see Figure 21). None of the statements in cluster 1 was considered more important and more difficult. Statements s2 (Students should have the chance to easily change their advisors when necessary) and s33 (Students should select their advisors at an early stage in their doctoral education), which were rated as less difficult and more difficult respectively, were perceived as less important.

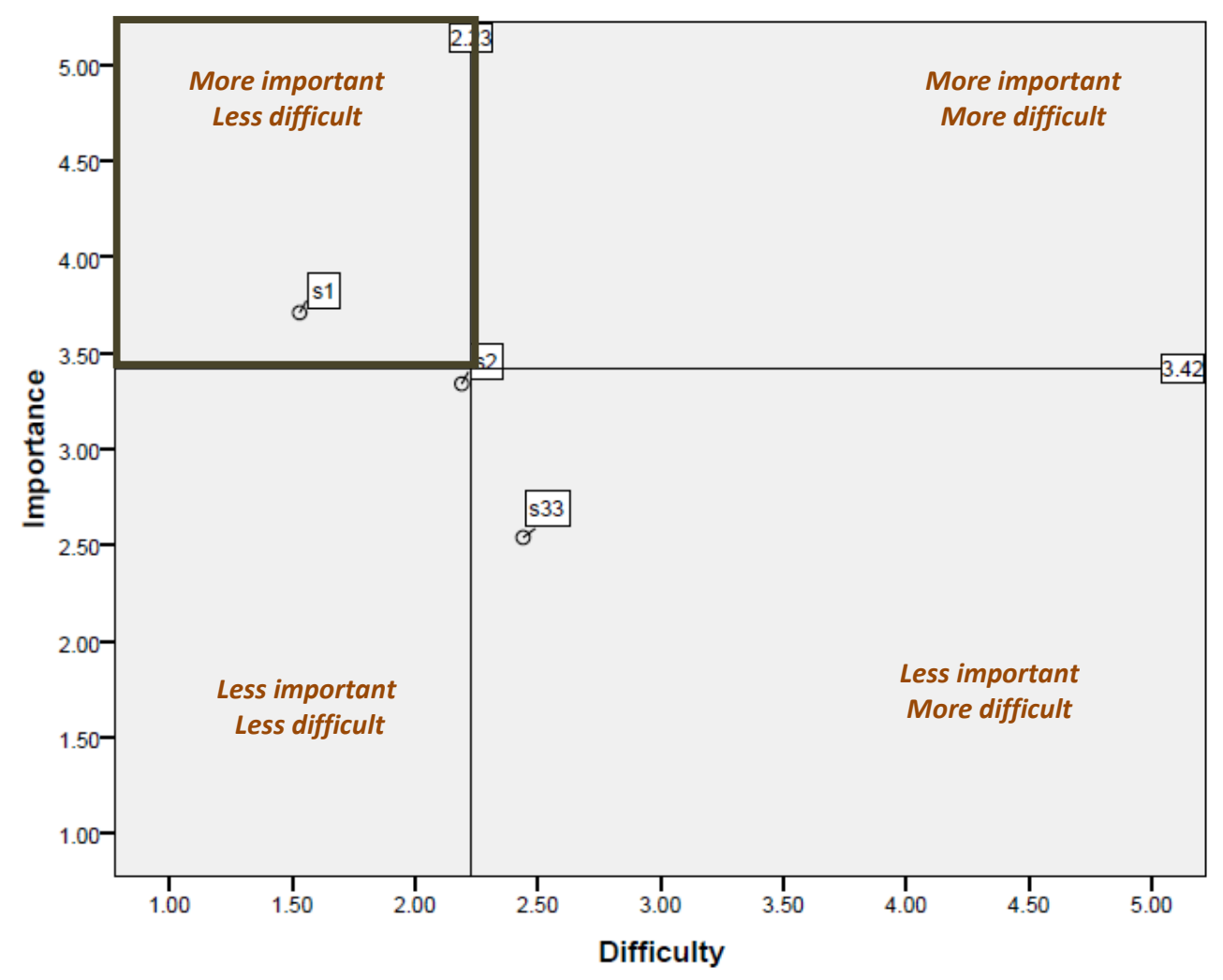

Figure 21. Go-zone graph displaying statements in cluster 1 in their respective quadrants (based on professors' data) 
Table 31

List of statements in cluster 6 and their mean ratings in terms of their difficulty and importance (based on professors' data)

\begin{tabular}{|c|c|c|c|}
\hline & $\begin{array}{c}\text { Cluster } 1 \text { (Selecting advisors in an early stage and having } \\
\text { the chance to change them) }\end{array}$ & $\begin{array}{l}\text { Difficulty } \\
(\mathrm{M}=2.06)\end{array}$ & $\begin{array}{c}\text { Importance } \\
(\mathrm{M}=3.2)\end{array}$ \\
\hline $\mathrm{s} 1$ & $\begin{array}{l}\text { Students should be given the opportunity to choose their } \\
\text { advisors. }\end{array}$ & 1.53 & 3.71 \\
\hline $\mathrm{s} 2$ & $\begin{array}{l}\text { Students should have the chance to easily change their } \\
\text { advisors when necessary. }\end{array}$ & 2.19 & 3.34 \\
\hline s33 & $\begin{array}{l}\text { Students should select their advisors at an early stage in } \\
\text { their doctoral education. }\end{array}$ & 2.44 & 2.54 \\
\hline
\end{tabular}

Statements in cluster 2 (Enhancing advisor-advisee interaction in a supportive environment). Cluster 2 has an acceptable internal consistency $(\alpha)$ for difficulty (.79) and importance (.76) rating. The go-zone graph (Figure 22), displaying the statements in this cluster shows statements $\mathrm{s} 3$ (Advisors should be accessible to students), s4 (Advisors and students should meet frequently to talk about issues related to dissertations), s7 (There should be honest communication between advisors and students), s9 (Students should be well-informed about the research interest, advising style, and expectations of potential advisors), and s37 (Advisors should be ready to listen to the concerns of their students) at the upper-left quadrant (go-zone). These statements (in cluster 2) were viewed as more important but less difficult to implement (see Table 32).

Also, statements s16 (Students should be able to express their disagreement when necessary) and s19 (Advisors should provide students with needed support) were labeled as more important to the successful completion of students' dissertations but more difficult to carry out. Statements s5 (Advisors should provide adequate support for students in terms of carrying out specific tasks) and s14 (Advisors and students should build trust through negotiation and 
agreement), which were rated as less difficult and more difficult respectively, were perceived by professors as less important.

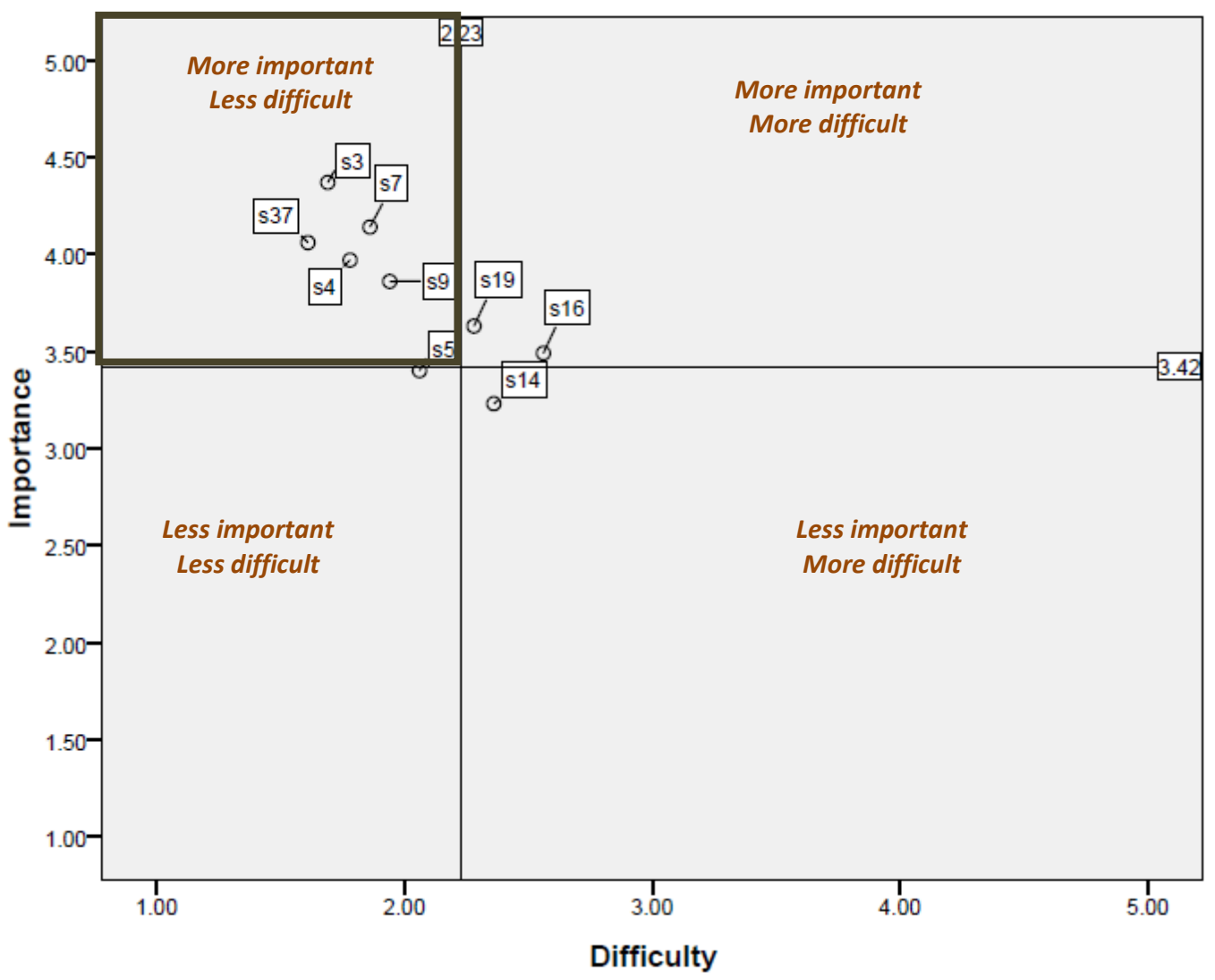

Figure 22. Go-zone graph displaying statements in cluster 2 in their respective quadrants (based on professors' data) 
Table 32

List of statements in cluster 2 and their mean ratings in terms of their difficulty and importance (based on professors' data)

\begin{tabular}{|c|c|c|c|}
\hline & $\begin{array}{c}\text { Cluster } 2 \text { (Enhancing advisor-advisee interaction in a } \\
\text { supportive environment) }\end{array}$ & $\begin{array}{l}\text { Difficulty } \\
(\mathrm{M}=2.02)\end{array}$ & $\begin{array}{c}\text { Importance } \\
(\mathrm{M}=3.79)\end{array}$ \\
\hline s3 & Advisors should be accessible to students. & 1.69 & 4.37 \\
\hline s4 & $\begin{array}{l}\text { Advisors and students should meet frequently to talk about } \\
\text { issues related to dissertations. }\end{array}$ & 1.78 & 3.97 \\
\hline s5 & $\begin{array}{l}\text { Advisors should provide adequate support for students in } \\
\text { terms of carrying out specific tasks. }\end{array}$ & 2.06 & 3.4 \\
\hline s7 & $\begin{array}{l}\text { There should be honest communication between advisors } \\
\text { and students. }\end{array}$ & 1.86 & 4.14 \\
\hline s9 & $\begin{array}{l}\text { Students should be well-informed about the research } \\
\text { interest, advising style, and expectations of potential } \\
\text { advisors. }\end{array}$ & 1.94 & 3.86 \\
\hline s14 & $\begin{array}{l}\text { Advisors and students should build trust through negotiation } \\
\text { and agreement. }\end{array}$ & 2.36 & 3.23 \\
\hline s16 & $\begin{array}{l}\text { Students should be able to express their disagreement when } \\
\text { necessary. }\end{array}$ & 2.56 & 3.49 \\
\hline s19 & Advisors should provide students with needed support. & 2.28 & 3.63 \\
\hline s37 & $\begin{array}{l}\text { Advisors should be ready to listen to the concerns of their } \\
\text { students. }\end{array}$ & 1.61 & 4.06 \\
\hline
\end{tabular}

Statements in cluster 3 (Maintaining a good relationship through dialogue and clarity of expectations). Cluster 3 has a relatively high internal consistency $(\alpha)$ with .76 for difficulty and .83 for importance ratings. Two out of ten statements in this cluster were found at the go-zone: meaning they were rated by professors as more important and less difficult to implement (see Figure 23). They included; statements s8 (There should be open dialogue concerning making decisions and resolving conflicts) and $\mathrm{s} 12$ (Procedures for writing dissertations should be explicitly explained to doctoral students). Three statements were rated as more important and more difficult. They were; s21 (Advisors should give timely feedback to students) s30 (Students should feel comfortable sharing their academic challenges with advisors), and s35 (Advisors and students should clearly define their expectations and goals). 
Professors perceived five statements in cluster 3 as less important. They included; s6 (Advisors should take the initiative in building and maintaining a good relationship), s11 (Advisors should make efforts to identify the needs of their students), s13 (Advisors should be sensitive to the needs of their students), s15 (The boundaries of the relationship should be welldefined), and s17 (Students should clearly define what they expect from potential advisors). In terms of difficulty, only statement s17 was viewed as more difficulty compared to the other four statements, which was rated as less difficult.

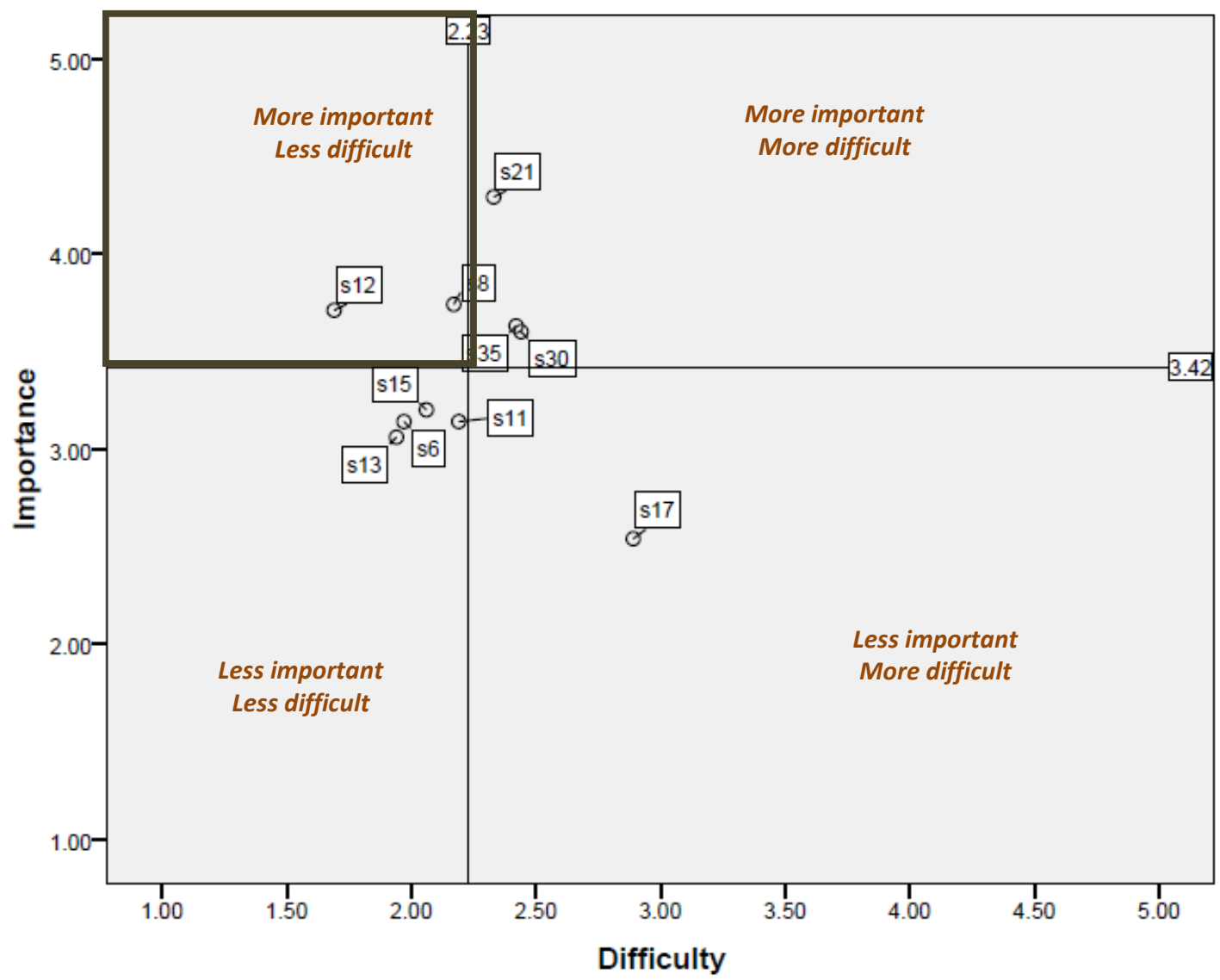

Figure 23. Go-zone graph displaying statements in cluster 3 in their respective quadrants (based on professors' data) 
Table 33

List of statements in cluster 3 and their mean ratings in terms of their difficulty and importance (based on professors' data)

\begin{tabular}{|c|c|c|c|}
\hline & $\begin{array}{c}\text { Cluster } 3 \text { (Maintaining a good relationship through } \\
\text { dialogue and clarity of expectations) }\end{array}$ & $\begin{array}{l}\text { Difficulty } \\
(\mathrm{M}=2.21)\end{array}$ & $\begin{array}{c}\text { Importance } \\
(\mathrm{M}=3.41)\end{array}$ \\
\hline s6 & $\begin{array}{l}\text { Advisors should take the initiative in building and } \\
\text { maintaining a good relationship. }\end{array}$ & 1.97 & 3.14 \\
\hline s8 & $\begin{array}{l}\text { There should be open dialogue concerning making } \\
\text { decisions and resolving conflicts. }\end{array}$ & 2.17 & 3.74 \\
\hline s11 & $\begin{array}{l}\text { Advisors should make efforts to identify the needs of their } \\
\text { students. }\end{array}$ & 2.19 & 3.14 \\
\hline s12 & $\begin{array}{l}\text { Procedures for writing dissertations should be explicitly } \\
\text { explained to doctoral students. }\end{array}$ & 1.69 & 3.71 \\
\hline s13 & Advisors should be sensitive to the needs of their students. & 1.94 & 3.06 \\
\hline s15 & The boundaries of the relationship should be well-defined. & 2.06 & 3.2 \\
\hline s17 & $\begin{array}{l}\text { Students should clearly define what they expect from } \\
\text { potential advisors. }\end{array}$ & 2.89 & 2.54 \\
\hline s21 & Advisors should give timely feedback to students. & 2.33 & 4.29 \\
\hline s30 & $\begin{array}{l}\text { Students should feel comfortable sharing their academic } \\
\text { challenges with advisors. }\end{array}$ & 2.44 & 3.6 \\
\hline s35 & $\begin{array}{l}\text { Advisors and students should clearly define their } \\
\text { expectations and goals. }\end{array}$ & 2.42 & 3.63 \\
\hline
\end{tabular}

Statements in cluster 4 (Matching interests through negotiation in the selection process).

Cluster 4 has a relatively moderate Cronbach's alpha $(\alpha)$ reliability of .69 for difficulty and .65 for importance ratings. Further analysis of this cluster indicated that statements s25 (Advisors should have the chance to choose who they want to work with) and s38 (There should be mutual respect between advisors and students) were labeled as an "actionable statement" because they were located in the upper-left quadrant (Kane \& Tronchim, 2007, p. 22). There was no statement at the upper-right quadrant of the go-zone graph (see Figure 24).

Professors perceived three statements in cluster 4 as less important. They included; s10 (Advisors and students should have similar research interests), s18 (Advisors and students should have matched goals and expectations), and s27 (Advisors and students should negotiate 
their roles and responsibilities). In terms of difficulty, only statement s10 was viewed as less difficult compared to the other two statements, which was rated as more difficult.

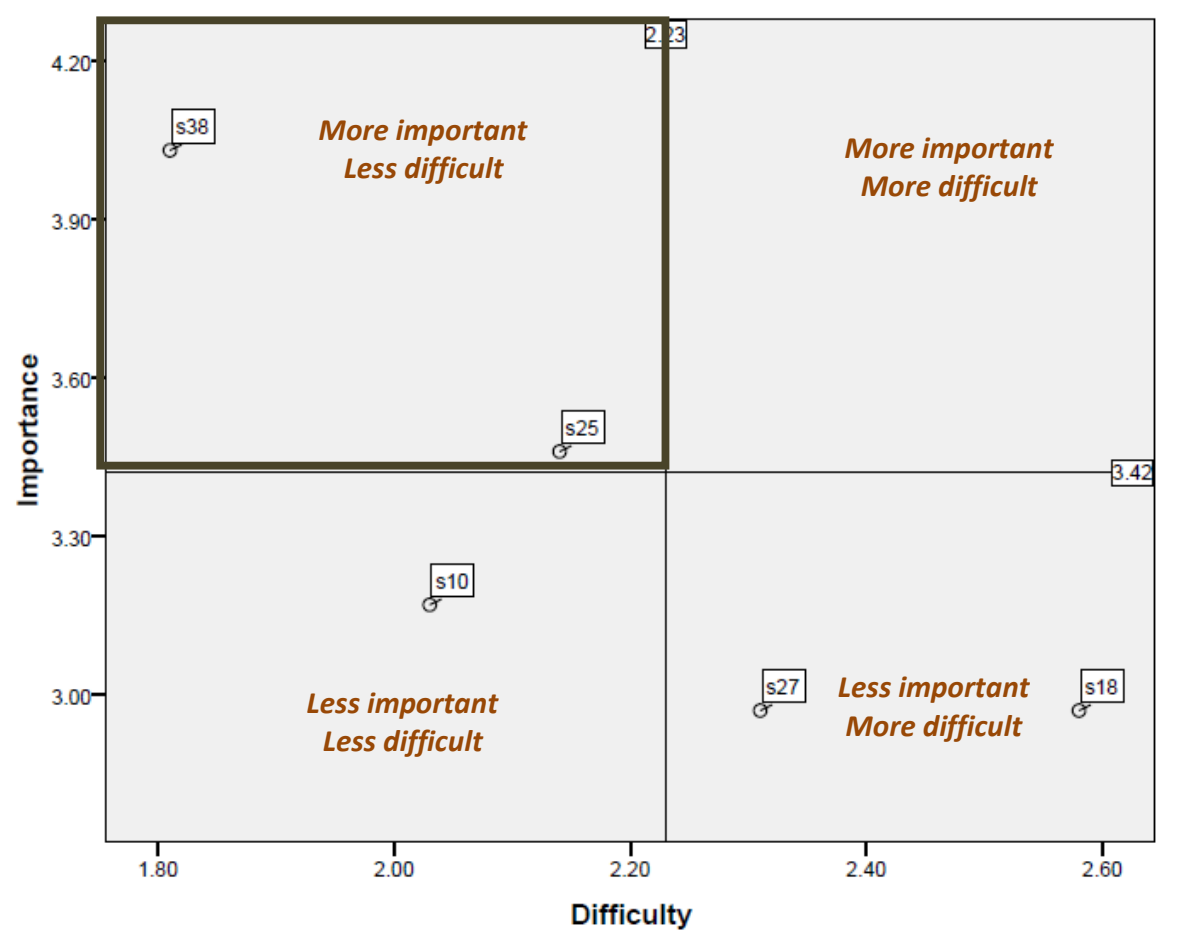

Figure 24. Go-zone graph displaying statements in cluster 4 in their respective quadrants (based on professors' data) 
Table 34

List of statements in cluster 4 and their mean ratings in terms of their difficulty and importance (based on professors' data)

\begin{tabular}{|c|c|c|c|}
\hline & $\begin{array}{c}\text { Cluster } 4 \text { (Matching interests through negotiation in the } \\
\text { selection process) }\end{array}$ & $\begin{array}{l}\text { Difficulty } \\
(\mathrm{M}=2.17)\end{array}$ & $\begin{array}{c}\text { Importance } \\
(\mathrm{M}=3.32)\end{array}$ \\
\hline $\mathrm{s} 10$ & $\begin{array}{l}\text { Advisors and students should have similar research } \\
\text { interests. }\end{array}$ & 2.03 & 3.17 \\
\hline s18 & $\begin{array}{l}\text { Advisors and students should have matched goals and } \\
\text { expectations. }\end{array}$ & 2.58 & 2.97 \\
\hline s25 & $\begin{array}{l}\text { Advisors should have the chance to choose who they want } \\
\text { to work with. }\end{array}$ & 2.14 & 3.46 \\
\hline s27 & $\begin{array}{l}\text { Advisors and students should negotiate their roles and } \\
\text { responsibilities. }\end{array}$ & 2.31 & 2.97 \\
\hline s38 & $\begin{array}{l}\text { There should be mutual respect between advisors and } \\
\text { students. }\end{array}$ & 1.81 & 4.03 \\
\hline
\end{tabular}

Statements in cluster 5 (Promoting students' independence with advisors' guidance).

Cluster 5 has an acceptable internal consistency $(\alpha)$ with .73 for difficulty and relatively moderate for .65 for importance ratings. The go-zone graph (Figure 25) displaying the statements in cluster 5 shows statements s32 (Advisors should make sure students follow procedures acceptable to the research community) and s40 (Advisors should give constructive criticism on students' dissertations) at the upper-left area. They are more important and less difficult statements in cluster 5. Professors rated statements s26 (Students should be independent) and s39 (Advisors should be ready to intervene when students are going off-track.) as more important and more difficult.

Five statements in cluster 4 were rated as less important. They included; s20 (Students should be allowed to take charge of their dissertation process), s22 (Students should be aware of the complexities of advisor-advisee relationships), s24 (Advisors should exercise their power (expert knowledge) when necessary), s34 (Students should be able to adjust to changing 
expectations and roles) and s36 (Advisors should frequently reflect on their advising style or approach). In terms of difficulty, statement s24 and s36 were viewed as less difficult compared to the remaining three statements, which were rated as more difficult.

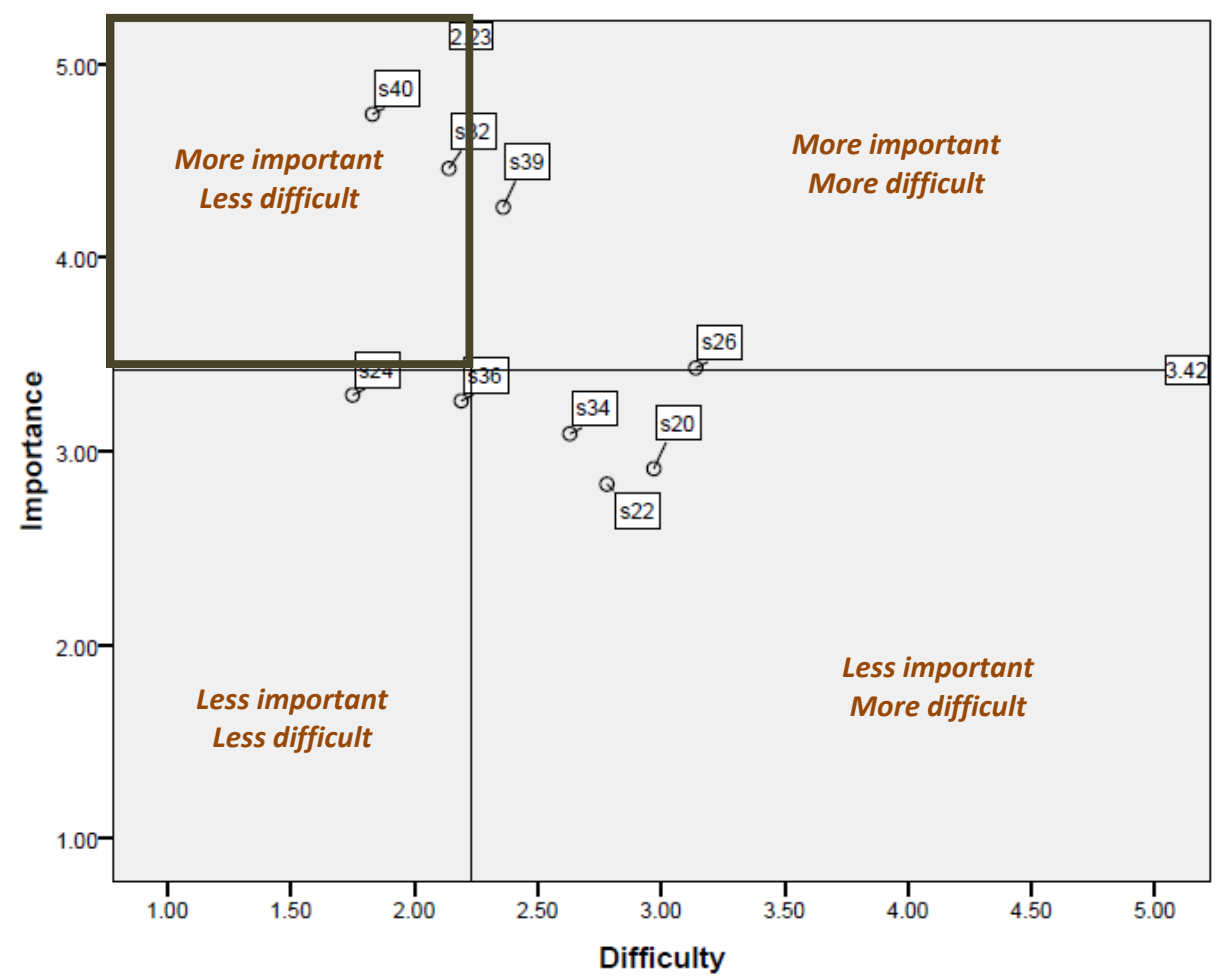

Figure 25. Go-zone graph displaying statements in cluster 5 in their respective quadrants (based on professors' data) 
Table 35

List of statements in cluster 5 and their mean ratings in terms of their difficulty and importance (based on professors' data)

\begin{tabular}{|c|c|c|c|}
\hline & $\begin{array}{c}\text { Cluster } 5 \text { (Promoting students' independence with advisors' } \\
\text { guidance) }\end{array}$ & $\begin{array}{l}\text { Difficulty } \\
(\mathrm{M}=2.42)\end{array}$ & $\begin{array}{c}\text { Importance } \\
(\mathrm{M}=3.58)\end{array}$ \\
\hline s20 & $\begin{array}{l}\text { Students should be allowed to take charge of their } \\
\text { dissertation process. }\end{array}$ & 2.97 & 2.91 \\
\hline $\mathrm{s} 22$ & $\begin{array}{l}\text { Students should be aware of the complexities of advisor- } \\
\text { advisee relationships. }\end{array}$ & 2.78 & 2.83 \\
\hline s24 & $\begin{array}{l}\text { Advisors should exercise their power (expert knowledge) } \\
\text { when necessary. }\end{array}$ & 1.75 & 3.29 \\
\hline s26 & Students should be independent. & 3.14 & 3.43 \\
\hline s32 & $\begin{array}{l}\text { Advisors should make sure students follow procedures } \\
\text { acceptable to the research community. }\end{array}$ & 2.14 & 4.46 \\
\hline s34 & $\begin{array}{l}\text { Students should be able to adjust to changing expectations } \\
\text { and roles. }\end{array}$ & 2.63 & 3.09 \\
\hline s36 & $\begin{array}{l}\text { Advisors should frequently reflect on their advising style or } \\
\text { approach. }\end{array}$ & 2.19 & 3.26 \\
\hline s39 & $\begin{array}{l}\text { Advisors should be ready to intervene when students are } \\
\text { going off-track. }\end{array}$ & 2.36 & 4.26 \\
\hline s40 & $\begin{array}{l}\text { Advisors should give constructive criticism on students' } \\
\text { dissertations. }\end{array}$ & 1.83 & 4.74 \\
\hline
\end{tabular}

Statements in cluster 6 (Encouraging students to follow advisors' directions). Because of relatively low internal consistency $(\alpha)$ of .64 for difficulty and .53 for importance' ratings of cluster 6 , it is particularly important to examine individual statements and their respective ratings. Table 36 provides the means (M) for the statements in cluster 6 . All four statements in cluster 6 were rated as less important (see Figure 26). They included; s23 (Students have to respect the authority of their advisors), s28 (Students should strictly follow the directions provided by advisors), s29 (Advisors should focus on directing students toward set goals), and s31 (There should be an equal balance of power between advisors and advisees). In terms of difficulty, statement s23 and s28 were viewed as less difficult while s29 and s31 were rated as more difficult. 


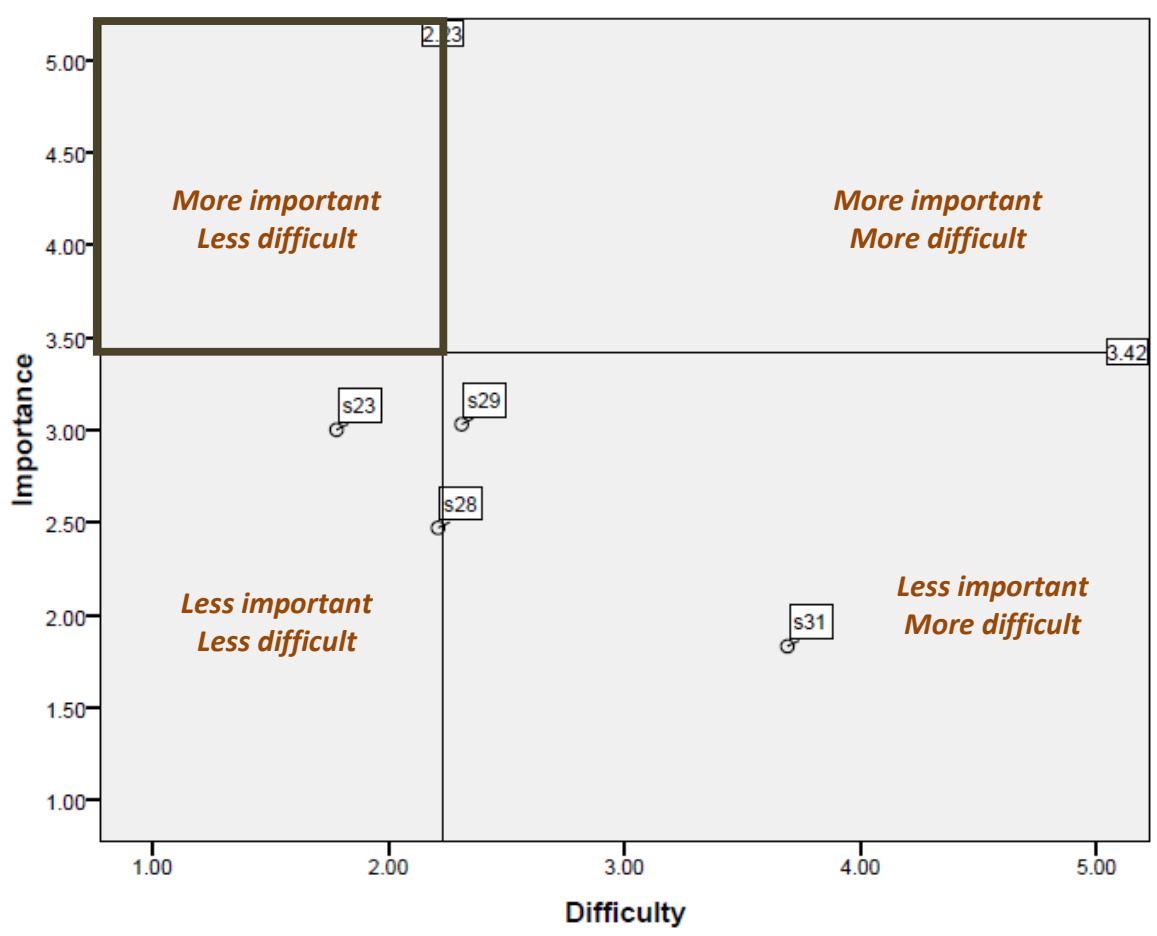

Figure 26. Go-zone graph displaying statements in cluster 6 in their respective quadrants (based on professors' data)

Table 36

List of statements in cluster 6 and their mean ratings in terms of their difficulty and importance (based on professors' data)

\begin{tabular}{|c|c|c|c|}
\hline & $\begin{array}{c}\text { Cluster } 6 \text { (Encouraging students to follow advisors' } \\
\text { directions) }\end{array}$ & $\begin{array}{l}\text { Difficulty } \\
(\mathrm{M}=2.5)\end{array}$ & $\begin{array}{c}\text { Importance } \\
(\mathrm{M}=2.58)\end{array}$ \\
\hline s23 & Students have to respect the authority of their advisors. & 1.78 & 3 \\
\hline s28 & $\begin{array}{l}\text { Students should strictly follow the directions provided by } \\
\text { advisors. }\end{array}$ & 2.21 & 2.47 \\
\hline s29 & $\begin{array}{l}\text { Advisors should focus on directing students toward set } \\
\text { goals. }\end{array}$ & 2.31 & 3.03 \\
\hline s31 & $\begin{array}{l}\text { There should be an equal balance of power between } \\
\text { advisors and advisees. }\end{array}$ & 3.69 & 1.83 \\
\hline
\end{tabular}


Research question 1c: How are the professors' conceptualizations of advising-related activities similar to or different from that of doctoral students'?

Although the six-cluster solution adequately represents how both professors and students sorted the statements, the number of statements in each cluster for professors were different from that of students. Both cluster groups (for professors and students) share a significant number of statements indicating that there are similarities between some of the professor and student clusters. For instance, professor cluster 2 (Enhancing advisor-advisee interaction in a supportive environment) and student cluster 2 (Promoting a supportive advisor-advisee relationship coupled with negotiations) have eight statements in common. The pair of clusters with the second highest number of shared statements was professor cluster 3 and student cluster 2 . This is followed by professor cluster 5 and student cluster 4, then professor and student cluster 1, professor and student cluster 6, and lastly, professor cluster 4 and student cluster 3 (see Table 37 and Figure 27).

Table 37

Number of statements in common (in terms of how they were sorted) between professor and student clusters

\begin{tabular}{cccccccc}
\hline & $\begin{array}{c}\text { Student } \\
\text { Cluster 1 }\end{array}$ & $\begin{array}{c}\text { Student } \\
\text { Cluster 2 }\end{array}$ & $\begin{array}{c}\text { Student } \\
\text { Cluster 3 }\end{array}$ & $\begin{array}{c}\text { Student } \\
\text { Cluster 4 }\end{array}$ & $\begin{array}{c}\text { Student } \\
\text { Cluster 5 }\end{array}$ & $\begin{array}{c}\text { Student } \\
\text { Cluster 6 }\end{array}$ & $\begin{array}{c}\text { Total } \\
\text { number of } \\
\text { statements }\end{array}$ \\
\hline Prof. Cluster 1 & 3 & & & & & & 3 \\
Prof. Cluster 2 & & 8 & 1 & & & & 9 \\
Prof. Cluster 3 & & 7 & 1 & 1 & 1 & & 10 \\
Prof. Cluster 4 & 1 & & 2 & 1 & 1 & 2 & 5 \\
$\begin{array}{c}\text { Prof. Cluster 5 } \\
\text { Prof. Cluster 6 }\end{array}$ & & & 5 & 2 & 3 & 4 \\
\hline $\begin{array}{c}\text { Total number of } \\
\text { statements }\end{array}$ & 4 & 15 & 4 & 8 & 4 & 5 & 40 \\
\hline
\end{tabular}


-Prof. Cluster 2 (9 statements): Enhancing advisor-advisee interaction in a supportive environment

-Stud. Cluster 2 (15 statements): Promoting a supportive advisoradvisee relationship coupled with negotiations

\section{8 statements} in common
- Prof. Cluster 3 (10 statements): Maintaining a good relationship through dialogue and clarity of expectations

- Stud. Cluster 2 (15 statements): Promoting a supportive advisoradvisee relationship coupled with negotiations

\section{7 statements}

\section{in common}

- Prof. Cluster 6 (4 statements): Encouraging doctoral students to follow advisors' directions

-Stud. Cluster 6 (5 statements): Exercising power in advising relationships

\section{3 statements}

\section{in common}

-Prof. Cluster 5 (9 statements):

Promoting students'

independence with advisors'

guidance

-Stud. Cluster 4 (8 statements): Guiding advisees in a

professional manner as they take a responsible role

\section{5 statements}

\section{in common}

Selecting advisors in an early stage and having the chance to change them

-Stud. Cluster 1 (4 statements): Exercising freedom and flexibility in the advisor/advisee selection

3 statements in common
- Prof. Cluster 4 (5 statements): Matching interests through negotiation in the selection process

-Stud. Cluster 3 (4 statements): Attaining the 'best' match during the advisor selection process

\section{2 statements}

in common

Figure 27. Breakdown of paired clusters that have statements in common

Figure 28 shows that 12 statements rated by professors were located in the upper-left quadrant. To professors, these statements were more important and less difficult to implement. Comparatively, nine statements were located in the upper-left quadrant of the go-zone graph for students. Interestingly, only seven statements were found on the upper-right of professor go-zone graph compared to 12 statements for the doctoral students. This indicated that a substantial amount of statements were more important but difficult to implement, according to the students' perspectives. Moreover, students viewed 11 statements as less important and less difficult compared to 10 statements perceived by professors. 
Both professors and students rated eight statements (s1 (Students should be given the opportunity to choose their advisors), s3 (Advisors should be accessible to students), s7 (There should be honest communication between advisors and students), s9 (Students should be wellinformed about the research interest, advising style, and expectations of potential advisors), s12 (Procedures for writing dissertations should be explicitly explained to doctoral students), s32 (Advisors should make sure students follow procedures acceptable to the research community), s38 (There should be mutual respect between advisors and students), s40 (Advisors should give constructive criticism on students' dissertations)) as more important and less difficult, six statements (s16 (Students should be able to express their disagreement when necessary), s19 (Advisors should provide students with needed support), s21 (Advisors should give timely feedback to students), s30 (Students should feel comfortable sharing their academic challenges with advisors), s35 (Advisors and students should clearly define their expectations and goals), s39 (Advisors should be ready to intervene when students are going off-track)) as more important and more difficult, five statements (s6 (Advisors should take the initiative in building and maintaining a good relationship), s10 (Advisors and students should have similar research interests), s15 (The boundaries of the relationship should be well-defined), s23 (Students have to respect the authority of their advisors), s24 (Advisors should exercise their power (expert knowledge) when necessary)) as less important and less difficult, and five statements (s14 (Advisors and students should build trust through negotiation and agreement), s17 (Students should clearly define what they expect from potential advisors), s20 (Students should be allowed to take charge of their dissertation process), s27 (Advisors and students should negotiate their roles and responsibilities), s31 (There should be an equal balance of power between advisors and advisees)) as less important and more difficult (see Table 38). 


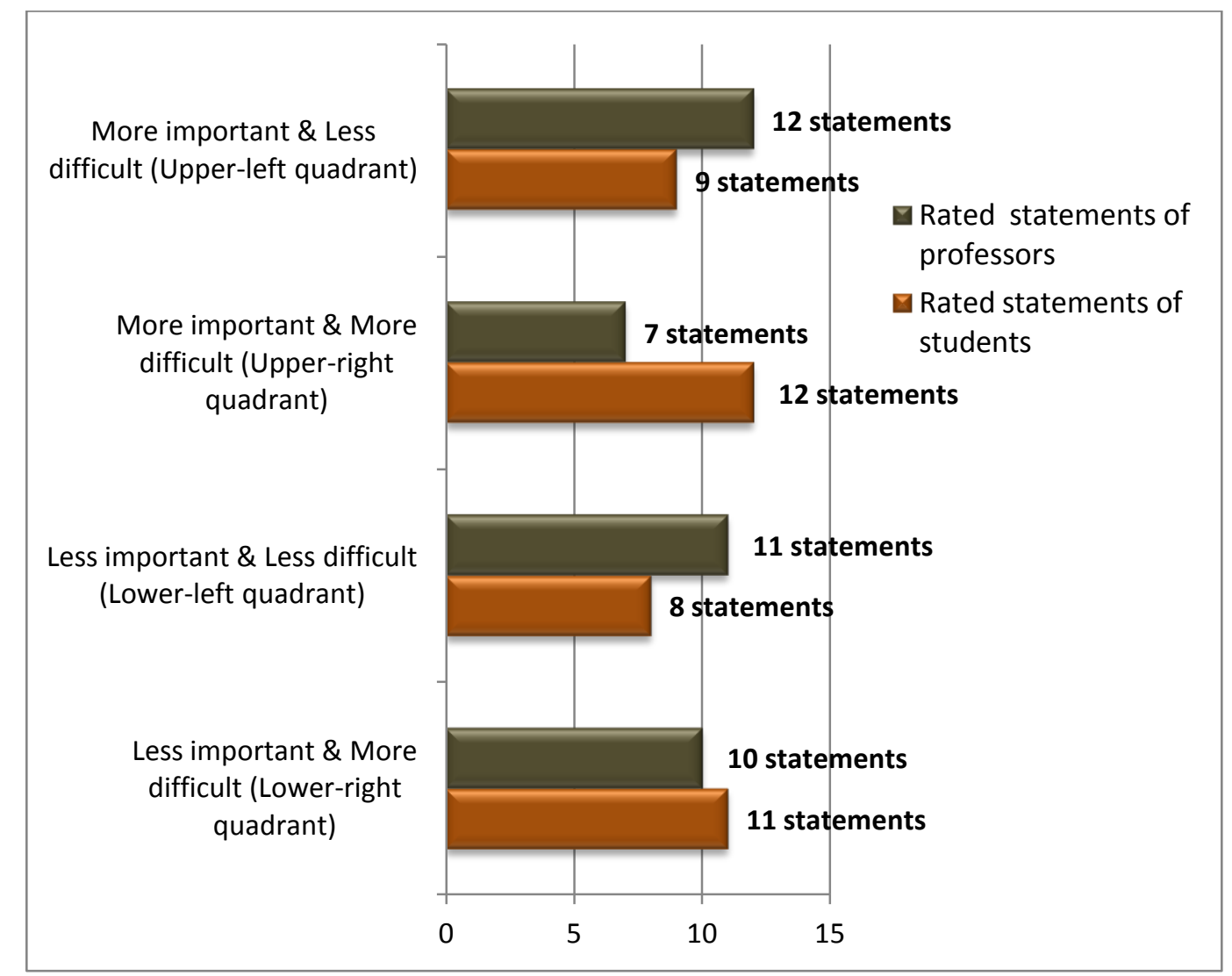

Figure 28. Bar chart showing number of statements in each quadrant of the go-zone graph for professors and students 
Table 38

Number of statements in common (in terms of how they were rated) between professors and students

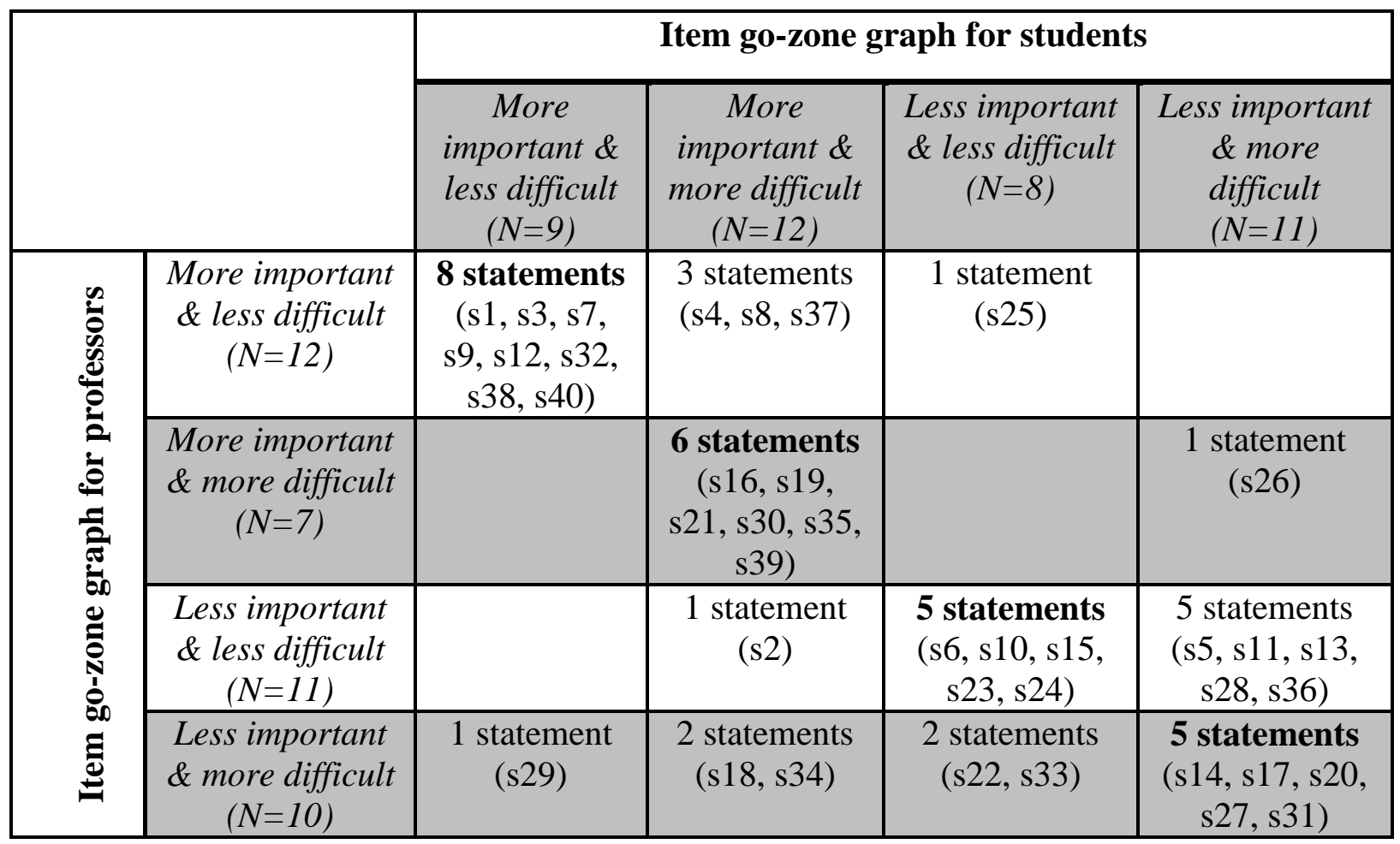

Note. This table is based on the location of the statements on the go-zone graph

Additional qualitative data. During the administration of the survey, participants were given an option to state what they thought should be added to the 40 statements. All the additional statements were qualitatively analyzed: reviewing the statements to identify any patterns and similarities. The statements were also categorized based on already created clusters for both professors' and students' data. Statements unrelated to the existing clusters were put into new groups. Tables 39 and 40 show the statements and their respective categories. 
Table 39

Categories of students' response to the open-ended statement; "Please type any statement that

you think should be added to the statements above"

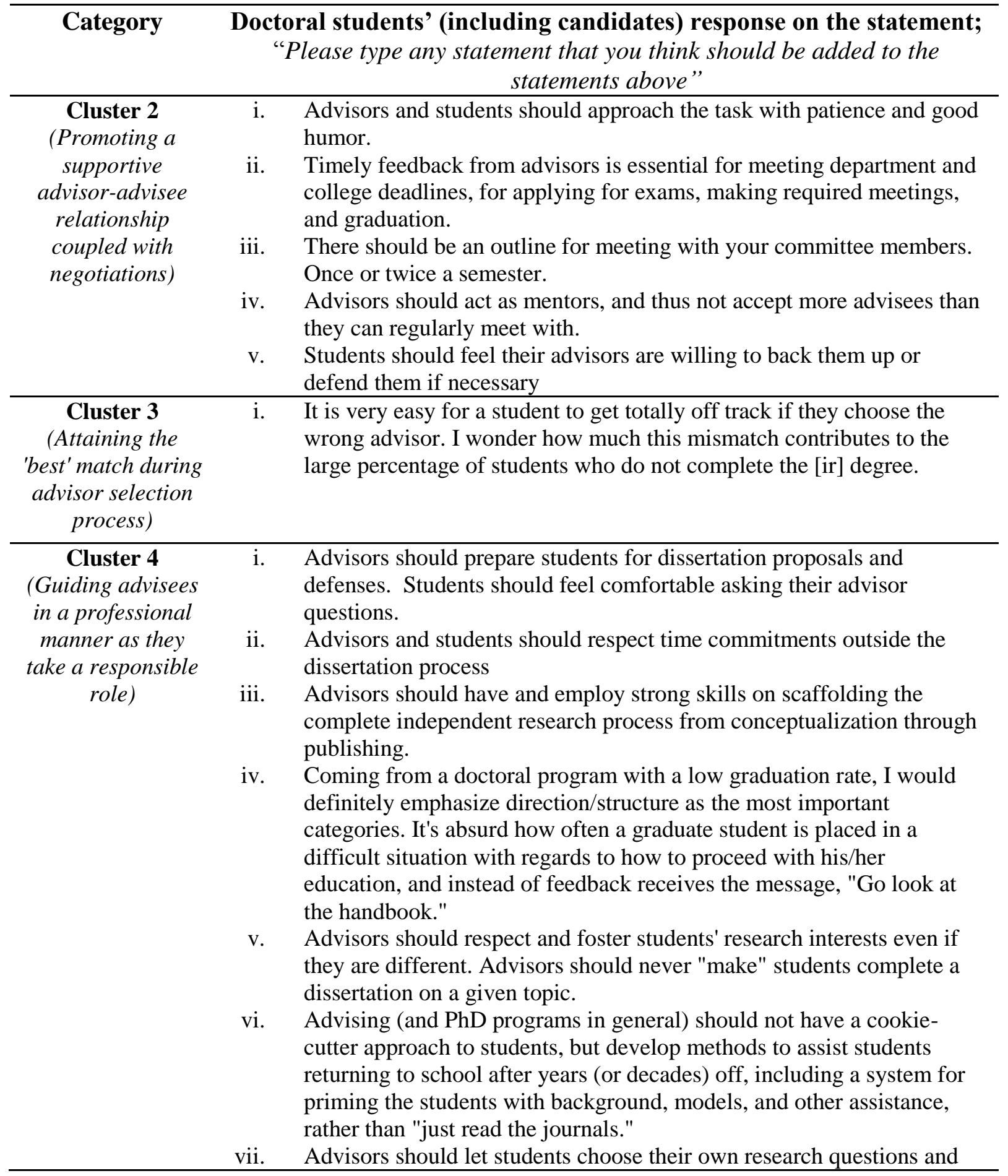


method... i.e. not make it compulsory to do a mixed method research if the student does not want to.

Cluster $\mathbf{5}$
(Understanding
the changing
expectations and
complex nature of
doctoral advising)

ii.

i. Building a solid relationship between advisor and student is key to successfully completing the program in a timely manner. It's a whole new world to the student and the advisor, not only advisors, but is a guide through the labyrinth of paperwork and courses. Students benefit from advisors who have a keen understanding of the intricacies of the process with a broad view of the entire system.

. Advisors should understand that students are not solely here to support or work for them, and require time of their own to successfully complete degree requirements Students should have time limitations to be present in lab defined by the department, rather than decided by the advisor, to avoid advisor ability to monopolize student's time (i.e. more than $20 \mathrm{hrs}$ per week dependent on assistantship or fellowship assignment)

Personal
experience/stories

i.

"Implementing" the statements was at times difficult to apply to some of these statements. Some items are difficult because the advisor does not have or make time for students. For others, the item is difficult because it is a challenging skill (negotiation, for example). Overall, throughout graduate school I feel I have not been given enough support, time, training, or guidance. I think this is directly related to the research pressures put on our faculty, they are too busy to devote enough time to their students. This is a systemic problem within the University, not simply an advisor problem.

ii. I am not sure about the questions regarding negotiating roles. I believe my advisor has the responsibility to perform a job. I will respect his authority and judgment in that area. He is the expert and knows the guidelines. I don't plan to question what he says or suggest otherwise. Unless there is something I find in writing (in the graduate catalog, etc.), I believe what he says and WILL follow his suggestions and rules.

iii. I see many of these items being related to personality conflicts between myself and my advisor, however, he's the right person for the job and I believe, without him, I would not be able to complete my program.

iv. My experience in the Sociology $\mathrm{PhD}$ program at .... (name of the university withheld) has been a joke. The faculty on my dissertation committee never read my work. I am not exaggerating. Faculty also don't really teach here. I wonder why we are all here. At least I will have a PhD from a prestigious university and what I've learned from reading books.

The structure and content of the survey i. The last series of 40 statements are all context specific - these are all very easy with my advisor - it all depends on the people involved. For me, in the relationship with my advisor, these all come very easy. And I believe all of them are important.

ii. I had difficulty understanding the meaning behind these questions. Ease of implementation from what perspective? An organizational perspective? A personal perspective? The student, the professor?

iii. This survey was way too long, and the grouping statements confusing (despite a graduate education including survey methods). 
Table 40

Categories of professors' response to the open-ended statement; "Please type any statement

that you think should be added to the statements above"

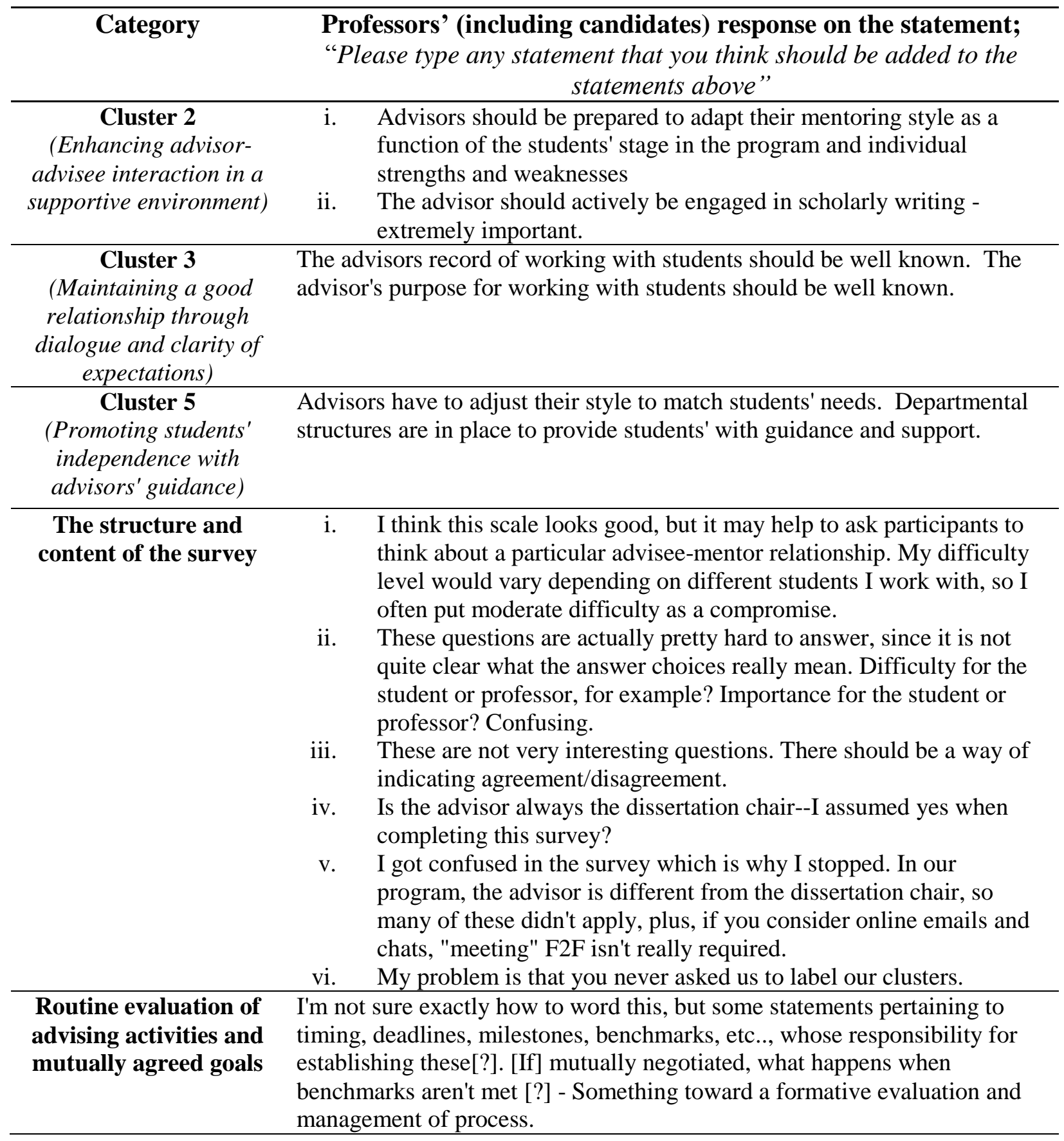




\section{Summary of Findings}

After conducting Multidimensional Scaling (MDS) and Hierarchical Cluster Analysis (HCA), I arrived at six cluster solutions for both professors and students. The cluster go-zone graph for students shows that clusters 2 (Promoting a supportive advisor-advisee relationship coupled with negotiations) and 4 (Guiding advisees in a professional manner as they take a responsible role) were considered more important to the successful completion of students' dissertations. In terms of the level of difficulty, students perceived cluster 4 as less difficult while cluster 2 was viewed as more difficult to implement (see Figure 10). Statements in cluster 4 were related to three of the five components of doctoral advising derived from the literature: advising approach (4 statements), advisor-advisee relationship (1 statement), and power relations (3 statements) (see Table 19). Five of the statements in cluster 4, statements s12, s29, s32, s38, and s40 were rated as actionable statements (i.e. they were more important and less difficult statements) (see Figure 15). Cluster 2 had the highest number of statements with a high Cronbach's alpha coefficient for internal consistency. The 15 statements in cluster 2 were related to four of the five components of doctoral advising with the exception being selection process. Eight of the 15 statements in cluster 2, statements s4, s8, s16, s19, s21, s30, s35, and s37 were considered more important and more difficult (see Figure 13).

The cluster go-zone graph for professors shows that clusters 2 (Promoting a supportive advisor-advisee relationship coupled with negotiations) and 5 (Promoting students' independence with advisors' guidance) were considered more important to the successful completion of students' dissertations (see Figure 19). In terms of the level of difficulty, professors perceived cluster 2 as less difficult while cluster 5 was viewed as more difficult to implement. Each component of doctoral advising had its related statement in cluster 2 (see Table 
20). Five of the statements in cluster 2 , statements s3, s4, s7, s9, and s37 were rated as actionable statements (i.e. they were more important and less difficult statements) (see Figure 22). The nine statements in cluster 5 were related to four of the five components of doctoral advising with the exception being selection process. Two of the nine statements in cluster 5, statements s 26 , and s39 were considered more important and more difficult (see Figure 25).

Although there were disparities in the way both groups sorted the 40 statements, there were similarities between the content of the professor and student clusters. For instance, professor and student cluster 2 have eight statements in common, and professor cluster 3 and student cluster 2 have seven statements in common. There were similarities in how professors and students rated the statements. Both professors and students rated eight statements (s1, s3, s7, s9, s12, s32, s38, s40) as more important to the successful completion of dissertations and less difficult to accomplish. Lastly, professors and students rated 6 statements (s16, s19, s21, s30, s35, s39) as more important and more difficult (see Table 38). In all 24 professors' and students' rated statements fell into the same quadrant. 


\section{Chapter 5}

\section{Discussion}

In this chapter, I focus on the implications and recommendations from the study for conceptualizing the perspectives of professors and doctoral students on doctoral advising. I will briefly review the study findings addressing each research question. I will then discuss implications of those findings organized around the five components of advising derived from the literature. The statements and clusters perceived as more important will also be discussed. Lastly, I will present limitations of study and suggestions for future research.

\section{Overview of Study}

About half of doctoral students fail or are unable to complete their doctoral education (Ferrer de Valero, 2001; Golde, 2000; Hoskins \& Goldberg, 2005; Spillett \& Moisiewicz, 2004). Studies have shown that doctoral advising is one of the contributing factors to students' dissertation completion. Due to the complex nature of doctoral advising, just following ideal roles, responsibilities, and expectations will not necessarily lead to a reduction of attrition rate at the graduate level. As Acker et al. (1994) indicated, advisors “...cannot be 'trained' in any overly simplified way to adopt a series of steps, which will inevitably lead to a satisfied student and a completed thesis" ( p. 496).

To help address these advising-related problems, researchers have identified some contributing factors that influence one's decision to leave a program. Acker et al. (1994) grouped advising related literature into four areas: "advisor selection, roles and functions, types of relationships, and outcomes" (p. 34). Building upon Acker et al.'s study, I conducted qualitative document analysis of the literature and categorized studies into the following five components. 
They were; (a) advising approach, (b) selection process, (c) roles, responsibilities, and expectations, (d) advisor-advisee relationship, and (e) power relations. The document analysis also revealed interrelationships among these factors of doctoral advising. With this background, the purpose of this study was to conceptualize the perspectives of professors and doctoral students on doctoral advising using concept mapping. The research questions were as follows;

1. How can we conceptualize the perspectives of professors and doctoral students on doctoral advising?

a. How do the five components of doctoral advising from the literature, map onto both doctoral students' and professors' conceptualization of advising?

b. How do professors and doctoral students rate the importance and difficulty of the advising statements/activities?

c. How are the professors' conceptualizations of advising-related activities similar to or different from that of doctoral students'?

Informed by the existing literature on doctoral advising, I generated 40 statements related to the five components of advising (eight for each component). After creating a survey, and getting IRB approval, I sent the link of the online survey to college deans and/or heads of departments to distribute to professors and doctoral students in their respective colleges/departments. Participants were given the statements online to sort and rate. In all, 152 out of 278 completed the survey: indicating a 55\% response rate. Thirty eight of the participants were professors, $47.4 \%$ of them were males $(n=18)$ and $52.6 \%$ were females $(n=20)$. Regarding student participants, 114 doctoral students (including doctoral candidates) completed the survey. The gender composition was 30 males and 84 females constituting $26.3 \%$ and $73.7 \%$ of the student participants respectively. 


\section{Summary of Findings}

Research question 1. How can we conceptualize the perspectives of professors and doctoral students on doctoral advising? Analysis of the hierarchical cluster tree (dendrogram) and two-dimensional point map showed that a six-cluster solution reflected how both professors and doctoral students sorted the 40 statements. Results showed that doctoral students sorted the statements under the following categories; cluster 1 (Exercising freedom and flexibility in the advisor/advisee selection), cluster 2 (Promoting a supportive advisor-advisee relationship coupled with negotiations), cluster 3 (Attaining the 'best' match during the advisor selection process), cluster 4 (Guiding advisees in a professional manner as they take a responsible role), cluster 5 (Understanding the changing expectations and complex nature of doctoral advising), and cluster 6 (Exercising power in advising relationships), which contained 4, 15, 4, 8, 4, and 5 statements, respectively (see Tables 7, 8, 9, 10, and 11). Examination of the proximity among clusters on the named cluster map (see Figure 7) and statements in each cluster indicated a relation between clusters 1 and 3 . These two clusters focused on the selection process in advising. Similarly, clusters 2 and 4 emphasized on support and guidance for students. Although clusters 5 and 6 were visually close, they were different in content.

Similar to students' overall categorization of the statements, analysis of professors' sorted data revealed six clusters. They included; cluster 1 (Selecting advisors in an early stage and having the chance to change them), cluster 2 (Enhancing advisor-advisee interaction in a supportive environment), cluster 3 (Maintaining a good relationship through dialogue and clarity of expectations), cluster 4 (Matching interests through negotiation in the selection process), cluster 5 (Promoting students' independence with advisors' guidance), and cluster 6 (Encouraging students to follow advisors' directions), which contained 3, 9, 10, 5, 9, and 4 
statements, respectively (see Tables 14, 15, 16, 17, and 18). Besides their content similarities, clusters 2, 3, and 5 were in close proximity on the named cluster map (see Figure 8). There were also content similarities between clusters 1 and 4 but they were not in close proximity.

Research question 1a. How do the five components of doctoral advising from the literature, map onto both doctoral students' and professors' conceptualization of advising? Doctoral students' categorization of the 40 statements seemed to be more consistent in relation to how the statements were grouped under the five components of doctoral advising compared to professors' classification (see Tables 19 and 20). For instance, all the statements in student clusters 1 (Exercising freedom and flexibility in the advisor/advisee selection) and 3 (Attaining the 'best' match during the advisor selection process) were related to the selection process component. Most of the statements in student cluster 2 (Promoting a supportive advisor-advisee relationship coupled with negotiations) came from roles, responsibilities, and expectations, and the advisor-advisee relationship component.

With regard to the professors' sorting, the statements under each of the five components of doctoral advising were more spread out across professor clusters in comparison to the student clusters (see Tables 19 and 20). Each advising component had at least one of its statements in four of the professors' six clusters. For instance, professor clusters 2 (Enhancing advisor-advisee interaction in a supportive environment) and 3 (Maintaining a good relationship through dialogue and clarity of expectations) had at least one of their statements in each of the five advising components. 
Research question $1 \boldsymbol{b}$ : How do professors and doctoral students rate the importance and difficulty of the advising statements/activities? The students' go-zone graph displaying the various clusters showed that cluster 4 (Guiding advisees in a professional manner as they take a responsible role) was viewed as more important to the successful completion of dissertations and less difficult to implement. Five out of eight statements in cluster 4 were rated as more important and less difficult (see Table 41). They included; s12 (Procedures for writing dissertations should be explicitly explained to doctoral students), s29 (Advisors should focus on directing students toward set goals), s32 (Advisors should make sure students follow procedures acceptable to the research community), s38 (There should be mutual respect between advisors and students), and s40 (Advisors should give constructive criticism on students' dissertations). Doctoral students perceived cluster 2 as more important and more difficult. Eight out of 15 statements in cluster 2 were rated as more important and more difficult (see Table 41). They were; s4 (Advisors and students should meet frequently to talk about issues related to dissertations), s8 (There should be open dialogue concerning making decisions and resolving conflicts), s16 (Students should be able to express their disagreement when necessary), s19 (Advisors should provide students with needed support), s21 (Advisors should give timely feedback to students), s30 (Students should feel comfortable sharing their academic challenges with advisors), s35 (Advisors and students should clearly define their expectations and goals), and s37 (Advisors should be ready to listen to the concerns of their students). 
Table 41

A list of statements in their respective clusters found in each quadrant of the go-zone graph (based on students' sorted and rated data)

\begin{tabular}{lcccc}
\hline Cluster & $\begin{array}{c}\text { More important } \\
\text { \& less difficult } \\
(9 \text { items })\end{array}$ & $\begin{array}{c}\text { More important } \\
\text { \& more difficult } \\
(12 \text { items })\end{array}$ & $\begin{array}{c}\text { Less important \& } \\
\text { less difficult } \\
(8 \text { items })\end{array}$ & $\begin{array}{c}\text { Less important \& } \\
\text { more difficult } \\
(11 \text { items })\end{array}$ \\
\hline $\begin{array}{l}\text { Cluster 1 } \\
\text { (4 statements })\end{array}$ & $\mathrm{s} 1$ & $\mathrm{~s} 2$ & $\mathrm{~s} 25, \mathrm{~s} 33$ & \\
$\begin{array}{l}\text { Cluster 2 } \\
(15 \text { statements })\end{array}$ & $\mathrm{s} 3, \mathrm{~s} 7$ & $\mathrm{~s} 4, \mathrm{~s} 8, \mathrm{~s} 16, \mathrm{~s} 19$, & $\mathrm{s} 6$ & $\mathrm{~s} 5, \mathrm{~s} 11, \mathrm{~s} 13, \mathrm{~s} 14$ \\
$\begin{array}{l}\text { Cluster 3 } \\
(4 \text { statements })\end{array}$ & $\mathrm{s} 9$ & $\mathrm{~s} 18$ & $\mathrm{~s} 30, \mathrm{~s} 35, \mathrm{~s} 37$ & $\mathrm{~s} 17$ \\
$\begin{array}{l}\text { Cluster } 4 \\
(8 \text { statements })\end{array}$ & $\begin{array}{c}\mathrm{s} 12, \mathrm{~s} 29, \mathrm{~s} 32, \\
\mathrm{~s} 38, \mathrm{~s} 40\end{array}$ & $\mathrm{~s} 39$ & $\mathrm{~s} 10$ & $\mathrm{~s} 20, \mathrm{~s} 36$ \\
$\begin{array}{l}\text { Cluster 5 } \\
(4 \text { statements })\end{array}$ & & $\mathrm{s} 34$ & $\mathrm{~s} 15, \mathrm{~s} 22$ & $\mathrm{~s} 27$ \\
$\begin{array}{l}\text { Cluster 6 } \\
(5 \text { statements })\end{array}$ & & $\mathrm{s} 23, \mathrm{~s} 24$ & $\mathrm{~s} 26, \mathrm{~s} 28, \mathrm{~s} 31$ \\
\hline
\end{tabular}

The professors' go-zone graph displaying the various clusters showed that cluster 2 (Enhancing advisor-advisee interaction in a supportive environment) was viewed as more important to the satisfactory completion of dissertation requirements and less difficult to implement. Five out of nine statements in cluster 2 were perceived as more important and less difficult (see Table 42). They were; s3 (Advisors should be accessible to students), s4 (Advisors and students should meet frequently to talk about issues related to dissertations), s7 (There should be honest communication between advisors and students), s9 (Students should be wellinformed about the research interest, advising style, and expectations of potential advisors), and s37 (Advisors should be ready to listen to the concerns of their students). The go-zone graph in Figure 19 also indicated that professors viewed cluster 5 (Promoting students' independence with advisors' guidance) as more important and more difficult. Only two of the nine statements (s26 
(Students should be independent) and $\mathrm{s} 39$ (Advisors should be ready to intervene when students are going off-track)) in cluster 5 were rated as more important and more difficult (see Table 42).

Table 42

A list of statements in their respective clusters found in each quadrant of the go-zone graph (based on professors' sorted and rated data)

\begin{tabular}{|c|c|c|c|c|}
\hline Cluster & $\begin{array}{l}\text { More important } \\
\& \text { less difficult } \\
\text { (12 items) }\end{array}$ & $\begin{array}{l}\text { More important } \\
\& \text { more difficult } \\
(7 \text { items })\end{array}$ & $\begin{array}{c}\text { Less important \& } \\
\text { less difficult } \\
\text { (11 items) }\end{array}$ & $\begin{array}{c}\text { Less important \& } \\
\text { more difficult } \\
(10 \text { items })\end{array}$ \\
\hline $\begin{array}{l}\text { Cluster } 1 \\
\text { (3 statements) }\end{array}$ & s1 & & $\mathrm{s} 2$ & s33 \\
\hline $\begin{array}{l}\text { Cluster } 2 \\
\text { (9 statements) }\end{array}$ & $\mathrm{s} 3, \mathrm{~s} 4, \mathrm{~s} 7, \mathrm{~s} 9, \mathrm{~s} 37$ & s16, s19 & s5 & s14 \\
\hline $\begin{array}{l}\text { Cluster } 3 \\
\text { (10statements) }\end{array}$ & $\mathrm{s} 8, \mathrm{~s} 12$ & $\mathrm{~s} 21, \mathrm{~s} 30, \mathrm{~s} 35$ & s6, s11, s13, s15 & s17 \\
\hline $\begin{array}{l}\text { Cluster } 4 \\
\text { (5 statements) }\end{array}$ & $\mathrm{s} 25, \mathrm{~s} 38$ & & s10 & s18, s27 \\
\hline $\begin{array}{l}\text { Cluster } 5 \\
\text { (9 statements) }\end{array}$ & $\mathrm{s} 32, \mathrm{~s} 40$ & s26, s39 & s24, s36 & s20, s22, s34 \\
\hline $\begin{array}{l}\text { Cluster } 6 \\
\text { (4 statements) }\end{array}$ & & & s23, s28 & s29, s31 \\
\hline
\end{tabular}

Research question 1c: How are the professors' conceptualizations of advising-related activities similar to or different from that of doctoral students'? The results showed that there were differences between how professors and students sorted the statements in terms of the number of advising activities in each cluster and their content. However, some of professor clusters have statements in common with student clusters. For instance, student cluster 2 (Promoting a supportive advisor-advisee relationship coupled with negotiations) had eight and seven statements in common with professor clusters 2 (Enhancing advisor-advisee interaction in 
a supportive environment) and 3 (Maintaining a good relationship through dialogue and clarity of expectations) respectively.

Similarly, professors' and students' go-zone graph showed that both professors and students rated eight statements (s1, s3, s7, s9, s12, s32, s38, s40) as more important and less difficult, six statements (s16, s19, s21, s30, s35, s39) as more important and more difficult, five statements (s6, s10, s15, s23, s24) as less important and less difficult, and five statements (s14, s17, s20, s27, s31) as less important and more difficult. However, there were existing differences in how professors and students rated some of the statements. For example, professors viewed statement s25 (Advisors should have the chance to choose who they want to work with) as more important and less difficult while students perceived it as less important and less difficult. Also, professors rated statements s18 (Advisors and students should have matched goals and expectations) and s34 (Students should be able to adjust to changing expectations and roles) as less important and more difficult but students rated them as more important and more difficult (see Table 38).

\section{Interpretations of Findings}

In this section, the interpretations of findings are presented based on six themes. The first five include; selection process, advising approach, advisor-advisee relationship, roles, responsibilities, and expectations, and power relations (i.e. the five components of advising). The last theme is based on the professors' and student clusters that were rated as more important.

Selection process. Advising process always starts with selection of an advisor or assigning a doctoral student to an advisor. Researchers have suggested the need for students to choose their advisors (Sangganjanavanich \& Magnuson, 2009; Schlosser et al., 2003). Both 
professors and doctoral students (in this study) rated statement s1 (Students should be given the opportunity to choose their advisors) as more important (see Figures 29 and 31, and Tables 43 and 45). This means that having the chance to select their advisors was thought to greatly contribute to students' effective dissertation completion. They also believed that the task of selecting advisors can be easy if the faculty/department/college make available useful information about potential advisors. Professors and students viewed s9 (Students should be well-informed about the research interest, advising style, and expectations of potential advisors) as more important. This is consistent with Sangganjanavanich and Magnuson's (2009) suggestion that students should be given "advisor disclosure statements" (p. 195), which spell out potential advisors' expectations, roles, research interests, and advising style. Statements s1 and s9 were also viewed by professors and students as less difficult to accomplish.

Professors seem to suggest that there should be an equal opportunity for both potential advisors and doctoral students during the selection process. They indicated that "advisors should have the chance to choose who they want to work with" (s25) (see Figure 31 and Table 45). However, students saw this statement as less important to the successful completion of their dissertations. They did not see the connection between accepting to work with students and their dissertation completion. To professors, both parties have to agree to work together to attain shared goals.

Another opportunity that students wanted was "...the chance to easily change their advisors when necessary" (s2). But they viewed this advising activity as more difficult to carry out. In the same vein, participants in Ferre de Valero's (2001) study indicated the relevance of having the opportunity to change their advisors but expressed that they were unwilling to do so. Professors had a completely different view on this issue: they perceived statement s2 as less 
important to the successful completion of students' dissertations and less difficult to accomplish. In my opinion, creating an atmosphere where students can easily move from one advisor to another may not be beneficial to professors and students. Students may frequently change their advisors as a way of avoiding dealing with conflict or disagreements that emerge. Making the changing of advisors the last resort creates an avenue for students and professors to engage in dialogue so as to resolve their differences. It is also important to note that there are some situations where changing advisors may be the best option (Golde, 2000). For instance, when a professor fails to carry out his/her basic duties as an advisor.

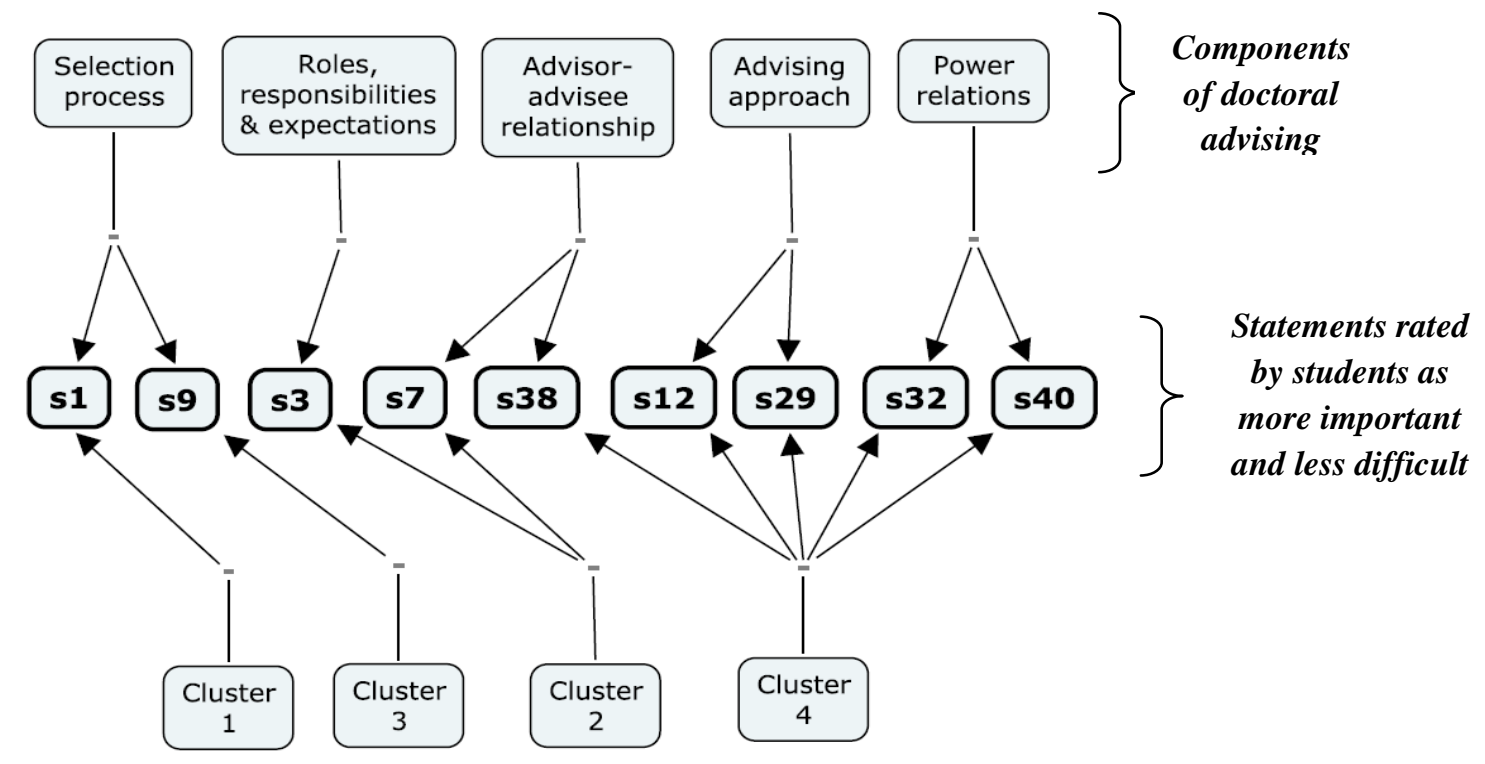

Figure 29. Statements rated by students as more important and less difficult and their relations with advising components and clusters.

Note. Each statement belongs to one of the following clusters; cluster 1 (Exercising freedom and flexibility in the advisor/advisee selection), cluster 2 (Promoting a supportive advisor-advisee relationship coupled with negotiations), cluster 3 (Attaining the 'best' match during the advisor selection process), and cluster 4 (Guiding advisees in a professional manner as they take a responsible role). 
Table 43

Content of the statements rated by students as more important and less difficult

\begin{tabular}{cl}
\hline Statement & \multicolumn{1}{c}{ Content } \\
\hline s1 & Students should be given the opportunity to choose their advisors \\
s3 & Advisors should be accessible to students \\
s7 & There should be honest communication between advisors and students \\
s9 & Students should be well-informed about the research interest, advising style, and \\
& expectations of potential advisors \\
s12 & $\begin{array}{l}\text { Procedures for writing dissertations should be explicitly explained to doctoral } \\
\text { students }\end{array}$ \\
s29 & Advisors should focus on directing students toward set goals \\
s32 & Advisors should make sure students follow procedures acceptable to the research \\
& community \\
s38 & There should be mutual respect between advisors and students \\
s40 & Advisors should give constructive criticism on students' dissertations \\
\hline
\end{tabular}




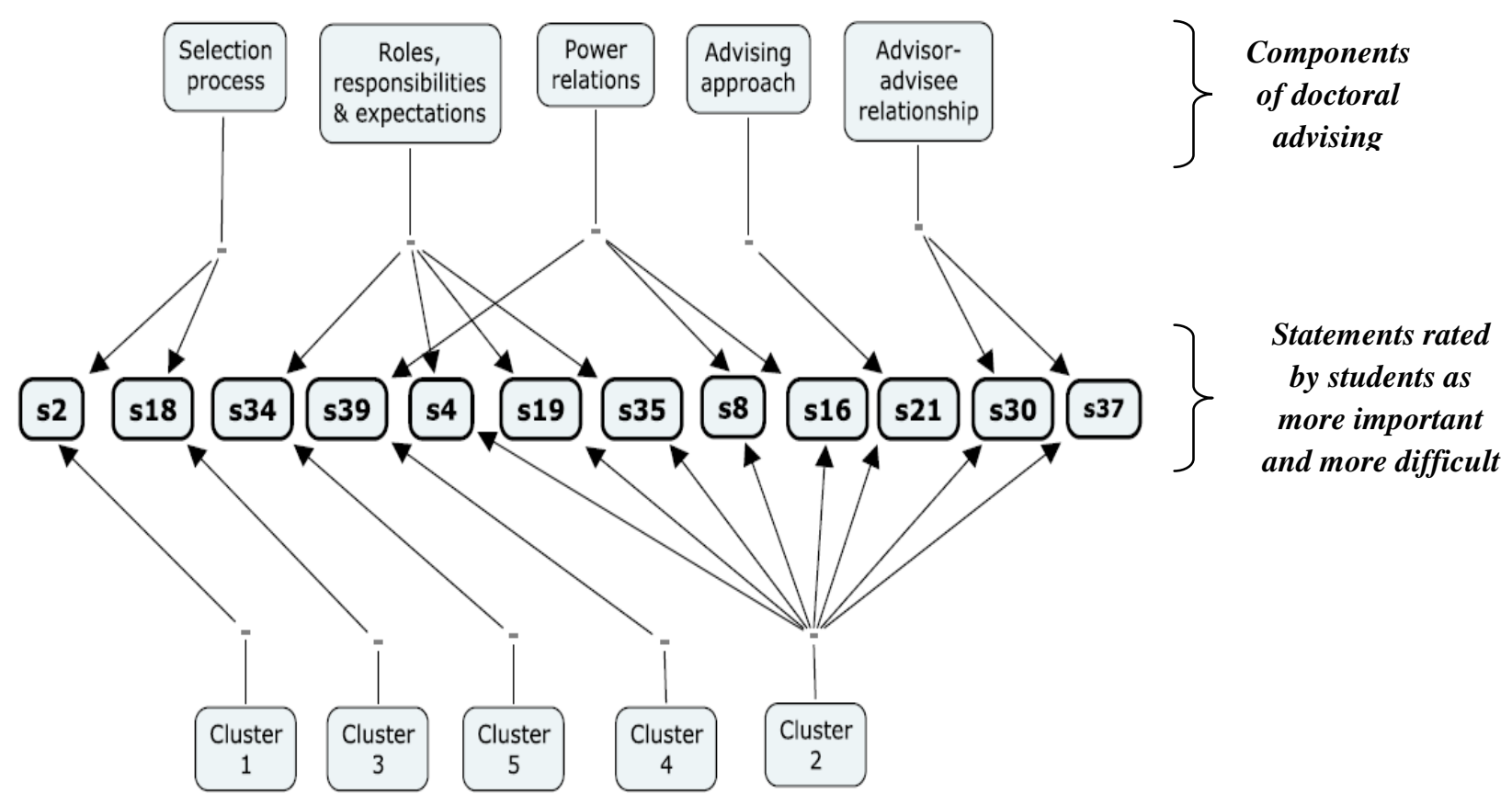

Figure 30. Statements rated by students as more important and more difficult and their relations with advising components and clusters.

Note. Each statement belongs to one of the following clusters; cluster 1 (Exercising freedom and flexibility in the advisor/advisee selection), cluster 2 (Promoting a supportive advisor-advisee relationship coupled with negotiations), cluster 3 (Attaining the 'best' match during the advisor selection process), cluster 4 (Guiding advisees in a professional manner as they take a responsible role), and cluster 5 (Understanding the changing expectations and complex nature of doctoral advising). 
Table 44

Content of the statements rated by students as more important and more difficult

\begin{tabular}{|c|c|}
\hline Statement & Content \\
\hline s2 & Students should have the chance to easily change their advisors when necessary \\
\hline s4 & $\begin{array}{l}\text { Advisors and students should meet frequently to talk about issues related to } \\
\text { dissertations }\end{array}$ \\
\hline s8 & $\begin{array}{l}\text { There should be open dialogue concerning making decisions and resolving } \\
\text { conflicts }\end{array}$ \\
\hline s16 & Students should be able to express their disagreement when necessary \\
\hline s 18 & Advisors and students should have matched goals and expectations \\
\hline s19 & Advisors should provide students with needed support \\
\hline s21 & Advisors should give timely feedback to students \\
\hline s30 & Students should feel comfortable sharing their academic challenges with advisors \\
\hline s34 & Students should be able to adjust to changing expectations and roles \\
\hline s35 & Advisors and students should clearly define their expectations and goals \\
\hline s37 & Advisors should be ready to listen to the concerns of their students \\
\hline s39 & Advisors should be ready to intervene when students are going off-track \\
\hline
\end{tabular}




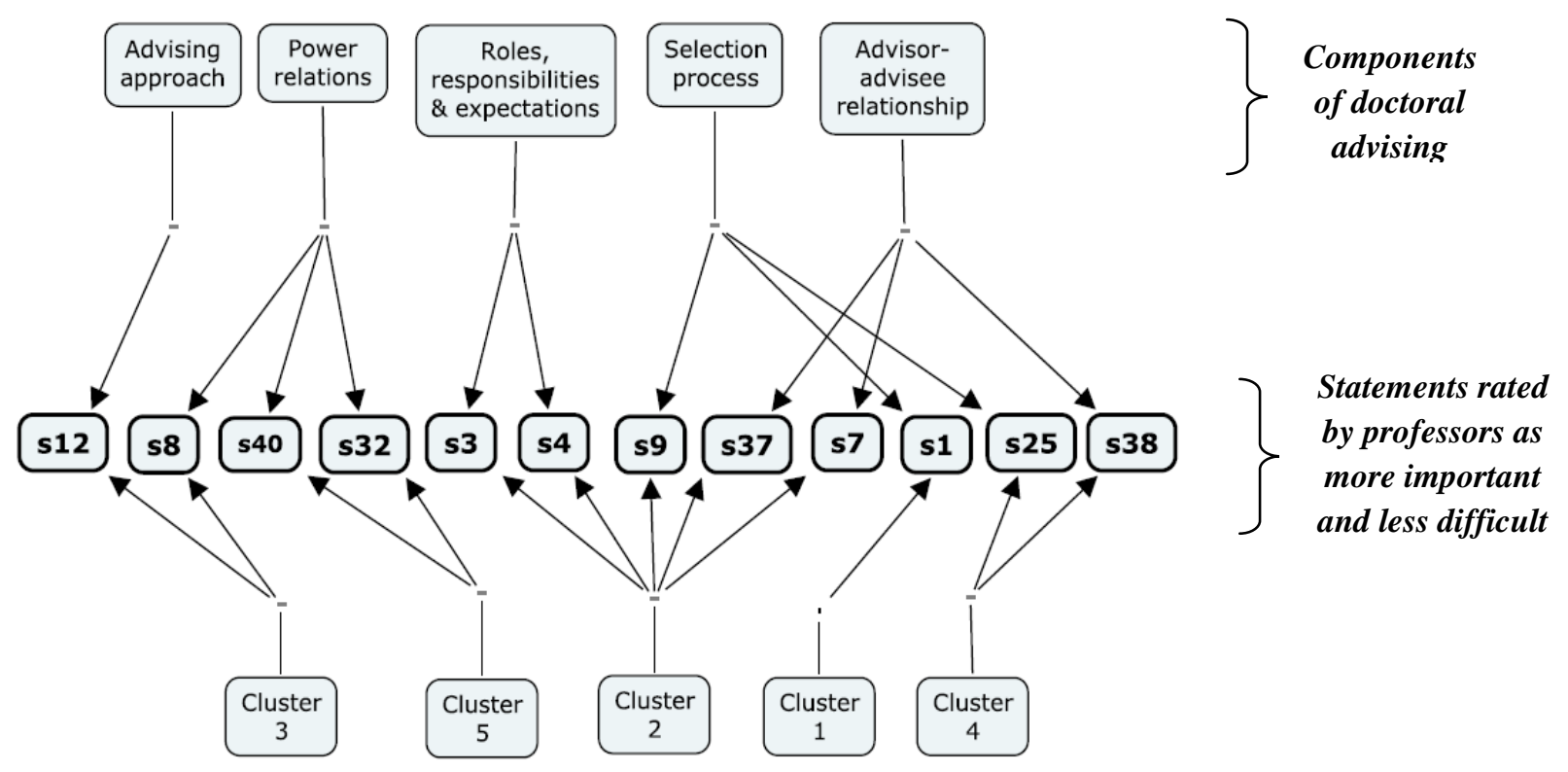

Figure 31. Statements rated by professors as more important and less difficult and their relations with advising components and clusters.

Note. Each statement belongs to one of the following clusters; cluster 1 (Selecting advisors in an early stage and having the chance to change them), cluster 2 (Enhancing advisor-advisee interaction in a supportive environment), cluster 3 (Maintaining a good relationship through dialogue and clarity of expectations), cluster 4 (Matching interests through negotiation in the selection process), and cluster 5 (Promoting students' independence with advisors' guidance). 
Table 45

Content of the statements rated by professors as more important and less difficult

\begin{tabular}{|c|c|}
\hline Statement & Content \\
\hline s1 & Students should be given the opportunity to choose their advisors \\
\hline s3 & Advisors should be accessible to students \\
\hline s4 & $\begin{array}{l}\text { Advisors and students should meet frequently to talk about issues related to } \\
\text { dissertations }\end{array}$ \\
\hline s7 & There should be honest communication between advisors and students \\
\hline s8 & $\begin{array}{l}\text { There should be open dialogue concerning making decisions and resolving } \\
\text { conflicts }\end{array}$ \\
\hline s9 & $\begin{array}{l}\text { Students should be well-informed about the research interest, advising style, and } \\
\text { expectations of potential advisors }\end{array}$ \\
\hline s 12 & $\begin{array}{l}\text { Procedures for writing dissertations should be explicitly explained to doctoral } \\
\text { students }\end{array}$ \\
\hline s25 & Advisors should have the chance to choose who they want to work with \\
\hline s32 & $\begin{array}{l}\text { Advisors should make sure students follow procedures acceptable to the research } \\
\text { community }\end{array}$ \\
\hline s37 & Advisors should be ready to listen to the concerns of their students \\
\hline s38 & There should be mutual respect between advisors and students \\
\hline s40 & Advisors should give constructive criticism on students' dissertations \\
\hline
\end{tabular}




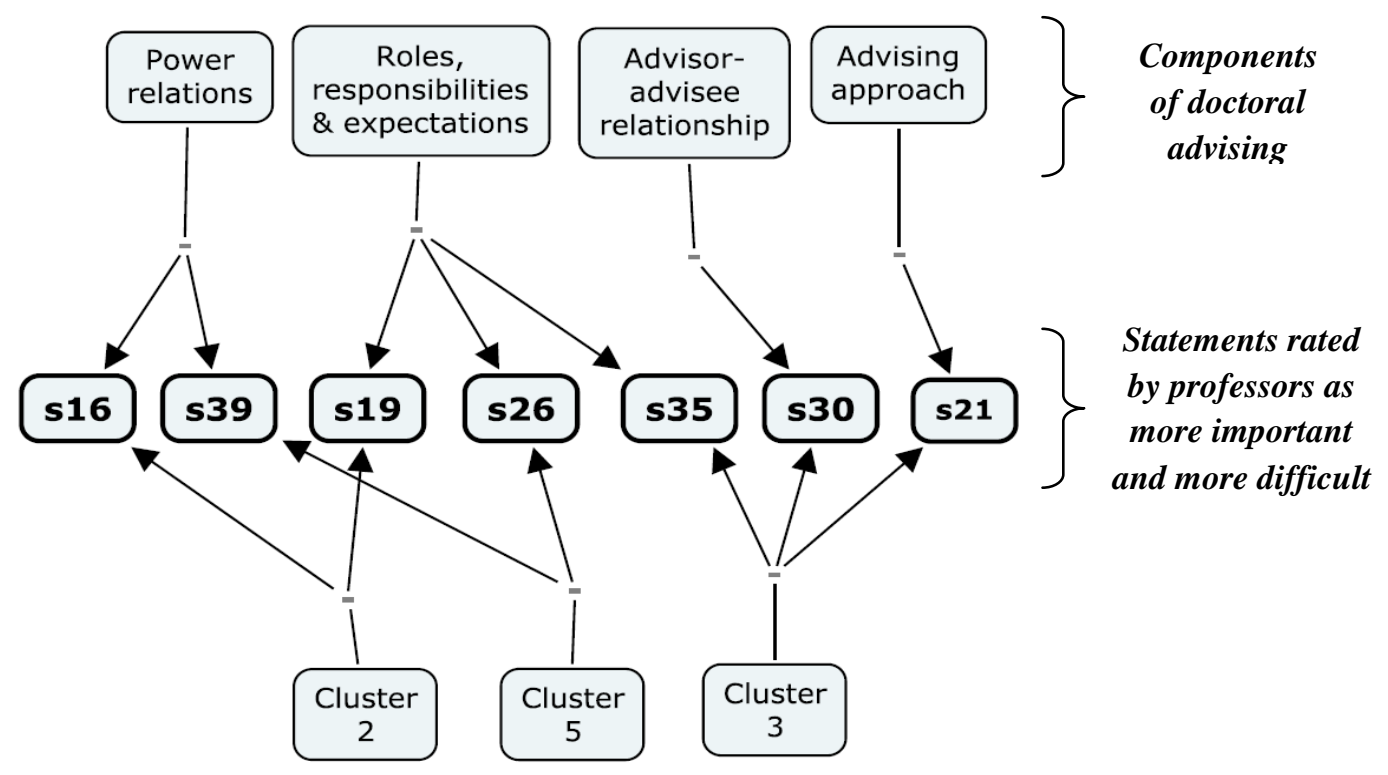

Figure 32. Statements rated by professors as more important and more difficult and their

relations with advising components and clusters.

Note. Each statement belongs to one of the following clusters; cluster 2 (Enhancing advisoradvisee interaction in a supportive environment), cluster 3 (Maintaining a good relationship through dialogue and clarity of expectations), and cluster 5 (Promoting students' independence with advisors' guidance).

Table 46

Content of the statements rated by professors as more important and more difficult

\begin{tabular}{cl}
\hline Statement & \multicolumn{1}{c}{ Content } \\
\hline s16 & Students should be able to express their disagreement when necessary \\
s19 & Advisors should provide students with needed support \\
s21 & Advisors should give timely feedback to students \\
s26 & Students should be independent \\
s30 & Students should feel comfortable sharing their academic challenges with advisors \\
s35 & Advisors and students should clearly define their expectations and goals \\
s39 & Advisors should be ready to intervene when students are going off-track \\
\hline
\end{tabular}


The results of a study conducted by Hoskins and Goldberg (2005) showed that the main contributing factor to attrition was lack of shared goals and expectations between advisors and advisees. In my study, students perceived having matched goals and expectations (i.e. statement s18 (Advisors and students should have matched goals and expectations)) as more important but more difficult to accomplish (see Figure 30 and Table 44). Some students lack the necessary resources and skills to match their own interest to that of their potential advisors. It is a herculean task for students because it involves actively searching for potential advisors whose research interests are similar to theirs and engaging in conversation with the aim of coming up with clear and mutually agreed goals and expectations. Professors also acknowledged the difficulty of carrying out this task (Statement s18) (see Table 41). However, they rated this advising activity (s18) as less important to successful dissertation completion: meaning, students do not have to have advisors with matched goals and expectations to be successful in their doctoral experience.

Advising approach. In Acker et al.'s (1994) study on doctoral advising style, they suggested that while some students preferred a more structured approach to advising, others wanted an unstructured approach that gives more room for creativity. Some of the advisors they interviewed indicated that their style of advising changes depending on the situation and needs of students. As identified in this study, students rated statement s29 (Advisors should focus on directing students toward set goals) as more important and less difficult to carry out. Students would like clear and specific steps for their dissertation completion. But as Petersen (2007) stated, doctoral education is an induction process aimed at preparing students to be independent scholars and to be inducted into the research community (see Figure 2). To professors, solely "...directing students towards the set goals" (s29) may defeat the main purpose of doctoral education. It is not surprising that they rated statement s29 as less important and more difficult. I 
can envision how challenging it could be for advisors to be more direct in their advising style in a doctoral program that promotes independence in research.

That is not to say that professors should not direct students. In fact, students do need guidance (in some specific situations) to be successful in their doctoral education. For example, they could use clarification in the steps and procedures that are to be followed in the dissertation process. In this study, both professors and students perceived statement s12 (Procedures for writing dissertations should be explicitly explained to doctoral students) as more important and less difficult (see Figures 29 and 31 and Tables 43 and 45). Advisors still expect students to independently work on their dissertations and report back to them. They could then assess what students have done and give feedback. Professors and students understand the importance of providing feedback to students during the dissertation process: this is why they rated statement s21 (Advisors should give timely feedback to students) as more important. However, they rated the statement (s21) as more difficult to implement (see Figures 30 and 32 and Tables 44 and 46). This could be because giving feedback on dissertations can be time consuming on the part of professors and students tend not to have much control over the immediacy, frequency, and sufficiency of the feedback.

Advisor-advisee relationship. Both professors and students are aware of the importance of having interactions and negotiations and their effect on the advisor-advisee relationship. The findings of a research study by Schlosser et al. (2003) showed that satisfied students reported having a positive relationship (such as working collaboratively, having honest discussions, and negotiations) with their advisors. Hoskins and Goldberg (2005) and Mackenzie and Ling (2009) suggested that honest communication and mutual respect between advisors and advisees promote successful completion of doctoral education. In this study, I identified four interconnecting 
factors that contribute to good advisor-advisee relationships. They were; advisee's willingness to share, advisor's readiness to listen, mutual respect, and honest communication (see Figure 33). Professors and students in this study rated statements s7 (There should be honest communication between advisors and students) and s38 (There should be mutual respect between advisors and students) as more important and less difficult to accomplish. Honest communication between advisors and students (s7) can be achieved if students feel comfortable sharing (s30 (Students should feel comfortable sharing their academic challenges with advisors)) and advisors are ready to listen to students' concerns (s37 (Advisors should be ready to listen to the concerns of their students)). In addition, these actions should be alloyed with mutual respect (s38). Both parties acknowledged students' difficulty in comfortably talking to advisors about their academic challenges. But when it comes to implementing statement s37, professors saw it as less difficult while students perceived it as more difficult. This is not surprising because professors (as advisors) see statement s37 as their responsibility, which can be easily carried out. 


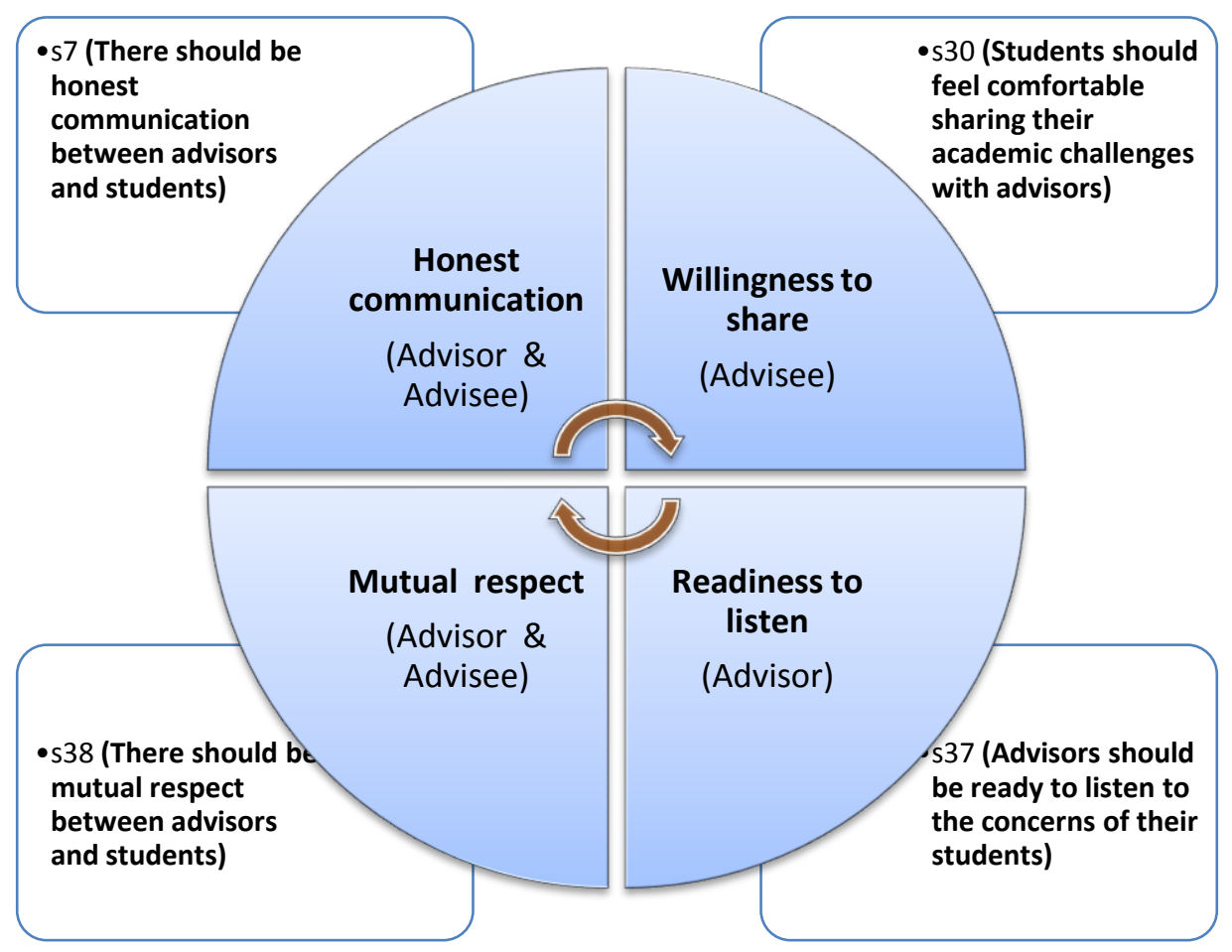

Figure 33. Illustration of the four statements related to advisor-advisee relationship and rated as more important by both professors and students

Role, responsibilities and expectations. One of the main roles of advisors is to "...be accessible to students" (s3). Both professors and doctoral students viewed this role as more important and less difficult to perform. Advising accessibility involves being available “...to talk about issues related to dissertations" (s4). Apart from the role of advising students, professors may have teaching and/or research responsibilities; so it may be challenging for them to meet advisees on a regular basis. Yet, it is not surprising for professors and students to rate statement s4 (Advisors and students should meet frequently to talk about issues related to dissertations) as less difficult and more difficult respectively. Many students understand the fact that the decision 
to meet largely depends upon professors' availability and workload, while professors know they must gauge their time based upon these personal factors. One student mentioned;

Some items are difficult because the advisor does not have or make time for students. For others, the item is difficult because it is a challenging skill (negotiation, for example).

Overall, throughout graduate school I feel I have not been given enough support, time, training, or guidance. I think this is directly related to the research pressures put on our faculty, they are too busy to devote enough time to their students.

Because availability can be quite variable, most students may feel that they do not have much control over this situation. So in response, some learn that they must adjust and become more independent (Acker et al., 1994; Gardner, 2008).

Students have realized the importance of and difficulty in “....adjust[ing] to changing expectations and roles" (s34). Professors on the other hand, perceived statement s34 (Students should be able to adjust to changing expectations and roles) as less important to the successful completion of their dissertations, but did agree that it was not easy, as they rated it as more difficult to implement. Professors and students can address the difficulty in adjusting to expectations and roles by clarifying them (i.e. 335 (Advisors and students should clearly define their expectations and goals)).

Advisors want students to be independent (Gardner, 2008). While at the same time, students need support as they journey to a stage where they can do things on their own (Spillett \& Moisiewicz, 2004). In effect, advisors try to take the role of not giving too much support in order to prevent students' from becoming totally dependent (Gardner, 2008). These assertions reflect how professors rated statements s26 (Students should be independent) and s19 (Advisors 
should provide students with needed support). They perceived these statements (s26 and s19) as more important but more difficult. On the contrary, students believed that attaining independence is less relevant when it comes to the successful completion of their dissertations but more difficult to put into action. They seem to feel that the more support they receive, the more likely they will be successful in their doctoral education completion.

Power relations. Doctoral advising involves guiding students as they engage in their independent research projects. During this process, students are expected to work within certain academic boundaries (Gordon, 2000; Pertersen, 2007). These boundaries are intended to shape how students "act, speak, think and write and feel as [scholars]" (Pertersen, 2007, p. 477). Moreover, advisors have been delegated to protect these boundaries (Pertersen, 2007; Walker, Golde, Jones, Bueschel \& Hutchings, 2008). Some advisors' boundary protection roles include: “... [to] make sure students follow procedures acceptable to the research community" (s32) and “... [to] give constructive criticism on students' dissertations (s40). The findings from my study suggest that professors and students acknowledged the importance of these roles and their impact on successful dissertation completion. This can be seen in statements s32 (Advisors should make sure students follow procedures acceptable to the research community) and s40 (Advisors should give constructive criticism on students' dissertations) as more important and less difficult to implement.

In the same vein, it is very important that professors are aware of the progress of their students' dissertations. They must be alert to whether or not students are following and progressing toward their dissertation goals. This was apparent in statement s39 (Advisors should be ready to intervene when students are going off-track). Professors must tread a fine line when intervening, as their intervention must be one of guidance, and not an overtaking of their 
students' dissertations. They must be able to provide a balance of solid instruction and autonomy, which still allows students to progress as independent yet guided scholars. Thus, they must be able to maintain the proper balance of power and assistance. This reflects why professors and students rated statement s39 as more important and yet more difficult to implement (see Figures 30 and 32). It is important to note that when students rated this statement as more difficult, it might mean they fear their advisors dictating specifically what they have to do, which could then lead to a shift in the focus of their research and time already spent. For example, one student remarked; "advisors should let students choose their own research questions and method... i.e. not make it compulsory to do a mixed method research if the student does not want to". This is an indication of the conflict between independence in doctoral research and advisors' intervention.

The conflict between advisors and advisee can be resolved through dialogue (Petersen, 2007). Because of power inequality in advisor-advisee relationships, students may find it difficult to take initiative in conflict resolution compared to professors (Manthunga, 2007). This may explain why professors and students rated statement s8 (There should be open dialogue concerning making decisions and resolving conflicts) as less difficult and more difficult respectively. Similarly, professors and students labeled statement s16 (Students should be able to express their disagreement when necessary) as more important but more difficult. Their response to this affirms the assertion that the imbalance of power contributes to advisees' reluctance to utter their grievances.

Clusters rated as more important. Students perceived cluster 4 (Guiding advisees in a professional manner as they take a responsible role) as more important and less difficult to implement. Seeking guidance from advisors and taking responsibility as independent researchers 
are among the topmost priorities of doctoral students. In that they are connected to their ultimate goal, which is to successfully complete their dissertations. Many expect advisors to direct them at each dissertation stage (s29). This direction begins by explicitly explaining to students the procedures for writing dissertations (s12). It is then followed by making sure students work within their academic boundaries (s32). Lastly, it also involves giving constructive criticism on students' dissertations (s40). To students, all these activities should be done with an understanding of shared mutual respect (s38). Students categorized these five actionable statements (s12, s29, s32, s38, and s40) under cluster 4 and rated them as more important to the successful completion of their dissertations and less difficult to accomplish (see Table 40).

Doctoral students want structure in the dissertation process. Before they start working on their dissertations, they expect advisors to give a step by step procedure of carrying out this project. Many have the perception that there is a direct link between giving a clear explanation on how to perform specific tasks at each dissertation stage and the successful completion of their dissertations. Students see the difficulty and frustration associated with working on their dissertations without the needed support (Gardner, 2008). To support these assertions, below are two students' responses to the open-ended statement; "Please type any statement that you think should be added to the statements above";

Coming from a doctoral program with a low graduation rate, I would definitely emphasize direction/structure as the most important categories. It's absurd how often a graduate student is placed in a difficult situation with regards to how to proceed with his/her education, and instead of feedback receives the message, "go look at the handbook." 
Advising (and PhD programs in general) should not have a cookie-cutter approach to students, but develop methods to assist students returning to school after years (or decades) off, including a system for priming the students with background, models, and other assistance, rather than "just read the journals."

Besides wanting direction and structure in working on their dissertations, students want a good relationship and frequent interactions with advisors. They rated cluster 2 (Promoting a supportive advisor-advisee relationship coupled with negotiations) as more important and more difficult. On one hand, they acknowledge the importance of having open dialogue in decision making and conflict resolution (s8), being able to express their dissatisfaction (s16), and "... sharing their academic challenges with advisors" (s30). On the other hand, they understand the difficulty in carrying out these tasks. Some doctoral students lack the skills needed to resolve disagreements with their advisors. In response, they try to cope with the situation by avoiding any action that could ignite conflict.

Power inequality between advisors and students can make it challenging for students to take initiative in resolving conflict. But if advisors are "... ready to listen to the concerns of their students" (s37). This may contribute to students' willingness to have their voice heard. According to students, it takes time and dedication to create this supportive advising environment and it is the responsibility of advisors to initiate the building of that condition. Advisors and students can start the process of establishing supportive relationships by having frequent meetings (s4), giving the necessary support (s19), providing immediate feedback (s21), and clearly defining their expectations (s35). In summary, students rated eight statements, (i.e. 
s4, s8, s16, s19, s21, s30, s35, and s37) in cluster 2 as more important but more difficult (see Table 40).

Professors' approach to increasing the dissertation completion rate is quite different from that of doctoral students. Compared to students that believe in a directed step by step approach, professors believe that frequent, open, and clear lines of discussion between advisors and students is the key to the timely completion of students dissertations (s7). Findings showed that professors rated cluster 2 (Enhancing advisor-advisee interaction in a supportive environment) as more important and less difficult. Professors understand the fact that every student wants to pursue their doctoral education at a place where their needs are cared for. In this caring atmosphere, students are “...well-informed about the research interest, advising style, and expectations of potential advisors" (s9). In other words, an important interaction between professors and students starts at the selection process stage, and continues after they have agreed to work together. The strength of the advisor-advisee relationship partly depends on advisors' accessibility as well as their readiness to listen (s3 and s37) and the frequency of their conversations on "issues related to dissertations" (s4) (see Table 41).

Professors viewed statements s3, s4, s7, s9, and s37 as more important and less difficult. This is because they think their responsibilities as advisors go beyond just assisting students to complete their dissertations. One of their roles is to prepare students to be independent scholars and contributors to knowledge in their respective fields. Based on professors' perspectives, students learn better when they are given the opportunity to explore research/dissertation related issues with little or no guidance, report the progress of and challenges during exploration, discuss related issues, and receive feedback from advisors (see Figure 34). These may be the reasons 
why advisors are hesitant to give specific steps in carrying out a task at each dissertation stage. However, with this style of advising some students may feel abandoned.

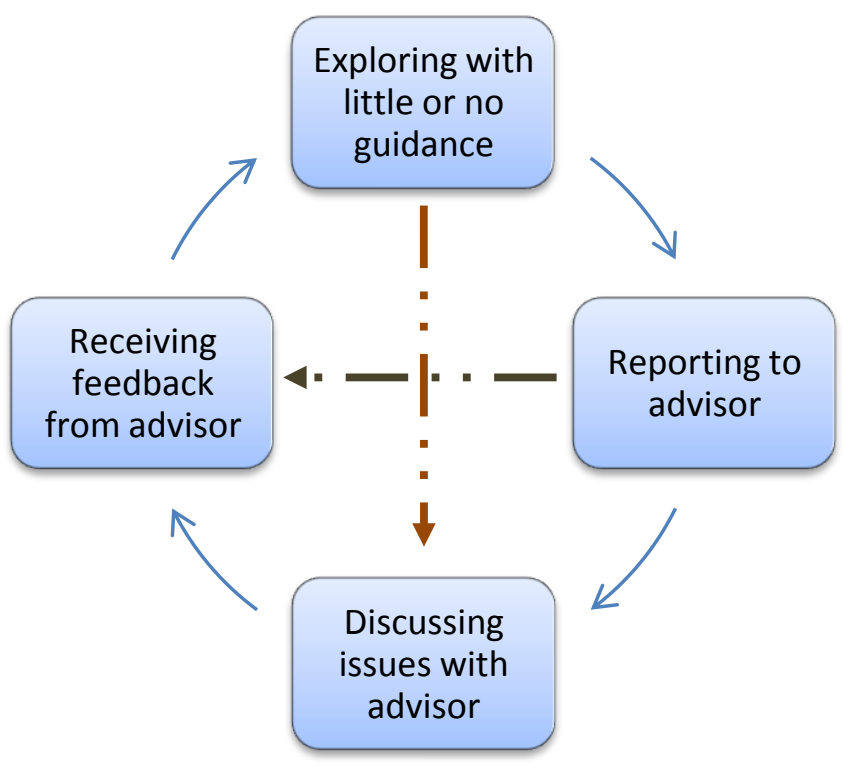

Figure 34. A diagram depicting professors' approach to advising

Professors are aware of the challenges involved in encouraging students to be independent, and at the same time monitoring their academic activities to make sure they are on track. In other words, advisors are faced with opposing responsibilities: (a) promoting independence and (b) guiding and monitoring to prevent students from going beyond their academic boundaries, and/or falling off track. Evidently, professors rated cluster 5 (Promoting students' independence with advisors' guidance) and two of its statements (i.e. s26 (Students should be independent), and s39 (Advisors should be ready to intervene when students are going off-track)) as more important to the successful completion of students' dissertation but more difficult to carry out. This shows that they acknowledge the inherent difficulty and challenge that lies in trying to maintain the balance between being a successful promoter of students' autonomy as well as an effective guide. 


\section{Implications of Findings}

This study has demonstrated how one can use the concept mapping method in research to effectively design an online survey, distribute it to increase response rates, analyze and integrate sorted and rated data, and meaningfully present the findings. Further implications will be described in two themes. They are contributions to doctoral advising research and implications for practice.

Contributions to doctoral advising research. This study has established the importance of the five components of doctoral advising to the doctoral students' completion of their education. The five components included: selection process, advising approach, advisor-advisee relationship, roles, responsibilities, and expectations, and power relations. I have also identified specific advising activities under each advising component viewed by professors and doctoral students as more important to the successful completion of students' dissertations (see Figures 35, 36, and 37). Each of the advising components has at least two of its statements rated as more important. Professors and doctoral students perceived 19 and 21 statements (advising activities), respectively, as more important. Figure 37 shows statements rated by both professors and students as more important. Fourteen statements that were rated by professors as more important were also viewed by students as more important.

Based on these findings, researchers can design an evaluation tool to examine students' understanding of advising and what they expect from their relationship with advisors. For instance, researchers/evaluators can ask students to rank or rate the 21 advising activities in terms of their importance (see Figure 35). The results may help professors/advisors to address the needs of students and discuss their expectations. Professors can also use the 19 advising 
activities to assess their roles as advisors and beliefs about doctoral advising (see Figure 36). This could greatly help in clarifying the inherent needs, roles, and responsibilities of both professors and students. Both professors and students can resolve their differences by first identifying what they have in common, which consist of 14 advising activities (see Figure 37). Finding a common ground reduces dissatisfaction during the doctoral advising process, and increase effective communication: promoting greater satisfaction and tranquility between them.

The results of this study suggest that the first priority of doctoral students at the dissertation stage is to seek guidance and a specific framework, in order to map out the steps of finding their particular topic of study (see Figure 35). Advisors work with students whose academic success is partly linked to their ability to independently conduct a research study and report the findings. Because most doctoral students do not have experience in research, their dream is to look for a person (an expert) with in-depth knowledge in research who could help them carry out an independent research study. Advisors have been entrusted to support students as they work on their dissertations. Therefore, doctoral students are preoccupied with seeking specific direction and structure on how to implement their dissertation projects. However, one of the toughest roles in advising is to give students guidance while promoting students' independence in research. This is professors' second priority advising role (see Figure 36). 


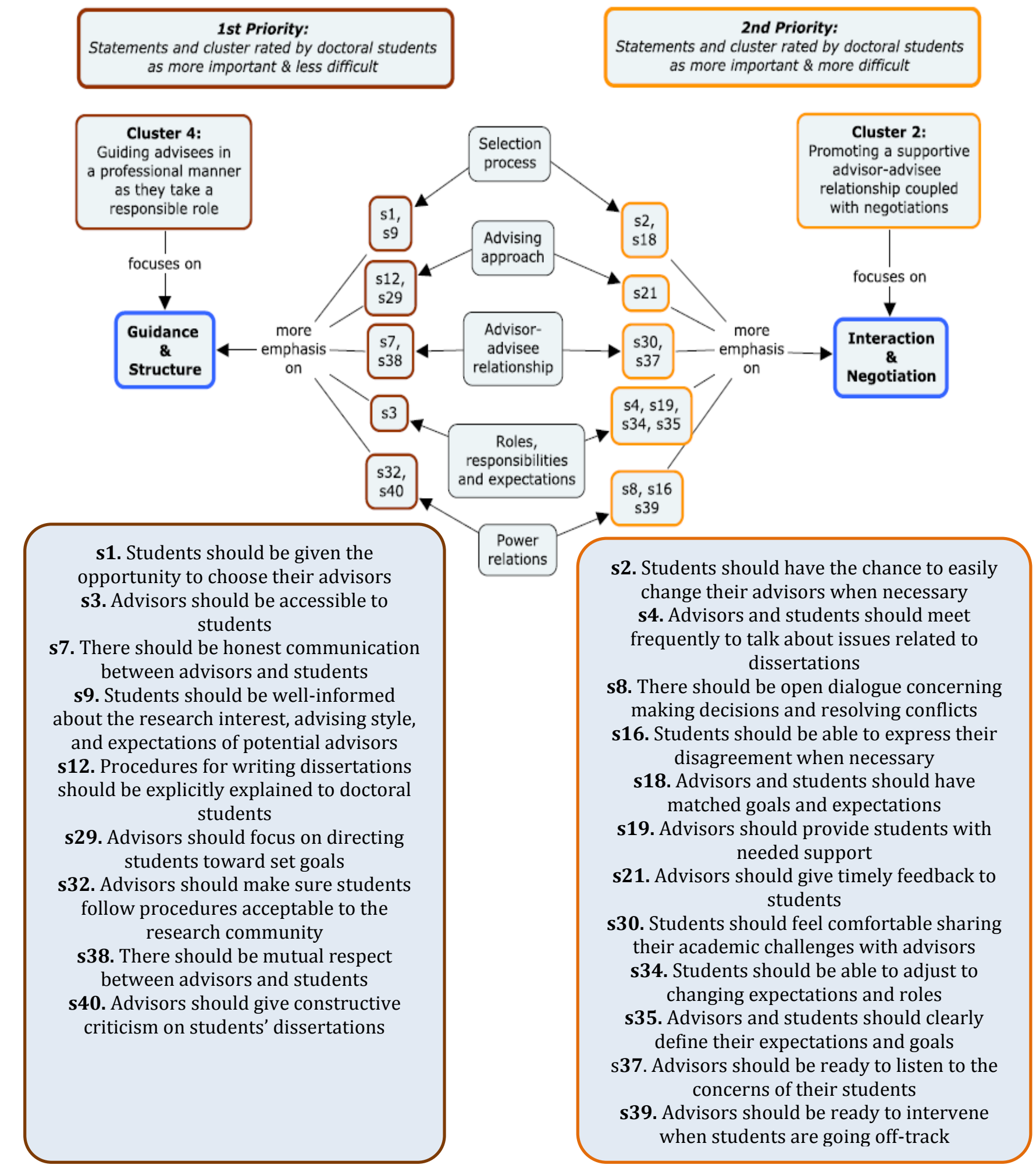

Figure 35. A model conceptualizing doctoral students' perspectives on doctoral advising 


\section{1st Priority:}

Statements and cluster rated by professors as more important \& less difficult 2nd Priority:

Statements and cluster rated by professors as more important \& more difficult

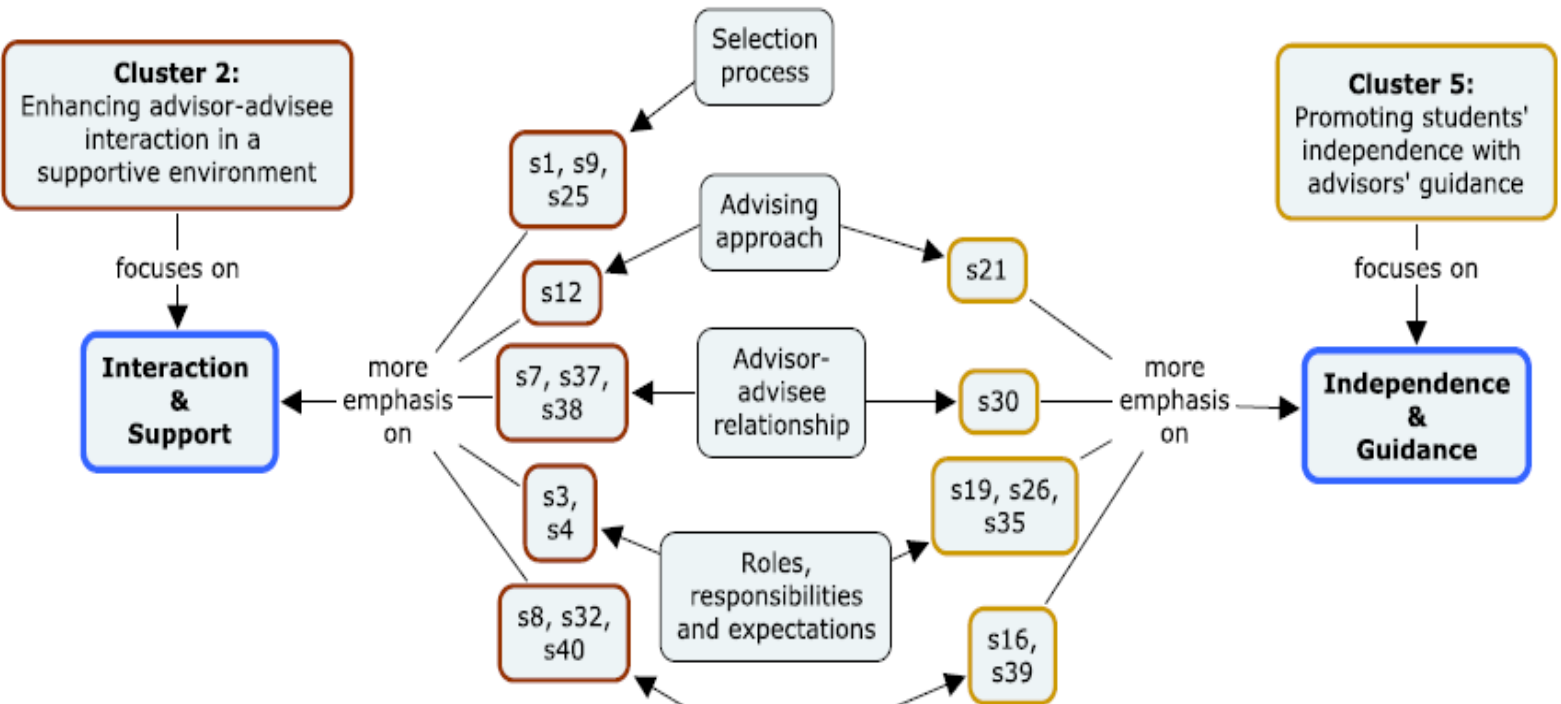

s1. Students should be given the opportunity to choose their advisors

s3. Advisors should be accessible to students s4. Advisors and students should meet frequently to talk about issues related to dissertations

s7. There should be honest communication between advisors and students

s8. There should be open dialogue concerning making decisions and resolving conflicts

s9. Students should be well-informed about the research interest, advising style, and expectations of potential advisors

s12. Procedures for writing dissertations should be explicitly explained to doctoral students s25. Advisors should have the chance to choose who they want to work with

s32. Advisors should make sure students follow procedures acceptable to the research community

s37. Advisors should be ready to listen to the concerns of their students

s38. There should be mutual respect between advisors and students

s40. Advisors should give constructive criticism on students' dissertations
Power relations

s16. Students should be able to express their disagreement when necessary s19. Advisors should provide students with needed support

s21. Advisors should give timely feedback to students

s26. Students should be independent s30. Students should feel comfortable sharing their academic challenges with advisors

s35. Advisors and students should clearly define their expectations and goals

s39. Advisors should be ready to intervene when students are going offtrack

Figure 36. A model conceptualizing professors' perspectives on doctoral advising 


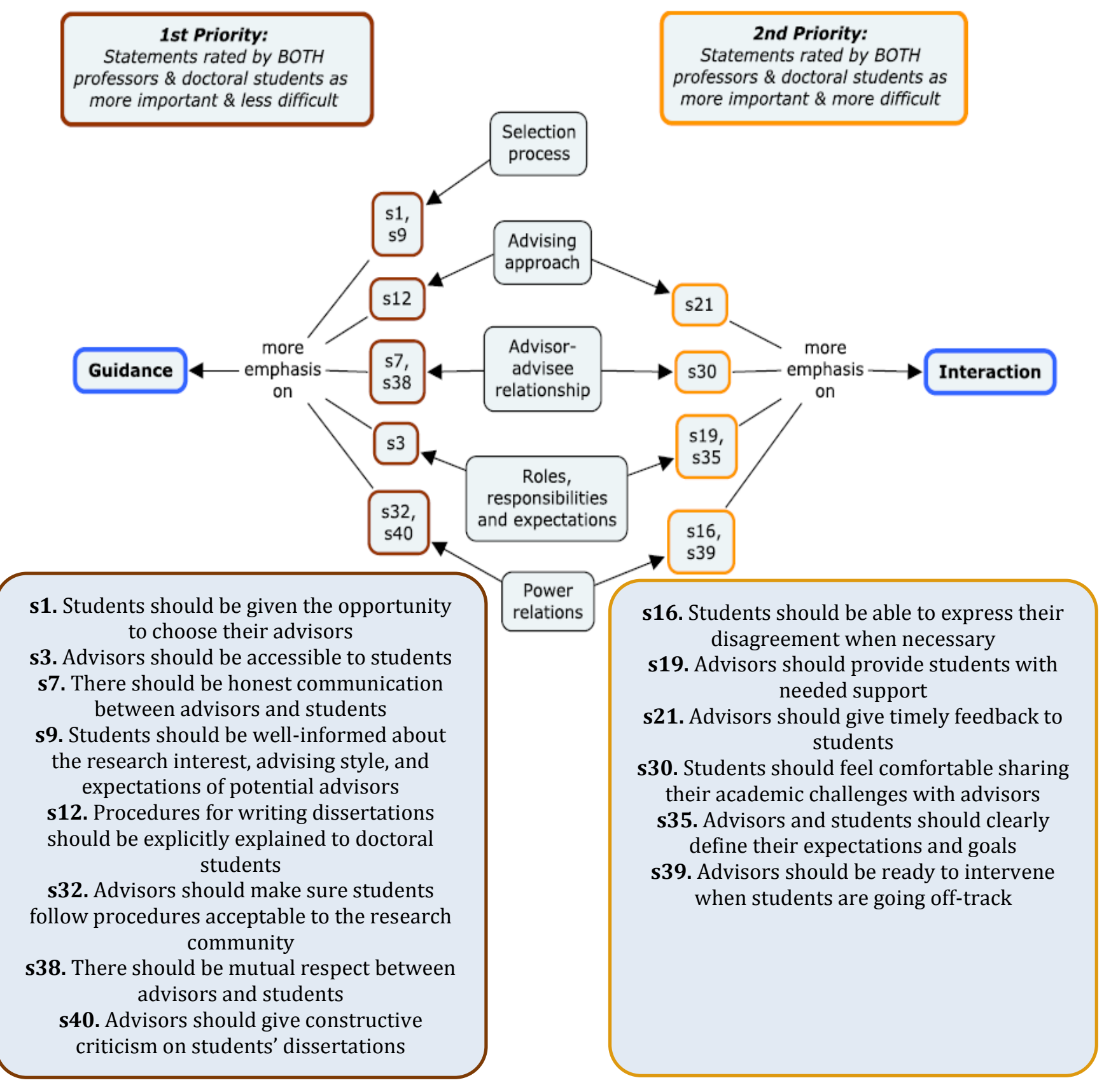

Figure 37. A model depicting similarities between professors' and doctoral students'

perspectives on doctoral advising 
If students are given the necessary guidance and structure on how a dissertation is done, more students will be able to successfully complete their dissertations. This can be achieved by implementing the nine advising activities (statements) rated by students as more important and less difficult to carry out (see Figure 35). They include statements s1, s3, s7, s9, s12, s29, s32, s38 and s40. One doctoral student stated;

I believe my advisor has the responsibility to perform a job. I will respect his authority and judgment in that area. He is the expert and knows the guidelines. I don't plan to question what he says or suggest otherwise. Unless there is something I find in writing (in the graduate catalog, etc.), I believe what he says and will follow his suggestions and rules.

I would want to emphasize that doctoral education is not only about completing one's dissertation. It is also about acquainting oneself with the process of effectively conducting studies and presenting findings. The main job of every advisor is to help doctoral students to acquire the skills needed to conduct future research studies and contribute to their respective field of study. That is in fact most important aspect of doctoral education. It is the process that prepares doctoral students to be independent scholars and inducts them into a research community (Petersen, 2007).

Instead of giving specific directions and outlines on how to conduct a research study, advisors' first priority is to provide students with needed support as they engage in a meaningful discussion on research related issues (see Figure 36). For instance, one of the roles of advisors is to assist students in coming up with a dissertation topic. Before students carry out the task of finding a topic or identifying an interest, advisors and students may discuss students' interests 
and how they would search for literature related to their interests. Students' task may include searching, reading and critiquing the literature they find, and reporting back to their advisors. Subsequently, students would present to their advisors how they arrived at the topic(s), possible research questions, appropriate method(s), and how they would analyze the data. During this process, students would learn how to verbally present ideas, argue or defend their stance, and accept suggestions (Petersen, 2007). This activity can be effective if advisors take time to explain to students how it contributes to finishing their dissertations and the skill needed to be autonomous researchers.

Most doctoral students are aware of the benefit of having frequent interaction with their advisors. They know that it creates an avenue for them to share their needs, challenges, and expectations with advisors. Also, it is an opportunity for students to orient themselves with the academic boundaries, which involves learning how to negotiate and work within the guidelines (Petersen, 2007). As Walker, et al. (2008) indicated, "students need to learn to debate ideas and develop their own judgment about their relative merits" (p.45). From students' perspective, advising activities that emphasize on discussions and negotiations are difficult to carry out without support of their advisors (see Figure 35). Some of them are statements s4 (Advisors and students should meet frequently to talk about issues related to dissertations), s8 (There should be open dialogue concerning making decisions and resolving conflicts), s30 (Students should feel comfortable sharing their academic challenges with advisors), and s37 (Advisors should be ready to listen to the concerns of their students). Students rated these statements as more important to the effective completion of their dissertations and more difficult to accomplish. They are students' second priority. 
Despite the differences in professors' and students' perspectives on doctoral advising, these are some similarities between them. Both professors and doctoral students rated eight statements (s1, s3, s7, s9, s12, s32, s38, and s40) as more important to the successful completion of students' dissertations and less difficult to impletion (see Figure 37). All these statements emphasize on guidance. Professors and students agreed to the fact that providing guidance is the primary responsibility of advisors. But they may disagree with the frequency and intensity of the guidance.

Professors and students also agreed that advisee-advisee interaction influence students completion of their doctoral education. They rated six statements (s16, s19, s21, s30, s35, and s39) as more important and more difficult (see Figure 37). Advising activities such as: students should be able to express their disagreement when necessary (s16), students should feel comfortable sharing their academic challenges with advisors (s30), and advisors and students should clearly define their expectations and goals (s39) place more emphasis on interaction. From professors' and students' perspective, advisors' and advisees' second priority is to promote interaction between them.

Implications for practice. There are practical implications that can be drawn from this study. The following are the implications of the study organized around the five components of advising: (a) advising approach, (b) selection process, (c) roles, responsibilities, and expectations, (d) advisor-advisee relationship, and (e) power relations.

Selection process. The findings suggest that selection process (as one of the doctoral advising component) influences students' successful dissertation completion. Professors and students rated statements s1 (Students should be given the opportunity to choose their advisors) 
and s9 (Students should be well-informed about the research interest, advising style, and expectations of potential advisors) as more important. Both acknowledged the need for students to play an active role in the selection process. They also rated statements s1 and s 9 as less difficult to implement. Professors rated statement s25 (Advisors should have the chance to choose who they want to work with) as more important and less difficult: implying that, students should recognize that the freedom to choose goes with advisors' willingness to work with them. In an advising arena, it is not difficult for professors to say no if they think they cannot work with students. The successful completion of students' dissertation is partly based on whether advisors and advisees are willing to work together.

There are numerous factors that contribute to an unwillingness to cooperate with each other. Incompatibility of research interests, unsatisfactory advising style, inadequate feedback, and lack of support are some of the factors that can influence a student to look for another advisor. Students rated statement s2 (Students should have the chance to easily change their advisors when necessary) as more important and more difficult. This suggests that students want the freedom to choose and change their advisors. Students acknowledge the challenges they may face in making a change, especially when the condition is not conducive for that adjustment. Either party should not be forced to be in a relationship if it is not working. The department/college should create an atmosphere where advisees can easily and responsibly change their advisors: ensuring the smooth transfer of a student from one advisor to another. However, care should be taken to prevent students from frequent changing their advisors just to avoid addressing disagreements with them.

Advising approach. Advising style has an influence students' completion of their doctoral education. Professors and students viewed statements s12 (Procedures of writing 
dissertation should be explicitly explained to doctoral students) and s21 (Advisors should give timely feedback to students) as more important. This shows that students need guidance to be able to successfully complete their dissertations. Students' perception of s29 (Advisor should focus on directing students towards the set goals) as more important indicates that they expect advisors to give them more specific directions during the dissertation process. Students' description of Statement s29 as less difficult implies that they believe advisors have what it takes to guide advisees and they expect advisors to give them clear steps for dissertation completion.

Based on the students' conceptualization of doctoral advising activities (related to advising approach) in terms of their importance, it is clear that they want guidance and structure. However, the doctoral education experience, in which advising plays a large role, goes beyond just providing specific directions to students. According to Petersen (2007), doctoral education is a process of induction: preparing students to be independent scholars. The doctoral experience should not only focus on learning the specific steps to carry out dissertation projects, but on an understanding of the broader significance of engaging in independent research. Students should be informed and reminded about this overarching objective of doctoral education though seminars and their interactions with advisors. During seminars, professors and students could discuss concepts related to doctoral education such as the induction process, academic boundaries, being an independent scholar, identity development, and doctoral advising (see Figure 2).

Advisor-advisee relationship. In terms of importance, both professors and students agreed that four statements under advisor-advisee relationship contribute to students' dissertation completion. They rated statements s7 (There should be an honest communication between advisors and students), s30 (Students should feel comfortable sharing their academic challenges 
with advisors), s37 (Advisors should be ready to listen to the concerns of students), and s38 (There should be a mutual respect between advisors and students) as more important. Professors and students seem to depict communication as the heart of advisor-advisee relationship. They may not be satisfied with the relationship if it lacks communication. Students' description of statements s30 and s37 as more important and more difficult shows that they believe in the importance of interaction in advising, and also acknowledge the difficulties in implementing the four advising activities. As it can be difficult for students to engage in this form of dialogue, advisors should create an environment conducive for honest and open expression. Professors' perception of statements s37 as more important but less difficult implies that, advisors can easily open a conversation compared to advisees. Advisors may initiate communication by asking students to talk about their academic challenges as well as the areas they need help in. Interactions like this help in building a good advisor-advisee relationship, which may contribute to the satisfactory completion of students' educational requirements.

Roles, responsibilities, and expectations. Both professors and students agreed to the assertion that advisors' availability and support, frequency of meeting between advisor and advisee, and clarity of roles and expectations were vital to students' successful completion of their dissertations. They rated statements s3 (Advisors should be accessible to students), s4 (Advisors and students should meet frequently to talk about issues related to dissertations), s19 (Advisors should provide students with needed support), and $\mathrm{s} 35$ (Advisors and students should clearly define their expectations and goals) as more important. Advisor's and advisees' ability to execute some of these advising activities partly depend on time available, skilled needed, kind of outcome, and/or available resources. This means that any of these factors can obstruct advisors and/or advisees from performing the four advising tasks. In response to this challenge, students 
understand the need for advisees "to adjust to changing expectations and roles" (s34). Students rated statement s34 as more difficult to carry out: acknowledging that it is not easy to take an independent role. Professors thought, the way forward was to encourage students to be independent (s26). But they admitted that it is more difficult to promote this sense of autonomy among students.

In most cases, there are differences between advisors' and advisees' expectations. These may be attributed to differences in roles, background, and perceptions about doctoral advising. Besides this, expectations change at each dissertation stage. This calls for a continuous review and clarification of what they expect from each other. Students are more likely to be satisfied with the relationship, hence, promoting students' ability to complete their dissertations on time.

Power relations. From professors' and students' perspective, power plays an important role in advisor-advisee relationships. Both professors and students rated five statements under power relations component as more important. They were: statements s8 (There should be an open dialogue concerning making decisions and resolving conflicts), s16 (Students should be able to express their disagreement when necessary), s32 (Advisors should make sure students follower procedure acceptable to the research community), s39 (Advisors should be ready to intervene when students are going off-track), and s40 (Advisors should give a constructive criticism on students' dissertation product). Statements s32, s39, and s40 revolve around one of the main roles of an advisor, which is to make sure students work within their academic boundaries. Protecting the boundaries without creating an avenue to open dialogue and expression of disagreement, can be counterproductive. This reason may have contributed to professors' and students' rating of statements s8 and s16 as more important. In order to make power productive, advisors should encourage negotiation between advisees and themselves. 
Professors described statement $\mathrm{s} 8$ as less difficult but students rated it as more difficult. This emphasizes advisees' inability at times to initiate or promote dialogue. Participants rated statement s16 as more difficult, which means the existing imbalance of power makes it difficult for advisees to air their grievances.

Professors' and students' representation of statements s32 and s40 as less difficult suggests that, advisors feel capable supervising dissertation projects. However, when it comes to intervening, advisors seem to be cautious, due to the independent nature of one's dissertation project. It was not surprising that both professors and students described statements s39 as more difficult to carry out.

Other implications. A professor's response to the open-ended statement, "please type any statement that you think should be added to the statements above", drew my attention to the need for accountability, responsibility, and evaluation in doctoral advising. He stated that;

I'm not sure exactly how to word this, but some statements pertaining to timing, deadlines, milestones, benchmarks, etc.., whose responsibility for establishing these[?]. [If] mutually negotiated, what happens when benchmarks aren't met [?] - Something toward a formative evaluation and management of process.

Accountability. Advisors have been entrusted by their respective colleges/departments to guide students throughout their dissertation process. Generally, advisors are expected to report advising activities and outcomes, a students' progress and shortcomings directly linked to the advising relationship. To ensure accountability in advising at the doctoral level, the advisor and/or advisee could write a report, or schedule a face-to-face or online meeting with their college deans or heads of department at least once a semester in order to give an account of 
advising related issues and students' academic progress. However, it is important to note that college deans and heads of departments may not have time to assess individual reports because they may have other pressing commitments. The same could even be applied to an advisors' situation. With this said, a possible alternative process of accountability should be established. I think that one's advising style could be more effective if the advisees' accountability is enhanced rather than that of the advisor. Students tend to take mutually agreed goals, deadlines, and benchmarks seriously, and make conscious efforts to meet them if they know that they will be asked to give an account.

Responsibility. Although the dissertation experience is challenging, it is also rewarding after completion. Students learn a lot when they are allowed to figure things out on their own during the dissertation process. They gain necessary skills associated with searching for literature related to their interest, designing a study, collecting and analyzing data, and presenting findings. In this exploratory experience, students are allowed to manage every activity at each stage of the dissertation process as advisors provide guidance. They are expected to make responsible decisions at each stage of the dissertation. For example, advisees should be ready to explain to their advisors why they chose a particular topic, method, and qualitative, quantitative and/or mixed method choice for their research. Some students may not like this approach but it is important for advisors to reiterate the significance of this experience.

Evaluation. This is the process of examining specific aspect(s) of the advising experience so as to establish strengths and limitations (Stake, 2003). Continuous assessment of aspects such as advisor-advisee relationships, advising style, and advising related activities would help both advisors and advisees to address factors that inhibit the achievement of shared goals. Formative evaluation, which is done during the dissertation process, can be more beneficial to both parties 
compared to summative evaluation, which focuses on assessing the advising experience after the completion of one's dissertation. With regards to the former, advisors and students can get the chance to identify negative areas of the advising experience like ineffective roles, unrealistic expectations, and unmet goals and devise ways of resolving them, which in effect, can reduce the attrition. It is also a way of finding out what works in the advising relationship and encouraging each other to keep on nourishing it.

\section{Limitations of the Study}

1. The concept mapping approach to this study only focused on exploring and describing doctoral advising factors that contribute to the successful completion of doctoral students' dissertations (Bedi, 2006). This study was not an experimental research study, which focuses on the establishing of cause and effect. Therefore, the advising factors identified should not be interpreted as the causes of students' successful completion of their doctoral education. However, they could be considered as being part of numerous contributing factors.

2. The findings of this study did not represent the views of all professors and doctoral students in US higher institutions. The generalization was limited to professors and doctoral students (from one of the five social science colleges/departments stated above) in universities categorized as having high or very high research activities.

3. Because mostly quantitative data were collected, findings lacked information about the reason behind the way participants sorted and rated the statements. It was challenging to figure out the bases of the sorting and rating of statements (Robinson \& Trochim, 2007). Therefore, names for the clusters developed during the concept mapping analysis stage 
may not necessarily reflect how participants would have labeled the clusters if they had been given the chance.

4. There might be differences in perspectives on doctoral advising across genders, promotional levels of professors (assistant, associate, and full), and college or department affiliations. However, this study did not focus on them. The primary focus was to conceptualize doctoral advising from professors' and doctoral students' perspectives.

\section{Future Research}

Below are suggestions for further studies on doctoral advising;

1. Analysis of the participants' responses to the open-ended question showed that a few participants were not clear about the instructions of the survey. To address this problem beforehand, we created and distributed a video on how to complete the survey. This is one of the limitations of using concept mapping as a research method, in which data is collected online. There was no face-to-face meeting or communication with participants to brief them about what concept mapping was all about. It would be interesting to conduct this same study in a face-to-face setting: meaning, bringing both professors and doctoral students to one location and explaining to them the meaning of concept mapping as well as giving them the opportunity to sort and rate the 40 statements at that time. This strategy may help to address any ambiguity associated with the instructions for categorizing and rating statements.

2. This study only focused on participants from five selected colleges/departments in universities with high and very high research activities. Further research studies may 
focus on conceptualizing the perspectives of professors and doctoral students from all universities in the US offering doctoral programs.

3. The findings suggested what professors' and doctoral students' perspectives about doctoral advising were, but not much was known about the reasoning behind their views. Future researchers may conduct qualitative study to find out why the top priorities of most professors were interaction and support and those of doctoral students were guidance and structure.

4. Researchers can use statements rated as more important to design scales to measure doctoral students' perceived guidance and structure, and advisor-advisee interaction and negotiation. Statements s1, s3, s7, s9, s12, s29, s32, s38, and s40 are related to guidance and structure, while statements s2, s4, s8, s16, s18, s19, s21, s30, s34, s35, s37, and s39 are part of advisor-advisee interaction and negotiation. Those scales could be used to facilitate advisor-advisee communication and to evaluate their relationship.

5. Based on the results, researchers can use advising activities rated as more important to design scales to measure professors' perceived advisor-advisee interaction and support, and independence and guidance. Statements s1, s3, s4, s7, s8, s9, s12, s25, s32, s37, s38, and s40 are related to advisor-advisee interaction and advisors' support, while statements s16, s19, s21, s26, s30, s35, and s39 belong to students' independence and guidance.

6. In this study, professors and doctoral students provided what they thought were more important advising-related activities that contribute to the successful completion of dissertations. Future researchers can look at the degree to which professors (as advisors) and students (as advisees) actually perform those activities. 


\section{Summary}

Research showed that about half of doctoral students in the US do not finish their doctoral programs (Ferrer de Valero, 2001; Golde, 2000; Hoskins \& Goldberg, 2005; Spillett \& Moisiewicz, 2004). Advising related problems were one of the main factors contributing to high attrition among doctoral students. Qualitative document analysis of the literature on doctoral advising suggested five components of advising, which included; (a) advising approach, (b) selection process, (c) roles, responsibilities, and expectations, (d) advisor-advisee relationship, and (e) power relations. These factors directly or indirectly contribute to the successful completion of students' dissertations. The main purpose of this study was to conceptualize the perspectives of professors and doctoral students on advising using concept mapping (Kane \& Tronchim, 2007).

Concept mapping method began by analyzing advising related literature. In this study I categorized the literature into the five components of advising and generated eight statements under each component. Based on these 40 advising activities (statements), I then designed an online survey. Participants were asked to sort and rate the statements. The participants consist of 30 professors and 114 doctoral students from universities with high and very high research activities.

Initially, I conducted Multidimensional Scaling Analysis (MDS) and Hierarchical Cluster Analysis (HCA) creating a Hierarchical Cluster Trees or dendrograms, two-dimensional named cluster maps, and go-zone graphs based on professors' and doctoral students' sorted and rated data. Further analysis indicated that six cluster solutions reflected how both professors' and students' sorted data. The results showed that students viewed cluster 4 (Guiding advisees in a 
professional manner as they take a responsible role) as more important to the successful completion of their dissertations and less difficult to implement. Nine statements, s1, s3, s7, s9, $\mathrm{s} 12, \mathrm{~s} 29, \mathrm{~s} 32, \mathrm{~s} 38$, and $\mathrm{s} 40$, that were rated as more important and less difficult to accomplish emphasized guidance and structure. Student cluster 2 (Promoting a supportive advisor-advisee relationship coupled with negotiations) was perceived as more important but more difficult to carry out. They also rated statements s2, s4, s8, s16, s18, s19, s21, s30, s34, s35, s37, and s39 as more important and more difficult. These statements evolve around the themes, advisor-advisee interaction and negotiation.

The findings showed that professors rated cluster 2 (Enhancing advisor-advisee interaction in a supportive environment) as more important and less difficult. They gave the same rating for statements s1, s3, s4, s7, s8, s9, s12, s25, s32, s37, s38, and s40, which focus on advisor-advisee interaction and advisors' support. Professors also rated cluster 5 (Promoting students' independence with advisors' guidance) as more important but more difficult. Similarly, they rated statements s16, s19, s21, s26, s30, s35, and s39 as more important but more difficult. These statements are more geared towards students' independence and guidance.

This study shows that although there are similarities in how professors and doctoral students rated the statements, there are also differences in their conceptualization of doctoral advising. There should be a willingness to work together and there should be a supporting environment for the smooth transfer of any unsatisfied students from their current advisors to another. Advisors and advisees should continuously identify, discuss, and clarify their expectations. Creating an atmosphere in which advisors and students can frequently communicate and carry on dialogue is the best way of building healthy advisor-advisee relationships and increasing the graduation rate among doctoral students. Lastly, it is having 
accountability, responsibility, and an environment supportive of ongoing evaluation that help to center the advisor and advisee, and promote a successful doctoral experience, and completed goals. 


\section{References}

Acker, S., Hill, T., \& Black, E. (1994). Thesis supervision in the social sciences: Managed or negotiated? Higher Education, 28(4), 483-498.

Adu, P., Curtis, R., Carrick, R., Kohlmeyer, C., \& Rahman, A. (2011, April). Preparing doctoral students for their dissertation: What makes it a complex experience? Paper presented at the American Educational Research Association Annual Meeting, New Orleans, Louisiana.

Bargar, R. R., \& Mayo-Chamberlain, J. (1983). Advisor and advisee issues in doctoral education. Journal of Higher Education, 54(4), 407-432.

Barnes, B. J., Williams, E. A., \& Archer, S. A. (2010). Characteristics that matter most: Doctoral students' perceptions of positive and negative advisor attributes. NACADA Journal, 30(1), 34-46.

Barnes, B., \& Austin, A. (2009). The role of doctoral advisors: A look at advising from the advisor's perspective. Innovative Higher Education, 33(5), 297-315. doi:10.1007/s10755008-9084-х

Bedi, R. P. (2006). Concept mapping the client's perspective on counseling alliance formation. Journal of Counseling Psychology, 53(1), 26-35. doi:10.1037/00220167.53.1.26

Bedi, R. P., \& Alexander, D. A. (2009). Using multivariate concept-mapping for examining client understandings of counselling. Canadian Journal of Counselling / Revue Canadienne De Counseling, 43(2), 76-91.

Berger, P. L., \& Luckmann, T. (1967). The social construction of reality: A treatise in the sociology of knowledge. NY: Anchor Books. 
Burchinal, L. G. (2010). Methods for the Social Researchers in Developing Countries. Retrieved Oct. 27, 2010, from Sudan-American Foundation for Education, Inc., Falls Church, VA. Web site: $\underline{\text { http://srmdc.net/chapter5/1.htm. }}$

Butler, J. (1997) The psychic life of power: Theories in subjection. Stanford, CA: Stanford UniversityPress.

Capper, C. (1998). Critically oriented and postmodern perspectives: Sorting out the differences and applications for practice. Educational Administration Quarterly, 34(3), 354-379.

Clark, V. P., \& Creswell, J. W. (2007). Designing and conducting mixed methods research. California: Sage Publications, Inc.

Clark, V. P., \& Creswell, J. W. (2008). The mixed methods reader. California: Sage Publications, Inc.

Cook, S. (1999). The Mentor: An Academic Advising Journal. a Chronology of Academic Advising in America. Retrieved Dec. 5, 2009, from Pennsylvania State University, PA. Web site: http://www.psu.edu/dus/mentor/011015sc.htm.

Crookston, B. B. (2009). A developmental view of academic advising as teaching. NACADA Journal, 29(1), 78-82.

Ferrer de Valero, Y. (2001). Departmental factors affecting time-to-degree and completion rates of doctoral students at one land-grant research institution. Journal of Higher Education, 72(3), 341-67.

Friedman, N. (1987). Mentors and supervisors. New York: institute of International Education. 
Frost, S. H. (2000). Academic Advising in Higher Education. Retrieved Dec. 5, 2009, from Answer.com, USA. Web site: http://www.answers.com/topic/academic-advising-inhigher-education.

Gardner, S. K. (2007). "I heard it through the grapevine": Doctoral student socialization in chemistry and history. Higher Education, 54, 723-740.

Gardner, S. K. (2008). What's too much and what's too little?: The process of becoming an independent researcher in doctoral education. The Journal of Higher Education, 79(3), 327-349.

Gardner, S. K., Hayes, M. T., \& Neider, X. N. (2007). The dispositions and skills of a Ph.D. in education: Perspectives of faculty and graduate students in one college of education. Innovative Higher Education, 31(5), 287-299. doi:10.1007/s10755-006-90291

Gillispie, B. (2009). History of Academic Advising. Retrieved Dec. 5, 2009, from NACADA, USA. Web site: http://www.nacada.ksu.edu/Clearinghouse/AdvisingIssues/History.htm.

Golde, C. M. (2000). Should I stay or should I go: Student descriptions of the doctoral attrition process. Review of Higher Education, 23(2), 199-227.

Gordon, D. (2000). Power, autonomy, authorship, and community: Foucault as educational guru. Curriculum Inquiry, 30(2), 215.

Goulden, N. R. (1991). Report of the perceptions of communication and relationships during the dissertation process by speech communication doctoral advisors and advisees. Association for Communication Administration Bulletin, (76), 39-48. 
Gurr, G. M. (2001). Negotiating the "rackety bridge": A dynamic model for aligning supervisory style with research student development. Higher Education Research \& Development, 20(1), 81-92.

Heinrich, K. T. (1995). Doctoral advisement relationships between women: On friendship and betrayal. Journal of Higher Education, 66(4), 447-469.

Heiss, A. M. (1970) Challenges to graduate schools. San Francisco: Jossey Bass.

Hoskins, C. M., \& Goldberg, A. D. (2005). Doctoral student persistence in counselor education programs: Student-program match. Counselor Education \& Supervision, 44(3), 175-188.

Kane, M., \& Trochim, W.M.K. (2007). Concept mapping for planning and evaluation. In L. Bickman and D.J. Rog (Eds.), Applied Social Research Methods Series: Vol. 50. Thousand Oaks, CA: Sage Publications.

Katz, E. (1995, April). The Dissertation: Academic Interruptus. Paper presented at the annual meeting of the AERA, San Francisco, CA.

Keele, U. (2000). Computer-assisted analysis: Coding and indexing. In M.W. Bauer \& G. Gaskell (Eds.), Qualitative researching with test, image and sound: A practical handbook (pp.282-294). Thousand Oaks, CA: Sage Publications.

Lan, W., \& Williams, A. (2005). Doctoral students' perceptions of advising style and development and the relationship between them. NACADA Journal, 25(1), 31-41.

Leech, N. L., \& Goodwin, L. D. (2008). Building a methodological foundation: Doctoral-level methods courses in colleges of education. Research in the Schools, 15(1), 1-8.

Lenz, K. S. (1997). Nontraditional-aged women and the dissertation: A case study approach. New Directions for Higher Education, (99), 65. 
Mackenzie, N. M., \& Ling, L. M. (2009). The research journey: A lonely planet approach. Issues in Educational Research, 19(1), 48-60.

Manathunga, C. (2007). Supervision as mentoring: The role of power and boundary crossing. Studies in Continuing Education, 29(2), 207-221. doi:10.1080/01580370701424650

McClellan, J. L. (2009). The Mentor: An Academic Advising Journal. the Importance of Values and Values Management in Advising Administration and Leadership. Retrieved Dec. 5, 2009, from Pennsylvania State University, PA. Web site: http://www.psu.edu/dus/mentor/091014jm.htm.

Miller, M. (1995, April). ABD status and degree completion: A student's perspective. Paper presented at the annual meeting of the AERA, San Francisco, CA.

Noonan, M. J., Ballinger, R., \& Black, R. (2007). Peer and faculty mentoring in doctoral education: Definitions, experiences, and expectations. International Journal of Teaching \& Learning in Higher Education, 19(3), 251-262.

Novak, J D. (2010). Learning, creating, and using knowledge. Oxon, UK: Routlege

Patton, M. Q. (2002). Qualitative research and evaluation methods ( $3^{\text {rd }}$ ed.). Thousand Oaks, CA: Sage.

Petersen, E. B. (2007). Negotiating academicity: Postgraduate research supervision as category boundary work. Studies in Higher Education, 32(4), 475-487.

Petress, D. K. (2000). How to be a good advisee. Education, 120(3), 598.

Phillips, G. M. (1979). The peculiar intimacy of graduate study: A conservative view. Communication Education, 28, 339-345. 
Plotnick, E. (2001). A graphical system for understanding the relationship between concepts. Teacher Librarian, 28(4), 42.

Punyanunt-Carter, N., \& Wrench, J. S. (2008). Advisor-advisee three: Graduate students' perceptions of verbal aggression, credibility, and conflict styles in the advising relationship. Education, 128(4), 579-587.

Robinson, J. M., \& Trochim, W. (2007). An examination of community members', researchers' and health professionals' perceptions of barriers to minority participation in medical research: An application of concept mapping. Ethnicity \& Health, 12(5), 521-539.

Rose, G. L. (2003). Enhancement of mentor selection using the ideal mentor scale. Research in Higher Education, 44(4), 473.

Rudolph, D. E. (1994). Constructing an apprenticeship with discourse strategies: Professorgraduate student interactions. Language in Society, 23(2), 199-230.

Sangganjanavanich, V. \& Magnuson, S. (2009). Averting role confusion between doctoral students and major advisors: Advisor disclosure statements. Counselor Education and Supervision, 48, 194-203.

Schlosser, L. Z., Knox, S., Moskovitz, A. R., \& Hill, C. E. (2003). A qualitative examination of the graduate advising relationships: The advisee perspective. Journal of Counseling Psychology, 50, 178-188.

Shambaugh, N. R. (2000). Reframing doctoral programs: A program of human inquiry for doctoral students and faculty advisors. Innovative Higher Education, 24(4), 295-308.

Slavin, R. E. (2007). Educational research: In an age of accountability. USA: Pearson Education, Inc. 
Spillett, M. A., \& Moisiewicz, K. A. (2004). Cheerleader, coach, counselor, critic: Support and challenge roles of the dissertation advisor. College Student Journal, 38(2), 246-256.

Stake, R E. (2003). Standards-based and responsive evaluation. London: SAGE Publications, Incorporated.

The Carnegie Foundation, (2010). Carnegie Classifications | Standard Listings. Retrieved Oct. 28, 2010, from The Carnegie Foundation for the advancing of teaching, Stanford, CA. Web site: http://classifications.carnegiefoundation.org/lookup_listings/custom.php.

Walker, G. E., Golde, C. M., Jones, L., Bueschel, A. C., \& Hutchings, P. (2008). The formations of scholars. CA: Jossey-Bass.

Watkins, P. (1989). Leadership, power and symbols in educational administration. In J. Smyth (Ed.), Critical perspectives on educational leadership (pp. 9-37). Philadelphia, PA: Falmer Press.

Wopereis, I. G. J. H., Kirschner, P. A., Paas, F., Stoyanov, S., \& Hendriks, M. (2005). Failure and success factors of educational ICT projects: A group concept mapping approach. British Journal of Educational Technology, 36(4), 681-684.

doi:10.1111/j.1467-8535.2005.00546.x

Wrench, J. S., \& Punyanunt, N. M. (2004). Advisor-advisee communication: An exploratory study examining interpersonal communication variables. Communication Quarterly, 53(3), 224-37.

Zhao, C., Golde, C. M., \& McCormick, A. C. (2007). More than a signature: How advisor choice and advisor behavior affect doctoral student satisfaction. Journal of Further and Higher Education, 31(3), 263-281. 


\section{Appendices}

\section{Appendix A: Tables and Figures (based on students' data)}

Table A1

The coordinates generated for the 40 sorted statements by students using MDS two-dimensional solution

\begin{tabular}{|c|c|c|c|}
\hline Item & Statement text & Dimension 1 & Dimension 2 \\
\hline s1 & $\begin{array}{l}\text { Students should be given the opportunity to choose their } \\
\text { advisors. }\end{array}$ & 2.70 & -0.19 \\
\hline s2 & $\begin{array}{l}\text { Students should have the chance to easily change their } \\
\text { advisors when necessary. }\end{array}$ & 2.33 & 0.12 \\
\hline s3 & Advisors should be accessible to students. & 1.43 & -0.15 \\
\hline s4 & $\begin{array}{l}\text { Advisors and students should meet frequently to talk about } \\
\text { issues related to dissertations. }\end{array}$ & 1.16 & 0.00 \\
\hline s5 & $\begin{array}{l}\text { Advisors should provide adequate support for students in } \\
\text { terms of carrying out specific tasks. }\end{array}$ & 0.71 & -0.01 \\
\hline s6 & $\begin{array}{l}\text { Advisors should take the initiative in building and } \\
\text { maintaining a good relationship. }\end{array}$ & 0.29 & 0.15 \\
\hline s7 & $\begin{array}{l}\text { There should be honest communication between advisors } \\
\text { and students. }\end{array}$ & 0.39 & 0.09 \\
\hline s8 & $\begin{array}{l}\text { There should be open dialogue concerning making } \\
\text { decisions and resolving conflicts. }\end{array}$ & 0.39 & 0.10 \\
\hline s9 & $\begin{array}{l}\text { Students should be well-informed about the research } \\
\text { interest, advising style, and expectations of potential } \\
\text { advisors. }\end{array}$ & 0.62 & 0.63 \\
\hline s10 & $\begin{array}{l}\text { Advisors and students should have similar research } \\
\text { interests. }\end{array}$ & 0.07 & 1.32 \\
\hline s11 & $\begin{array}{l}\text { Advisors should make efforts to identify the needs of their } \\
\text { students. }\end{array}$ & 0.53 & -0.02 \\
\hline s12 & $\begin{array}{l}\text { Procedures for writing dissertations should be explicitly } \\
\text { explained to doctoral students. }\end{array}$ & -0.11 & -0.90 \\
\hline s13 & Advisors should be sensitive to the needs of their students. & 0.35 & -0.12 \\
\hline s14 & $\begin{array}{l}\text { Advisors and students should build trust through } \\
\text { negotiation and agreement. }\end{array}$ & 0.39 & 0.10 \\
\hline s15 & The boundaries of the relationship should be well-defined. & -0.86 & 0.21 \\
\hline s16 & $\begin{array}{l}\text { Students should be able to express their disagreement when } \\
\text { necessary. }\end{array}$ & 0.38 & 0.06 \\
\hline s17 & $\begin{array}{l}\text { Students should clearly define what they expect from } \\
\text { potential advisors. }\end{array}$ & 0.29 & 1.17 \\
\hline s18 & $\begin{array}{l}\text { Advisors and students should have matched goals and } \\
\text { expectations. }\end{array}$ & 0.20 & 0.91 \\
\hline s19 & Advisors should provide students with needed support. & 0.77 & -0.26 \\
\hline
\end{tabular}


s20 Students should be allowed to take charge of their

s21 Advisors should give timely feedback to students.

s22 Students should be aware of the complexities of advisoradvisee relationship.

s23 Students have to respect the authority of advisors.

s24 Advisors should exercise their power (expert knowledge)

s25 Advisors should have the chance to choose who they want to work with.

s26 Students should be independent.

s27 Advisors and students negotiate their roles and responsibilities.

s28 Students should strictly follow the directions provided by advisors.

s29 Advisor should focus on directing students toward set goals.

s30 Students should feel comfortable sharing their academic

s31 There should be an equal balance of power between advisors and advisees.

s32 Advisors should make sure students follow procedures acceptable to the research community.

s33 Students should select their advisors at an early stage in their doctoral education.

s34 Students should be able to adjust to changing expectations $\quad-1.08 \quad 1.17$ and roles.

s35 Advisors and students should clearly define their expectations and goals.

s36 Advisors should frequently reflect on their advising style or approach.

s37 Advisors should be ready to listen to the concerns of their students.
s38 There should be mutual respect between advisors and students.

s39 Advisors should be ready to intervene when students are $\quad-0.59 \quad-0.95$ going off-track.

s40 Advisors should give constructive criticism on students' $\quad-0.07 \quad-0.85$ dissertations. 


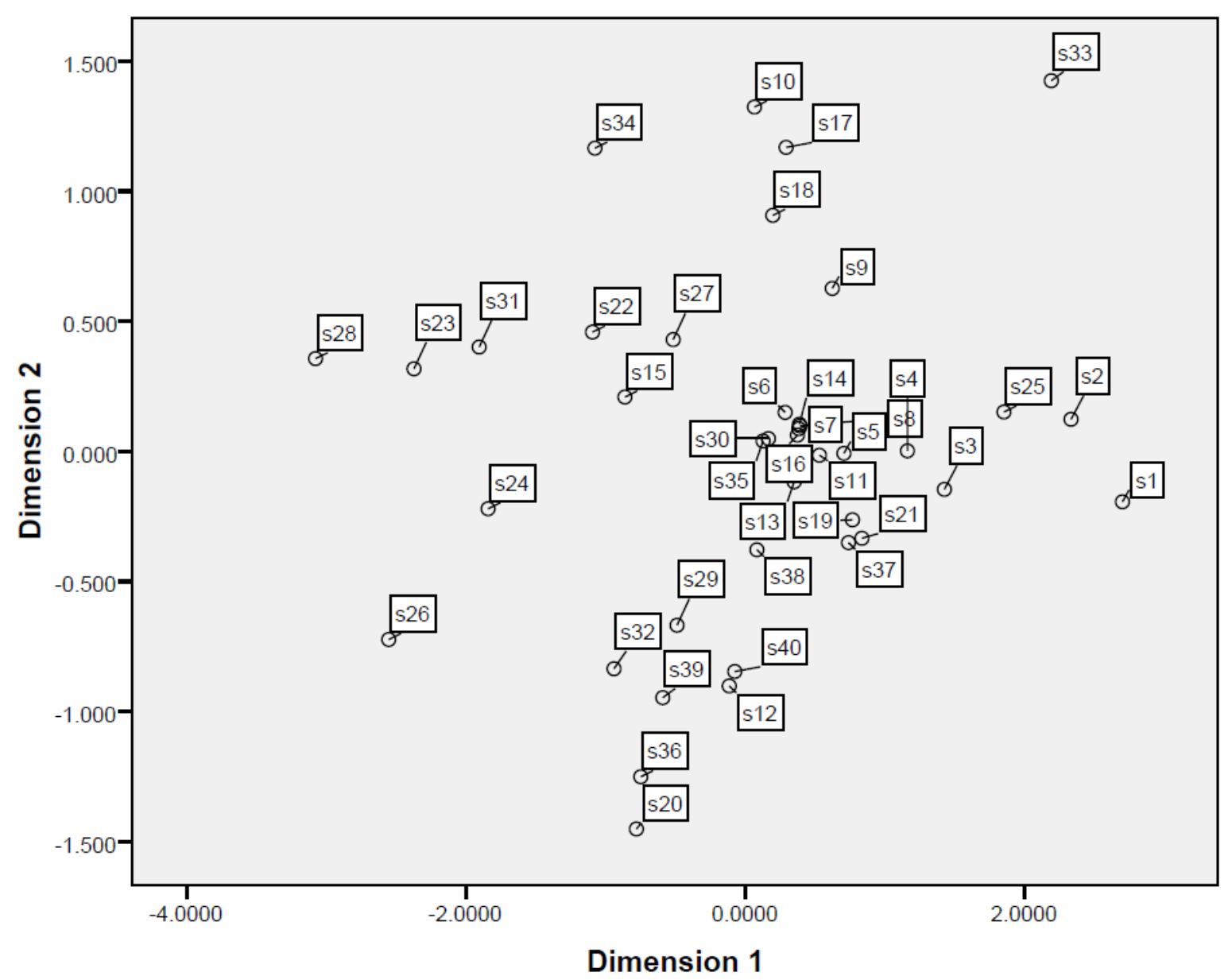

Figure A1. Two-dimensional point map displaying the locations and distance among the 40 statements that were sorted by students. 


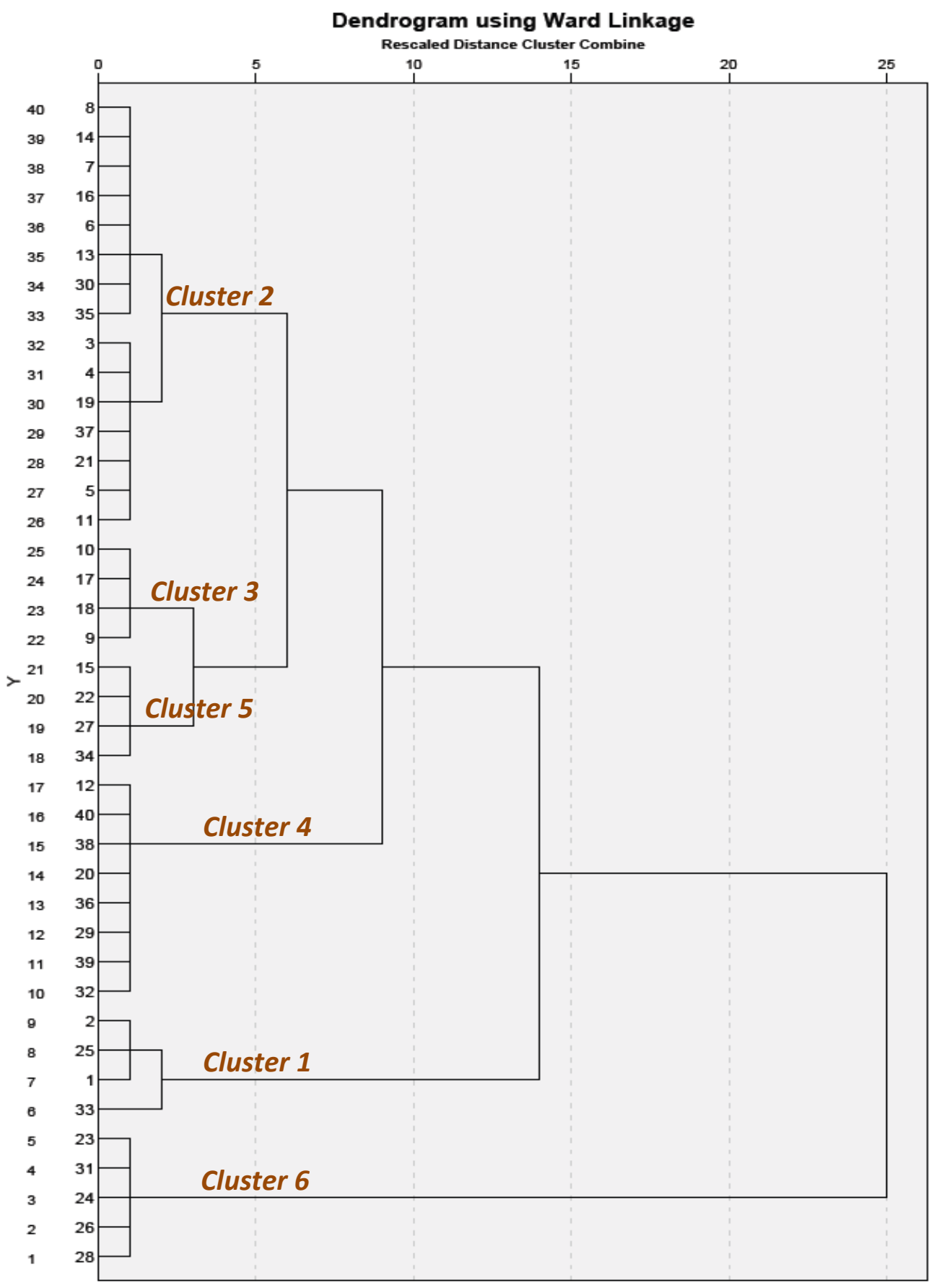

Figure A2. The Hierarchical Cluster Tree (dendrogram) indicating the six-cluster solution for students' sorted data 
Table A2

Statements in their clusters and respective doctoral advising components (based on students' data)

\begin{tabular}{|c|c|c|}
\hline $\begin{array}{l}\text { Item } \\
\text { code }\end{array}$ & Statement & $\begin{array}{l}\text { Components of } \\
\text { doctoral advising }\end{array}$ \\
\hline \multicolumn{3}{|c|}{$\begin{array}{l}\text { Cluster } 1 \text { (Exercising freedom in the advisor/advisee } \\
\text { selection) }\end{array}$} \\
\hline s1 & $\begin{array}{l}\text { Students should be given the opportunity to choose their } \\
\text { advisors. }\end{array}$ & Selection process \\
\hline s2 & $\begin{array}{l}\text { Students should have the chance to easily change their advisors } \\
\text { when necessary. }\end{array}$ & Selection process \\
\hline $\mathrm{s} 25$ & $\begin{array}{l}\text { Advisors should have the chance to choose who they want to } \\
\text { work with. }\end{array}$ & Selection process \\
\hline s33 & $\begin{array}{l}\text { Students should select their advisors at an early stage in their } \\
\text { doctoral education. }\end{array}$ & Selection process \\
\hline
\end{tabular}

Cluster 2 (Promoting a supportive advisor-advisee relationship coupled with negotiations)

s5 Advisors should provide adequate support for students in terms of carrying out specific tasks.

s13 Advisors should be sensitive to the needs of their students.

s21 Advisors should give timely feedback to students.

s6 Advisors should take the initiative in building and maintaining a good relationship.

s7 There should be honest communication between advisors and students.

s14 Advisors and students should build trust through negotiation and agreement.

s30 Students should feel comfortable sharing their academic challenges with advisors.

s37 Advisors should be ready to listen to the concerns of their students.

s8 There should be open dialogue concerning making decisions and resolving conflicts.

Advising approach

Advising approach

Advising approach

Advisor-advisee relationship

Advisor-advisee relationship

Advisor-advisee relationship

Advisor-advisee relationship

Advisor-advisee relationship

Power relations

Power relations

s16 necessary.

Roles, responsibilities, and expectations

Advisors and students should meet frequently to talk about issues related to dissertations.

Roles, responsibilities, and expectations

s11 Advisors should make efforts to identify the needs of their Roles, responsibilities, 
students.

Advisors should provide students with needed support.

Advisors and students should clearly define their expectations and goals. and expectations

Roles, responsibilities, and expectations

Roles, responsibilities, and expectations

Cluster 3 (Attaining the 'best' match during advisor selection process)

s9 Students should be well-informed about the research interest, advising style, and expectations of potential advisors.

Selection process

s10 Advisors and students should have similar research interests.

Selection process

s17

Students should clearly define what they expect from potential advisors.

Selection process

Advisors and students should have matched goals and expectations.

Selection process

\section{Cluster 4 (Guiding advisees in a professional manner as they take a responsible role)}

s12 Procedures for writing dissertations should be explicitly explained to doctoral students.

Advising approach Students should be allowed to take charge of their dissertation s20 process.

s29 Advisors should focus on directing students toward set goals.

s36 Advisors should frequently reflect on their advising style or approach.

s38 There should be mutual respect between advisors and students.

Advisors should make sure students follow procedures acceptable to the research community.

Advising approach

Advising approach

Advising approach

Advisor-advisee relationship

Power relations

Advisors should be ready to intervene when students are going off-track.

Power relations

Advisors should give constructive criticism on students' dissertations.

Power relations

\section{Cluster 5 (Understanding the changing expectations and} complex nature of doctoral advising)

s15 The boundaries of the relationship should be well-defined.

Advisor-advisee relationship

s22 Students should be aware of the complexities of advisoradvisee relationships.

Advisor-advisee relationship

Advisors and students should negotiate their roles and

Roles, responsibilities, responsibilities.

and expectations

s34 Students should be able to adjust to changing expectations and roles.

Roles, responsibilities, and expectations 


\section{Cluster 6 (Exercising power in advising relationships)}

s28 Students should strictly follow the directions provided by advisors.

s23 Students have to respect the authority of their advisors.

s24

Advisors should exercise their power (expert knowledge) when necessary.

s31 There should be an equal balance of power between advisors and advisees.

s26
Advising approach

Power relations

Power relations

Power relations

Roles, responsibilities, and expectations 


\section{Appendix B: Tables and Figures (based on professors' data)}

Table B1

The coordinates generated from the statements (sorted by professors) using MDS twodimensional solution

\begin{tabular}{|c|c|c|c|}
\hline Item & Statement text & Dimension 1 & Dimension 2 \\
\hline s1 & $\begin{array}{l}\text { Students should be given the opportunity to choose } \\
\text { their advisors. }\end{array}$ & 2.55 & 0.30 \\
\hline s2 & $\begin{array}{l}\text { Students should have the chance to easily change their } \\
\text { advisors when necessary. }\end{array}$ & 2.38 & 0.46 \\
\hline s3 & Advisors should be accessible to students. & 1.47 & 0.04 \\
\hline s4 & $\begin{array}{l}\text { Advisors and students should meet frequently to talk } \\
\text { about issues related to dissertations. }\end{array}$ & 1.23 & -0.39 \\
\hline s5 & $\begin{array}{l}\text { Advisors should provide adequate support for students } \\
\text { in terms of carrying out specific tasks. }\end{array}$ & 0.82 & 0.04 \\
\hline s6 & $\begin{array}{l}\text { Advisors should take the initiative in building and } \\
\text { maintaining a good relationship. }\end{array}$ & 0.31 & -0.11 \\
\hline s7 & $\begin{array}{l}\text { There should be honest communication between } \\
\text { advisors and students. }\end{array}$ & 0.71 & -0.25 \\
\hline s8 & $\begin{array}{l}\text { There should be open dialogue concerning making } \\
\text { decisions and resolving conflicts. }\end{array}$ & 0.21 & -0.38 \\
\hline s9 & $\begin{array}{l}\text { Students should be well-informed about the research } \\
\text { interest, advising style, and expectations of potential } \\
\text { advisors. }\end{array}$ & 1.05 & 0.21 \\
\hline s10 & $\begin{array}{l}\text { Advisors and students should have similar research } \\
\text { interests. }\end{array}$ & 0.27 & -1.43 \\
\hline s11 & $\begin{array}{l}\text { Advisors should make efforts to identify the needs of } \\
\text { their students. }\end{array}$ & 0.38 & 0.10 \\
\hline s12 & $\begin{array}{l}\text { Procedures for writing dissertations should be } \\
\text { explicitly explained to doctoral students. }\end{array}$ & -0.13 & 0.18 \\
\hline s13 & $\begin{array}{l}\text { Advisors should be sensitive to the needs of their } \\
\text { students. }\end{array}$ & 0.19 & 0.08 \\
\hline s14 & $\begin{array}{l}\text { Advisors and students should build trust through } \\
\text { negotiation and agreement. }\end{array}$ & 0.69 & 0.03 \\
\hline s15 & $\begin{array}{l}\text { The boundaries of the relationship should be well- } \\
\text { defined. }\end{array}$ & -0.43 & -0.20 \\
\hline s16 & $\begin{array}{l}\text { Students should be able to express their disagreement } \\
\text { when necessary. }\end{array}$ & 0.69 & 0.39 \\
\hline s17 & $\begin{array}{l}\text { Students should clearly define what they expect from } \\
\text { potential advisors. }\end{array}$ & 0.32 & 0.65 \\
\hline s18 & $\begin{array}{l}\text { Advisors and students should have matched goals and } \\
\text { expectations. }\end{array}$ & -0.34 & -0.86 \\
\hline
\end{tabular}


s19 Advisors should provide students with needed support.

s20 Students should be allowed to take charge of their dissertation process.

s21 Advisors should give timely feedback to students.

0.41

0.26

s22 Students should be aware of the complexities of

$-0.61$

0.50 advisor-advisee relationship.

s23 Students have to respect the authority of advisors.

$-1.43 \quad-0.27$

s24 Advisors should exercise their power (expert knowledge) when necessary.

s25 Advisors should have the chance to choose who they

$-0.10$ want to work with.

s26 Students should be independent.

s27 Advisors and students negotiate their roles and

$-0.28$ responsibilities.

s28 Students should strictly follow the directions provided by advisors.

$-2.15 \quad-0.18$ goals.

s30 Students should feel comfortable sharing their

0.06 academic challenges with advisors.

s31 There should be an equal balance of power between advisors and advisees.

s32 Advisors should make sure students follow procedures acceptable to the research community.

s33 Students should select their advisors at an early stage in their doctoral education.

s34 Students should be able to adjust to changing

$-0.38$ expectations and roles.

s35 Advisors and students should clearly define their

$-0.12$

$-0.04$ expectations and goals.

s36 Advisors should frequently reflect on their advising

$-0.23$ style or approach.

s37 Advisors should be ready to listen to the concerns of

0.59 their students.

s38 There should be mutual respect between advisors and students.

s39 Advisors should be ready to intervene when students are going off-track.

s40 Advisors should give constructive criticism on students' dissertations. 


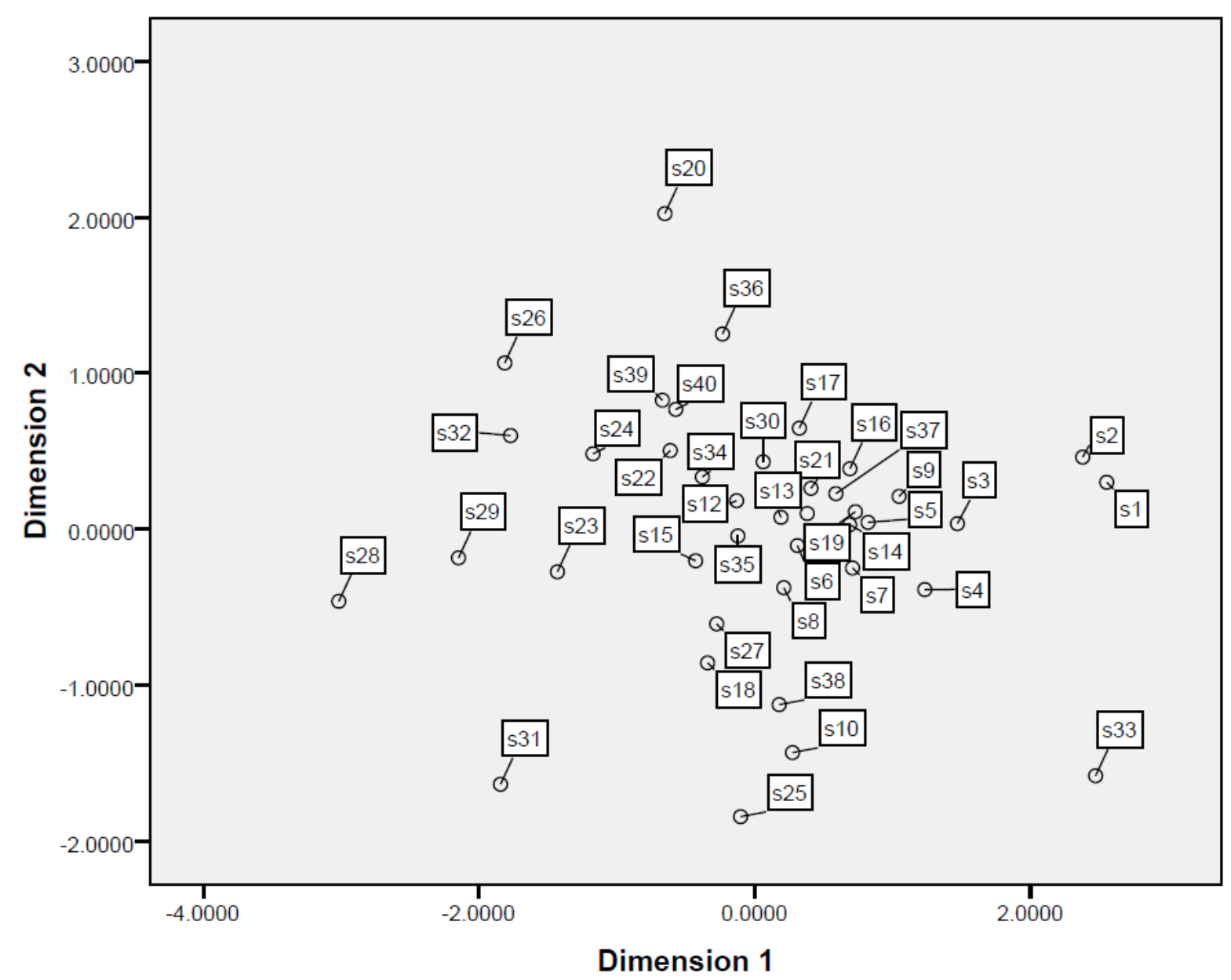

Figure A2. Two-dimensional point map displaying the locations and the relationships among the 40 statements rated and sorted by professors 


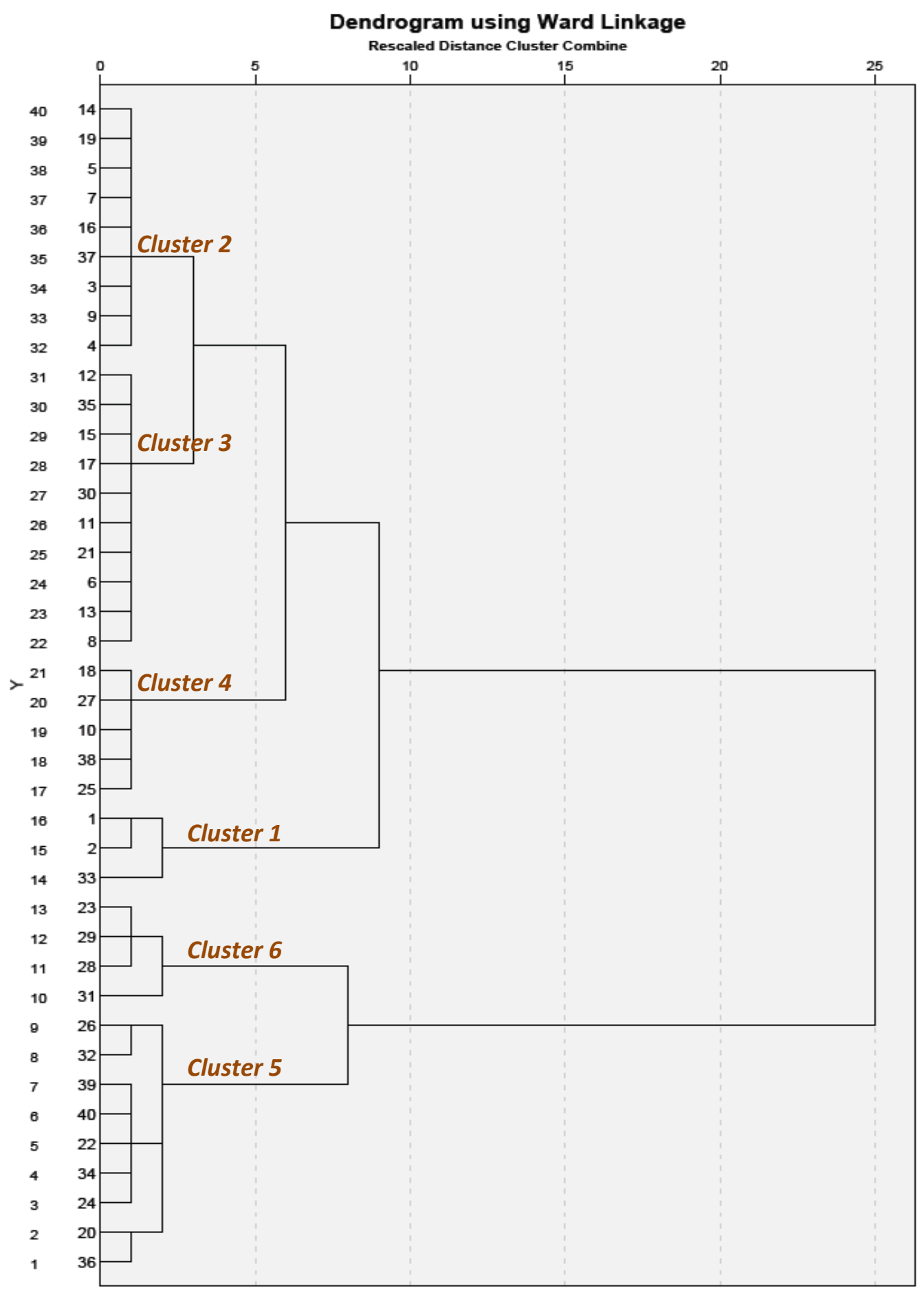

Figure B2. The Hierarchical Cluster Tree (dendrogram) indicating a six-cluster solution, which represent the 40 statements sorted by professors 
Table B2

Statements in their clusters and respective doctoral advising components (based on professors' data)

\begin{tabular}{|c|c|c|}
\hline $\begin{array}{l}\text { Item } \\
\text { code }\end{array}$ & Statements & $\begin{array}{l}\text { Components of } \\
\text { doctoral advising }\end{array}$ \\
\hline & $\begin{array}{c}\text { Cluster } 1 \text { (Selecting advisors in an early stage and } \\
\text { having the chance to change them) }\end{array}$ & \\
\hline s1 & $\begin{array}{l}\text { Students should be given the opportunity to choose their } \\
\text { advisors. }\end{array}$ & Selection process \\
\hline s2 & $\begin{array}{l}\text { Students should have the chance to easily change their } \\
\text { advisors when necessary. }\end{array}$ & Selection process \\
\hline s33 & $\begin{array}{l}\text { Students should select their advisors at an early stage in } \\
\text { their doctoral education. }\end{array}$ & Selection process \\
\hline
\end{tabular}

\title{
Cluster 2 (Enhancing advisor-advisee interaction in a supportive advising environment)
}

s5 Advisors should provide adequate support for students in terms of carrying out specific tasks.

s7 There should be honest communication between advisors and students.

s14 Advisors and students should build trust through negotiation and agreement.

s37 Advisors should be ready to listen to the concerns of their students.

s16 Students should be able to express their disagreement when necessary.

s3 Advisors should be accessible to students.

s4 Advisors and students should meet frequently to talk about issues related to dissertations.

s19 Advisors should provide students with needed support. Students should be well-informed about the research

s9 interest, advising style, and expectations of potential advisors.

\author{
Advising approach \\ Advisor-advisee \\ relationship \\ Advisor-advisee \\ relationship \\ Advisor-advisee \\ relationship \\ Power relations \\ Roles, responsibilities, \\ and expectations \\ Roles, responsibilities, \\ and expectations \\ Roles, responsibilities, \\ and expectations \\ Selection process
}

\section{Cluster 3 (Maintaining a good relationship through dialogue and clarity of expectations)}
s12 Procedures for writing dissertations should be explicitly explained to doctoral students.
s13 Advisors should be sensitive to the needs of their students. Advising approach


s21 Advisors should give timely feedback to students.

Advising approach Advisors should take the initiative in building and maintaining a good relationship.

Advisor-advisee relationship

Advisor-advisee relationship

s15 The boundaries of the relationship should be well-defined.

Advisor-advisee relationship challenges with advisors.

There should be open dialogue concerning making decisions and resolving conflicts.

Power relations

s11 Advisors should make efforts to identify the needs of their students.

Roles, responsibilities, and expectations

Advisors and students should clearly define their expectations and goals.

Roles, responsibilities, and expectations Students should clearly define what they expect from potential advisors.

Selection process

\section{Cluster 4 (Matching interests through negotiation in the selection process)}

There should be mutual respect between advisors and students.

s27 Advisors and students should negotiate their roles and responsibilities.

s10 Advisors and students should have similar research interests.

Advisor-advisee relationship

Roles, responsibilities, and expectations

Selection process Advisors and students should have matched goals and expectations.

Selection process Advisors should have the chance to choose who they want to work with.

Selection process

\section{Cluster 5 (Promoting students' independence with advisors' guidance)}

Students should be allowed to take charge of their dissertation process.

Advising approach

Advisors should frequently reflect on their advising style or approach.

Students should be aware of the complexities of advisoradvisee relationships.

Advisors should exercise their power (expert knowledge) when necessary.

Advising approach

Advisor-advisee relationship

Power relations

Power relations acceptable to the research community.

s39 Advisors should be ready to intervene when students are going off-track.

Power relations Advisors should give constructive criticism on students' dissertations.

Power relations

s26 Students should be independent. 
and expectations

s34 Students should be able to adjust to changing expectations

Roles, responsibilities, and roles. and expectations

\section{Cluster 6 (Encouraging students to follow advisors'} directions)

s28 Students should strictly follow the directions provided by advisors.

Advising approach

Advisors should focus on directing students toward set

s29 goals.

s23 Students have to respect the authority of their advisors.

Advising approach

Power relations

s31 There should be an equal balance of power between advisors and advisees.

Power relations 


\title{
Appendix C: IRB approval letter
}

\section{WestVirginiaUniversity \\ Office of Research Compliance}

\section{IRB Protocol-Exemption}

\author{
To: $\quad$ Curtis, Reagan \\ From: $\quad$ WVU Office of Research Compliance \\ Date: $\quad$ Monday, January 24, 2011 \\ Subject: Exemption Acknowledgement
}

Tracking \#: $\mathrm{H}-22972$

Title: Conceptualizing doctoral advising from professors' and doctoral students' perspectives using concept mapping

The above-referenced study was reviewed by the West Virginia University Institutional Review Board (IRB) and was granted exemption in accordance with 45 CFR 46.101(2).

This protocol was reviewed using the following:

Exemption Checklist (210r)

This research study was granted an exemption because the Research involves educational tests, survey procedures, interview procedures or observation of public behavior and (i) information obtained is recorded in such a manner that human subjects cannot be identified, directly or through identifiers linked to the subjects; and (ii) any disclosure of the human subjects responses outside the research could not reasonably place the subjects at risk of criminal or civil liability or be damaging to the subjects' financial standing, employability, or reputation [45 CFR 46.101(2)].

The following documents have been acknowledged for use in this study and are available in the BRAAN system:

Surveys, Questionnaires, Interviews

Attachments

Survey - doctoral advising.pdf Attached is the survey that will be sent to potential participants online.

Advertisements

Advertisement 
Attachments - Invitation letters

College Dean's and Department Head's Invite letter.pdf Recruitment Letter Invitation letter.pdf Recruitment Letter

Miscellaneous Attachments

Attachments

Cover letter.pdf This cover letter is the first page of the online survey.

PhoneScript.doc Script for phone call following initial email invitation to participate

Thank you.

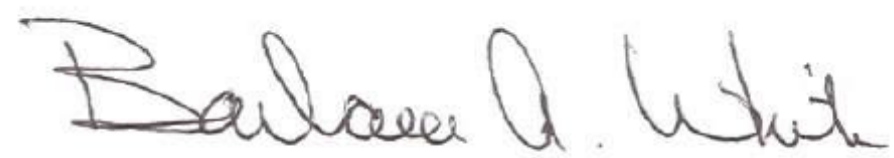

Board Designee: White, Barbara

Letter Sent By: White, Barbara, 1/24/2011 1:35 PM

Once you begin your human subject research, the following regulations apply:

1. Any modifications to the study protocol must be reviewed and acknowledged by the IRB prior to implementation.

2. You may not use a modified form until it has been acknowledged by the IRB. 


\section{Appendix D: Sample of the online survey}

\section{Conceptualizing the perspectives on doctoral advising}

\section{Cover letter}

Dear professor/doctoral student,

We (Reagan Curtis, PhD., an associate professor, and Philip Adu, a doctoral candidate at the College of Human Resources and Education, West Virginia University) are conducting research to conceptualize the perspectives of professors and doctoral students on doctoral advising. Please help us to improve the quality of doctoral advising by participating in this study.

We are aware of the value in collecting participants-driven data. In response, we are using concept mapping as a research method in collecting and analyzing data. Concept mapping processes include direct involvement of participants in sorting and rating statements on a questionnaire.

We welcome your input in this study by (a) sorting statements related to advising, and (b) rating the statements in terms of their importance, and the level of difficulty in implementing them. It will take 25-30 minutes to complete this survey. After completion, you can participate in the $\$ 25$ gift certificate drawing, where you stand the chance of being one of the ten winners.

Participation is entirely voluntary. The issue of confidentiality is of utmost importance to us. In fact, your responses on this survey will be completely anonymous, meaning that there will be no information collected from the survey that could possibly identify you.

If you have any questions or concerns, please do not hesitate to contact us. You will have the opportunity to request that our results be emailed to you.

Reagan Curtis, Ph.D - 304-293-2098 or reagan.curtis@mail.wvu.edu

Philip Adu - 7402741097 or padu@mix.wvu.edu

For information regarding your rights as a research participant, you may contact the Office of Research Compliance at 304-293-7073. IRB approval of this research project is on file.

Thank you

Sincerely,

Reagan Curtis, Ph.D

Principal Investigator

Philip Adu

Co-Investigator 


\section{Conceptualizing the perspectives on doctoral advising}

\section{Demographic information}

Please choose the one most applicable to you.

* I am a...

$\bigcirc$ Professor

Doctoral candidate

Doctoral student 


\section{Conceptualizing the perspectives on doctoral advising}

3. Demographic information (professor)

\section{Gender}

$\bigcirc$ Male

Female

\section{Ethnicity}

White/Caucasian

African America or Black

$\bigcirc$ Hispanic/Latino

$\bigcirc$ Asian/Pacific Islander

Native American

other

Other (please specify)

\section{Affiliated College or department}
$\bigcirc$ Education
$\bigcirc$ Political Science
$\bigcirc$ communication
Sociology/Anthropology
Psychology
other

Other (please specify) 


\section{Conceptualizing the perspectives on doctoral advising}

What is your academic title?

$\bigcirc$ Professor Emeritus/Emerita

Professor

Associate Professor

Assistant Professor

$\bigcirc$ Adjunct Professor

$\bigcirc$ Visiting Professor

Lecturer

Other

Other (please specify)

I have been advising doctoral students for....

$\bigcirc 0-2$ years

3-4 years

5-6 years

7-8 years

$\bigcirc 9$ years and over 
Conceptualizing the perspectives on doctoral advising

4. Demographic information (student)

$$
\begin{aligned}
& \text { Gender } \\
& \text { Male } \\
& \text { Oremale }
\end{aligned}
$$

\section{Ethnicity}
White/Caucasian
African America or Black
Hispanic/Latino
Asian/Pacific Islander
$\bigcirc$ Native American
Other

Other (please specify)

Affiliated College or department
$\bigcirc$ Education
$\bigcirc$ Political Science
$\bigcirc$ communication
Sociology/Anthropology
$\bigcirc$ Psychology
Other

Other (please specify)

I am pursuing ....
OPhD
$\bigcirc \mathrm{EdD}$
other

Other (please specify) 


\section{Conceptualizing the perspectives on doctoral advising}

I am a.....

$\bigcirc$ Full time student

$\bigcirc$ Part time student

Other

Other (please specify)

Which of the following describes you? (You can choose more than one)

I am taking courses toward my degree

I have passed my comprehensive exams

I am working on my dissertation prospectus

I am working on my dissertation

I have recently defended my dissertation

Other

Other (please specify)

I have been working on my doctoral education for....
$0-2$ years
3 $3-5$ years
6-8 years
9 years and over 


\section{Conceptualizing the perspectives on doctoral advising}

\section{SORTING STATEMENTS}

\section{INSTRUCTIONS:}

Please categorize the statements below into clusters in a way that makes sense to you by clicking the buttons below. Remember that there is no right or wrong answer. different people will group the statements differently.

Please take note of the following when sorting the statements;

(a) Do NOT group ALL the statements into one cluster.

(b) No statement can belong to more than one cluster.

To ensure successful completion of their doctoral dissertation .....

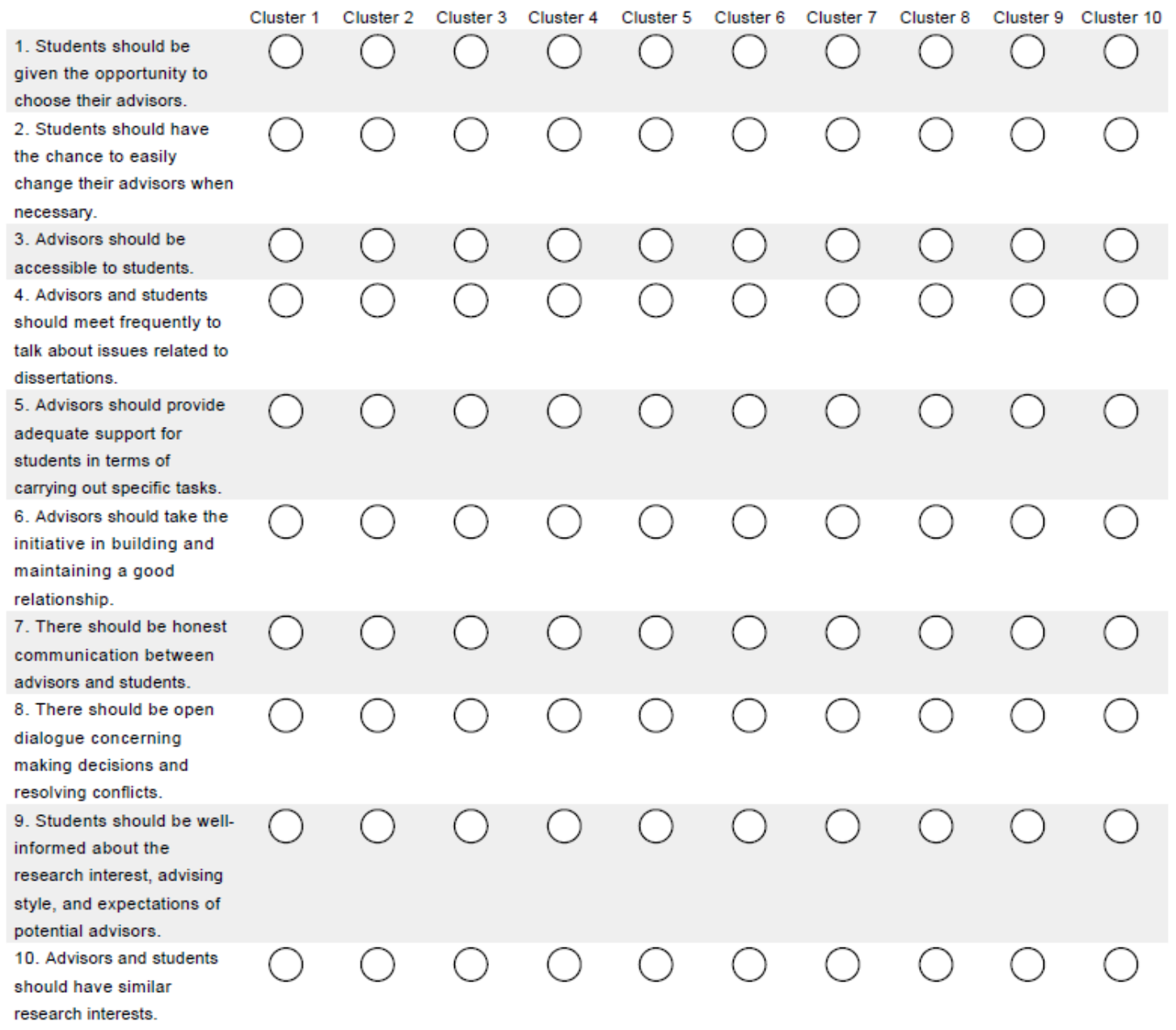




\section{Conceptualizing the perspectives on doctoral advising}

Continue....

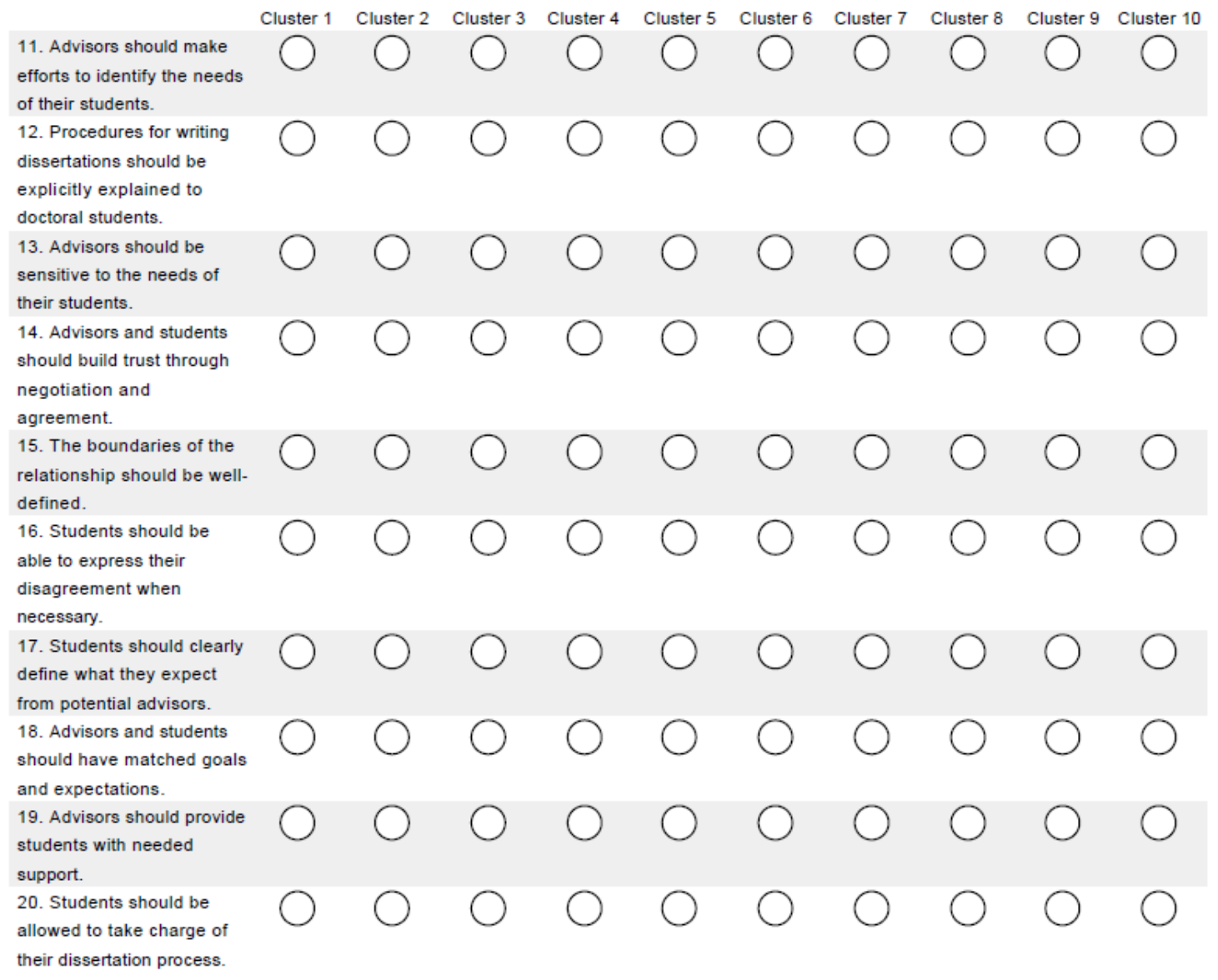




\section{Conceptualizing the perspectives on doctoral advising}

\section{Continue.....}

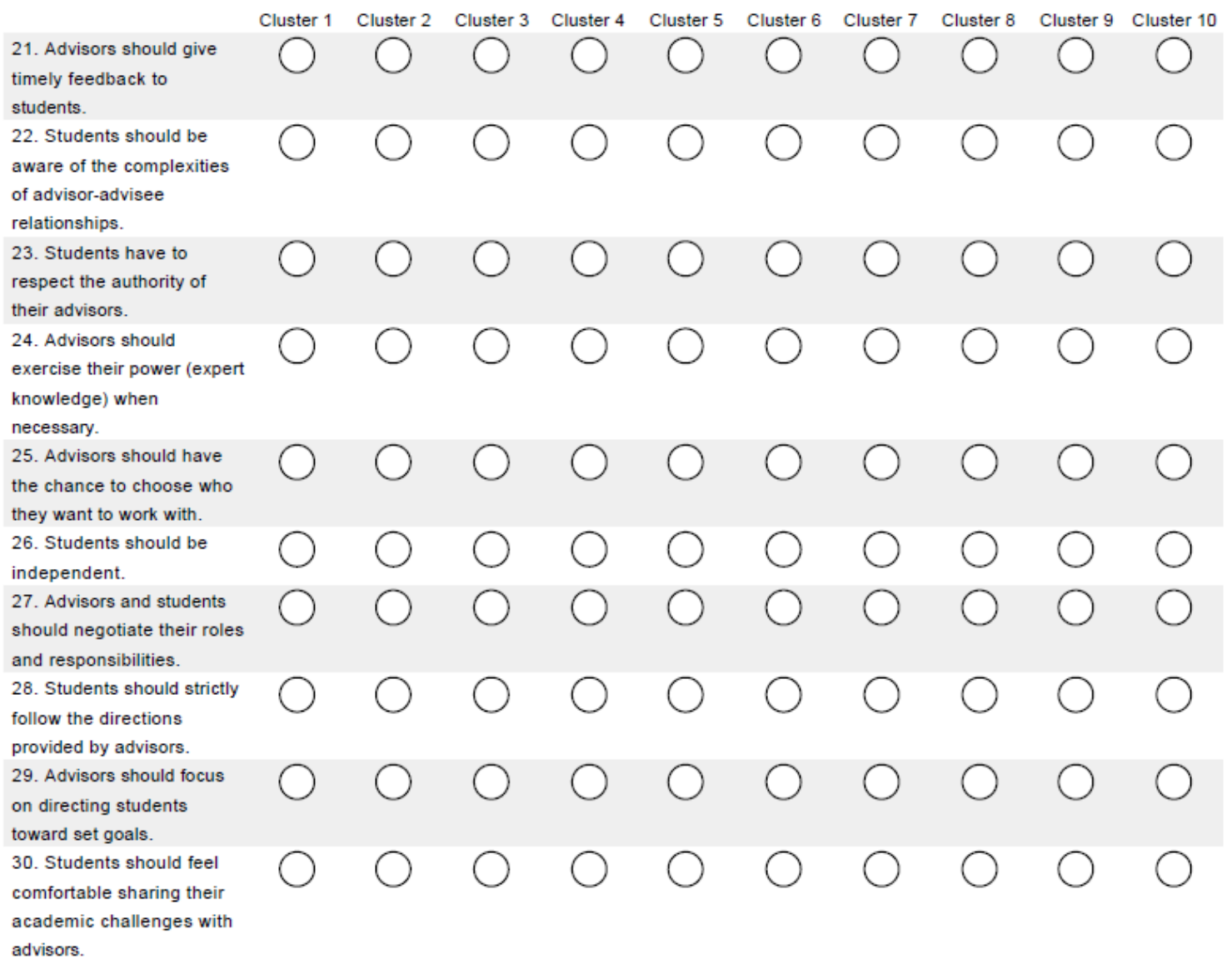




\section{Conceptualizing the perspectives on doctoral advising}

\section{Continue....}

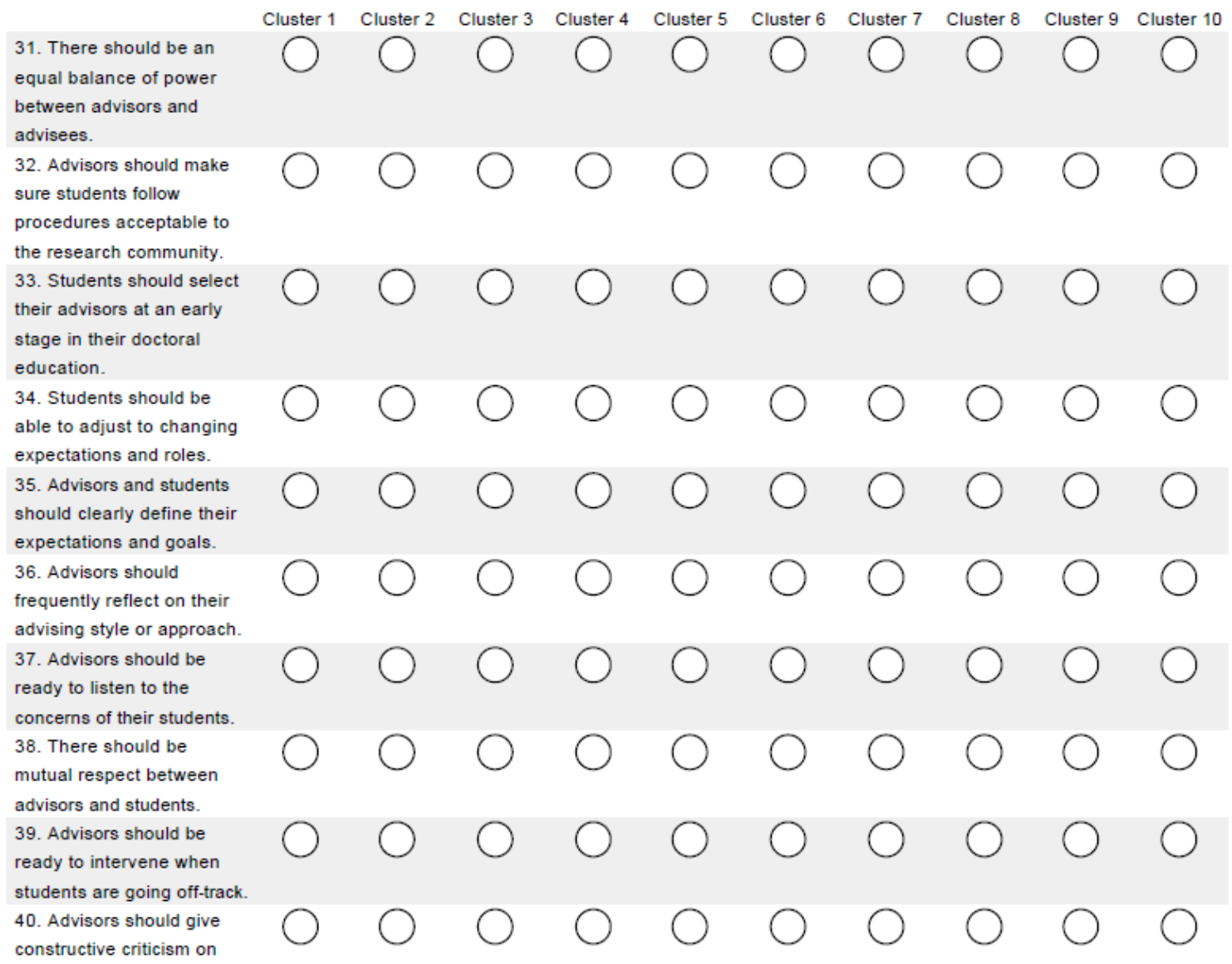

constructive criticism on

students' dissertations. 


\section{Conceptualizing the perspectives on doctoral advising}

\section{RATING STATEMENTS}

INSTRUCTIONS:

Please rate the statements based on;

(a) the level of difficulty in carrying out the statements (activities).

(b) their importance to the successful completion of doctoral students' dissertations.

\section{To ensure successful completion of their doctoral dissertations.....}

Difficulty (implementing these statements)

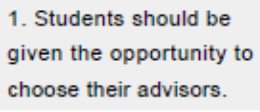

1. Students should be given the opportunity to

choose their advisors.

2. Students should have the chance to easily

change their advisors when necessary

\section{Advisors should be accessible to students.}

4. Advisors and students should meet frequently to talk about issues related to dissertations.

5. Advisors should provide adequate support for

students in terms of carrying out specific tasks.

6. Advisors should take the initiative in building and maintaining a good

relationship.

7. There should be honest communication between

advisors and students.

8. There should be open dialogue concerning making decisions and resolving conflicts.

9. Students should be wellinformed about the research interest, advising style, and expectations of potential advisors.

10. Advisors and students should have similar research interests.

11. Advisors should make efforts to identify the needs of their students.

12. Procedures for writing
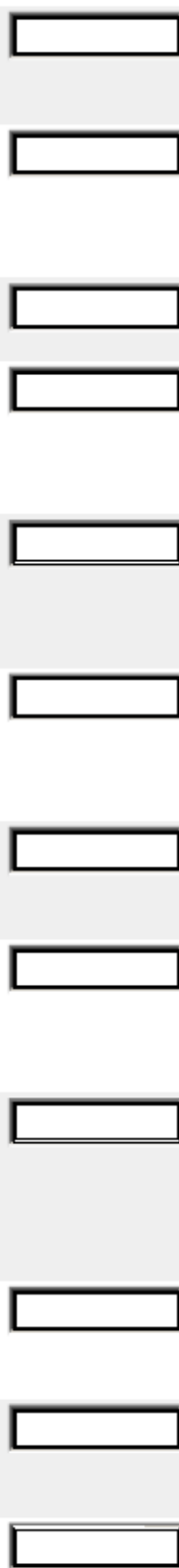

Importance (successful completion of their dissertations)
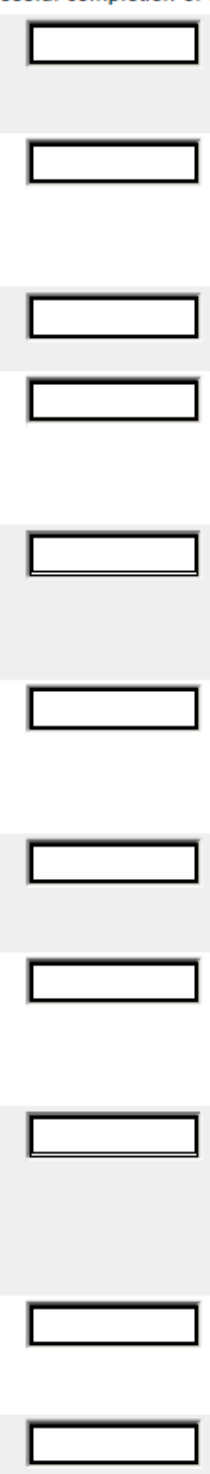


\section{Conceptualizing the perspectives on doctoral advising}

dissertations should be

explicitly explained to

doctoral students.

13. Advisors should be

sensitive to the needs of
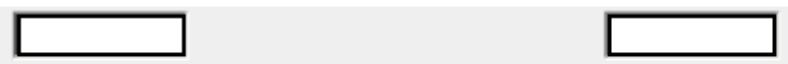

their students.

14. Advisors and students
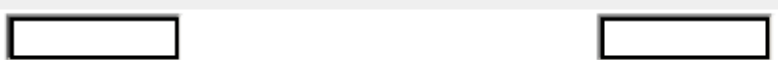

should build trust through

negotiation and

agreement.

15. The boundaries of the relationship should be

well-defined.

16. Students should be

able to express their

disagreement when

necessary

17. Students should clearly define what they expect

from potential advisors.

18. Advisors and students should have matched goals and expectations.

19. Advisors should provide students with

needed support.

20. Students should be allowed to take charge of their dissertation process

21. Advisors should give timely feedback to

students.

22. Students should be aware of the complexities
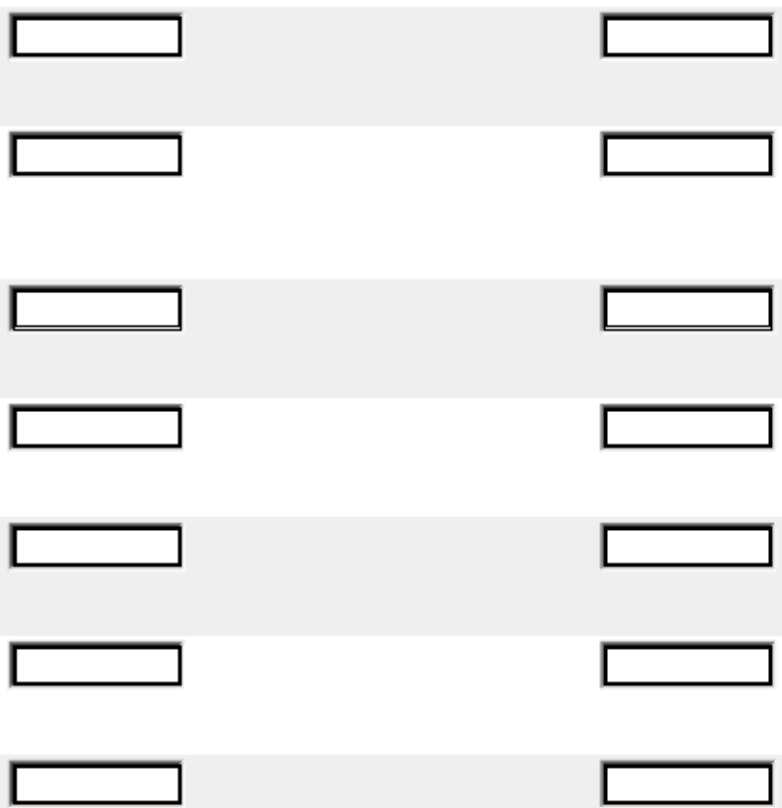

of advisor-advisee

relationships.

23. Students have to respect the authority of their advisors.

24. Advisors should exercise their power (expert knowledge) when necessary

25. Advisors should have the chance to choose who
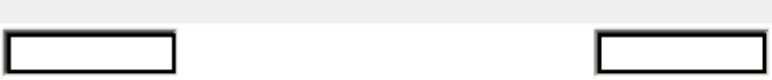
they want to work with.

26. Students should be independent.

27. Advisors and students should negotiate their
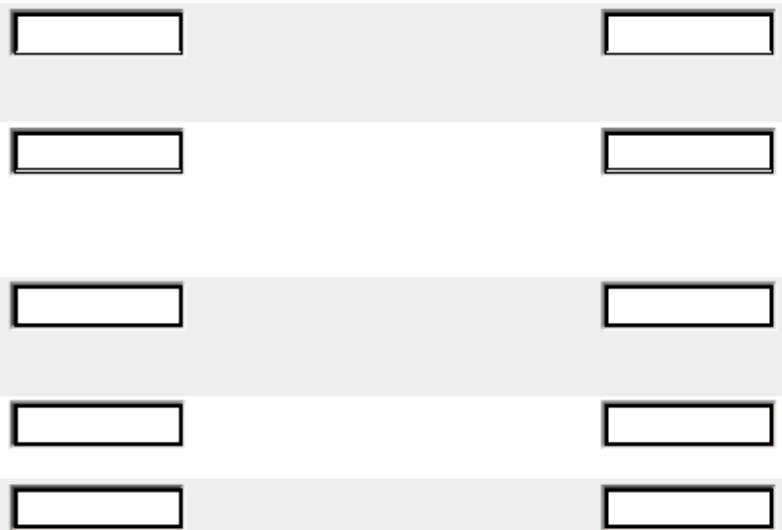


\section{Conceptualizing the perspectives on doctoral advising}

roles and responsibilities.

28 . Students should strictly

follow the directions
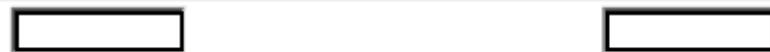

provided by advisors.

29. Advisors should focus

on directing students
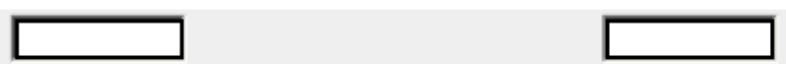

toward set goals.

30. Students should feel comfortable sharing their
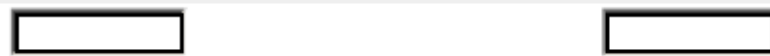

academic challenges with

advisors.

31. There should be an equal balance of power

between advisors and

advisees.

32. Advisors should make

sure students follow

procedures acceptable to

the research community.

33. Students should select their advisors at an early

stage in their doctoral

education.

34. Students should be able to adjust to changing expectations and roles.

35. Advisors and students should clearly define their expectations and goals.

36. Advisors should

frequently reflect on their

advising style or approach.

37. Advisors should be

ready to listen to the

concerns of their students.

38. There should be

mutual respect between

advisors and students.

39. Advisors should be

ready to intervene when
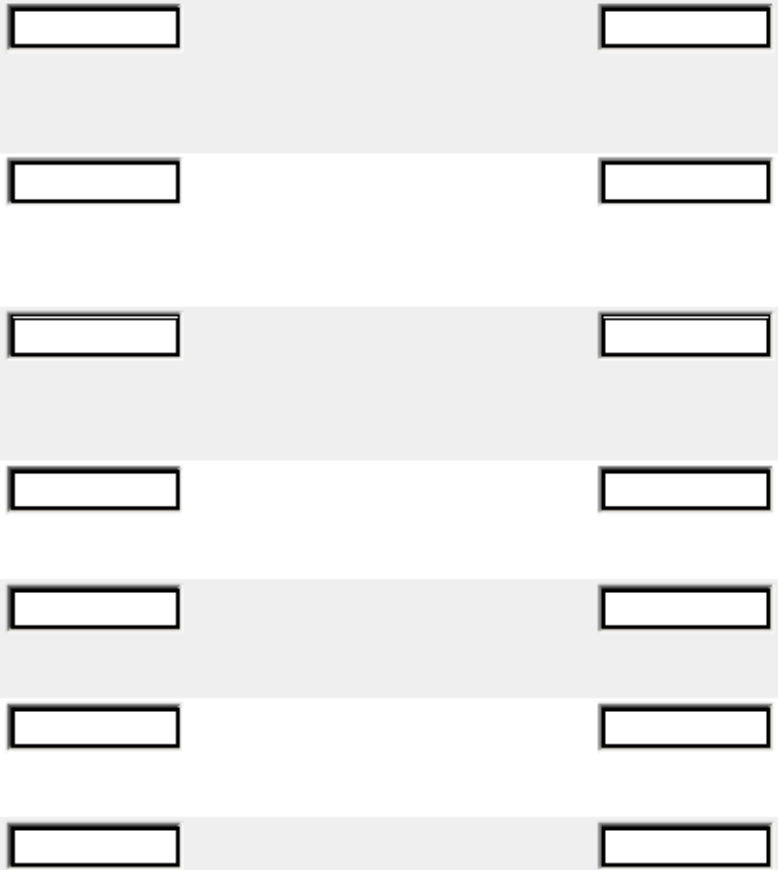
students are going off-

track.

40. Advisors should give constructive criticism on
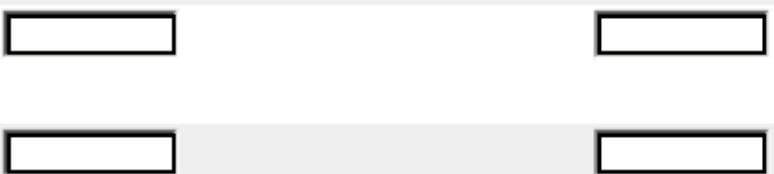

students' dissertations.

Please type any statement that you think should be added to the statements above.

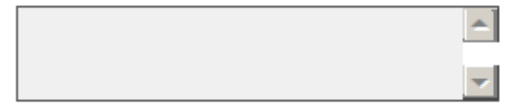




\section{Conceptualizing the perspectives on doctoral advising}

Thank you for completing this survey. If you want to participate in the $\$ 25$ gift certificate drawing, please provide your email address below. Ten winners will be randomly selected.

Please note that email for the drawings will be separated from individual participants' survey responses.

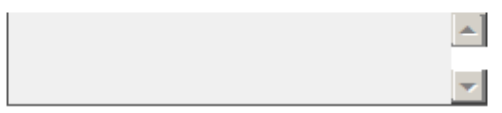

Please provide your email address below if you want us to send you the results. Note that email for getting the results will be separated from individual participants' survey responses.

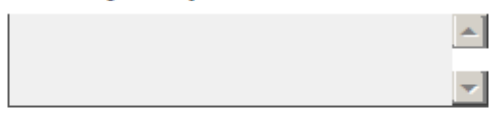




\title{
Appendix E: A copy of my CV
}

\author{
Philip K. Adu \\ 9016 Gables Lane \\ Atlanta, GA 30350 \\ Tel. (740) 2741097 \\ Email: kontorphilip@gmail.com
}

\section{Education}

Ph.D. West Virginia University, Morgantown, Anticipated time of completion, fall 2011

Field: Interdisciplinary PhD in Education with emphasis in Learning, Instructional Design and Technology

Dissertation Title: Conceptualizing doctoral advising from professors' and doctoral students' perspectives using concept mapping

M.A. Ohio University, Athens Ohio, 2008

Field: International Development Studies

Capstone project (Proposal): Upgrading slum dwellers at Old Fadama in Accra, Ghana

B.A. University of Ghana, Accra Ghana, 2004

Major field: Psychology

Thesis topic: Students' Attitude towards Public Speaking

\section{Professional Interests}

- Doctoral preparation and academic advising

- Multimedia in distance education

- Concept mapping for action oriented research, program planning and evaluation

- Research methodology (qualitative, quantitative, and mixed method)

\section{Professional Membership}

- American Educational Research Association (AERA)

AERA Division Membership: Research, Evaluation and Assessment in Schools

\section{Award}

Dissertation Fellowship (2011)

This award was given to students with outstanding academic performance and achievement toward the completion of their dissertations.

\section{External Grant Funding}

Graduate Assistant (working with a Co-investigator) (2010-2011) "Quality Rating and Improvement for West Virginia Child Care”, West Virginia Department of Health and Human Resources funded project (total awarded \$ 629,000).

I was working with Dr. R. Curtis (Mentor and Advisor) analyzing data from child care centers in over 50 counties in the state of West Virginia. My responsibility was to supervise data entry personnel, conduct data analyses, and generate reports. 
Graduate Assistant (working with Internal Evaluator/Senior Personnel) (2008-2010) "Engineers of Tomorrow", National Science Foundation, (NSF)

Award No. 0525484 (total awarded \$1,998,446).

I assisted in evaluating two components of this NSF funded program: (a) Tools for Integrating Math and Engineering (TIME) Kits and (b) Summer Experience Program. My tasks included data entry and analysis using IBM SPSS software and generating preliminary reports.

\section{Work Experience}

Faculty Advisor - Global Young Leaders Conference (GYLC) Washington DC (June-August, 2008)

I facilitated the teaching of educational curricula for high school students from all over the world (between the ages of 16 and 18). The curriculum was geared towards the understanding of global issues and challenges of international organizations, as well as enhancing cross-cultural communication skills, and improving leadership skills.

Program Coordinator - Students and Youth Travel Organization (SYTO) Accra, Ghana (July 2004-2006)

I was responsible for recruiting students from the various Universities in Ghana for the Students Work Abroad Program (SWAP) and assisting in organizing orientation sessions for volunteers from the USA, Ireland, UK, Belgium, Canada, Germany and Australia.

\section{Teaching Experience}

Co-instructor (spring, 2010), Statistical Methods 2 - this was an advanced statistical methods course using IBM SPSS.

Some of the topics treated were partial and semi-partial correlation, simple and multiple regressions, factorial ANOVA, repeated measures ANOVA, ANCOVA, and several nonparametric tests. As a co-instructor, I presented a review of what was covered in Statistics I, graded homework, gave individualized and prompt feedback to students, and provided out of class assistance to students who had trouble in the course.

Co-instructor (fall, 2009), Statistical Methods 1 - a course designed to introduce graduate students to descriptive and inferential statistics and IBM SPSS software.

I collaborated with Dr. R. Curtis to plan and deliver course content including reviewing assignments at the beginning of each class session and delivering portions of each class lecture. I graded all assignments providing detailed feedback to students and held office hours to help students who sought additional assistance.

\section{Technical Reports Authored}

Warash, B., Curtis, R., Ahern, T., Pelliccioni, Smith, K., Adu, P., Clausell, C. (2011). Quality rating and improvement for West Virginia child care. Final report submitted to West Virginia Department of Health and Human Resources / Bureau of Children and Families.

Adu, P. \& Curtis, R. (2010). Usability of My Next Horizon social networking site and its effect on the users' interest in Science, Technology, Engineering, and Math, (STEM). Report prepared for the Edventure Group. 
This was a formative evaluation focused on assessing how usable the social networking site, My Next Horizon, was and the site's effect on students' (K7 to 12) interest in STEM related courses and careers. I started the evaluation process in the fall of 2009 with a proposal for IRB approval. After the approval, I conducted an online survey, analyzed the data and wrote the final report. All these activities were supervised by Dr. Curtis.

\section{Presentations at Professional Meetings}

Adu, P., Curtis, R., Carrick, R., Kohlmeyer, C., \& Rahman, A. (2011, April). Preparing doctoral students for their dissertations: What makes it a complex experience? Paper presented at the annual meeting of the American Educational Research Association, New Orleans, LA.

This qualitative study investigated the perceptions and opinions of doctoral students and faculty in relation to how effective core research methods courses and other support systems were in preparing doctoral students for their dissertation research. I conducted face-to-face interviews and collaborated on qualitative data analysis and proposal generation.

Curtis, R., Adu, P., \& Ahern, T. (2011, April). STARS in graduate statistics and research methods: Implications for instructional practice. Paper presented at the annual meeting of the American Educational Research Association, New Orleans, LA.

We surveyed graduate students in research and statistics courses regarding statistical content knowledge and statistics-related anxiety at the start, midterm, and end of semester. We tailored instruction for statistics students based on interim analyses of this data utilizing an information processing model and explicitly addressed anxiety issues that in the past had remained below the surface.

Curtis, R., Adu, P., Fitzpatrick, S. \& Quartiroli, A. (2011, April). Integrating concept mapping into a program evaluation course: A postsecondary action research investigation. Paper presented at the annual meeting of the American Educational Research Association, New Orleans, LA.

We used Concept Mapping to inform our instruction and provide our students with hands on experience of a powerful program development and evaluation tool. All 19 students in a graduate level Program Evaluation course participated fully in each stage guided by the first author as facilitator. Preliminary analyses and graphic representations were explored with the class and implications for utilization during future instruction were discussed. I contributed to data analyses (multidimensional scaling and hierarchical cluster analysis) and proposal generation.

Curtis, R., Winn, G., Hensel, R., Adu, P., \& Kher, N. (2011, March). Recruiting Appalachian girls to STEM educational and career paths. Paper presented at the Annual Meeting of the Society for Information Technology and Teacher Education, Nashville, TN.

Adu, P., Curtis, R., Hayes, S.B., Shambaugh, N., \& Smith, J.J. (2010, May). Preservice teacher action research reports demonstrate impact on pupil learning. Paper presented at the annual meeting of the AERA, Denver, CO.

This research focused on analyzing preservice teachers' action research reports so as to determine their impact on pupil learning. We found quantitative and qualitative evidence of 
instructional effects on students' learning, as well as our own effects on the development of an inquiry stance in our preservice teacher candidates. My role was to facilitate qualitative and quantitative data analyses.

Curtis, R., Winn, G., Hensel, R., \& Adu, P. (2010, May). Recruiting Appalachian girls to STEM educational and career paths. Paper presented at the AERA, Denver, CO.

This study was conducted to help us understand how High School girls and underrepresented minorities from the Appalachian region could be effectively recruited to Science, Technology, Engineering, and Math (STEM) disciplines. We collected data from participants of a National Science Foundation funded program, Engineers of Tomorrow (EoT) Summer Experience. EoT Summer Experience is an intensive weeklong program for High School students from West Virginia. It focused on introducing a basic knowledge of STEM, providing information about campus experience, and assisting them to prepare for the SAT/ACT. I helped with the data analysis and report generation. Dr. Curtis and I presented this study at the AERA annual meeting on May 3, 2010 in Denver.

Adu, P. (2007, April). When substantial investment in education brings low returns. Paper presented at the African Education Research Network (AERN) Conference, Ohio University, Athens, $\mathrm{OH}$.

This study was to find out whether increase in expenditure in education brings about increase in GDP per capital of countries. I used a secondary data source from the World Bank website and analyzed educational expenditures and GDP per capita from 136 countries. I then focused on 10 countries to identify variables that might have contributed to increases or decreases in their GDP per capita.

\section{Conference proposals accepted (AREA 2012 annual meeting)}

Adu, P., Curtis, R., (2012, April). Conceptualizing doctoral advising from professors' and doctoral students' perspectives using concept mapping. Paper accepted to be presented at the annual meeting of the American Educational Research Association, Vancouver, British Columbia, Canada.

Curtis, R., Warash, B., Ahern, T., Smith, K., Adu, P., Clausell, C. (2012, April). Quality Rating and Improvement for West Virginia Child Care. Paper accepted to be presented at the annual meeting of the American Educational Research Association, Vancouver, British Columbia, Canada.

\section{Published Proceedings}

Curtis, R., Winn, G., Hensel, R., Adu, P., \& Kher, N. (2011). Recruiting Appalachian girls to STEM educational and career paths. Proceedings of the Society for Information Technology and Teacher Education.

\section{Publication}

Curtis, R., Winn, G., Hensel, R., Adu, P., \& Kher, N. (2011). Recruiting Appalachian girls to STEM educational and career paths: Implications for teacher education. In Maddux, C.D., Gibson, D. \& Dodge, B. (Eds.), Research Highlights in Technology and Teacher Education 2011. Chesapeake, VA: SITE. 


\section{Reviewer (2010)}

Special Interest Group (SIG), Instructional Technology: American Educational Research Association (AERA) annual meeting.

\section{Member of Editorial Review Board}

Advancing Women in Leadership Journal: College of Education, Sam Houston State University, Huntsville, TX. 